LUCIANA APARECIDA MARTINEZ ZAINA

\title{
AVALIAÇÃO DO PERFIL DO ALUNO BASEADO EM INTERAÇÕES CONTEXTUALIZADAS PARA ADAPTAÇÃO DE CENÁRIOS DE APRENDIZAGEM
}


LUCIANA APARECIDA MARTINEZ ZAINA

\section{AVALIAÇÃO DO PERFIL DO ALUNO BASEADO EM INTERAÇÕES CONTEXTUALIZADAS PARA ADAPTAÇÃO DE CENÁRIOS DE APRENDIZAGEM}

Tese apresentada à Escola Politécnica da Universidade de São Paulo para obtenção do título de doutora em Engenharia 


\section{AVALIAÇÃO DO PERFIL DO ALUNO BASEADO EM INTERAÇÕES CONTEXTUALIZADAS PARA ADAPTAÇÃO DE CENÁRIOS DE APRENDIZAGEM}

Tese apresentada à Escola Politécnica da Universidade de São Paulo para obtenção do título de doutora em Engenharia

Área de Concentração:

Sistemas Digitais

Orientadora: Profa. Dra. Graça Bressan 
Este exemplar foi revisado e alterado em relação à versão original, sob responsabilidade única do autor e com a anuência de seu orientador.

São Paulo, 10 de abril de 2008.

Assinatura do autor

Assinatura do orientador

Zaina, Luciana Aparecida Martinez

Avaliação do perfil do aluno baseado em interações contextualizadas para adaptação de cenários de aprendizagem / L.A.M. Zaina. - Edição Revisada -- São Paulo, 2008.

$171 \mathrm{p}$.

Tese (Doutorado) - Escola Politécnica da Universidade de São Paulo. Departamento de Engenharia de Computação e Sistemas Digitais.

1. Aprendizagem eletrônica 2. Ensino por computador I. Universidade de São Paulo. Escola Politécnica. Departamento de Engenharia de Computação e Sistemas Digitais II. t. 
Pedras no caminho? Guardo todas, um dia vou construir um castelo...

(Fernando Pessoa)

Ao meu marido Fábio pelo companherismo. Ao meu filho Murilo por iluminar os meus dias com sua alegria de viver. 


\section{AGRADECIMENTOS}

À minha orientadora Profa. Dra. Graça Bressan pela condução deste trabalho. As discussões e reflexões realizadas durante estes anos foram primordiais para a conclusão deste trabalho.

Ao Prof. Titular Wilson Ruggiero por ter me dado a oportunidade de trabalhar em um projeto tão importante quanto o Tidia-AE.

À Fapesp pelo patrocínio do projeto Tidia-AE.

Ao Prof. Dr. Romero Tori pelas sugestões e contribuições feitas durante a qualificação deste trabalho.

Aos meus colegas de projeto Tidia-AE pelas discussões sobre o tema de aprendizagem eletrônica que muito enriqueceram meus conhecimentos sobre o assunto.

Às "amigas - mães" Luisa Gonzalez, Itana Stiubiener e Ana Maria pela troca de experiências maternas.

A todos os colegas do LARC com os quais compartilhei muitos momentos importantes durante minha passagem pelo laboratório.

Aos meus pais Luiz e Ivanilda por toda a ajuda dada nos cuidados com o pequeno Murilo.

Ao meu marido Fábio, pelo carinho, paciência, compreensão e, sobretudo por me incentivar a não desistir do meu sonho e a valorizar sempre o meu trabalho.

Ao meu amado filho Murilo, por resgatar em mim sentimentos preciosos, e me mostrar como é bom pisar descalço na grama úmida pelo orvalho e construir castelos de areia nos domingos de manhã. 
Não há saber mais ou saber menos.

Há saberes diferentes.

(Paulo Freire) 


\section{RESUMO}

ZAINA, L. A. M. Avaliação do Perfil do Aluno Baseado em Interações Contextualizadas para Adaptação de Cenários de Aprendizagem. 2008.172 p. Tese (Doutorado) - Escola Politécnica da Universidade de São Paulo, São Paulo, 2008.

A identificação de características que sejam importantes sobre um dado estudante durante o processo de ensino-aprendizagem tem sido alvo de muitos estudos nos últimos tempos. Docentes, coordenadores e pedagogos têm defendido que cada indivíduo possui características particulares e importantes dentro do processo de desenvolvimento do conhecimento. A necessidade de adaptar as estratégias de ensino de acordo com as preferências do aprendiz é uma realidade dentro das salas de aula, sejam estas presenciais ou virtuais. Porém, isto não significa que numa sala de aula deva haver criação de um método para cada aluno, mas sim que se aponte qual a melhor forma de interação para cada um deles construindo grupos de aprendizes com características comuns. Trabalhando desta forma se torna possível identificar perfis de aprendizes dentro de um conjunto de estudantes, possibilitando que se possa trabalhar com conteúdos e ambientes de aprendizagem mais adequados aos aprendizes.O objetivo deste trabalho é apresentar a arquitetura de um sistema que possibilita a criação de cenários de aprendizagem baseados no perfil do aluno. $O$ docente deve indicar as características que devem ser observadas durante as interações do aprendiz em um dado ambiente de aprendizagem eletrônica. Estas características serão modeladas como informações de contexto, permitindo que os pontos definidos como observáveis sejam organizados e modelados de forma a facilitar a monitoração das interações. A classificação do aluno em um determinando tipo de perfil de aprendizagem, previamente definido pelo docente, é realizado considerando-se as informações sobre o contexto da interação e os tipos de perfis de aprendizagem. Para que seja possível construir os cenários de aprendizagem considerando o perfil do aluno este trabalho propõe criar um relacionamento entre os tipos de perfis de aprendizagem e as estratégias de ensino através das categorias descritoras dos objetos de aprendizagem.

Palavras-chaves: Aprendizagem eletrônica. Computação Ciente de Contexto. Modelo do aluno. Objetos de Aprendizagem. Padrões de ensino. Perfil de aprendizagem. Perfil do aluno. 


\begin{abstract}
ZAINA, L. A. M. Evaluation of Learner Profile Based on Contextual Interactions to Adaptation of Learning Scenarios. 2008.172 p. Thesis (Doctoral) - Escola Politécnica da Universidade de São Paulo, São Paulo, 2008.

The identification of characteristics of a given student that are important during the teachinglearning process has been the focus of numerous studies in recent years. Teachers, coordinators and pedagogues have defended the notion that each individual presents particular and important characteristics in the developing knowledge process. The need to adapt teaching strategies to the student's preferences is a reality in classrooms, being physical or virtual classrooms. However, this does not mean that a method should be created for each student in a classroom, but that the best form of interaction for each of them be identified, building groups of learners with common characteristics. Working in this way makes it possible to identify learner profiles within a group of students, allowing one to work with learning contents and environments more suited to the learners. The objective of this work is to present the architecture of a system that allows for the creation of learning scenarios based on the studen profile. The teacher should point out the features which may be observed during the student interaction in a given e-elearning environment. These features are designed as context information, allowing defined observation points to be organized and modeled for facilitating the monitoring of interactions. The student classification in a given learning profile type, defined previously by the teacher, is realized considering information about the context of interaction and the learning profile types.

For the learning environment to build the learning scenarios according to the student profile, this work proposes to create a relationship between the learning profile types and the teaching strategies through the description of learning objects categories.
\end{abstract}

Keywords: Eletronic Learning. Context Aware Computing. Learner Model. Learning Objects. Teaching Standards. Learning Profile. Learner Profile. 


\section{LISTA DE FIGURAS}

Figura 1 - Modelo do Aluno, adaptado de Rosatelli e Tedesco, 2003; Kobsa, Koenemann e Pohl, 2001. 27

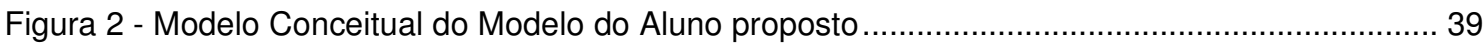

Figura 3 - Modelo da Unidade de Aprendizagem (KOPPER e MANDERVELD, 2004) ........................ 49

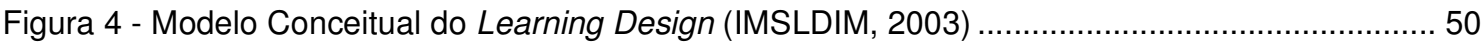

Figura 5 - Arquitetura clássica dos STI adaptado de Mcarthur apud Rosatelli (2000) ......................... 54

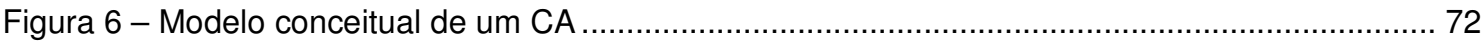

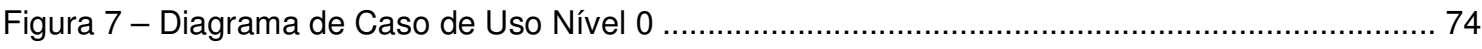

Figura 8 - Modelo conceitual da arquitetura para adaptação de CAs................................................ 75

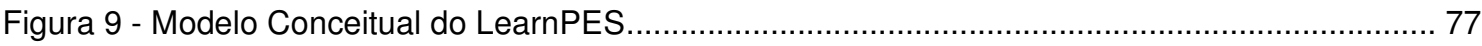

Figura 10 - Pesquisador de característica monitoráveis de uma ferramenta ..................................... 82

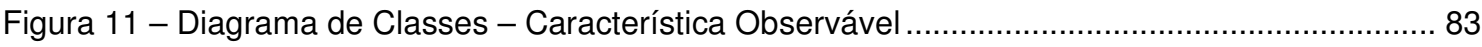

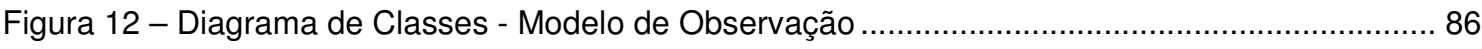

Figura 13 - Entidades para definição do Modelo de Observação ......................................................... 88

Figura 14 - Criação de Tipos de Perfis de Aprendizagem Visual-Ativo ……...................................... 90

Figura 15 - Criação de Tipos de Perfis de Aprendizagem Verbal-Reflexivo.......................................... 91

Figura 16 - Modelo Conceitual para Definição de Tipos de Perfis de Aprendizagem ......................... 92

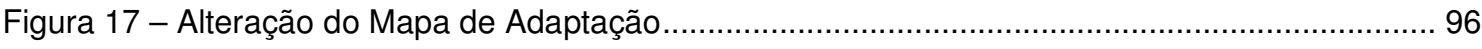

Figura 18 - LearnPES envia Modelo de Observação ao Módulo de Monitoração................................ 97

Figura 19 - Modelo de um CA com a sinalização sobre o monitoramento .......................................... 98

Figura 20 - Modelo Conceitual do Módulo de Planejamento ........................................................ 100

Figura 21 - Captura do contexto da interação do aprendiz para características observáveis do tipo interações do aprendiz .................................................................................... 104

Figura 22 - Captura do contexto da interação do aprendiz através de uma ferramenta para

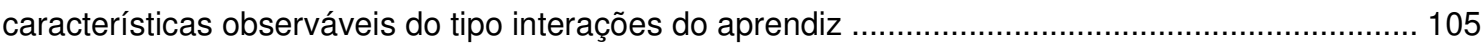

Figura 23 - Captura do contexto da interação do aprendiz para características observáveis do tipo

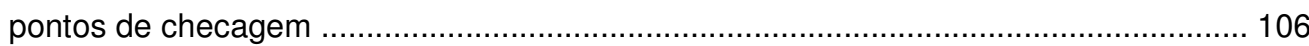

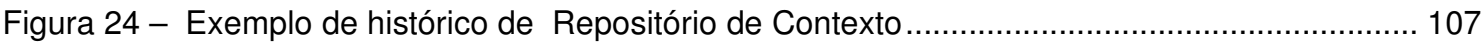

Figura 25 - Diagrama de seqüência da avaliação das características observadas e da atualização do

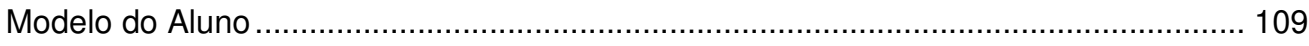

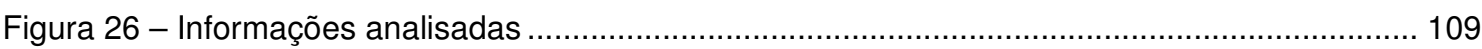

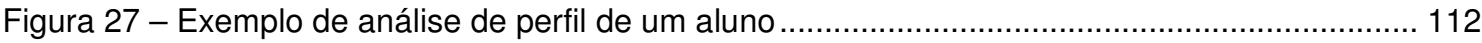

Figura 28 - Classificação do aluno através da menor distância..................................................... 114

Figura 29 - Modelo conceitual do Módulo Avaliador de Perfis .................................................... 115

Figura 30 - Etapas para localizar o objeto de aprendizagem .................................................... 119

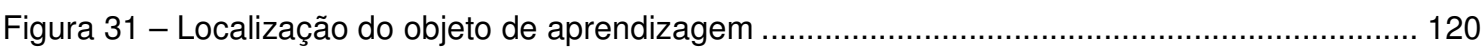

Figura 32 - Estrutura de um CA para perfil com característica seqüencial..................................... 121 
Figura 33 - Construção do CA para alunos com característica de ordem de apresentação

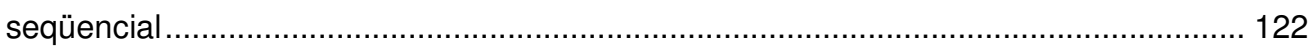

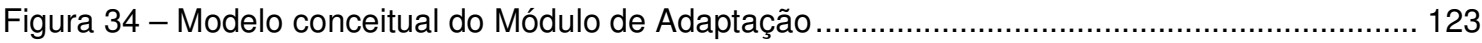

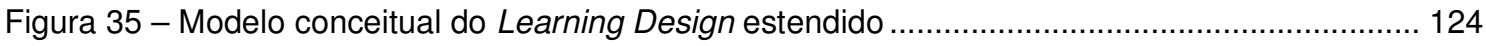

Figura 36 - Etapas que serão realizadas no estudo de caso ..................................................... 126

Figura 37 - Exemplo de cadastro de Característica Observável do tipo ......................................... 129

Figura 38 - Exemplo de cadastro de Característica Observável relacionada a uma ferramenta

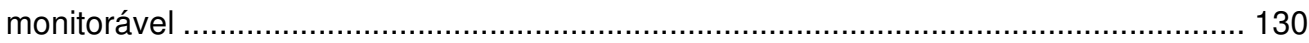

Figura 39 - Exemplo de metadado que descreve caracteristicas monitoráveis................................. 131

Figura 40 - Exemplo de cadastro de Característica Observável do tipo........................................... 132

Figura 41 - Exemplo de cadastro de Tipo de Perfil de Aprendizagem............................................ 134

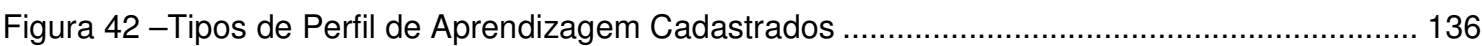

Figura 43 - Alteração do tipo de perfil adotado pelo Mapa de Adaptação ....................................... 137

Figura 44 - Sinalização de AA do tipo interações do aprendiz monitorável...................................... 138

Figura 45 - Sinalização de AA do tipo ponto de checagem monitorável ......................................... 138

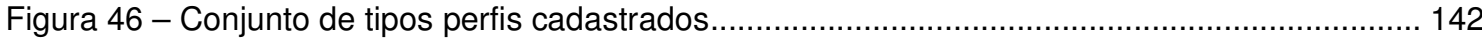

Figura 47 - Cálculo das distâncias entre os tipos de perfis e o perfil analisado .................................. 143

Figura 48 - Primeira etapa de localização de objetos de aprendizagem ......................................... 145

Figura 49 - Segunda etapa de localização de objetos de aprendizagem ......................................... 146

Figura 50 - Terceira etapa de localização de objetos de aprendizagem ……….............................. 147

Figura 51 - Cenário de Aprendizagem apresentado ao aluno ..................................................... 148

Figura 52 - Próxima atividade apresentada ao aluno..................................................................... 149 


\section{LISTA DE TABELAS}

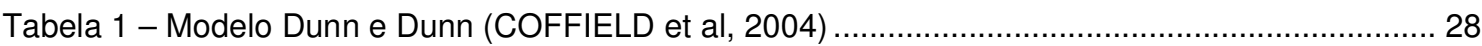

Tabela 2 - Indicadores MBTI (FELDER; BRENT, 2005 e COFFIELD et al, 2004) .............................. 30

Tabela 3 - Modelo propostos por Kolb (FELDER; BRENT, 2005; COFFIELD et al, 2004) ................. 31

Tabela 4 - Modelo de Honey e Mumford (MAGOULAS; PAPANIKOLAOU; GRIGORIADOU, 2003) . 32

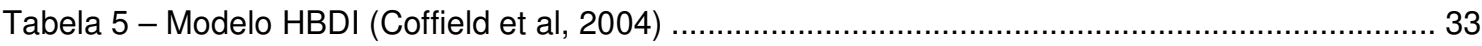

Tabela 6 - Modelo Felder-Silverman (FELDER; BRENT, 2005) ....................................................... 34

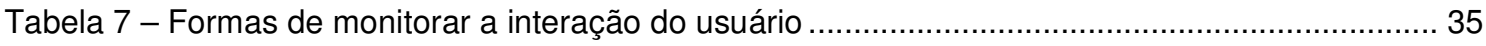

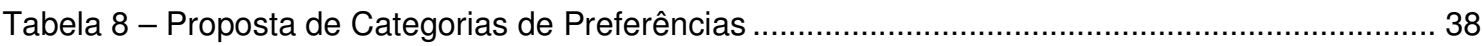

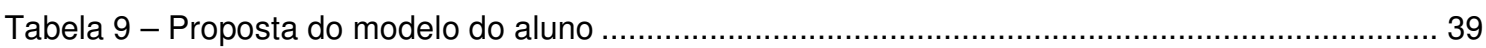

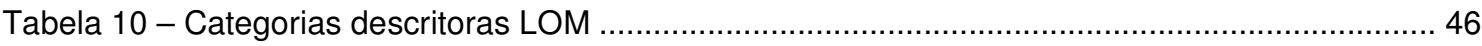

Tabela 11 - Comparação entre ambientes e projetos que não adotam padrões.................................. 68

Tabela 12 - Comparação entre trabalhos estudados que adotam padrões de ensino ......................... 69

Tabela 13 - Estrutura do Mini-curso - Física Geral I................................................................... 79

Tabela 14 - Detalhamento sobre as entidades do Diagrama de Classes - Característica

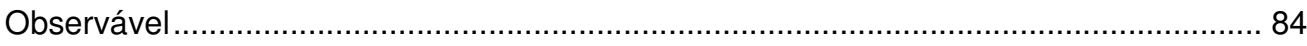

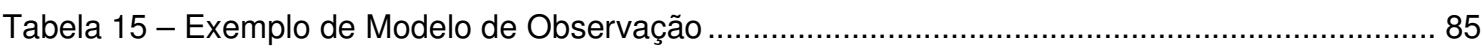

Tabela 16 - Detalhamento das entidades - Tipos de Perfil de Aprendizagem ................................... 92

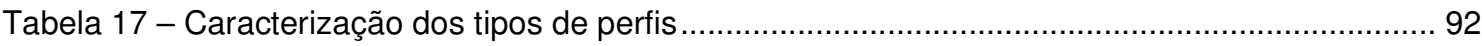

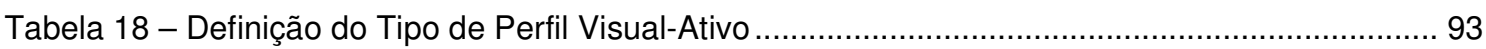

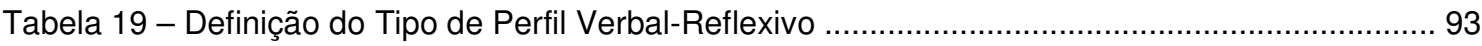

Tabela 20 - Exemplo de Mapa de Adaptação alterado pelo docente ……......................................... 95

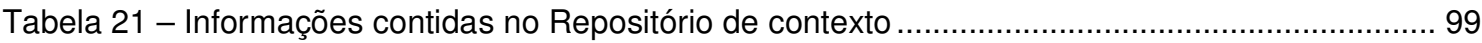

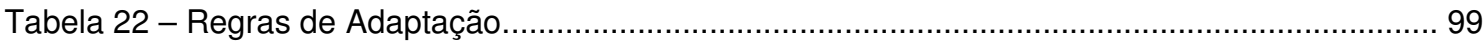

Tabela 23 - Exemplo de Modelo do Aluno atualizado após avaliação das características

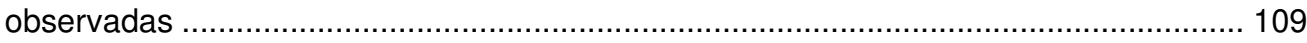

Tabela 24 - Relacionamento entre o perfil de aprendizagem e os objetos de aprendizagem........... 118

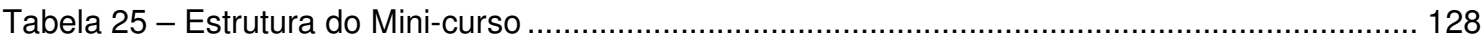

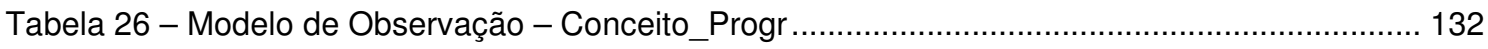

Tabela 27 - Tipo de Perfil Pragmático - Conceito_Progr.................................................................. 134

Tabela 28 - Tipo de Perfil Reflexivo - Conceito_Progr ................................................................. 135

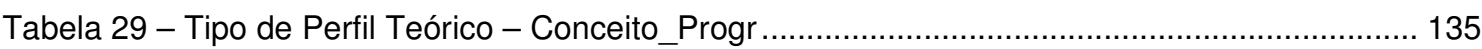

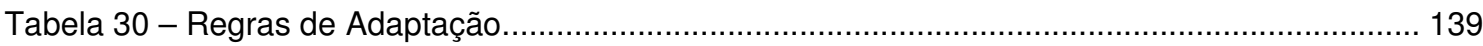

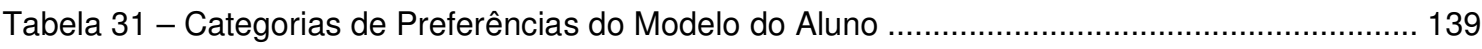

Tabela 32 - Exemplo de histórico de repositório de contexto ...................................................... 141

Tabela 33 -Modelo do Aluno após a avaliação das informações de contexto .................................... 141 


\section{LISTA DE ABREVIATURAS E SIGLAS}

\begin{tabular}{|c|c|}
\hline AA & Atividade de Aprendizagem \\
\hline ADL & Advanced Distributed Learning \\
\hline AES-CS & Adaptive Educational System based on Cognitive Styles \\
\hline $\mathrm{AHA}$ & Adaptive Hypermedia Architecture \\
\hline AHAM & Adaptive Hypermedia Architecture Model \\
\hline ALD & Adaptive Learning Design \\
\hline API & Application Programming Interface \\
\hline CA & Cenário de Aprendizagem \\
\hline CAI & Computer Aided Instruction \\
\hline COL & Sistema de Gerenciamento de Cursos Online \\
\hline ELM-ART & ELM Adaptive Remote Tutor \\
\hline EML & Educational Modelling Language \\
\hline FAPESP & Fundação de Amparo à Pesquisa do Estado de São Paulo \\
\hline FAQ & Frequently Asked Questions \\
\hline HA & Hipermídia Adaptativa \\
\hline HBDI & Instrumento de Inteligência Dominante de Herrmann \\
\hline HyCo_LD & Hypermedia Composer Learning Design \\
\hline IA & Interações do Aprendiz \\
\hline IEEE & Institute of Electronic \& Electrical Engineering \\
\hline $\mathrm{IHC}$ & Interface Humano-Computador \\
\hline IMS & Instructional Management Systems \\
\hline JISC & Joint Information Systems Committee \\
\hline LAMS & Learning Activity Management System \\
\hline LD & Learning Design \\
\hline LearnPES & Learning Profile Evaluator System \\
\hline LMS & Learning Management System \\
\hline LOM & Learning Object Metadata \\
\hline MBTI & Indicador de Myers-Briggs \\
\hline PAP & Política de Aprendizagem Personalizada \\
\hline PC & Ponto de Checagem \\
\hline PDA & Personal Digital Assistant \\
\hline QTI & Question \& Test Interoperability \\
\hline
\end{tabular}




$\begin{array}{ll}\text { Reload } & \text { Reusable eLearning Object Authoring \& Delivery } \\ \text { SCORM } & \text { Shareable Content Object Reference Model } \\ \text { SEDHI } & \text { Sistema Educacional Hipermídia } \\ \text { SLeD } & \text { Service-based Learning Design } \\ \text { STI } & \text { Sistemas Tutores Inteligentes } \\ \text { TIDIA-AE } & \text { Tecnologia da Informação no Desenvolvimento da Internet Avançada - Aprendizado } \\ \text { UML } & \text { Eletrônico } \\ \text { W3C } & \text { Unified Modelling Language } \\ \text { XML } & \text { World Wide Web Consortium } \\ & \text { eXtensible Mark-up Language }\end{array}$




\section{SUMÁRIO}

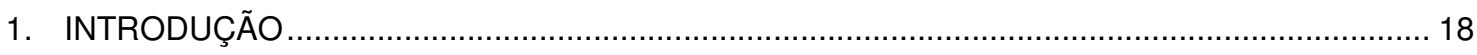

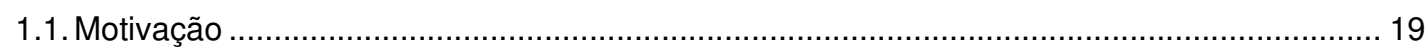

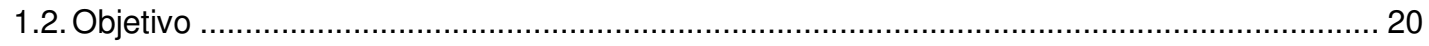

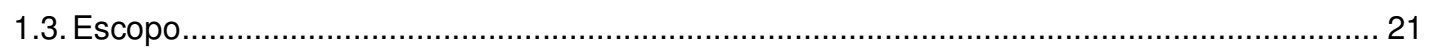

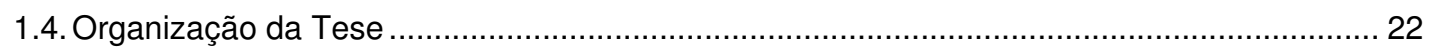

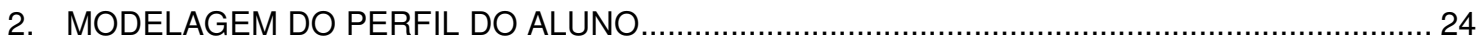

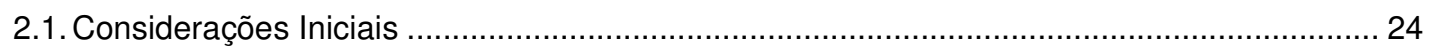

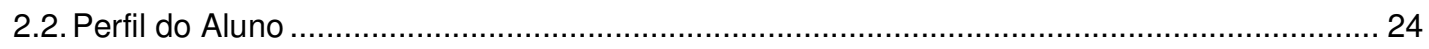

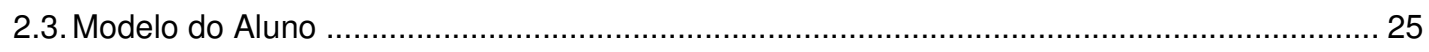

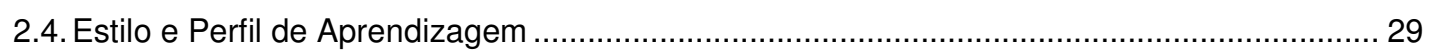

2.4.1. Classificação do aluno através de estilos de aprendizagem .................................... 30

2.5. Estilos de Aprendizagem e a Aprendizagem Eletrônica ........................................................ 34

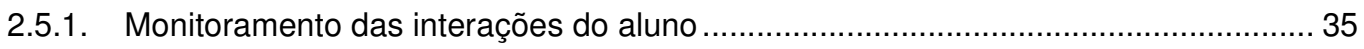

2.5.2. Experiências de classificação de estilos de aprendizagem na aprendizagem

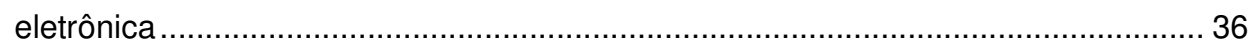

2.6. Proposta de Modelagem do Aluno para Ambiente de Aprendizagem Eletrônica na Web ..... 37

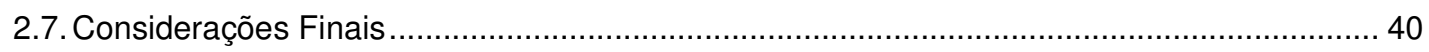

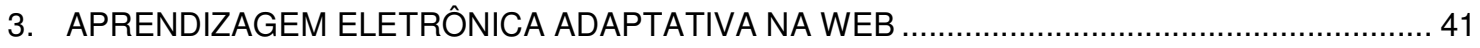

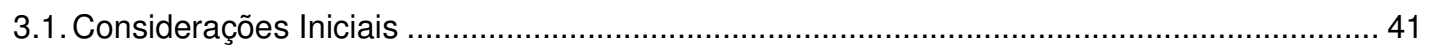

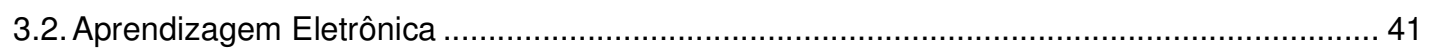

3.2.1. Fundamentos da Aprendizagem Eletrônica ....................................................... 42

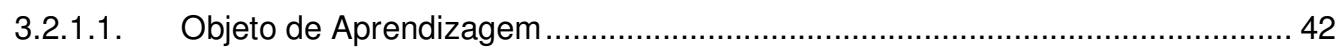

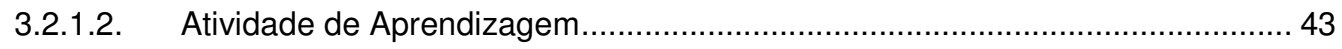

3.2.1.3. Sistemas Gerenciadores de Aprendizagem ................................................. 44

3.2.1.4. Sistemas Gerenciadores de Atividades de Aprendizagem ............................... 44

3.3. Padrões para Implementação de Ambientes de Aprendizagem Eletrônica ........................... 45

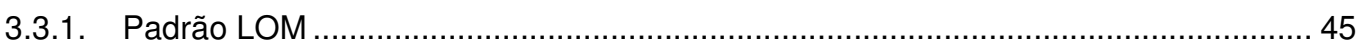

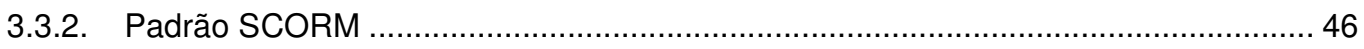

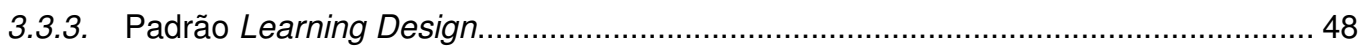

3.3.3.1. Unidades de Aprendizagem ................................................................. 49

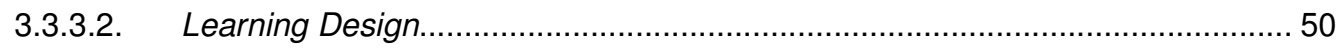

3.3.3.3. Diretivas para definição da adaptação ....................................................... 52

3.4. Ambientes de Aprendizagem Eletrônica Adaptativos ......................................................... 53

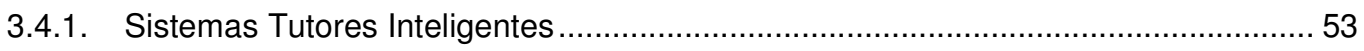

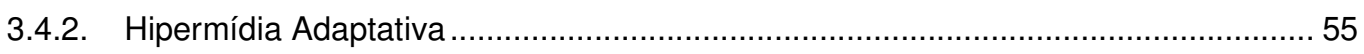

3.4.3. Sistemas Educacionais Adaptativos e Inteligentes baseados na Web ..................... 56

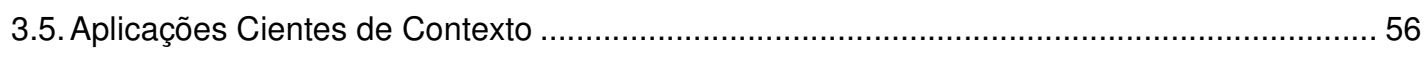

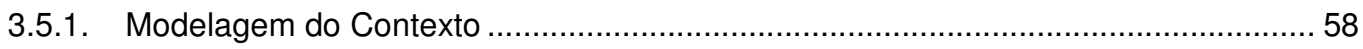


3.6. Ambientes e Projetos de Aprendizagem Adaptativa........................................................... 59

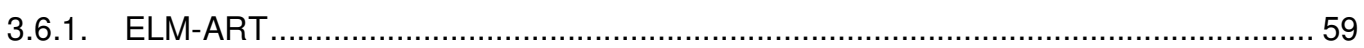

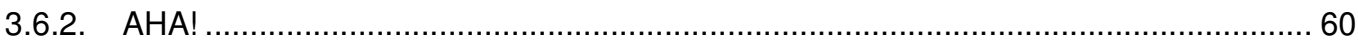

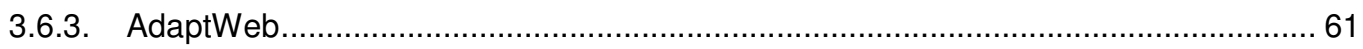

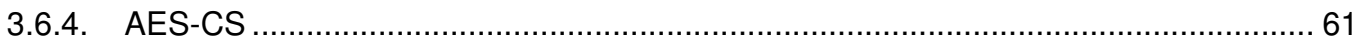

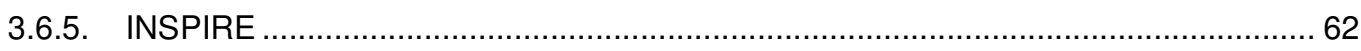

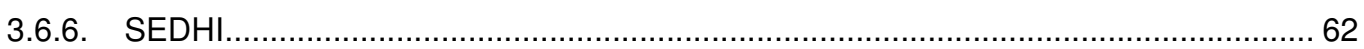

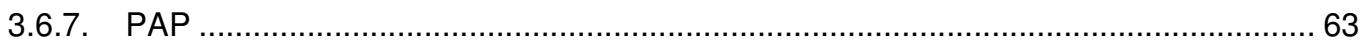

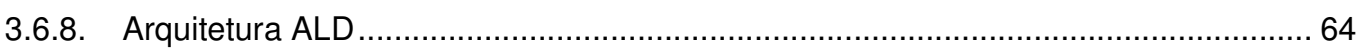

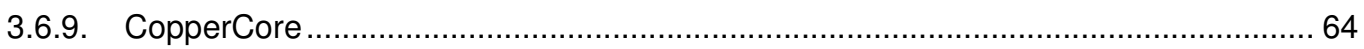

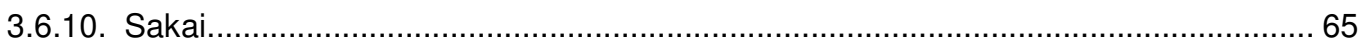

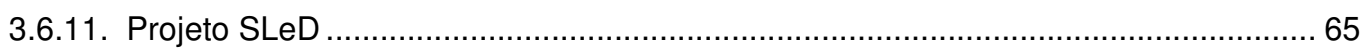

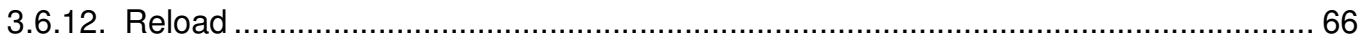

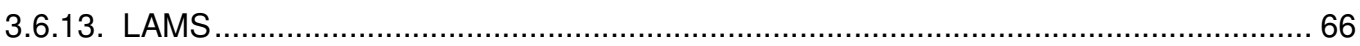

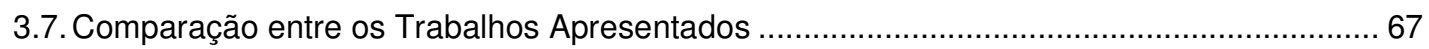

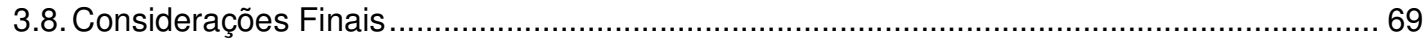

4. PROPOSTA DE UMA ARQUITETURA PARA ADAPTAÇÃO DE CENÁRIOS DE APRENDIZAGEM ATRAVÉS DA AVALIAÇÃO DO PERFIL DE APRENDIZAGEM DO ALUNO ....... 71

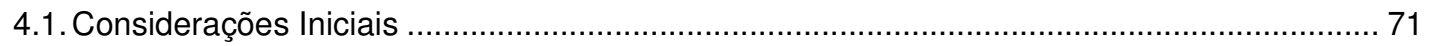

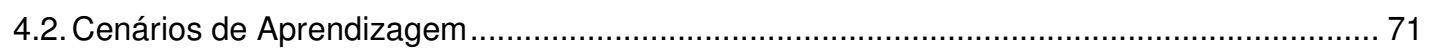

4.3. Requisitos para Desenvolvimento da Arquitetura Proposta ............................................... 73

4.4. Arquitetura para Adaptação de Cenários de Aprendizagem .............................................. 74

4.4.1. Sistema Avaliador de Perfil de Aprendizagem - Learning Profile Evaluator System

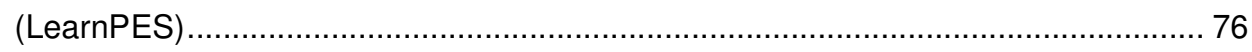

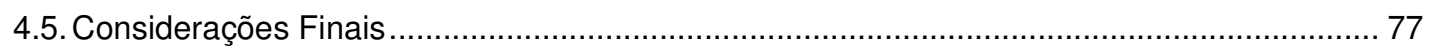

5. MODELAGEM E PLANEJAMENTO DA OBSERVAÇÃO, DA CLASSIFICAÇÃO DOS PERFIS DE APRENDIZAGEM E DA ADAPTAÇÃO

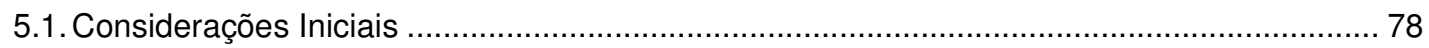

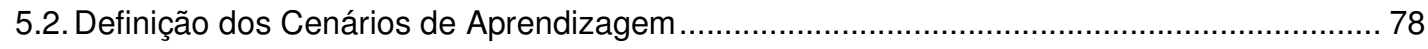

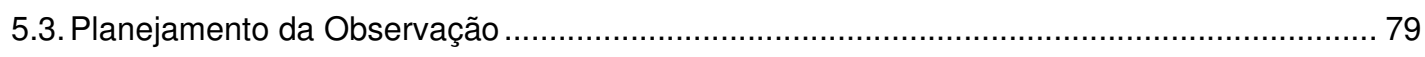

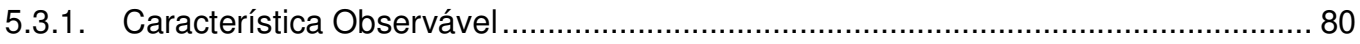

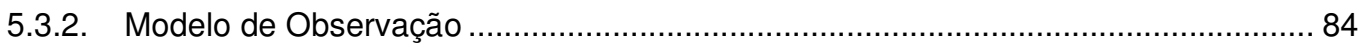

5.3.3. Construção do Modelo de Observação através do LearnPES ................................. 87

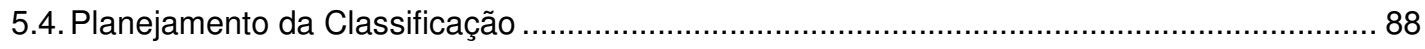

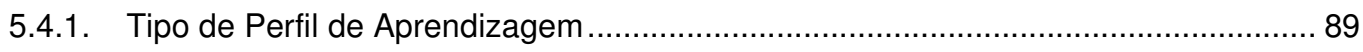

5.4.2. Definição de Tipos de Perfil de Aprendizagem através do LearnPES ...................... 91

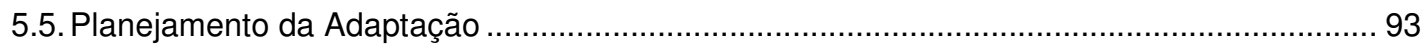

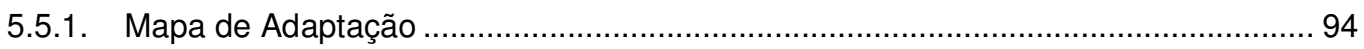

5.5.2. Configuração do Mapa de Adaptação através do LearnPES ..................................... 95

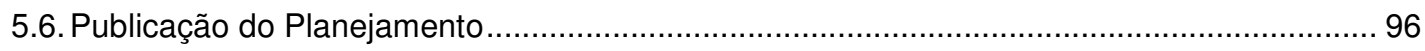

5.6.1. Envio do Modelo de Observação ao Módulo de Monitoração ..................................... 97 
5.6.2. Sinalização dos Cenários de Aprendizagem Monitoráveis....................................... 97

5.6.3. Geração do Repositório de Contexto ....................................................................... 98

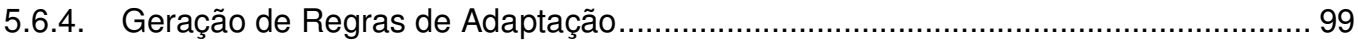

5.6.5. Envio das Características Observáveis ao Modelo do Aluno ................................. 100

5.7. Modelo Conceitual do Módulo de Planejamento............................................................. 100

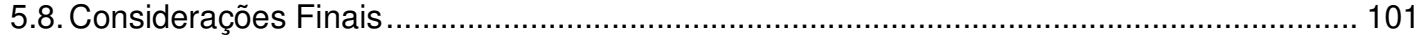

6. ACOMPANHAMENTO DA INTERAÇÃO DO APRENDIZ, AVALIAÇÃO DO PERFIL DE APRENDIZAGEM E ADAPTAÇÃO DO CENÁRIO DE APRENDIZAGEM .................................... 102

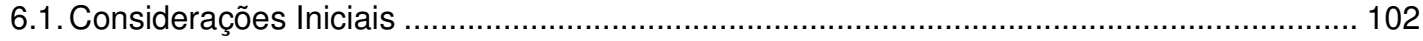

6.2. Monitoração do Contexto da Interação do Aprendiz ........................................................... 102

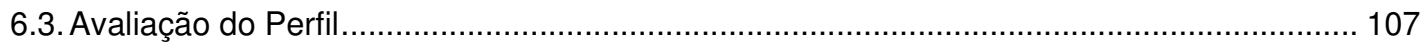

6.3.1. Avaliação das Características Observadas ...................................................... 107

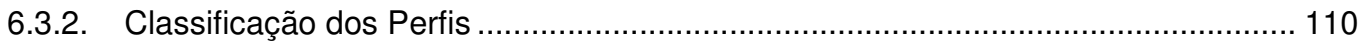

6.3.3. Modelo Conceitual do Módulo Avaliador de Perfis ............................................... 114

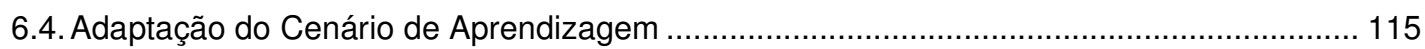

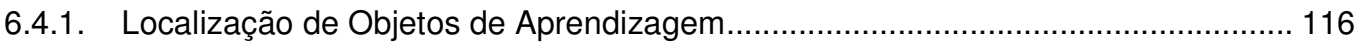

6.4.2. Construção do Cenário de Aprendizagem .......................................................... 120

6.4.3. Modelo Conceitual do Módulo de Adaptação ..................................................... 122

6.5. Modelo do Aluno Incorporado ao Modelo Conceitual do Learning Design........................... 123

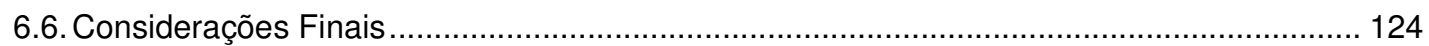

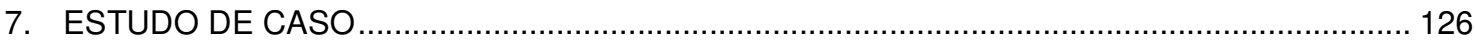

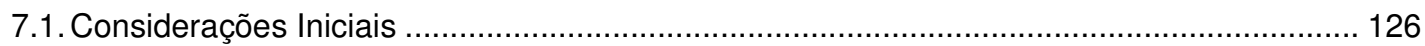

7.2. Definição dos Cenários de Aprendizagem e dos Objetos de Aprendizagem ....................... 127

7.3. Planejamento da Observação, da Classificação dos Perfis e da Adaptação .......................... 128

7.3.1. Definição do Modelo Observação .......................................................................... 129

7.3.2. Definição de Tipos de Perfis de Aprendizagem ................................................... 133

7.3.3. Planejamento da Adaptação ............................................................................ 136

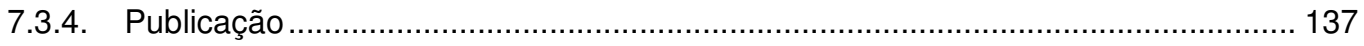

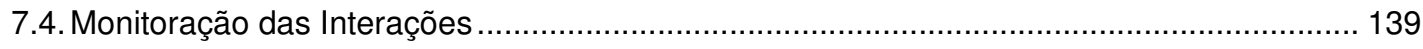

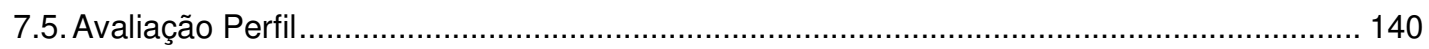

7.5.1. Avaliação das Características Observadas ............................................................ 140

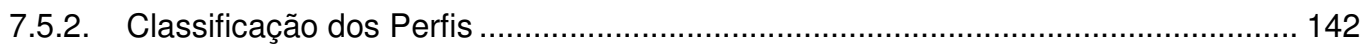

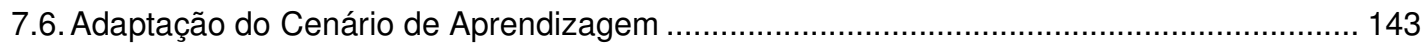

7.6.1. Localização de Objetos de Aprendizagem............................................................ 144

7.6.2. Construção do Cenário de Aprendizagem .............................................................. 148

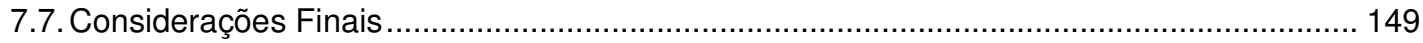

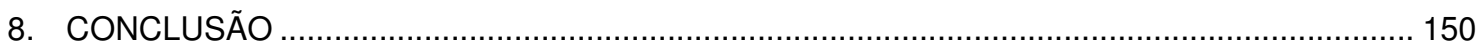

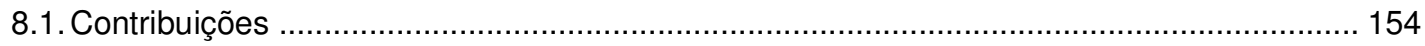

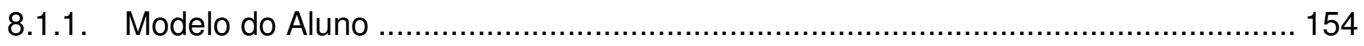

8.1.2. Modelagem da Observação e Monitoração das Interações do Aluno ...................... 155

8.1.3. Avaliação do Perfil de Aprendizagem e Adaptação de Cenários de Aprendizagem 156 
8.2. Trabalhos Futuros

8.2.1. Incorporação da proposta da tese no projeto Tidia-AE ................................... 157

8.2.2. Realização de testes com a arquitetura para diferentes modelos de perfis ............ 158

8.2.3. Adoção de técnicas otimizadas para classificação de perfis ................................ 158

8.2.4. Estender a arquitetura para aplicações de aprendizagem móveis ....................... 158

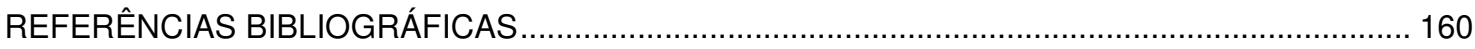

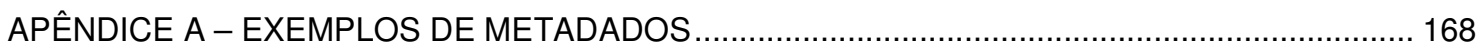

APÊNDICE B - EXEMPLO DE HISTÓRICO REPOSITÓRIO DE CONTEXTO ............................ 170 


\section{INTRODUÇÃO}

O processo de aprendizagem não pode ser definido de forma estática através de moldes únicos e inflexíveis. O conhecimento é um produto adquirido através de ações que ocorrem durante a aprendizagem como percepção, interpretação e análise, que permitem ao indivíduo assimilar e incorporar informações à sua estrutura cognitiva.

Adequar os meios tradicionais de ensino ao aprendizado eletrônico é uma tarefa árdua e tem sido tema de estudo tanto na área educacional como na área tecnológica. Há um esforço no desenvolvimento de infra-estruturas tecnológicas que dão suporte ao uso de novas tecnologias de ensino.

Questões relevantes ao comportamento de aprendizado do aluno são normalmente alteradas de acordo com características inerentes ao ambiente e ao conteúdo com o qual o estudante interage. Um mesmo aprendiz pode ter comportamentos diferentes quando muda de ambiente, ou mesmo, quando é alterado $\mathrm{o}$ assunto abordado no curso.

Não é possível observar os estilos de aprendizagem dos alunos sob um único prisma. Cada estudante possui potenciais distintos para o desenvolvimento de suas habilidades e o processo motivacional de sua aprendizagem está intimamente relacionado com os estímulos recebidos durante essa fase.

A possibilidade de personalizar 0 ambiente onde 0 estudante interage, buscando a individualização do ensino, auxilia tanto o docente quanto 0 aluno a atingirem os objetivos principais da aprendizagem.

Contudo, deve-se observar que a imposição de métodos e metodologias únicas de ensino pode acabar por não atender de fato às necessidades do perfil do aluno. As preferências do aprendiz podem se modificar de acordo com o momento e com o assunto que ele está estudando. Delimitar o escopo de escolha pode acarretar em possíveis falhas do processo de aprendizagem. 


\subsection{MOTIVAÇÃO}

As necessidades individuais de cada estudante fazem com que as aplicações para ensino sofram modificações de forma a se encaixar em diferentes situações de aprendizagem. Uma das principais funções da personalização é adaptar os conteúdos, atividades e ferramentas através de diferentes visualizações ou mesmo a diferentes tipos de conteúdos, dando a sensação ao usuário de que existem ambientes adequados ao seu perfil em um mesmo sistema. $O$ objetivo é satisfazer o usuário através de formas visuais, cores e contextos distintos que possam facilitar sua interação com o ambiente, fazendo com que o usuário seja o foco principal de um ambiente deixando para o sistema o esforço de se moldar às necessidades deste.

O crescimento cada vez maior de usuários na Web fez com que os sistemas, das mais diversas áreas, tivessem que se preocupar não somente em satisfazer os requisitos básicos de funcionamento, mas também contemplasse a adequação do conteúdo e da visualização aos diferentes perfis de usuários destes sistemas.

A área de desenvolvimento de ambientes de aprendizagem eletrônica adaptativas ainda encontra-se em fase de expansão e criação, vivendo um momento de amadurecimento. Alguns ambientes educacionais atuais estão mais focados no gerenciamento de objetos de aprendizagem, tendo um funcionamento similar ao de repositórios de material educacional, onde é permitido a reutilização de conteúdos. Outros ambientes apontam para desenvolvimento de fragmentos adaptativos que sejam orientados aos serviços que o ambiente pode prestar aos alunos de forma a adaptar as visualizações e apresentações de acordo com as preferências e conhecimentos prévios do estudante.

O conceito de adaptação do ambiente às necessidades do aprendiz pode ser observado sob diferentes óticas, podendo ser aplicado desde ao aspecto da interface de interação do aluno até aos tipos de dispositivos com que este interage. É possível destacar como focos importantes dentro do contexto da adaptação algumas áreas em especial. Uma delas é denominada de IHC (Interface HomemComputador) que trabalha com questões relativas à configuração da interface com o usuário. O objetivo principal desta área é especificar itens que estejam relacionados com o layout e a interação do aluno com o ambiente de aprendizagem, como por 
exemplo, posicionamento de links, cores aplicadas ao ambiente, disposição dos elementos no ambiente, etc. O controle sobre o conteúdo apresentado e a forma de navegação do curso é outro ponto considerado em questões adaptativas. Este tipo de controle permite que possam ser implementadas no ambiente, maneiras distintas de apresentar um mesmo conteúdo dependendo do perfil do aprendiz e das metodologias que se deseja adotar no processo de ensino aprendizagem. Ou mesmo, que o conteúdo possa ser apresentado de acordo com o grau de maturidade de conhecimento do aluno.

Um fator fundamental durante o processo de acompanhamento do aluno é ter ciência do contexto onde o aluno está agindo. Uma aplicação ciente de contexto é aquela que tem domínio das informações sobre o contexto em que interage, onde contexto é definido por um grupo de informações relevantes sobre a interação do usuário com a aplicação, incluindo o próprio usuário e a aplicação.

A área de Modelagem do Usuário apresenta aspectos relevantes sobre a modelagem do perfil do aluno durante a interação deste em um ambiente adaptativo. Através da modelagem é possível se obter informações que possam determinar como será apresentada a resposta de uma interação de acordo com os interesses do usuário. Tais informações se tornam ainda mais importantes dentro do contexto de aprendizagem onde se deseja apresentar ao aluno opções adequadas ao estilo de aprendizagem dele, permitindo, assim, a adoção de um ensino individualizado.

\subsection{OBJETIVO}

O objetivo deste trabalho é definir uma arquitetura para adaptação de cenários de aprendizagem que seja baseado em concepções de aplicações cientes de contexto e que permita a reutilização de modelos de perfil definidos dentro de um determinado ambiente de aprendizado eletrônico na Web. A partir de dados obtidos das interações do aluno em um determinado mecanismo de monitoração, deve-se observar o comportamento deste aluno e então adaptar o ambiente segundo as preferências e necessidades do aprendiz considerando as necessidades metodológicas de um dado assunto.

A adaptação do processo de aprendizagem em ambientes de aprendizagem eletrônica deve ser baseada nas informações extraídas da interação do aluno e nos 
modelos de perfis previamente cadastrados, relacionando os mesmos ao ambiente em que o aluno está inserido no momento. O foco é oferecer ao aluno as ferramentas, conteúdos e tarefas que sejam adequados ao seu perfil de aprendizagem, analisando os dados associados à sua interação.

Os modelos de perfis são definidos por um elaborador de perfis, que é a pessoa responsável por especificar quais são os aspectos relevantes ao escopo de ensino num dado cenário de aprendizagem. A arquitetura irá relacionar as definições do elaborador de perfis com as entidades que criam os modelos sistemicamente, criando modelos de perfis que possam ser portáveis a diferentes cenários de aprendizagem.

Um objetivo específico é possibilitar que a arquitetura proposta possa ser futuramente incorporada ao projeto Tidia-AE ${ }^{1}$ (Tecnologia da Informação no Desenvolvimento da Internet Avançada - Aprendizado Eletrônico) patrocinado pela FAPESP ${ }^{2}$.

O Tidia-AE foi criado com o objetivo de motivar a pesquisa científica e tecnológica para desenvolvimento de ambientes e de experiências na área de aprendizado eletrônico. Muitas universidades localizadas no estado de São Paulo desenvolviam projetos na área de aprendizado eletrônico, porém os esforços ficavam isolados. Através do projeto, foi possível integrar diferentes trabalhos através de um desenvolvimento colaborativo entre laboratórios situados geograficamente distantes (ZAINA; BRESSAN; RUGGIERO, 2006).

\subsection{ESCOPO}

O trabalho proposto se insere no escopo de aplicações para aprendizado eletrônico onde seja possível adaptar o ambiente ao perfil do aluno de acordo com estilos de aprendizagem. Este trabalho não abordará técnicas e modelos relativos à monitoração das interações do aluno. Será considerado que os dados utilizados já foram obtidos previamente através de um módulo de monitoração de aplicações cientes de contexto. Além disto, não se encontra dentro do escopo deste trabalho realizar adaptações que considerem os diferentes equipamentos. Outro ponto não

\footnotetext{
${ }^{1}$ http://www.tidia.fapesp.br/portal

${ }^{2}$ http://www.fapesp.br/
} 
contemplado no escopo deste trabalho é relativo a questões de IHC. Não serão abordados os modelos e mecanismos referentes à adaptação visual do ambiente de aprendizagem. O trabalho encontra-se delimitado dentro do contexto do desenvolvimento da adaptação e dos cenários de aprendizagem em relação ao perfil do aluno, não considerando, por exemplo, os diferentes formatos de compressão de mídias, resolução de tela de diferentes dispositivos, adequação de cores, layout de tela, etc.

\subsection{ORGANIZAÇÃO DA TESE}

O trabalho está organizado em oito capítulos conforme descrito a seguir:

- Capítulo 1: Introdução. Este capítulo tem por finalidade situar o leitor sobre a tese apresentando a motivação do trabalho, seu objetivo, escopo e organização do documento.

- Capítulo 2: Modelagem do perfil do aluno. Este capítulo apresenta a definição de conceitos relacionados ao perfil do aluno, modelo do aluno e estilos de aprendizagem. São apresentados alguns modelos referentes a estilos de aprendizagem. Além disto, são apresentadas algumas experiências sobre a adoção de modelos de estilos de aprendizagem no ensino on-line.

- Capítulo 3: Aprendizagem eletrônica adaptativa na Web. Este capítulo descreve conceitos sobre aprendizagem eletrônica aplicados no desenvolvimento de ambientes. São abordados fundamentos sobre a especificação dos padrões SCORM, Learning Design e LOM. Questões sobre a ciência de contexto no desenvolvimento de aplicações são apresentadas também. As áreas de Sistemas de Tutores Inteligentes e de Hipermídia Adaptativa são brevemente discutidas. Por fim, é apresentado um estudo de trabalhos que aplicam os conceitos de adaptação, modelagem do usuário e adaptação em sua implementação.

- Capítulo 4: Proposta de uma Arquitetura para Adaptação de Cenários de Aprendizagem através da Avaliação do Perfil de Aprendizagem do Aluno. Este capítulo apresenta, através de uma visão geral, a proposta de 
uma arquitetura para adaptação de Cenários de Aprendizagem baseada na avaliação do perfil do aluno.

- Capítulo 5: Modelagem e Planejamento da Observação, da Classificação dos Perfis de Aprendizagem e da Adaptação. Este capítulo apresenta o detalhamento sobre o planejamento da observação que será realizada nas interações do aluno para que estes possam ser classificados em um determinado perfil de aprendizagem. Além disto, também descreve sobre o planejamento dos tipos de perfis de aprendizagem que serão considerados durante 0 processo de classificação dos perfis. Também descreve como será realizado o planejamento da adaptação.

- Capítulo 6: Acompanhamento da interação do aprendiz, Avaliação do Perfil de Aprendizagem e Adaptação do Cenário de Aprendizagem. Este capítulo detalha o acompanhamento das interações do aprendiz em um dado ambiente de aprendizagem. Além disto, é especificado como é realizada a avaliação do perfil de aprendizagem do aluno a partir do planejamento da observação (Capítulo 5). Por fim, descreve o processo de construção do cenário de aprendizagem do aluno de acordo com o perfil de aprendizagem em que o estudante foi classificado.

- Capítulo 7: Estudo de caso. Apresenta um estudo de caso hipotético aplicando a arquitetura proposta neste trabalho (Capítulos 4, 5 e 6).

- Capítulo 8: Conclusões. Finaliza a discussão sobre a proposta apresentando as contribuições do trabalho e as possíveis ramificações deste que podem gerar trabalhos futuros. 


\section{MODELAGEM DO PERFIL DO ALUNO}

\subsection{CONSIDERAÇÕES INICIAIS}

A necessidade de adaptar as estratégias de ensino de acordo com as necessidades de aprendizagem do estudante é uma realidade dentro das salas de aula, sejam estas presenciais ou virtuais. Porém, isto não significa que numa sala de aula deva haver criação de um método de ensino para cada aluno, mas sim que se aponte qual a melhor forma de interação para cada um deles construindo grupos de aprendizes com características comuns. Trabalhando desta forma se torna possível identificar perfis de aprendizes dentro de um conjunto de estudantes permitindo a oferta de conteúdos e atividades de aprendizagem mais adequados aos aprendizes.

Este capítulo tem como objetivo apresentar conceitos que estão diretamente relacionados ao perfil do aluno, como o modelo do aluno e os estilos de aprendizagem.

Serão apresentados também alguns modelos de estilos de aprendizagem definidos por pesquisadores da área de estilos de aprendizagem que podem ser encontrados em Coffield et al (2004). Os modelos que serão apresentados são aqueles que se destacam na área de ensino de engenharia, segundo Felder e Brent (2005).

Além disto, será abordada também a importância da adoção de estilos de aprendizagem na aprendizagem eletrônica, apresentando experiências em que foram adotados modelos de estilos de aprendizagem no ensino on-line.

Ao final será apresentada uma proposta de modelo do aluno que será utilizada neste trabalho.

\subsection{PERFIL DO ALUNO}

A necessidade de conhecer as características de um usuário surgiu com o desenvolvimento de aplicações adaptativas. Historicamente pode-se destacar que até 1996 eram utilizadas para a adaptação de um dado ambiente informações relevantes ao usuário tais como seus objetivos, conhecimentos atuais e adquiridos, sua experiência com o sistema e suas preferências. Porém, a partir de 1996, 
observou-se a necessidade de se organizar informações sobre o usuário de acordo com as demandas do ambiente, criando uma sinergia entre as informações obtidas a partir da interação do usuário e o ambiente em que este interagia, (BRUSILOVSKY, 2001).

O perfil do aluno é determinado através de elementos, traços que permitem ressaltar as características básicas deste aluno, permitindo que ele possa ser identificado a partir destas características.

Um perfil do aluno é composto por um conjunto de propriedades que caracterizam o estudante como: sua identificação pessoal, suas preferências pessoais e sociais, seu perfil de aprendizagem, seu conhecimento sobre determinados assuntos, etc. Algumas informações relativas ao perfil do aluno, como sua identificação pessoal, preferências pessoais e sociais, são raramente modificadas. Em contrapartida, informações que envolverm aspectos cognitivos como seu estilo de aprendizagem e seu conhecimento sobre um dado assunto, são constatemente alteradas. Além disto, as informações sobre os aspectos cognitivos estão diretamente relacionadas ao ambiente e ao escopo de aprendizagem, fazendo com que seja necessária a ocorrência de alterações dentro deste contexto (DOLOG; SCHAEFER, 2005; LEE et al, 2005).

Obter informações sobre o aluno que sejam relevantes ao processo de adaptação da aprendizagem é fundamental dentro do cenário de ensino. Porém, estas informações necessitam de uma organização, fazendo com que as mesmas se tornem mais aderentes ao sistema, facilitando assim uma possível interpretação e análise das informações. Uma das formas de organizar as informações referentes ao aluno é criar modelos que auxilem o sistema a agir e reagir de acordo com as necessidades do aprendiz. Tais modelos são denominados de modelo do aluno e retratam as informações referentes ao perfil do aluno.

\subsection{MODELO DO ALUNO}

Segundo Rosatelli e Tedesco (2003), a área de modelagem do usuário, de forma genérica, procura construir uma representação explícita do perfil de um usuário em particular, de forma que este possa auxiliar um dado ambiente eletrônico durante o processo de adaptação deste ambiente. 
Considera-se que o modelo do usuário é uma representação formal e explícita do perfil de um usuário. Modelar o usuário é o ato de criar um modelo, através do ambiente em que o usuário interage, que represente informações do usuário capturadas através de sua interação (KOBSA, 2001). Dentro do escopo de ambientes de aprendizagem eletrônica o usuário considerado é o aluno já que este é o centro do processo de aprendizagem.

O modelo do aluno tem como característica principal organizar as informações que identificam o perfil de um aluno de forma que estas possam ser interpretadas por um ambiente eletrônico. Pode-se afirmar que o modelo do aluno é a modelagem sistêmica do perfil do aluno.

A modelagem do aluno sempre foi um componente importante dentro do processo de adaptação de ambientes de aprendizagem eletrônica, pois é através dela que o sistema se direciona sobre as ações a serem realizadas de acordo com a interação do aluno. A organização das informações sobre o aprendiz em um modelo permite que os sistemas tornem-se mais extensíveis e modulares.

Rosatelli e Tedesco (2003) afirmam que algumas informações são fundamentais para a criação do modelo do usuário, como:

- Ter dados sobre as habilidades do usuário relevantes ao contexto em que o mesmo se encontra inserido, observando o quanto o usuário conhece sobre 0 assunto.

- Obter os padrões de comportamento do usuário com o sistema para que seja possível obter mecanismos que auxiliem na motivação do usuário dentro do ambiente.

- Considerar o momento e o local da interação para que isto auxilie o mapeamento das interações.

Pode-se afirmar que o modelo do aluno é formado por subconjuntos de informações que permitem traçar o perfil do aluno, como no exemplo ilustrado na Figura 1.

O subconjunto "conhecimento" apresentado no exemplo da Figura 1 tem como componentes as "crenças" que representam conhecimentos prévios do aluno e as "habilidades" que o aluno tem em um dado assunto que sejam relevantes ao escopo de ensino. As "preferências" podem ser constituídas por diversos 
componentes, pois podem englobar itens que representam diferentes características. Um ponto relevante é que através dos itens dos subconjuntos que formam o modelo do aluno é possível se obter outras informações a respeito do estudante. É possível, por exemplo, se obter informações sobre como o aluno prefere aprender observando seu comportamento em relação às suas "preferências", "conhecimento", etc. Um aluno que frequentemente opta por utilizar um dado tipo de mídia, como vídeo, durante suas interações com o ambiente de aprendizagem, pode estar demonstrando uma preferência em aprender com métodos de ensino que sejam visuais.

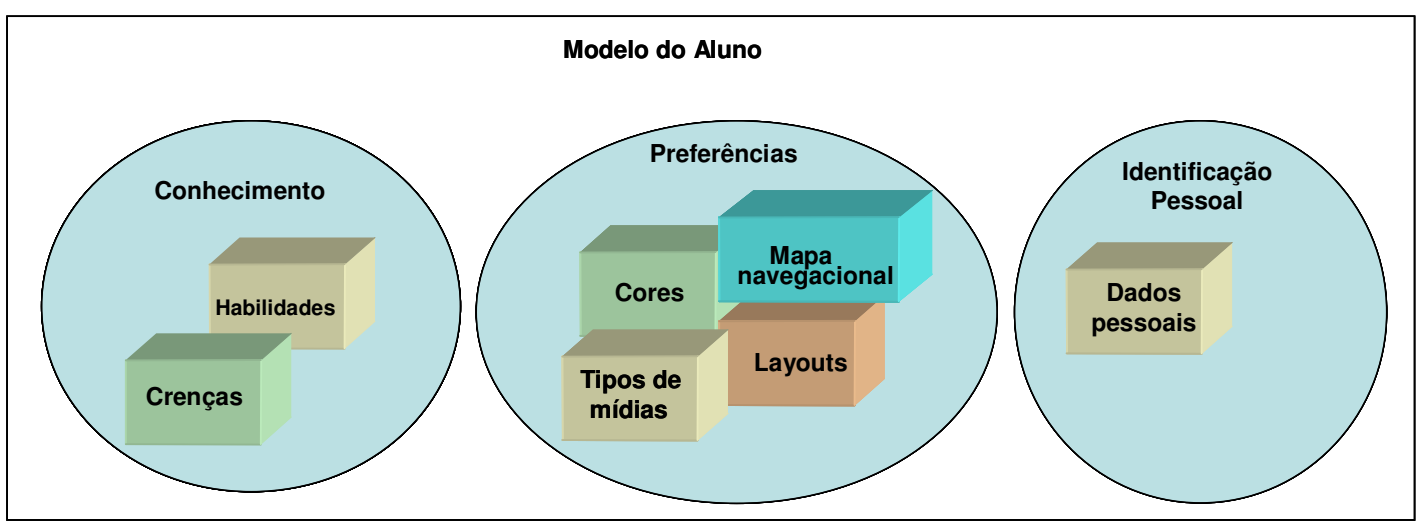

Figura 1 - Modelo do Aluno, adaptado de Rosatelli e Tedesco, 2003; Kobsa, Koenemann e Pohl, 2001

Para Stewart, Niederée e Metha (2004) é importante haver um modelo genérico que retrate os aspectos relativos ao perfil do aluno para que este seja utilizado como base para a construção de outros modelos. Deve-se permitir que novos modelos sejam criados a partir de um modelo base agregando-se informações fundamentais dentro do contexto analisado, considerando o conteúdo abordado bem como o ambiente de interação. Isto permite que a área de modelagem do perfil do aluno possa ser estendida com maior facilidade, construindo assim diferentes modelos de perfis.

A obtenção das informações que irão constituir o modelo do aluno pode ser realizada de diferentes maneiras e em diferentes escopos do ambiente educacional, que vai desde a captura de dados relativos às respostas do aluno a um dado problema até o monitoramento da interação do aluno com o ambiente.

Quando o usuário interage com o sistema ele está informando, de maneira implícita, suas atitudes e ações, permitindo ao ambiente explorar estes dados. 
Embora esta forma de captura de informações não seja totalmente eficaz, pois o ambiente pode realizar deduções inválidas a respeito das preferências do aprendiz, ela pode auxiliar o sistema a identificar pontos importantes sobre o usuário.

Fisher (2001) destaca que quando há a interação do aluno com o sistema é construído dois tipos de canais de comunicação: o explícito que é alimentado pelas informações passadas de forma objetiva ao sistema, e a implícita, na qual através da interação do aluno é possível obter dados a respeito de suas habilidades. É importante destacar que para que o canal implícito possa existir é necessário que o sistema já tenha um conhecimento sobre o contexto e sobre o processo de comunicação entre o aluno e o ambiente

Uma questão fundamental dentro da área de modelagem do aluno é determinar como construir modelos concisos que representem da melhor forma os aspectos cognitivos de um aprendiz em relação ao ambiente em que este se encontra. Um dos pontos é identificar qual estilo de aprendizagem está associado ao aluno para que seja possível traçar o perfil de aprendizagem do mesmo.

Muitos são os estímulos que podem incidir diretamente no comportamento do aluno agindo diretamente na construção do seu modelo e conseqüentemente na identificação do seu perfil. O Modelo Dunn e Dunn, proposto por Rita Dunn e Kenneth Dunn, trabalha com o princípio de que as preferências de um aprendiz estão diretamente relacionadas com outros fatores além da inteligência, como por exemplo, o ambiente em que ele aprende, as oportunidades que são dadas ao estudante durante a aprendizagem, etc. A Tabela 1 apresenta os estímulos ambientais definidos pelo modelo e suas principais características.

Tabela 1 - Modelo Dunn e Dunn (COFFIELD et al, 2004)

\begin{tabular}{|c||c||}
\hline Estímulos ambientais & \multicolumn{1}{c|}{ Características } \\
\hline \hline Ambiental & $\begin{array}{l}\text { Incorpora preferências individuais como elementos de som, luz, temperatura, } \\
\text { modelo das cadeiras, etc. }\end{array}$ \\
\hline \hline Emocional & $\begin{array}{l}\text { Está relacionado com o nível de motivação, persistência, maturidade do } \\
\text { aprendiz entre outros fatores }\end{array}$ \\
\hline \hline Sociológico & $\rightarrow \begin{array}{l}\text { Demonstra a preferência do aluno em estudar sozinho ou em grupo, realizar } \\
\text { trabalhos em grupos, etc. }\end{array}$ \\
\hline \hline Psicológico & $\rightarrow \begin{array}{l}\text { Verificam a intensidade da percepção de cada aluno (visual, auditiva, } \\
\text { sinestésica, etc), necessidades e reações com estímulos alimentares e } \\
\text { mobilidade enquanto aprende. }\end{array}$ \\
\hline \hline Elementos Psicológicos & $\rightarrow \begin{array}{l}\text { Incorporam o processamento de informações como global em relação ao } \\
\text { analítico, o impulsivo em relação ao reflexivo. }\end{array}$ \\
\hline $\begin{array}{l}\text { Elementos psicológicos que influenciam diretamente o processo de } \\
\text { aprendizagem. }\end{array}$ \\
$\rightarrow \begin{array}{l}\text { Procuram observar como o agrupamento de vários elementos podem } \\
\text { interferir no processo de aprendizagem. }\end{array}$ \\
\hline \hline
\end{tabular}


É constituído por cinco tipos de estímulos, onde existem variáveis que irão afetar as preferências do aprendiz como som, a mobilidade do aluno na sala, o trabalho em grupo, temperatura ambiente, tipo de iluminação, etc. O modelo introduz características biológicas como fatores importantes.

\subsection{ESTILO E PERFIL DE APRENDIZAGEM}

Um estilo de aprendizagem está relacionado às estratégias que um aluno tende a aplicar com freqüência a uma dada situação de ensino. Cada indivíduo pode se encaixar em diferentes estilos que fazem com que ele adote atitudes e comportamento que se repetem em diferentes momentos e situações. Para atender um dado estilo de aprendizagem é necessário que o docente utilize estratégias de ensino que possam suprir as diferentes perspectivas de aprendizagem.

Estilos de aprendizagem são características cognitivas, afetivas $\mathrm{e}$ psicológicas que determinam como um aluno interage e reage em um ambiente de aprendizado (FELDER; BRENT, 2005). Pode-se sintetizar que estilos de aprendizado se referem às características individuais que um aluno tem de organizar, perceber, processar, lembrar e pensar para resolver um problema (LIU; GINTHER 1999; TRIANTAFILLOU; POMPORTSIS; DEMETRIADIS, 2003).

Através da observação de um estilo de aprendizagem se deseja identificar quais são as características marcantes em um dado aprendiz de maneira que estas influenciem no processo de aprendizagem deste aluno. Observando a forma como o aluno exprime e exteritoriza sua interação com o ambiente de ensino (seu estilo de aprendizagem) é possível obter o perfil de aprendizagem do aluno. $\underline{0}$ perfil de aprendizagem pode ser definido como um conjunto de propriedades que identificam características marcantes do aluno durante o processo de aprendizagem.

Realizando uma comparação sucinta pode-se afirmar que enquanto o estilo de aprendizagem apresenta o modo pelo qual o aluno interage refletido através de seu comportamento e preferências, o perfil de aprendizagem determina as características que são marcantes em seu estilo.

A adoção de um dado estilo em um processo de aprendizagem possibilita que o aluno possa imprimir um ritmo mais eficiente de aprendizado. Através do estilo de aprendizagem é possível identificar o perfil de aprendizagem do aluno. 


\subsubsection{Classificação do aluno através de estilos de aprendizagem}

Existem diversos modelos que refletem formas de se classificar um aluno segundo estilos de aprendizagem. Os modelos representam práticas e classificações que permitem identificar um dado aluno dentro de um ambiente considerando características que sejam relevantes ao escopo de aprendizagem.

Segundo Felder e Brent (2005), embora existam muitos modelos para serem adotados como estilos de aprendizagem são cinco deles que se destacam na área de ensino de engenharia:

- Indicador de Myers-Briggs (Myers-Briggs Type Indicator - MBTI): é derivado da teoria de Jung de tipos psicológicos. Procurou-se alterar a teoria proposta por Jung para que os tipos psicológicos pudessem ser observados de forma mais concreta (Coffield et al, 2004). O MBTI apresenta os estilos individuais em quatro escalas com classificações bipolares para cada uma delas (Tabela 2).

Tabela 2 - Indicadores MBTI (FELDER; BRENT, 2005 e COFFIELD et al, 2004)

\begin{tabular}{|c|c|c|}
\hline $\begin{array}{c}\text { Estilos de } \\
\text { Aprendizagem }\end{array}$ & \multicolumn{1}{c|}{ Características } \\
\hline \hline Extrovertido & $\rightarrow$ Gosta de trabalhar em grupo \\
& $\rightarrow$ Focado no exterior das pessoas \\
\hline Introvertido & $\rightarrow$ Prefere o trabalho individual \\
& $\rightarrow$ Focado nas idéias \\
\hline \hline Racional & $\rightarrow$ Prático, orientado a detalhes \\
\hline Intuitivo & $\rightarrow$ Focado em fatos e procedimentos \\
\hline \hline Pensador & $\rightarrow$ Imaginativo, orientado a conceitos \\
\hline Observador & $\rightarrow$ Céticos \\
\hline \hline Julgador & $\rightarrow$ Tente a tomar as decisões baseados em regras e em lógicas \\
\hline Atento & $\rightarrow$ Tende a tomar as decisões considerando o lado pessoal \\
\hline & $\rightarrow$ Gogue um roteiro definido \\
\hline
\end{tabular}

Um aluno pode possuir diversos estilos de aprendizagem ao mesmo tempo. Por exemplo, um aluno pode possui características de "Extrovertido", "Racional", "Observador" e "Atento" ao mesmo tempo. 
- Estilo de Aprendizagem de Kolb: foca nas preferências de como o aluno recebe a informação (experimentos concretos ou conceitos abstratos) e como ele processa esta informação (experimentação ativa ou observação reflexiva), (FELDER e BRENT, 2005). Kolb desenvolveu uma classificação de estilos de aprendizagem que conseguisse posicionar um indivíduo entre o concreto e 0 abstrato e entre os experimentos e a observação reflexiva criando quatro estilos de aprendizagem apresentados na Tabela 3.

Tabela 3 - Modelo proposto por Kolb (FELDER; BRENT, 2005; COFFIELD et al, 2004)

\begin{tabular}{|c|c|}
\hline Estilo de Aprendizagem & Características \\
\hline $\begin{array}{l}\text { Não Focado (Diverger) }= \\
\text { Concreto + Reflexivo }\end{array}$ & $\begin{array}{l}\rightarrow \quad \begin{array}{l}\text { Necessita de experiências aplicadas para relacionar o conteúdo através } \\
\text { de reflexões feitas após a observação. }\end{array} \\
\rightarrow \quad \text { Possui criatividade e facilidade em desenvolver novas visões sobre o } \\
\text { conteúdo estudado. } \\
\rightarrow \text { Sua pergunta característica é "por que". } \\
\rightarrow \text { O professor deve agir como um motivador. }\end{array}$ \\
\hline $\begin{array}{c}\text { Assimilador (Assimilator) }= \\
\text { Abstrato + Reflexivo }\end{array}$ & $\begin{array}{l}\rightarrow \text { Grande capacidade no desenvolvimento de modelos teóricos. } \\
\rightarrow \text { Possui raciocínio indutivo (a partir da utilização de observações } \\
\text { individuais constrói regras gerais. Fundamenta-se numa relação de } \\
\text { causalidade sem bases sólidas. Constrói-se a partir das conclusões } \\
\text { pessoais). } \\
\rightarrow \text { Sua pergunta característica é "o que". } \\
\rightarrow \text { O docente deve agir como um especialista. }\end{array}$ \\
\hline $\begin{array}{c}\text { Focado }(\text { Converger })= \\
\quad \text { Abstrato }+ \text { Ativo }\end{array}$ & $\begin{aligned} & \rightarrow \text { Ênfase nas aplicações práticas. } \\
& \rightarrow \text { Focado em raciocínios sub-dedutivos (Raciocínio Dedutivo: a partir de um } \\
& \text { ou vários juízos tomados como premissas, conclui um novo juízo que é a } \\
& \text { sua conseqüência das premissas anteriores. Possui bases sólidas para a } \\
& \text { conclusão de premissas). } \\
& \rightarrow \text { Sua pergunta característica é "como". } \\
& \rightarrow \text { O docente deve agir como um treinador, guiando e dando retorno sobre o } \\
& \text { aprendizado. }\end{aligned}$ \\
\hline $\begin{array}{c}\text { Acomodador (Accomodator) } \\
=\text { Concreto + Ativo }\end{array}$ & $\begin{array}{l}\rightarrow \text { Resolve problemas de forma intuitiva. } \\
\rightarrow \text { Prefere aprender através de aplicações práticas. } \\
\rightarrow \text { Sua pergunta característica é "o que acontece se". } \\
\rightarrow \text { O docente deve maximizar as oportunidades para que o aluno busque } \\
\text { sozinho por novos conhecimentos. }\end{array}$ \\
\hline
\end{tabular}

- Questionário de estilo de aprendizagem de Honey e Mumford: Peter Honey e Alan Mumford ${ }^{3}$ realizaram vários experimentos para definir uma maneira de classificar os estilos de aprendizagem propostos por Kolb de forma que estes tivessem maneiras de validação dos estilos mais concretos (Coffield et al, 2004). Através da aplicação de um questionário classificaram

${ }^{3}$ Peter Honey e Alan Mumford criaram nos anos 80 uma teoria sobre estilos de aprendizagem publicado no livro The Manual of Learning Styles da Peter Honey Associates (http://www.peterhoney.com/product/brochure). 
os estilos de aprendizagem resumindo-os em Ativo, Reflexivo, Teórico e Pragmático. A Tabela 4 apresenta as características de cada um dos estilos.

Tabela 4 - Modelo de Honey e Mumford (MAGOULAS; PAPANIKOLAOU; GRIGORIADOU, 2003)

\begin{tabular}{|c||c|c|}
\hline $\begin{array}{c}\text { Estilo de } \\
\text { Aprendizagem }\end{array}$ & Características \\
\hline \hline \multirow{3}{*}{ Ativo } & $\rightarrow$ Aprender através de aplicações práticas. \\
& $\rightarrow$ Sente-se motivado por desafios novos. \\
& $\rightarrow$ Boa capacidade de trabalhar em grupo e de conduzir o mesmo. \\
& $\rightarrow$ Não aprecia explanações extensas. Prefere aplicar e a partir desta aprender. \\
\hline \hline Reflexivo & $\rightarrow$ Aprender a partir da observação sobre a aplicação. \\
& $\rightarrow$ Passa boa parte do tempo da aprendizagem considerando as informações a partir \\
& $\rightarrow$ Não possui perfil adequado para condução de grupos. \\
\hline \hline & $\rightarrow$ Prefere entender a teoria antes de agir. \\
& $\rightarrow$ Utiliza modelos e conceitos para sedimentar seu conhecimento. \\
& $\rightarrow$ Gosta de questionar e realizar provas dos conceitos aprendidos. \\
\hline \hline Pragrico & $\rightarrow$ Aprende observando aplicações. \\
& $\rightarrow$ Gosta de verificar a aplicação de algum conteúdo estudado para que tenha o real \\
& $\rightarrow$ entendimento \\
\hline
\end{tabular}

- Instrumento de Inteligência Dominante de Herrmann (HBDI): é definido através da aplicação de um questionário de auto-avaliação que identifica a partir de grupos de atividades qual é a inteligência dominante de um dado estudante. Para isto foram definidas quatro categorias de estilos de aprendizagem que são baseadas em apontar qual hemisfério do cérebro é dominante para um dado indivíduo dentro do processo de aprendizagem. Não significa que o indivíduo não use as outras partes do cérebro, mas sim que existe uma mais dominante que a outra. A Tabela 5 apresenta os estilos e suas características. 
Tabela 5 - Modelo HBDI (Coffield et al, 2004)

\begin{tabular}{|c|c|}
\hline $\begin{array}{c}\text { Estilos de } \\
\text { aprendizagem }\end{array}$ & Características \\
\hline Teóricos & $\begin{array}{l}\rightarrow \text { Utiliza o lado esquerdo do cérebro. } \\
\rightarrow \text { Personalidade racional. } \\
\rightarrow \text { Possui dificuldade em participar de trabalhos humanísticos. } \\
\rightarrow \text { Preferem aprender através da construção de casos e da formalização teórica. } \\
\rightarrow \text { Gostam de livros textos e aprendizagem programada. }\end{array}$ \\
\hline Organizador & $\begin{array}{l}\rightarrow \text { Utiliza a extremidade esquerda do cérebro. } \\
\rightarrow \text { Personalidade que aprecia a segurança. } \\
\rightarrow \text { Possue dificuldade em realizar trabalhos inovadores. } \\
\rightarrow \text { Prefere cursos estruturados que contenham uma sequencialização de conteúdos. } \\
\rightarrow \text { Gosta de organizar discussões, de livros textos e de estruturação no conteúdo. }\end{array}$ \\
\hline Inovador & $\begin{array}{l}\rightarrow \text { Utiliza o lado direito do cérebro. } \\
\rightarrow \text { Personalidade que gosta de experimentos. } \\
\rightarrow \text { Dificuldade em estilos organizadores. } \\
\rightarrow \text { Prefere realizar descobertas sozinhos, construir conceitos e explorar possibilidades ocultas. } \\
\rightarrow \text { Gosta da ausência de sequencialização, de estímulos visuais e da oportunidade de experimentar } \\
\quad \text { o que aprenderam. }\end{array}$ \\
\hline Humanitário & $\begin{array}{l}\rightarrow \text { Utiliza a extremidade direita do cérebro. } \\
\rightarrow \text { Personalidade sentimentalista. } \\
\rightarrow \text { Dificuldade em estilos racionais e teóricos. } \\
\rightarrow \text { Prefere o envolvimento emocional com a aprendizagem, escutar e compartilhar idéias. } \\
\rightarrow \text { Gosta de música, da interação em grupo e oportunidades de experimentar o que aprenderam. }\end{array}$ \\
\hline
\end{tabular}

- Modelo Felder-Silverman: modelo de classificação através de estilos de aprendizagem que fosse aplicável ao ensino de engenharia. Através de estudos realizados a partir dos diversos modelos existentes, Felder e Silverman (1988) propuseram um modelo de estilos de aprendizagem considerando métodos de ensino que pudessem atender tais estilos. A Tabela 6 apresenta as dimensões de estilos de aprendizagem propostas pelo modelo e o correspondente método de ensino sugerido para ser aplicado (FELDER; SILVERMAN, 1988; FELDER; BRENT, 2005).

Segundo Felder e Silverman (1988) um aluno pode ser classificado por um conjunto de estilos de aprendizagem. Isto porque cada um dos estilos descritos observa uma dimensão diferente do comportamento do aluno durante a aprendizagem. A partir de seu modelo é possível compor dezesseis estilos de aprendizagem distintos. 
Tabela 6 - Modelo Felder-Silverman (FELDER; BRENT, 2005)

\begin{tabular}{|c|c|c|}
\hline $\begin{array}{c}\text { Estilos de } \\
\text { Aprendizagem } \\
\end{array}$ & $\begin{array}{l}\text { Métodos de } \\
\text { Ensino }\end{array}$ & Características \\
\hline Sensorial & Concreto & \multirow{2}{*}{$\begin{array}{l}\rightarrow \text { Está relacionado ao tipo de percepção do aluno. } \\
\rightarrow \text { O método de ensino apresenta a forma como o conteúdo deve ser } \\
\text { apresentado. } \\
\rightarrow \text { O sensorial prefere experimentos, atividades práticas. } \\
\rightarrow \text { O intuitivo prefere as teorias. }\end{array}$} \\
\hline Intuitivo & Abstrato & \\
\hline Visual & Visual & \multirow{2}{*}{$\begin{array}{l}\rightarrow \text { Indica qual a melhor forma que um aluno tem de receber uma informação. } \\
\rightarrow \text { O método de ensino irá determinar a melhor maneira de apresentar um dado } \\
\text { conteúdo. } \\
\rightarrow \text { O visual prefere aprender através de figuras, diagramas, filmes, etc. } \\
\rightarrow \text { Já o auditivo aprende melhor quando escuta o conteúdo e melhor ainda } \\
\text { quando escuta e fala sobre o conteúdo. }\end{array}$} \\
\hline Auditivo & Verbal & \\
\hline Ativo & Ativo & \multirow{2}{*}{$\begin{array}{l}\rightarrow \text { Determina como o aluno processa melhor a informação apresentada. } \\
\rightarrow \text { O método de ensino irá determinar qual a melhor forma do aluno participar } \\
\text { do processo de aprendizagem. } \\
\rightarrow \text { O ativo aprende melhor quando pode interagir mais. Não gosta do excesso } \\
\text { de apresentação de conteúdo. } \\
\rightarrow \text { Já o reflexivo prefere ter um tempo para refletir sobre o conteúdo. }\end{array}$} \\
\hline Reflexivo & Passivo & \\
\hline Seqüencial & Seqüencial & \multirow{2}{*}{$\begin{array}{l}\rightarrow \text { Determina como deve ser a ordem de apresentação de um conteúdo. } \\
\rightarrow \text { O estilo de ensino irá determinar como o docente deve apresentar o } \\
\text { conteúdo. } \\
\rightarrow \text { O seqüencial prefere que as informações sejam apresentadas de forma } \\
\text { progressiva. } \\
\rightarrow \text { Já o global prefere ter uma visão do todo, dos objetivos para então visualizar } \\
\text { as partes. }\end{array}$} \\
\hline Global & Global & \\
\hline
\end{tabular}

É importante destacar que os modelos apresentados anteriormente apresentam estilos de aprendizagem semelhantes em alguns modelos. Por exemplo, o modelo MBTI possui estilos similares ao que aparecem no modelo apresentado por Felder e Silverman. Isto se deve ao fato de que estes modelos foram surgindo através de um amadurecimento dos modelos já existentes.

Este trabalho irá adotar o modelo proposto por Felder e Silverman na classificação de estilos de aprendizagem, conforme será apresentado posteriormente. A adoção deste se deve ao fato de o mesmo possuir uma relação entre os estilos de aprendizagem e os respectivos métodos de ensino adotados para atender tais estilos.

\subsection{ESTILOS DE APRENDIZAGEM E A APRENDIZAGEM ELETRÔNICA}

Buscar informações que retratem o perfil de um aluno torna-se muito importante em ambientes de aprendizagem eletrônica. A identificação das preferências de um aprendiz pode auxiliar no processo de motivação do estudante. 
Questões referentes à organização da apresentação dos conteúdos, suas informações pessoais, seu histórico de conhecimento, suas habilidades de interação, suas preferências durante a interação influenciam diretamente o caminho percorrido pelo aluno durante a aprendizagem. É fundamental, portanto, extrair informações referentes ao aprendiz construindo assim o perfil deste aluno.

Um dos pontos frequentemente observados durante a aprendizagem eletrônica é o estilo de aprendizagem adotado pelo aluno. Através do estilo de aprendizagem é possível classificar o aluno a partir de perfis de aprendizagem e escolher as estratégias de ensino que sejam mais adequadas ao perfil de aprendizagem deste aluno (FENRICH, 2006).

\subsubsection{Monitoramento das interações do aluno}

Uma das formas de obtenção das informações relativas ao perfil de aprendizagem do aluno normalmente é realizada através da monitoração das interações deste com o ambiente. O monitoramento pode ocorrer de diversas formas como através da verificação de ações de seleção em páginas, da observação das ações durante um dado período de tempo, através da realização de testes de conhecimento e da observação da seqüência de ações realizadas, (KOBSA; KOENEMANN; POHL, 2001). A Tabela 7 apresenta algumas formas de observação do comportamento do usuário.

Tabela 7 - Formas de monitorar a interação do usuário

\begin{tabular}{|c|c|c|}
\hline $\begin{array}{l}\text { Formas de } \\
\text { Monitoração }\end{array}$ & Características & Limitações \\
\hline Ações de seleção & $\begin{array}{l}\text { Links selecionados numa dada página, páginas } \\
\text { que foram acessadas e preferências por mídias. } \\
\text { Interações explícitas do aluno através de } \\
\text { entrevistas. }\end{array}$ & $\begin{array}{l}\text { Podem não definir características do } \\
\text { usuário de forma precisa. }\end{array}$ \\
\hline $\begin{array}{l}\text { Observação num } \\
\text { dado período da } \\
\text { interação }\end{array}$ & $\begin{array}{l}\text { Verificar o tempo de permanência num dado } \\
\text { ponto do sistema. }\end{array}$ & $\begin{array}{l}\text { Imprecisão na análise das } \\
\text { características de tempo. Não é } \\
\text { possível garantir que em todo o } \\
\text { tempo o usuário permaneceu } \\
\text { observando um dado ponto. }\end{array}$ \\
\hline $\begin{array}{l}\text { Testes de } \\
\text { conhecimento }\end{array}$ & $\begin{array}{l}\text { Aplicação de diferentes formas de testes de } \\
\text { conhecimento } \\
\text { Adequação dos tipos de testes com as } \\
\text { necessidades de monitoramento. }\end{array}$ & $\begin{array}{l}\text { Testes objetivos podem não ser } \\
\text { precisos, já que limitam o escopo da } \\
\text { resposta. }\end{array}$ \\
\hline $\begin{array}{l}\text { Seqüenciamento de } \\
\text { ações }\end{array}$ & $\begin{array}{l}\text { Mecanismos que possibilitem ao usuário } \\
\text { escolher a seqüência de ações que deseja } \\
\text { realizar para uma dada tarefa. }\end{array}$ & $\begin{array}{l}\text { São gerados poucos cenários } \\
\text { dificultando a obtenção de } \\
\text { informações. }\end{array}$ \\
\hline
\end{tabular}


A decisão sobre o que o modelo do aluno deve conter como informação está diretamente relacionada às necessidades que o ambiente tem para o processo de adaptação.

A delimitação do escopo de observação das interações do aluno determina quais dados são relevantes a um dado cenário da aprendizagem. Nas aplicações educacionais para Web torna-se importante ter domínio principalmente das informações que se referem às habilidades desenvolvidas pelo aluno e ao contexto da interação. Estas informações permitem um mapeamento sobre o conhecimento prévio do aluno e sobre suas preferências de aprendizagem, refletindo diretamente na identificação do estilo de aprendizagem mais evidente em um dado aprendiz.

\subsubsection{Experiências de classificação de estilos de aprendizagem na aprendizagem eletrônica}

Embora haja diversas opiniões a respeito do modelo de classificação de estilos de aprendizagem a ser adotado no aprendizado eletrônico, existe o concenso de que estes podem auxiliar no processo motivacional e de sucesso da aprendizagem em qualquer ambiente de ensino.

Diaz e Cartnal (1999) realizaram experiências comparativas do uso de estilos de aprendizagem no ensino presencial e no ensino a distância através da Web. Os autores destacam que a adoção de estilos de aprendizagem em cursos a distância potencializa a interação dos alunos através da sugestão de conteúdos mais adequados a cada perfil de aprendizagem.

Os modelos de estilos de aprendizagem normalmente adotados no campo da aprendizagem eletrônica são modelos adaptados dos modelos tradicionais. Ou seja, não são modelos desenvolvidos especificamente para serem utilizados em ambientes virtuais.

Soles e Moller (2001), por exemplo, retratam uma experiência de ensino a distância on-line adotando o MBTI como modelo de estilo de aprendizagem. Através dos indicadores descritos no MBTI foram especificadas atividades e ferramentas utilizadas como estratégia de ensino de forma que estas pudessem atender um dado perfil de aprendizagem especificado pelo modelo em questão. Por exemplo, caso fosse identificado um perfil "introvertido e racional" era oferecido ao aluno atividades 
assíncronas, com o uso de técnicas de resolução de problemas trabalhando a análise crítica deste aluno, permitindo que ele tivesse tempo para refletir sobre o problema. Já o perfil "extrovertido e racional" tinha um oferecimento de atividades síncronas, como vídeo conferências, com resoluções de exercícios que tivessem duração mais curta. Os autores concluíram que deveria haver uma atenção maior aos alunos em que fosse identificado um perfil "extrovertido" já que este possui uma necessidade de presença na interação. Como o curso acontecia a distância procurou-se oferecer aos alunos com este perfil atividades que envolvesse colaboração entre os vários integrantes do curso.

Outra experiência é retratada por Richmond e Cummings (2005) através da adoção do modelo proposto por Kolb. Foi proposto a partir do modelo de Kolb quais seriam as melhores maneiras de interação do aluno em um ambiente on-line a distância. No caso de alunos classificados pelo perfil de aprendizagem de "não focado", por exemplo, era oferecido a este aluno discussões em grupo referentes a leituras teóricas. Já os alunos classificados como "acomodados" eram estimulados a trabalhar em grupos na resolução de problemas.

\subsection{PROPOSTA DE MODELAGEM DO ALUNO PARA AMBIENTE DE APRENDIZAGEM ELETRÔNICA NA WEB}

A decisão sobre quais informações são relevantes ao modelo do aluno é diretamente dependente das necessidades do sistema. Ou seja, depende de quais informações são importantes para o funcionamento do sistema em questão.

Dentro do escopo de aprendizagem eletrônica na Web pode-se afirmar que alguns tópicos podem ser utilizados não só para diagnosticar um estilo de aprendizagem como também para trabalhar o aspecto motivacional do aluno. Como, por exemplo, oferecer ao aluno uma vídeo-aula sendo que este aluno está utilizando uma conexão discada. Ou mesmo, não permitir que um aluno possa realizar escolhas do tipo de conteúdo que deseja visualizar em um dado momento. Tais aspectos também agem diretamente no diagnóstico do perfil de aprendizagem do aluno.

Este trabalho propõe que as preferências do aluno sejam divididas em categorias que são baseadas na proposta de Felder e Silverman (1988). O objetivo é agrupar as preferências que estão relacionadas a diferentes tipos de observações 
que podem ser realizadas durante o acompanhamento das interações do aluno. Além de estar relacionada a um estilo de aprendizagem, cada categoria também se relaciona os métodos de ensino que podem ser aplicados quando o aluno é classificado em um dado estilo, conforme proposto no modelo de Felder-Silverman.

A Tabela 8 apresenta as categorias de preferências:

Tabela 8 - Proposta de Categorias de Preferências

\begin{tabular}{|c|c|c|c|}
\hline $\begin{array}{l}\text { Categorias de } \\
\text { Preferências } \\
\end{array}$ & Características & $\begin{array}{c}\text { Estilos de } \\
\text { Aprendizagem } \\
\end{array}$ & Métodos de Ensino \\
\hline \multirow{2}{*}{ Percepção } & \multirow{2}{*}{$\begin{array}{l}\text { Está relacionado a como o aluno recebe } \\
\text { o conteúdo, tipos de exercícios, por } \\
\text { exemplo. }\end{array}$} & Sensorial & Concreto \\
\hline & & Intuitivo & Abstrato \\
\hline \multirow{2}{*}{$\begin{array}{c}\text { Formato- } \\
\text { Apresentação }\end{array}$} & \multirow{2}{*}{$\begin{array}{l}\text { Está relacionado à forma como o } \\
\text { conteúdo é apresentado, tipos de } \\
\text { mídias, por exemplo. }\end{array}$} & Visual & Visual \\
\hline & & Auditivo & Verbal \\
\hline \multirow{2}{*}{$\begin{array}{l}\text { Participação do } \\
\text { Aluno }\end{array}$} & \multirow{2}{*}{$\begin{array}{l}\text { Representa o quanto o aluno gosta de } \\
\text { participar das atividades, se possui } \\
\text { liderança, se prefere refletir mais tempo } \\
\text { sobre um dado assunto. }\end{array}$} & Ativo & Ativo \\
\hline & & Reflexivo & Passivo \\
\hline \multirow{2}{*}{$\begin{array}{c}\text { Ordem da } \\
\text { Apresentação }\end{array}$} & \multirow{2}{*}{$\begin{array}{l}\text { Representa o tipo de visão que o aluno } \\
\text { prefere ter do conteúdo: fragmentada ou } \\
\text { global. }\end{array}$} & Seqüencial & Seqüencial \\
\hline & & Global & Global \\
\hline
\end{tabular}

É possível observar que as categorias possuem estilos de aprendizagem bipolares e que estes possuem métodos de ensino associados.

A Tabela 9 apresenta uma proposta de modelo do aluno destacando os componentes que influenciam diretamente na identificação do perfil de aprendizagem do aluno.

O estilo de aprendizagem representa as estratégias que o aluno utiliza durante o processo de aprendizagem e através destas estratégias é possível obter informações que resultam diretamente no perfil de aprendizagem. 
Tabela 9 - Proposta do modelo do aluno

\begin{tabular}{|c|c|c|}
\hline Componente & Atributos & Caracterização \\
\hline Dados Pessoais & $\begin{array}{ll}\circ & \text { Identificação no sistema } \\
\circ & \text { Nome } \\
\circ & \text { Grau de escolaridade } \\
\circ & \text { Curso de formação }\end{array}$ & $\begin{array}{l}\text { Os dados pessoais se caracterizam por } \\
\text { conter as informações pessoais do aluno que } \\
\text { raramente são alteradas. }\end{array}$ \\
\hline Categorias de Preferências & $\begin{array}{ll}\circ & \text { Categoria Percepção } \\
\circ & \text { Categoria Formato- } \\
& \text { Apresentação } \\
\circ & \text { Categoria Participação do } \\
& \text { Aluno } \\
\circ & \text { Categoria Ordem-Apresentação } \\
\end{array}$ & $\begin{array}{l}\text { As preferências são sensíveis a estímulos } \\
\text { psicológicos como tipos de mídia e } \\
\text { sociológicos como trabalho em grupo ou } \\
\text { individual. }\end{array}$ \\
\hline Conhecimento & $\begin{array}{l}\circ \text { Crenças (conhecimentos } \\
\text { prévios) } \\
\circ \text { Conhecimento atual }\end{array}$ & $\begin{array}{l}\text { As crenças podem auxiliar no direcionamento } \\
\text { do aluno dentro de um dado escopo de } \\
\text { aprendizagem, já que indicam um } \\
\text { conhecimento anterior do aluno. } \\
\text { O conhecimento atual irá conter itens que } \\
\text { reflitam questões referentes ao } \\
\text { acompanhamento do aluno em relação ao } \\
\text { conhecimento adquirido. }\end{array}$ \\
\hline Tecnologia & $\begin{array}{l}\text { - Tipo de conexão (banda } \\
\text { larga/linha discada) }\end{array}$ & $\begin{array}{l}\text { Esta informação deve ser obtida através da } \\
\text { intervenção direta do aluno permitindo que } \\
\text { sejam disponibilizados recursos mais } \\
\text { adequados a ele. }\end{array}$ \\
\hline Perfil de aprendizagem & - Categorias de Preferências & $\begin{array}{l}\text { O perfil de aprendizagem possui uma relação } \\
\text { com atributos definidos no componentes de } \\
\text { categorias de preferência já que estes } \\
\text { influenciam o processo de identificação do } \\
\text { estilo de aprendizagem. Através do estilo de } \\
\text { aprendizagem o aluno é classificado segundo } \\
\text { um dado perfil de aprendizagem. }\end{array}$ \\
\hline
\end{tabular}

O modelo conceitual do Modelo do Aluno proposto é apresentado na Figura 2:

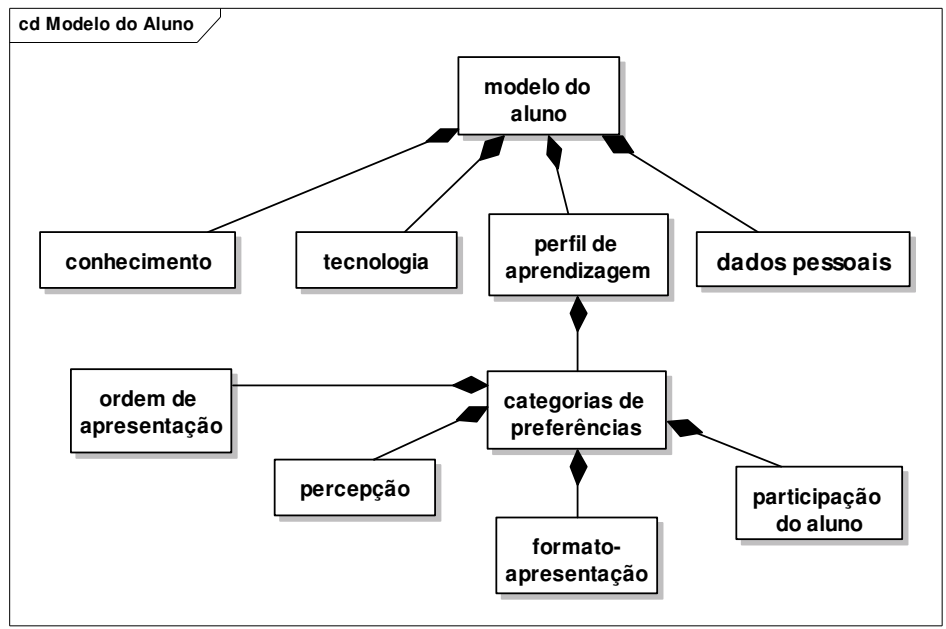

Figura 2 - Modelo Conceitual do Modelo do Aluno proposto 


\subsection{CONSIDERAÇÕES FINAIS}

A percepção das necessidades individuais do aprendiz é importante para que haja uma condução adequada do processo de aprendizagem. Porém, é preciso muito mais do que disponibilizar diferentes modelos de materiais. É preciso acompanhar o processo e identificar as necessidades.

Existem diversos modelos de estilos de aprendizagem que podem ser adotados dentro de um processo de ensino. Este capítulo procurou apresentar os modelos que os trabalhos acadêmicos destacam como os mais utilizados para o ensino na área de ensino de engenharia. Isto não significa que estes são os únicos que podem ser aplicados ou mesmo que um docente não possa elaborar um modelo mais apropriado para atender suas estratégias de ensino.

Este capítulo também propôs um modelo de aluno definido através de componentes com atributos que especificam características sobre o aprendiz. Dentre estas características algumas são diretamente influenciáveis na classificação do aluno em um dado perfil de aprendizagem. $O$ atributo de perfil de aprendizagem é orientado através de categorias de preferências que foram proposta com base no modelo de estilo de aprendizagem de Felder e Silverman (1988).

Um ponto crucial dentro da área de modelagem do perfil é a ausência de padrões de modelos que descrevam aspectos relativos a usuários na Web, onde cada modelo criado é relativo a um ambiente específico, não havendo interoperabilidade entre os ambientes. 


\section{APRENDIZAGEM ELETRÔNICA ADAPTATIVA NA WEB}

\subsection{CONSIDERAÇÕES INICIAIS}

A necessidade de adaptação de ambientes de aprendizagem eletrônica tem sido discutida desde os anos 70 quando se observou que a apresentação de um mesmo tipo de cenário de aprendizagem para todos os alunos realizados pelos sistemas CAI (Computer Aided Instruction) não poderiam atender os diferentes estilos de aprendizagem dos alunos.

A explosão do uso da Web alterou os rumos de desenvolvimento desses sistemas, procurando novas técnicas que atendessem às necessidades de um ambiente diversificado, com múltiplos tipos de usuários e que fosse distribuído. Embora haja uma diversificação, alguns conceitos foram se sedimentando dentro da área de aprendizado eletrônico, fortalecidos através da especificação de padrões de ensino que dessem subsídios para o desenvolvimento dos ambientes.

Este capítulo apresenta conceitos sobre aprendizagem eletrônica que são utilizados no desenvolvimento de ambientes. Também aborda os conceitos sobre Sistemas Tutores Inteligentes e Hipermídia Adaptativa e como estes convergiram para a área de Sistemas Adaptativos Inteligentes. A área de Aplicações Cientes de Contexto é apresentada formalizando os aspectos essenciais que a constituem e como esta pode ser aplicada para criação de modelos que auxiliem o processo de adaptação de um sistema. São apresentadas três especificações de padrões aplicados ao ensino (SCORM, LOM e Learning Design) que foram importantes na determinação de conceitos e organização de ambiente de aprendizagem eletrônica. Por fim, é apresentado um estudo de trabalhos que aplicam os conceitos de adaptação, modelagem do usuário e adaptação em sua implementação.

\subsection{APRENDIZAGEM ELETRÔNICA}

A aprendizagem eletrônica surgiu como uma forma de atender tanto as necessidades de utilizar a tecnologia como auxílio ao aprendizado como também para ser utilizada como suporte no ensino a distância. Pode-se definir aprendizagem 
eletrônica como o processo de ensino-aprendizagem que emprega algum meio eletrônico (CD, DVD, Web, etc) para fins de aprendizagem.

Uma aprendizagem eletrônica pode ocorrer em um computador isolado, sem estar conectado em uma rede, através de aplicações educativas. Porém, com a propagação do uso da Web pelo mundo observou-se um grande desenvolvimento de ambientes que pudessem auxiliar no processo de aprendizagem, fosse este exclusivamente a distância ou não.

A comunicação entre alunos e professores nos ambientes de aprendizagem eletrônica utilizados na Web pode ser tanto síncrona quanto assíncrona, sendo que a primeira se caracteriza por permitir que os envolvidos no processo de aprendizagem tenham contato no tempo em que estão interagindo, e a segunda, se caracteriza por permitir que os envolvidos possam interagir no momento em que considerarem mais adequado.

\subsubsection{Fundamentos da Aprendizagem Eletrônica}

Dentro do escopo de aprendizagem eletrônica alguns fundamentos e nomenclaturas foram sedimentados, sendo amplamente utilizados no desenvolvimento de ambientes de aprendizagem eletrônica. A seguir serão apresentados alguns deles.

\subsubsection{Objeto de Aprendizagem}

Um objeto de aprendizagem pode ser definido como uma entidade que pode ser utilizada dentro do processo de ensino-aprendizagem (LOM, 2002; MCGREAL, 2004). Pode ser um texto, um vídeo, uma figura, um simulador, etc.

Dentro do escopo de aprendizagem eletrônica o que se deseja é criar conteúdos em formato digital que possam ser reutilizáveis em diferentes objetivos de aprendizagem, ou mesmo que possam ser empregados na construção de outros objetos de aprendizagem (MCGREAL, 2004).

Uma das formas de organizar os objetos de aprendizagem para que eles possam ser reutilizados e empregados sistemicamente é através da descrição de 
metadados. Um metadado pode se definido como um conjunto de atributos que descrevem uma entidade, facilitando o entendimento, uso e gerenciamento desta entidade. Uma das especificações de metadados mais utilizadas é feita através do padrão LOM (Learning Object Metadata) do instituto IEEE que será abordado posteriormente neste capítulo (LOM, 2002).

Os metadados que descrevem os objetos de aprendizagem são organizados em repositórios que realizam a indexação desses objetos facilitando sua busca e recuperação (NEVEN; DUVAL, 2002).

\subsubsection{Atividade de Aprendizagem}

Uma atividade de aprendizagem representa um conjunto de tarefas que são oferecidas ao aprendiz como suporte a um processo de aprendizagem. São as atividades de aprendizagem que orientam o trajeto do aluno em um ambiente de aprendizagem.

Dentro dos ambientes de aprendizado eletrônico as atividades de aprendizagem são compostas por objetos de aprendizagem, ferramentas (chat, email, etc), entre outros elementos. Ou seja, são formadas por uma seqüência de tarefas que devem ser realizadas pelo aluno para que um objetivo educacional possa ser atingido.

Um dos pontos fundamentais é o reuso das atividades de aprendizagem. Assim como a reutilização de objetos de aprendizagem se torna importante dentro da aprendizagem eletrônica, a reutilização de atividades de aprendizagem permite que novos cenários possam ser compostos de acordo com as necessidades de ensino. Dentro deste contexto a criação de atividades de aprendizagem como entidades auxilia neste processo de reutilização, pois realiza um empacotamento das atividades através de metadados de forma que estas atividades possam ser acopladas em diferentes contextos (ZAINA, BRESSAN e RUGGIERO, 2006). 


\subsubsection{Sistemas Gerenciadores de Aprendizagem}

Os Sistemas Gerenciadores de Aprendizagem, conhecidos como LMS (Learning Management System) são ambientes integradores de ferramentas com o propósito de prover mecanismos e ferramentas que suportem o aprendizado eletrônico na Web.

Surgiram da necessidade de centralização das informações referentes aos cursos na Web. Um LMS reúne as ferramentas necessárias para o docente criar e gerenciar um curso, gerenciar turmas e alunos, tais como: chat, fórum, gerenciamento de conteúdo, formas de avaliações, além de páginas utilizadas para administrar e acompanhar a evolução do aluno (ZAINA, 2002). São exemplos de LMS o $\mathrm{COL}^{4}$ (utilizado na comunidade USP), AulaNet $^{5}$ (desenvolvido pela PUC-RJ), BlackBoard $^{6}$, Teleduc ${ }^{7}$ (desenvolvido pela UNICAMP), Moodle ${ }^{8}$ (projeto de código aberto), Sakai ${ }^{9}$ (projeto de código aberto), entre outros.

Atualmente, o desenvolvimento dos LMS está focado principalmente na adoção de especificações padronizadas para descrição das entidades de ensino e do funcionamento destas (como SCORM, LOM e Learning Design, que serão detalhados posteriormente neste capítulo) e na divisão sistemática de responsabilidades do ambiente, através do desenvolvimento componentizado (ZAINA, BRESSAN e RUGGIERO, 2006).

\subsubsection{Sistemas Gerenciadores de Atividades de Aprendizagem}

Os Sistemas Gerenciadores de Atividades de Aprendizagem (Learning Activities Management Systems) são responsáveis por possibilitar criar, editar, gerenciar e monitorar as atividades de aprendizagem. Surgem como uma solução sistêmica para implementação do padrão do Learning Design. Além disto, permite que a responsabilidade sobre o processo de aprendizagem seja concentrada em um

\footnotetext{
${ }^{4}$ http://col.redealuno.usp.br/portal/

5 http://www.eduweb.com.br/portugues/home.asp

${ }^{6}$ http://www.blackboard.com/us/index.Bb

${ }^{7}$ http://teleduc.nied.unicamp.br/pagina/

${ }^{8}$ http://moodle.org/

${ }^{9}$ http://sakaiproject.org/
} 
componente específico do sistema. Um Gerenciador de Atividades de Aprendizagem pode ser um componente de um LMS. Um exemplo de gerenciador de atividades é o LAMS $^{10}$ (Learning Activity Management System).

\subsection{PADRÕES PARA IMPLEMENTAÇÃO DE AMBIENTES DE APRENDIZAGEM ELETRÔNICA}

Um padrão para implementação de ambientes de aprendizagem eletrônica é uma especificação técnica e formal que determina como estes ambientes devem ser organizados no que se refere a sua arquitetura, organização e ao seu funcionamento.

A criação de padrões que suportassem o desenvolvimento de ambientes voltados à aprendizagem surgiu da necessidade de se criar conteúdos que pudessem ser reutilizados em diferentes ambientes.

Embora o intuito inicial dos padrões de ensino tenha sido permitir o reuso de conteúdos, houve uma evolução nesta abordagem. Atualmente existe uma demanda por padrões que permitam o reuso de conteúdos, porém de forma que o uso destes possa ser individualizado de acordo com as necessidades do aluno. Outro ponto importante é a necessidade de padronização do processo de aprendizagem. Tornam-se necessários padrões que permitam determinar não só uma adaptação de conteúdos, mas também de atividades, criando-se um modelo do processo de aprendizagem (AKHRAS; SELF, 2000).

\subsubsection{Padrão LOM}

O padrão LOM (Learning Object Metadata) é uma especificação definida pelo Learning Technology Standards Commitee da IEEE ${ }^{11}$ para definição de metadados que contenham informações sobre um objeto de aprendizagem, permitindo a organização destes, facilitando seu uso e reuso.

O padrão LOM (2002) possui uma estrutura que descreve objetos de aprendizagem através de categorias descritoras que detalham dados sobre um

\footnotetext{
${ }^{10}$ http://www.lamsinternational.com/

${ }^{11}$ http://ieeeltsc.org/
} 
determinado objeto de aprendizagem. Cada categoria tem uma finalidade específica como de descrever atributos gerais dos objetos, descrever os objetivos educacionais, entre outros.

A Tabela 10 descreve algumas das categorias descritoras e seus respectivos campos:

Tabela 10 - Categorias descritoras LOM

\begin{tabular}{|c|c|c|}
\hline Categoria LOM & Campo do LOM & Caracterização \\
\hline Geral & $\begin{array}{l}\text { - Identificador } \\
\text { - Tipo } \\
\text { - Língua } \\
\text { - Descrição } \\
\text { - Palavras-chaves }\end{array}$ & $\begin{array}{l}\text { Realiza descrição geral sobre o } \\
\text { objeto de aprendizagem }\end{array}$ \\
\hline Ciclo de vida & $\begin{array}{l}\text { - Versão } \\
\text { - Papel } \\
\text { - Entidade (responsável na } \\
\text { organização pelo objeto) } \\
\text { - Data }\end{array}$ & $\begin{array}{l}\text { Descrição de dados sobre a } \\
\text { evolução do objeto de } \\
\text { aprendizagem }\end{array}$ \\
\hline Técnico & $\begin{array}{l}\text { - Formato (tipo de formato de vídeo, } \\
\text { som) } \\
\text { - Tamanho digital } \\
\text { - Localização física } \\
\text { - Requisitos (para uso do objeto: } \\
\text { versão de software, por exemplo) }\end{array}$ & $\begin{array}{l}\text { Descrição de características } \\
\text { técnicas }\end{array}$ \\
\hline Educacional & $\begin{array}{l}\text { - Tipo de Interatividade (ativo, } \\
\text { expositivo) } \\
\text { - Tipo de Recurso da Aprendizagem } \\
\text { (exercício, simulação, questionário) } \\
\text { - Grau de dificuldade }\end{array}$ & $\begin{array}{l}\text { Descrição das funções } \\
\text { educacionais e características } \\
\text { pedagógicas do objeto }\end{array}$ \\
\hline Relacionamento & $\begin{array}{l}\text { - Tipo de relacionamento entre os } \\
\text { objetos } \\
\text { - Identificação do relacionamento }\end{array}$ & $\begin{array}{l}\text { Descreve o relacionamento } \\
\text { entre objetos de aprendizagem }\end{array}$ \\
\hline
\end{tabular}

O padrão LOM tem sido adotado por diversos ambientes de aprendizagem, inclusive pelo padrão Learning Design e SCORM para definição e catalogação dos conteúdos associados às atividades contidas em um dado escopo de ensino.

\subsubsection{Padrão SCORM}

O padrão SCORM (Shareable Content Object Reference Model) teve sua primeira versão definida em 1999 pela $\operatorname{ADL}^{12}$ (Advanced Distributed Learning) como

${ }^{12}$ http://www.adlnet.gov/index.cfm 
conseqüência das iniciativas do Departamento de Defesa do Governo dos Estados Unidos voltadas para a definição de modelos. Seu principal objetivo foi definir um modelo para criação de cursos na Web que permitisse a interoperabilidade e reutilização de conteúdos, determinando não só como estes conteúdos deveriam ser construídos bem como o seqüenciamento em que determinados conteúdos deveriam ser apresentados a um aluno.

O padrão SCORM pode ser definido como um modelo de referência constituído por um conjunto de especificações que permite a organização de objetos de aprendizagem, através da especificação de metadados, para que seja possível reutilizar conteúdos, permitindo que seja criado um sequenciamento para apresentação de conteúdos de ensino. O foco do padrão está na construção e reutilização de objetos de aprendizagem suportados pela implantação de repositórios de objetos de aprendizagem.

Porém, a sua última especificação também permite que seja realizado um processo de adaptação do conteúdo através da definição de regras que determinam o modelo de seqüência de navegação. Através deste modelo é possível planejar os conteúdos que serão apresentados aos alunos de acordo com a navegação realizada por ele (CIU, 2005).

O modelo SCORM agrega ao seu padrão modelos definidos por instituições como IEEE $^{13}$ Learning Technology Standards Committee e IMS Global Learning Consortium $^{14}$ para definir sua organização. Para uma visão mais detalhada sobre estes modelos podem ser consultados os documentos de referência do SCORM (ADL, 2004). O padrão LOM é utilizado nas unidades básicas do padrão SCORM para facilitar a utilização e reuso destas.

A especificação do padrão é dividida em três grandes modelos que são o modelo de agregação de conteúdo, o ambiente de execução e o modelo de seqüência de navegação.

Através do modelo de seqüência de navegação o padrão SCORM possibilita o acompanhamento do processo de aprendizagem do aluno e a oferta de conteúdos de acordo com a interação do estudante. É composto por 3 sub-modelos (CIU, 2005; ADL, 2004):

\footnotetext{
${ }^{13} \mathrm{http}: / /$ ieeeltsc.org/

${ }^{14} \mathrm{http}: / / \mathrm{www}$.imsglobal.org/
} 
- Modelo de Definição (Definition Model) permite configurar um conjunto de elementos que podem ser usados para descrever o comportamento que será adotado durante o seqüenciamento da navegação. A ação que deverá ser executada é diretamente relacionada a uma condição ser satisfeita ou não.

- Modelo de Comportamento (Behavior Model) define quais serão as operações a serem executadas sobre um conjunto de atividades abordando o processo de sequenciamento adotado.

- Modelo de Acompanhamento do Processo (Tracking Model) possui elementos que permitem verificar qual é a situação do aluno em um dado momento da aprendizagem. Realiza um monitoramento das interações do aluno dando um dinamismo adaptativo ao conteúdo que será apresentado a diferentes alunos.

\subsubsection{Padrão Learning Design}

O padrão do Learning Design (LD) ${ }^{15}$ foi especificado pelo IMS Global Learning Consortium $^{16}$ e se constitui em uma linguagem para especificação de processos de aprendizagem que sejam flexíveis pedagogicamente. Isto porque o padrão permite que o próprio docente determine o modelo pedagógico que deseja adotar e utilize o o LD para modelar.

O LD surgiu através da $\mathrm{EML}^{17}$ (Educational Modelling Language) que é definida como uma notação semântica que especifica unidades de aprendizagem para serem utilizadas no aprendizado, determinando um modelo de informações que descreve não somente o conteúdo relacionado como também o processo de ensino utilizado. O LD criou uma linguagem que permitisse definir em um ambiente de aprendizado eletrônico unidades de aprendizagem (KOPER, 2001).

Embora o padrão do Learning Design tenha suas origens nas especificações do EML (Educational Modeling Language) a diferença se encontra no fato de que o EML realiza uma modelagem encapsulando dados relativos à interação ensino e

\footnotetext{
${ }^{15}$ http://www.imsglobal.org/learningdesign/

${ }^{16} \mathrm{http}: / /$ www.imsglobal.org

17 http://eml.ou.nl/eml-ou-nl.htm
} 
aprendizagem enquanto que o padrão do Learning Design especifica explicitamente questões relativas a metadados e ao empacotamento de conteúdo através dos padrões definidos pelo IMS (IMSLDBP, 2003; BRITAIN, 2004; KOPER; MANDERVELD, 2004).

Em uma abordagem diferente dos padrões que focam somente no conteúdo, - Learning Design especifica o processo de aprendizagem onde é observada a interação do aluno em relação aos elementos que compõem o ambiente de aprendizagem (BURGOS; TATTERSALL; KOPER, 2006). Utiliza as especificações do padrão LOM para relacionar o conteúdo associado às atividades de aprendizagem com os conteúdos físicos dos objetos de aprendizagem que dão suporte a atividade de aprendizagem.

\subsubsection{Unidades de Aprendizagem}

Segundo o padrão do Learning Design, uma Unidade de Aprendizagem (UA) representa a organização dos elementos que irão atender um dado objetivo de aprendizagem. É constituída pelo elemento que descreve a organização do processo de aprendizagem e pela referência física dos objetos e ferramentas que são utilizados durante o processo de aprendizagem.

Uma UA é empacotada através de uma adaptação do IMS Content Package $^{18}$, especificação que determina como organizar conteúdos. A estrutura do Learning Design (arquivo contendo os metadados que especificam o processo de aprendizagem) constitui-se em um campo de uma Unidade de Aprendizagem (IMSCPIM, 2004).

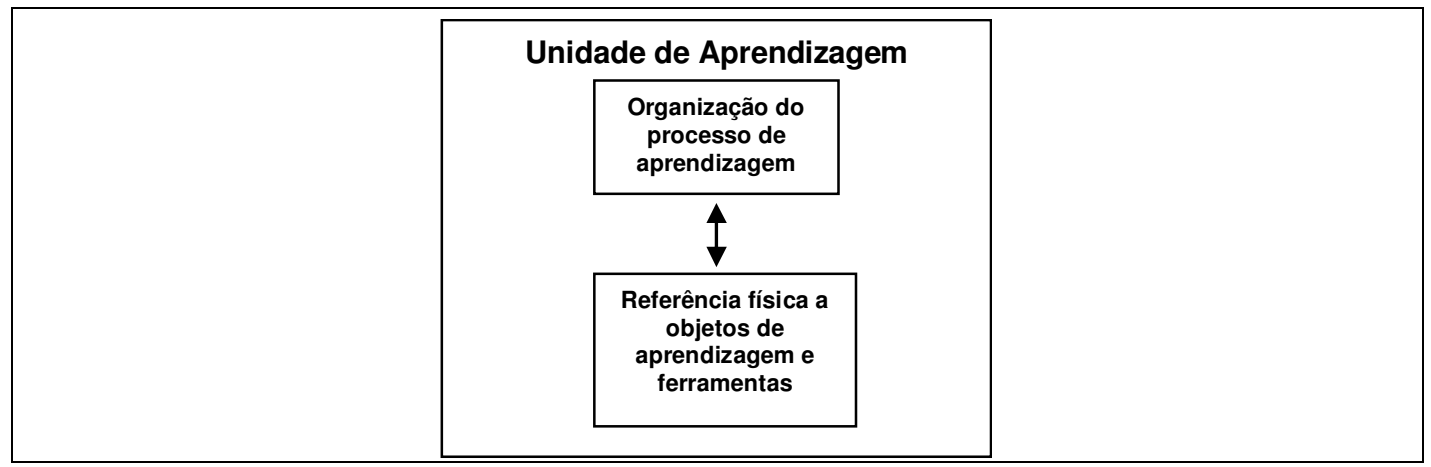

Figura 3 - Modelo da Unidade de Aprendizagem (KOPPER e MANDERVELD, 2004)

${ }^{18}$ http://www.imsglobal.org/content/packaging/index.html 


\subsubsection{Learning Design}

O metadado denominado de Learning Design especifica o processo de aprendizagem de acordo com a metodologia pedagógica adotada pelo elaborador do processo de aprendizagem. O metadado é composto por um conjunto de campos que especificam os elementos utilizados no processo. Este metadado será interpretado por uma unidade executora (runtime) adequada ao padrão (IMSLDIM, 2003).

O padrão do Learning Design é descrito através de um modelo conceitual (Figura 4) que apresenta como uma pessoa interage dentro do processo de ensino a partir das especificações realizadas pelo padrão. Segundo Koper e Oliver (2004) o modelo do Learning Design realiza uma metáfora com a apresentação de peças de teatro, onde uma pessoa tem um dado papel, executando, através deste papel, uma atividade dentro de um dado cenário (ambiente), onde o método é a peça de teatro que está sendo realizada.

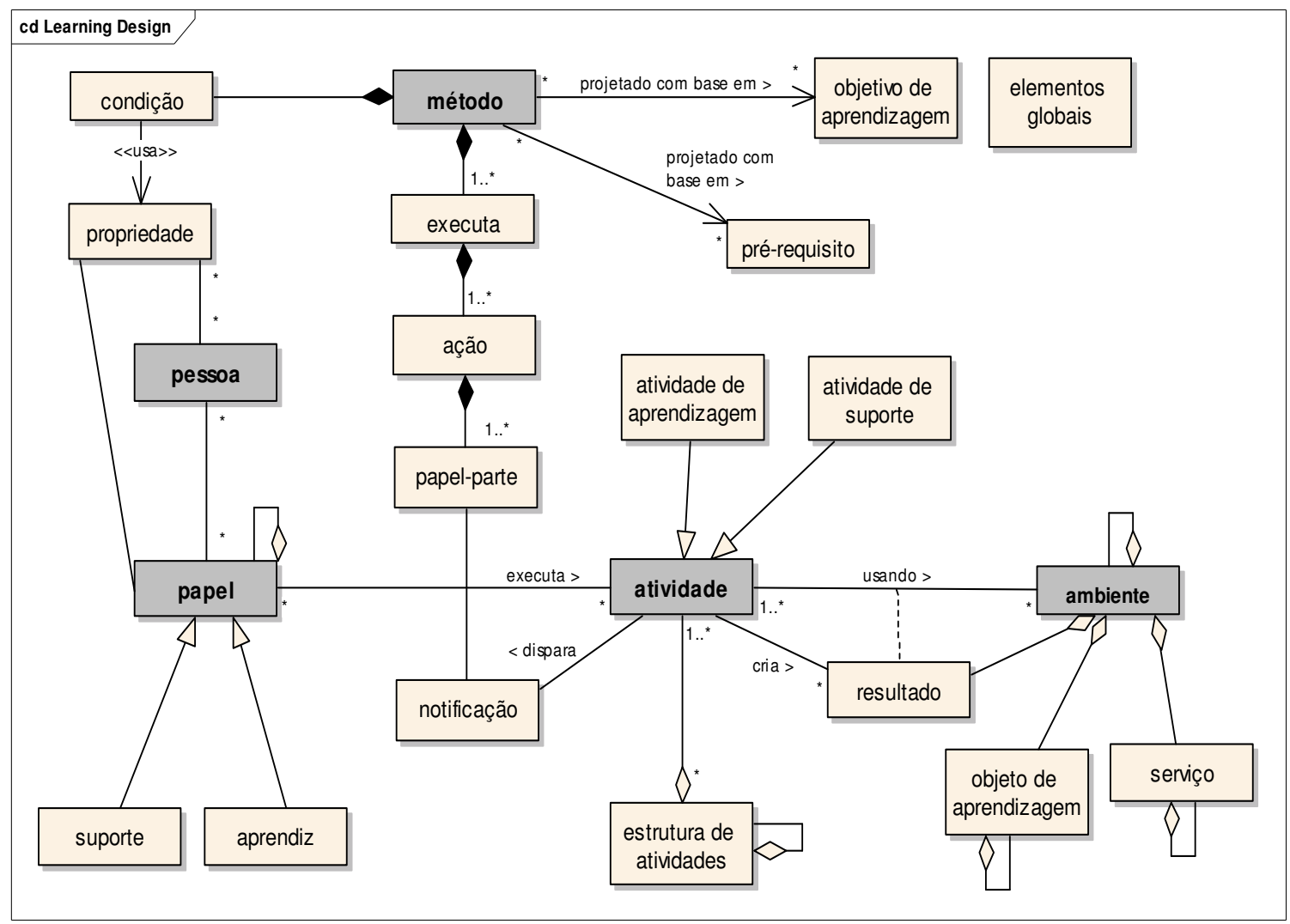

Figura 4 - Modelo Conceitual do Learning Design (IMSLDIM, 2003) 
De forma concisa, pode-se definir o processo genérico como: uma pessoa (person) que desempenha um dado papel (role) - aluno, professor, monitor, etc, dentro do processo de aprendizagem realiza uma atividade (activity) de aprendizagem que o permite atingir certos resultados em um dado ambiente (environment). Um ambiente pode ser visualizado como um objeto de aprendizagem e um serviço que é utilizado durante a execução da atividade. Um método (method) e uma notificação (notification) permitem delinear e direcionar os papéis a dadas atividades de acordo com a interação. São eles que realizam a comunicação entre um papel e uma atividade, (BRITAIN, 2004).

Pode-se afirmar que o centro do processo se encontra na definição das atividades de aprendizagem que comporão o modelo pedagógico adotado. Cada um dos elementos definidos pelo modelo conceitual (activity, role, environment, etc) possui um conjunto de atributos (definidos através de tags) que determinam sua composição (IMSLDBP, 2003).

O elemento estrutura de atividade (activity-structure), por exemplo, é composto por atividades (activity). Isto significa que uma estrutura de atividade é composta por elementos menores que são as atividades. Esta atividade pode especializar elementos denominados de atividades de aprendizagem (learning activity). As atividades de aprendizagem representam as entidades mais elementares dentro do escopo do processo de ensino-aprendizagem. Uma atividade de aprendizagem será constituída por objetos de aprendizagem ou por ferramentas. Cada atividade de aprendizagem possui um elemento denominado "item" que aponta para a localização física da ferramenta ou do objeto de aprendizagem que será referenciado durante a execução da atividade (IMSLDIM, 2003, IMSLDXB 2003).

O padrão do Learning Design permite especificar que um conjunto de atividades de aprendizagem pode ser apresentado de forma seqüencial ou podem ser selecionadas. Isto indica que o elaborador do curso pode criar um processo de sequencialização (sequence), onde existe uma ordem em que as atividades de aprendizagem que compõem uma atividade devem ser executadas. Ou então, permitir que o aprendiz selecione (selection) qual a ordem que deseja executar as atividades. Esta especificação é realizada através da criação de uma estrutura de atividades (activity-structure). A estrutura das atividades é que dá o dinamismo na execução das atividades de aprendizagem (IMSLDIM, 2003, IMSLDXB 2003). 


\subsubsection{Diretivas para definição da adaptação}

O processo de adaptação no Learning Design pode ser especificado pelo projetista do curso através da definição de condições (conditions) e propriedades (properties) que incidam diretamente na execução das atividades de aprendizagem dos alunos. O padrão especifica um conjunto de diretivas no formato de condicionais (if-else) que possibilita planejar a execução das atividades baseando-se nas interações dos alunos que são observadas através de propriedades definidas pelo elaborador do curso (IMSLDBP, 2003; IMSLDXB, 2003).

Porém a utilização de condicionais está relacionada ao modelo de complexidade de implementação do padrão do Learning Design. A especificação do padrão determina que existem três níveis de implementação do padrão que podem ser realizadas do nível mais básico, denominado de nível $A$, ao mais complexo, denominado de nível C. O que difere um nível do outro são as entidades adotadas em cada um deles o que reflete diretamente na capacidade de realizar determinadas tarefas, como por exemplo tarefas condicionais (IMSLDIM, 2003).

O nível A é o nível mais simples do modelo conceitual do Learning Design que tem como finalidade apenas a reutilização dos componentes e de atividades de aprendizagem. É a partir do nível B que se torna possível realizar o processo de adaptação através da adoção das entidades denominadas de conditions e properties. Tais entidades permitem que sejam aplicadas condições que irão verificar qual ação deverá ser executada de acordo com a interação do aluno.

O nível C acrescenta a capacidade de enviar notificações ao aprendiz conforme as adaptações vão ocorrendo. A entidade de notificação (notification) permite que seja planejado o envio de mensagens sobre o andamento do aluno, por exemplo. Através da entidade notificação é possível planejar a execução de eventos que são disparados quando uma dada condição é atendida ou não.

Existem várias iniciativas na definição de editores para o padrão do LD que tornem mais fácil a definição das diretrizes de adaptação (regras e propriedades). Pode-se encontrar uma destas iniciativas nos trabalhos de Berlanga e Garcia (BERLANGA, GARCÍA; CARABIAS, 2006; BERLANGA; GARCÍA, 2005a, 2005b) 


\subsection{AMBIENTES DE APRENDIZAGEM ELETRÔNICA ADAPTATIVOS}

Um ambiente de aprendizagem eletrônica adaptativo se caracteriza por considerar as características do aprendiz e do conteúdo a ser aprendido durante o processo de ensino, adaptando o ambiente às necessidades do estudante e do escopo de ensino. Para proporcionar as adaptações, estes ambientes utilizam o modelo do aluno para especificar quais características são relevantes ao processo de adaptação (TARPIN-BERNARD; HABIEB-MAMMAR, 2005).

Os Sistemas Tutores Inteligentes (STI) podem ser considerados um marco no desenvolvimento de ambientes de aprendizagem eletrônica adaptativas, pois possibilitavam, através da utilização de técnicas da Inteligência Artificial, que os ambientes pudessem ser personalizados de acordo com diferentes perfis de alunos.

No final dos anos 90 as áreas de Sistemas Tutores Inteligentes (STI) e da Hipermídia Adaptativa (HA) sofreram uma fusão dando origem a uma nova área denominada de Sistemas Adaptativos Inteligentes, cujo objetivo era desenvolver sistemas de apoio ao aprendizado na Web que utilizassem técnicas de Inteligência Artificial possibilitando assim a personalização do ambiente de acordo com perfil do aluno (BRUSILOVSKY, 1999). Algumas das características da HA foram agregadas aos STI para que estes pudessem se adaptar ao cenário dinâmico da Web.

\subsubsection{Sistemas Tutores Inteligentes}

Existem diversas definições para STI. Freedman (2000), por exemplo, determina que "o termo Sistemas Tutores Inteligentes é amplo abrangendo qualquer programa de computador que contém alguma inteligência e pode ser usado em aprendizagem". Já Wenger (1987) destaca que "os Sistemas Tutores Inteligentes são sistemas instrucionais baseados em computador com modelos de conteúdo instrucional que especificam o que ensinar, e estratégias de ensino que especificam como ensinar". Porém, a maioria dos autores convergem para a definição de que os STI são ambientes que possibilitam o aprendizado adaptando-se às necessidades de aprendizagem do aluno. 
Rosatelli e Tedesco (2003) destacam que os STI são focados em domínios específicos e geralmente criados para atender um assunto onde a seqüência de ensino não é pré-determinada, adaptando-se de acordo com as informações obtidas da interação do aluno. Um dado importante é que a área de STI foi a primeira a imprimir esforços no sentido de modelar o usuário objetivando criar sistemas mais personalizados.

O STI se caracteriza por utilizar modelos que subdividem o sistema, separando as responsabilidades do mesmo. Uma visão da arquitetura clássica que representa os modelos e a interação destes é apresentada na Figura 5.

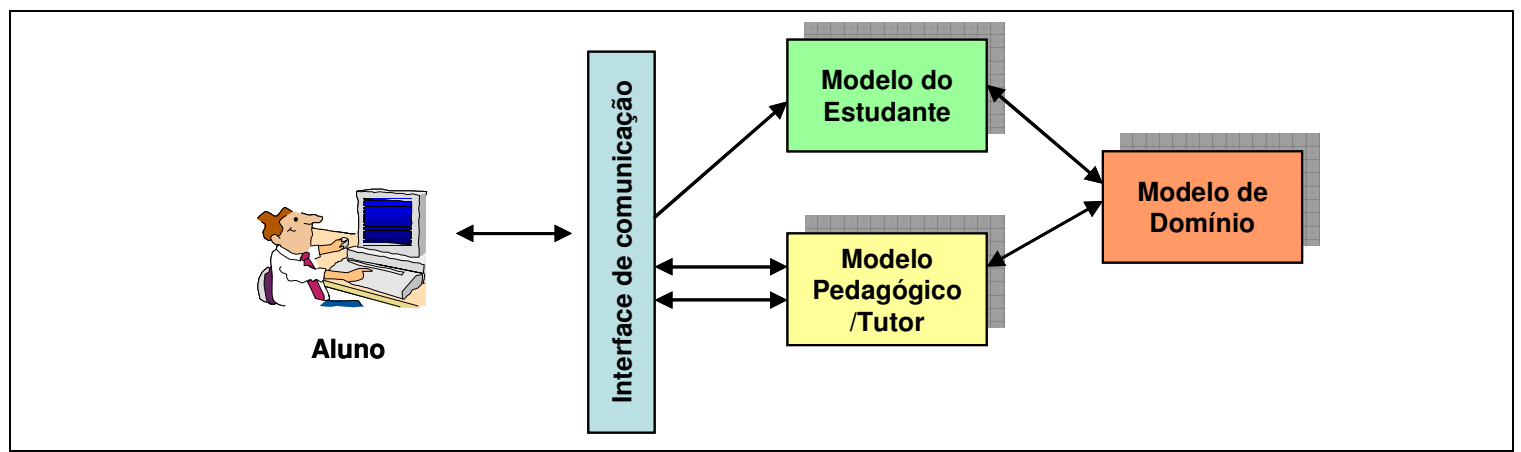

Figura 5 - Arquitetura clássica dos STI adaptado de Mcarthur apud Rosatelli (2000)

A criação de modelos permite que o sistema represente de forma separada 0 conteúdo relativo ao ensino (modelo de domínio) e a(s) estratégia(s) de aprendizagem (modelo pedagógico/tutor) que se deseja aplicar. Além disto, o modelo do aluno deverá conter informações que permitam realizar o processo de adaptação de acordo com as necessidades do aprendiz. De forma sucinta pode-se definir como responsabilidade dos modelos:

- Modelo de domínio: responsável pelo conteúdo pedagógico sobre o domínio da aprendizagem. Deve contar todo o conteúdo necessário para realizar o processo de aprendizagem.

- Modelo pedagógico/tutor: as estratégias de ensino que deverão ser adotadas no decorrer do processo de aprendizagem. Deve conter a forma de apresentar os conteúdos, exemplos, exercícios, entre outros de acordo com a interação do estudante. Funciona como um norteador das respostas que o sistema deverá dar de acordo com as interações do 
aprendiz. Normalmente, contém um conjunto de regras que possibilitam a adaptação de acordo com as informações obtidas do modelo do aluno.

- Modelo do estudante: contém informações obtidas a partir da interação do aluno que refletem o seu conhecimento sobre um dado assunto e seu perfil (suas preferências) num dado momento da interação.

- Interface de comunicação: contém recursos que viabilizem a apresentação do conteúdo de forma que esta seja adequada ao modelo do aluno. Permite também que o sistema possa extrair as informações sobre a interação do aluno com o sistema.

$\mathrm{Na}$ arquitetura clássica o aluno é supervisionado pelo sistema, através da interface de comunicação, que procura diagnosticar suas preferências e o conhecimento que ele detém sobre um dado assunto. $O$ resultado desta comparação é enviado ao modelo pedagógico/tutor que decide qual informação deverá ser transmitida ao aluno e como esta deverá ser apresentada através da interface de comunicação.

\subsubsection{Hipermídia Adaptativa}

A Hipermídia Adaptativa é a área que estuda o desenvolvimento de sistemas, arquiteturas, métodos e técnicas que promovam a adaptação de hipermídia em geral, relacionando as mesmas aos objetivos, necessidades e preferências $e$ desejos dos usuários envolvidos no sistema. A área de pesquisa da Hipermídia Adaptativa surgiu há muitos anos atingindo seu auge de maturidade nos anos 90 , quando os pesquisadores das áreas de Hipertexto e Modelagem do Usuário passaram a agregar novas contribuições dentro do contexto de adaptação (BRUSILOVSKY, 2001).

Brusilovsky (2001) destaca que podem existir dois tipos de adaptação relativos ao sistema adaptativo, descritos a seguir:

- Adaptação da apresentação: é focada na manipulação de como textos, mídias, navegação, entre outros, podem ser adaptados de acordo com as necessidades do usuário. Provê mecanismos que permitem realizar 
modificações na visualização do conteúdo de acordo com perfis de usuários extraídos das interações.

- Suporte à navegação adaptativa: provêem meios e mecanismos que visam permitir a adaptação e controlar a navegação do usuário. Os links são adaptados (ocultados, ordenados, entre outros) de acordo com as características obtidas.

\subsubsection{Sistemas Educacionais Adaptativos e Inteligentes baseados na Web}

A nova geração de ambientes gerenciadores de ensino tem não somente a responsabilidade de gestão, organização e reutilização de conteúdos, mas também de prover ambientes mais flexíveis no que concerne a oferta de conteúdos e ferramentas ao aluno (BRUSILOVSKY, 2003; DE BRA; AROYO; CRISTEA, 2004).

Brusilovsky e Peylo (2003) destacam que a partir da junção de aspectos relativos aos Sistemas Tutores Inteligentes e a Hipermídia Adaptativa surgiu a área de Sistemas Educacionais Adaptativos e Inteligentes baseados na Web. O objetivo principal era permitir que os sistemas fossem inteligentes, utilizando o controle do processo de navegação e adaptação da exibição de conteúdos Web provenientes das técnicas da Hipermídia Adaptativa. Atualmente, o desenvolvimento deste tipo de ambiente tem sido amplamento pesquisado, sendo que a área de Modelagem do Usuário é considerada um importante componente para a implementação destes ambientes (BRUSILOVSKY; KARAGIANNIDIS; SAMPSON, 2004).

Van Rosamlen et al, 2006 destacam que há uma carência de sistemas que trabalhem com a modelagem do usuário e que adotem a especificação dos padrões de ensino na construção dos ambientes.

\subsection{APLICAÇÕES CIENTES DE CONTEXTO}

O desenvolvimento de aplicações cientes de contexto se insere na área de computação ubíqua que tem por objetivo interconectar dispositivos computacionais com e sem fio, distribuídos e capazes de auxiliar o usuário na execução de tarefas 
dentro de um dado ambiente, (HENRICKSEN; INDULSKA; RAKATONIRAINY, 2002).

Schweitzer (2004) conceitua ambientes de computação ubíqua como aqueles constituídos de dispositivos interconectados que propiciam um acesso a qualquer hora e em qualquer momento. A mobilidade de acesso é propiciada pelo uso de dispositivos portáteis como notebooks com redes sem fio (wireless), PDAs (Personal Digital Assistant), telefones celulares, entre outros.

De maneira mais genérica pode-se definir contexto como um conjunto de condições relevantes e influências que possibilitam a compreensão de uma situação (BRÉZILLON, 1999). Estas condições e influências agem diretamente sobre entidades, onde estas entidades podem ser pessoas, um dispositivo, entre outros. É importante destacar que um contexto não pode ser visualizado como uma entidade autônoma, pois ele sempre vai existir quando relacionado a uma entidade em uma dada situação.

Dentro do ambiente de aprendizagem eletrônica, é importante destacar que a ciência sobre as informações relativas ao contexto da interação é fundamental para a adaptação e seleção adequada dos conteúdos e ferramentas a serem apresentados a um dado aluno. Um mesmo aluno em diferentes momentos pode criar um contexto diferente que requer uma adaptação diferenciada (DERNTL; HUMMEL, 2005; SCHMIDT, 2005; KURTI et al, 2006).

Para que as aplicações cientes de contexto possuam um desenvolvimento seguro e conciso é necessário gerenciar e disseminar as informações relativas ao contexto. Segundo Derntl e Hummel (2005), o contexto da interação de um processo de aprendizagem deve descrever o momento atual de um dado aluno relacionando este com uma dada atividade de aprendizagem incorporando a estas informações não só dados sobre o ambiente, mas também dados sobre os dispositivos utilizados e sobre o perfil do aluno que está interagindo. Uma modelagem do contexto da interação pode auxiliar no direcionamento do fluxo de aprendizagem do aluno.

Para que uma aplicação ciente de contexto possa realizar a adaptação de acordo com as necessidades de interação, sejam elas necessidades físicas ou relacionadas às preferências do usuário, é necessário que se tenham tanto informações explícitas, fornecidas pelo usuário, como informações percebidas (implícitas) pela aplicação. As informações que são percebidas pela aplicação são 
usualmente monitoradas a partir das interações do usuário (HENRICKSEN; INDULSKA, 2006).

\subsubsection{Modelagem do Contexto}

As dimensões de um contexto vão além de sua identidade e localização. Quando uma aplicação é ciente do contexto em que interage, ela consegue não só especificar os componentes que estão vinculados à aplicação, mas também customizar seu comportamento baseando-se no contexto a partir do qual a aplicação está inserida (BULCÃO NETTO; PIMENTEL, 2005; JAMESON, 2001).

Para Dey (2001), a interação do usuário com as aplicações é muitas vezes dificultada pela ausência de informações importantes sobre o contexto em que se está trabalhando. É necessário não só obter informações sobre a aplicação e sobre o usuário, mas também sobre a dependência que estas possuem com as tarefas que são executadas pelo usuário.

A modelagem do contexto em uma aplicação pode ser realizada através de diversas semânticas sendo que uma delas é denominada de W5H apresentada por Morse, Armstrong e Dey (2000) que define o contexto através de seis dimensões: who, what, where, when, why e how. A W5H discrimina itens que servirão de subsídios para a construção de um modelo do contexto:

-Who (quem): identifica o participante que está interagindo. Está diretamente relacionada às entidades que executam uma dada ação. Ou seja, os atores que desempenham um dado papel para executar a ação.

- Where (onde): determina o local onde o mesmo interage. Permite apontar a localização de onde a ação está ocorrendo. Este item é importante principalmente quando existe adaptação de ambiente dependendo de onde o usuário se encontra. Um dado usuário pode desempenhar o papel de estudante em contextos distintos tendo um tratamento diferenciado nestes, onde em cada contexto o estudante terá uma interação distinta.

- When (quando): especifica o caráter temporal da ação em questão. Determinar o tempo em que uma ação ocorreu permite diagnosticar perfis do usuário de acordo com o momento em que ele interagiu. 
- What (o que): descreve o que a ação proveniente da interação do usuário está representando. A ação isolada do usuário não tem significado relevante se não diagnosticada em conjunto com os outros $W$ descritos anteriormente. Uma mesma ação pode ter dimensões distintas dependentes do usuário, do local e do momento onde a mesma ocorreu.

- Why (por que): informa o porquê o usuário acessou a aplicação ou mesmo porque a aplicação é adequada a um dado momento.

- How (como): detalha questões especificas sobre o contexto onde a interação está ocorrendo. Especifica as características funcionais que o contexto possui para que o mesmo possa ser melhor adaptado ao usuário e ao momento da interação.

Jameson (2001) destaca que somente a modelagem do contexto não é suficiente para que uma aplicação ciente de contexto possa realizar adaptações consistentes. É necessário que estas sejam utilizadas em conjunto com as informações sobre o usuário que está interagindo (perfil do usuário).

\subsection{AMBIENTES E PROJETOS DE APRENDIZAGEM ADAPTATIVA}

Muitas são as iniciativas para desenvolvimento de ambientes adaptativos na Web que possam dar suporte ao desenvolvimento de aprendizado eletrônico. Buscou-se observar sistemas ou modelos que tivessem particularidades que se encaixassem dentro do contexto de adaptação e/ou de modelagem do aluno utilizada no processo de adaptação.

\subsubsection{ELM-ART}

O ambiente ELM-ART (ELM Adaptive Remote Tutor) ${ }^{19}$ surgiu da necessidade de desenvolver um tutor inteligente que possibilitasse o ensino da linguagem LISP. Com o passar dos anos o ambiente evoluiu para a nova demanda de sistemas que pudessem ser utilizados na Web.

\footnotetext{
${ }^{19}$ http://apsymac33.uni-trier.de:8080/Lisp-Course
} 
O modelo do usuário é representado através de multi-camadas que informam desde se o usuário visitou uma página até se um conhecimento foi adquirido ou não.

O processo de modelagem do usuário tem a colaboração do aluno. O ELMART apresenta uma tabela denominada de Learner Model onde o aluno pode opinar sobre seu conhecimento sobre um dado assunto. O sistema monta a tabela com base nos exercícios e testes resolvidos pelo aluno, indicando seus erros e acertos, e o aluno pode indicar se realmente concorda ou não com cada tópico. Adaptação é baseada na compilação destes dados do aluno (WEBER; BRUSILOVSKY,2001).

\subsubsection{AHA!}

O ambiente adaptativo AHA (Adaptive Hypermedia Architecture) ${ }^{20}$ teve o início do seu desenvolvimento em 1996 a partir da criação de um curso sobre hipermídia adaptativa. Nas primeiras versões era possível ao docente determinar como desejaria classificar os alunos definindo variáveis de observação e regras de adaptação. Através destas, o docente criava categorias de classificação de alunos.

A versão atual trabalha com estilos de aprendizagem, onde a classificação adotada foi a proposta por Honey e Mumford. O docente pode criar um gráfico sobre conceitos relacionados indicando para estes conceitos materiais que contemplem diferentes estilos de aprendizagem, (STASH; CRISTEA; DE BRA, 2004). O AHA! não possui nenhum questionário de onde são retiradas informações que seriam decisórias para escolha do estilo de aprendizagem do aluno. $O$ aluno pode escolher o estilo inicial e depois o ambiente vai se adequando ao estilo escolhido inicialmente.

Baseando-se no modelo do AHA! Wu (2002) propõem o AHAM (Adaptive Hypermedia Application Model) que se constitui numa redefinição da arquitetura do ambiente com o intuito de separar a visão de domínio, de usuário e de adaptação do ambiente.

${ }^{20}$ AHA! Project: http://aha.win.tue.nl/ 


\subsubsection{AdaptWeb}

Projeto desenvolvido pela Universidade do Rio Grande do Sul ${ }^{21}$, tem como objetivo prover docentes e alunos com um ambiente adaptativo que permita a adaptação do ambiente de acordo com as preferências de aprendizagem do aluno. O foco principal do projeto é permitir que o docente cadastre conteúdos e possa determinar quais deles serão acessados dependendo do estilo de aprendizagem de cada aluno através da configuração do ambiente.

O ambiente apresenta um modelo para adaptação de cursos na Web cujo foco principal é criar uma correlação entre o estilo cognitivo do aprendiz (observado e capturado a partir de suas interações com o sistema), o conteúdo estudado, representado a partir de objetos de aprendizagem (BRUNETTO et al, 2003).

O componente de adaptação do sistema possui dois elementos principais o filtro de conteúdo e o filtro de mídias. O primeiro é responsável pela adaptação do conteúdo de acordo com o curso que o aluno se encontra e o segundo com a adaptação da mídia mais adequada à conexão de rede utilizada pelo aluno (MUÑOZ; OLIVEIRA, 2004).

\subsubsection{AES-CS}

O AES-CS (Adaptive Educational System based on Cognitive Styles) é um sistema adaptativo com foco nos estilos cognitivos do aluno. Segundo Triantafillou, Pomportsis e Georgiadou (2002), o sistema permite realizar um controle dependente ou independente de domínio de acordo com as preferências do aprendiz. O sistema conduz o aluno de acordo com sua interação quando se trata de um controle dependente de domínio, enquanto que o controle é feito pelo aprendiz quando há a evidência de um estilo que seja independente do domínio.

O modelo do aluno é construído com base nas seguintes informações: perfil pessoal (constituído por dados estáticos como nome e senha), perfil cognitivo (possui dados relativos à adaptação de acordo com suas preferências cognitivas) e perfil do conhecimento do aluno (detalha informações sobre a aprendizagem do indivíduo em um dado tópico através de quatro níveis diferentes).

${ }^{21}$ AdaptWeb: http://adaptweb.sourceforge.net/ 
O perfil cognitivo é composto por informações relativas à organização do conteúdo, ao controle de navegação, ao tipo de retroalimentação, etc. Essas características determinam se 0 aluno terá uma navegação dependente ou independente.

\subsubsection{INSPIRE}

O ambiente INSPIRE foi concebido com funcionalidades de adaptação que são realizadas a partir dos objetivos de aprendizagem de um curso e dos estilos de aprendizagem de um aluno.

Mesmo provendo os mecanismos de adaptação que são baseados nas técnicas de seqüenciamento de currículo, o sistema permite que o aprendiz possa interferir em alguns pontos como na definição de suas próprias características e nas escolhas de conteúdos a serem estudados, permitindo que o aluno participe do processo de aprendizagem. Papanikolaou et al (2001) aborda que o ambiente adota a classificação de estilos de aprendizagem propostas por Honey e Mumford.

O modelo do aluno possui informações pessoais, informações sobre o estilo de aprendizagem e o estado corrente da aprendizagem (nível de conhecimento sobre diferentes conceitos e sobre objetivos de aprendizagem, resultado de testes, tipo e ordem de recursos acessados, etc). O nível de conhecimento do aluno sobre um determinado conteúdo é classificado em quatro níveis que vão do insuficiente até o suficiente. O estilo de aprendizagem inicial do aluno é obtido através de um questionário.

\subsubsection{SEDHI}

O SEDHI (Sistema Educacional Hipermídia) é um sistema para ser utilizado em cursos a distância na Web baseado nos mecanismos de Hipermídia Adaptativa e empregando algoritmos de Inteligência Artificial como suporte para o processo de adaptação através do perfil do aluno (SILVA; ROSATELLI, 2006).

O sistema realiza um acompanhamento das atividades realizadas pelo aluno e com base nestas e em seu perfil classifica o estudante em: iniciante, intermediário ou avançado. E é a partir desta classificação que o sistema realiza a adaptação da 
navegação no curso empregando as técnicas de ocultamento de links e de anotação de links.

O módulo de classificação considera um conjunto de atributos que estão relacionados ao curso para determinar o perfil do aluno. Estes atributos são obtidos através do tempo gasto na navegação, de questões feitas ao docente do curso (indica que o aluno precisou de ajuda), sua interação em listas de discussões, seu acesso ao FAQ (Frequently Asked Questions) do curso, o resultado obtido em exercícios e testes e sua experiência em outros cursos na Web. A partir das informações relacionadas aos atributos descritos anteriormente e de regras prédefinidas que envolvam estes atributos, o sistema verifica em qual grupo (iniciante, intermediário ou avançado) o aluno se encaixa, adaptando o curso de acordo com estas informações. Quando o aluno entra pela primeira vez no sistema este é classificado como iniciante.

\subsubsection{PAP}

O PAP (Política de Aprendizagem Personalizada) define um conjunto de regras e procedimentos que permitem organizar de maneira flexível as atividades que serão apresentadas aos alunos durante a aprendizagem eletrônica (STIUBIENER; ROSATELLI; RUGGIERO, 2007).

Durante a definição do PAP devem-se especificar as regras estabelecendo condições associadas a eventos que podem ocorrer durante uma experiência de aprendizagem e que pode estar relacionada a uma característica observável do aprendiz que comporá o seu perfil.

Através do PAP define-se uma camada de orientação que auxilia na especificação do que será observado sobre o aluno. Esta camada tem como finalidade apontar a dimensão da observação que será adotada dentro do processo de aprendizagem. Alguns exemplos de domínios de informação que podem ser utilizados como aspectos observáveis pela camada de orientação são: forma de apresentação do conteúdo (layout de tela), forma midiática (textos, vídeo, áudio, animações, entre outros), nível de conhecimento, estilos de aprendizagem, etc.

A partir da PAP, dos conjuntos de conteúdos e atividades didáticas e das camadas de orientação é possível oferecer ao aprendiz as atividades didáticas adaptadas de acordo com o perfil mais adequado a ele. 


\subsubsection{Arquitetura ALD}

Berlanga e García (2005a, 2005b) propõem uma arquitetura denominada de Adaptive Learning Design, em que através dos elementos definidos no padrão LD seja possível realizar adaptações de acordo com os estilos de aprendizagem dos alunos.

A arquitetura proposta é dividida em modelo de documentos (conteúdos, atividades de aprendizagem, etc), do usuário (características, conhecimentos e preferências), de observação (o que será observado durante a interação do usuário) e componente de adaptação (possui regras, baseado no modelo condição-ação, que realiza a adaptação de acordo com o modelo do usuário e o de observação).

A partir dos conteúdos definidos no modelo de documentos (learning objects, activities, etc) a adaptação realiza uma ação (act) que é executada (play) dependente do papel (role) e das propriedades (properties) do usuário que são obtidas a partir de condições (conditions) que extraem informações através do modelo de observação (por exemplo na execução de testes).

Para que fosse possível utilizar a arquitetura foi implementada uma ferramenta de autoria denominada de Hypermedia Composer Learning Design (HyCo_LD) (BERLANGA; GARCIA; CARABIAS, 2006) que permite ao autor montar a estrutura do curso de acordo com o padrão do Learning Design. O objetivo é gerar após a edição do curso um pacote (arquivo) contendo a estrutura do mesmo para que este possa ser utilizado em diferentes ferramentas que interpretem o padrão, como por exemplo, o CopperCore.

\subsubsection{CopperCore}

CooperCore $^{22}$ é um executor (runtime) para conteúdos que foi projetado a partir do padrão do Learning Design. Faz parte do conjunto de soluções desenvolvidas dentro do grupo $\mathrm{JISC}^{23}$ (Joint Information Systems Committee) que se baseiam em arquiteturas de software orientadas a serviços. O propósito do JISC é definir um conjunto de protocolos e padrões que orientem o desenvolvimento de

\footnotetext{
${ }^{22} \mathrm{http}: / /$ coppercore.sourceforge.net/

${ }^{23} \mathrm{http}: / / \mathrm{www} . j i s c . a c . u k /$
} 
ferramentas de apoio à aprendizagem eletrônica na Web, através da implementação de componentes e serviços.

É composto por três API (Application Programming Interface) que estão relacionadas à publicação de conteúdo e gerenciamento de usuários, a execução do conteúdo de acordo com a organização em unidades de aprendizagem e controle de eventos.

O objetivo é que o CopperCore seja a camada executora das unidades de aprendizagem desvinculada da interface de apresentação. Cabendo aos diversos ambientes construírem a camada de interface com o usuário da forma mais adequada às suas necessidades.

\subsubsection{Sakai}

O Sakai ${ }^{24}$ é um ambiente gerenciador de cursos (LMS) de código aberto desenvolvido em Java através de iniciativas de diversos grupos de pesquisa do mundo todo. O propósito do Sakai é prover o núcleo de um LMS permitindo que ferramentas de gerenciamento de conteúdos, colaborativas, entre outras, possam ser agregadas a ele. A flexibilidade de composição do LMS permite que cada instituição possa desenvolver ou incorporar ao núcleo as ferramentas que forem mais adequadas a realizadade educacional da mesma.

A versão atual do Sakai não possui suporte a processos de adaptação do ambiente de acordo com as necessidades de ensino ou mesmo das preferências do aluno.

\subsubsection{Projeto SLeD}

O projeto SLeD (Service-based Learning Design) patrocinado pelo JISC eLearning Programme ${ }^{25}$ teve como propósito desenvolver um executor (player) a partir do CopperCore, mas que fosse aderente a uma arquitetura orientada a serviços. Pode ser considerado uma evolução do CopperCore que permite a comunicação entre ferramentas que compõem uma atividade de aprendizado.

\footnotetext{
${ }^{24} \mathrm{http}: / /$ sakaiproject.org/

${ }^{25} \mathrm{http}: / /$ www.jisc.ac.uk/index.cfm?name=programme_elearning
} 
Além disto, uma nova versão do projeto denominada de SLeD2 incorporou ao projeto inicial o padrão QTI (Question \& Test Interoperability) ${ }^{26}$ do IMS que especifica um modelo de organização de vários formatos de testes.

\subsubsection{Reload}

O Reload ${ }^{27}$ (Reusable eLearning Object Authoring \& Delivery) vinculado ao JISC é um editor que permite a criação e distribuição de conteúdos para aprendizado eletrônico visando principalmente a interoperabilidade entre os diversos sistemas. O editor permite que sejam criadas unidades de aprendizagem especificadas nos padrões ADL SCORM e IMS Learning Design.

\subsubsection{LAMS}

O LAMS ${ }^{28}$ (Learning Activities Management System) é um ambiente que implementa as especificações do Learning Design permitindo a criação, gestão e monitoração de atividades realizadas na Web. Foi desenvolvido pela LAMS International e LAMS Foundation, organizações vinculadas a Macquarie University ${ }^{29}$ (Sidney - Austrália).

O esfoço em construir o LAMS surgiu da nova visão dentro do aprendizado eletrônico que focava o planejamento de atividades e não mais somente de conteúdos.

O LAMS apresenta uma ferramenta visual onde o docente pode elaborar sua seqüência de atividades de aprendizagem de forma que esta atenda uma dada metodologia de ensino-aprendizagem. Além disto, o docente seleciona o grupo de alunos que terão acesso à atividade de aprendizagem elaborada. A partir do momento que uma atividade de aprendizagem estiver ativa, os alunos podem executar a atividade, e o ambiente realiza a monitoração das interações do aluno com a dada atividade. $\mathrm{O}$ ambiente também permite que o docente possa visualizar dados sobre a interação de cada aluno na atividade de aprendizagem (DALZIEL, 2003).

\footnotetext{
${ }^{26}$ http://www.imsproject.org/question/index.html

27 http://www.reload.ac.uk/

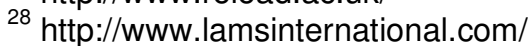

${ }^{29}$ www.mq.edu.au
} 
As atividades de aprendizagem podem ser reutilizadas durante a construção de outras atividades de aprendizagem.

\subsection{COMPARAÇÃO ENTRE OS TRABALHOS APRESENTADOS}

Para facilitar a análise dos trabalhos descritos anteriormente foram desenvolvidas as Tabela 11 e Tabela 12, onde a primeira compara ambientes e arquiteturas que não utilizam padrões para implementação de ambientes de aprendizado eletrônico e a segunda aqueles que utilizam estes padrões.

Foram adotados alguns pontos como itens comparativos entre os trabalhos apresentados para composição da Tabela 11:

- Tipo: define se é uma arquitetura ou um ambiente.

- Características da adaptação: quais são as formas de adaptação empregadas nos trabalhos (adoção de HA), em que a adaptação se baseia (em regras, estilos de aprendizagem, testes, etc), etc.

- Modelo do aluno: o que é relevante na modelagem do aluno para cada trabalho.

Para a Tabela 12 foram considerados os aspectos:

- Tipo: se é um executor (player - ambiente que apresenta o conteúdo desenvolvido num dado padrão), editor (elaboração de conteúdo), arquitetura (proposta) ou ambiente.

- Características da adaptação e Modelo do aluno: conforme itens descritos anteriormente.

- Padrão adotado: se o trabalho adota algum padrão como SCORM ou Learning Design.

O projeto Sakai não aparece nas tabelas a seguir devido ao fato do mesmo não se encaixar nas características utilizadas na comparação. A finalidade do ambiente do Sakai é prover o núcleo de uma arquitetura que permita que a mesma possa implementar as características relativas aos padrões e a modelagem do aluno. 
Tabela 11 - Comparação entre ambientes e projetos que não adotam padrões

\begin{tabular}{|c|c|c|c|}
\hline $\begin{array}{c}\text { Ambiente e } \\
\text { Projetos }\end{array}$ & Tipo & Características da Adaptação & Modelo do Aluno \\
\hline ELM-ART & ambiente & $\begin{array}{l}\text { - } \quad \text { Sequenciamento de currículo: o parâmetro para } \\
\text { adaptação é verificado através da execução de } \\
\text { testes. } \\
\text { - } \quad \text { Utilização de técnicas de HÁ como links para } \\
\text { diferenciar tópicos visitados ou não pelo aluno. } \\
\text { - } \quad \text { Adaptação baseada na definição de regras. } \\
\text { - O modelo de adaptação é baseado nos testes } \\
\text { ao final de cada capítulo. }\end{array}$ & $\begin{array}{l}\text { - O modelo do aluno é dividido em } \\
\text { camadas que determinam os } \\
\text { conteúdos visitados, aprendidos, por } \\
\text { ele. } \\
\text { - Aluno pode opinar sobre seu modelo } \\
\text { (Learner Model). }\end{array}$ \\
\hline AHA! & ambiente & $\begin{array}{l}\text { - } \quad \text { Sequenciamento de currículo. } \\
\text { - } \quad \text { Utiliza técnicas de HA para a adaptação dos } \\
\text { conteúdos e da navegação. } \\
\text { - } \quad \text { Pode haver propagação de conteúdos através } \\
\text { do uso de pré-requisitos. } \\
\text { - } \quad \text { Adaptação baseada na definição de regras que } \\
\text { são associadas aos estilos de aprendizagem. }\end{array}$ & $\begin{array}{l}\text { - O perfil é baseado em atributos } \\
\text { criados pelo docente, considerando o } \\
\text { modelo de estilos de aprendizagem } \\
\text { definidos por Honey e Mumford. } \\
\text { - Aluno realiza a escolha do seu perfil } \\
\text { inicial. }\end{array}$ \\
\hline Adapt-Web & ambiente & $\begin{array}{l}\text { - } \quad \text { Sequenciamento de currículo. } \\
\text { - } \quad \text { Utiliza técnicas de HA para adaptação da } \\
\text { navegação e de conteúdos. } \\
\text { - } \quad \text { Filtro de mídias que realiza a adaptação da } \\
\text { mídia de acordo com a conexão de rede do } \\
\text { aluno. } \\
\text { - } \quad \text { Adaptação baseada na definição de regras. }\end{array}$ & $\begin{array}{l}\text { - } \text { Modelo do aluno é criado a partir dos } \\
\text { exercícios resolvidos por ele e pela } \\
\text { monitoração de sua interação. } \\
\text { São informações relevantes o curso, } \\
\text { o tipo de conexão, o modo de } \\
\text { navegação (tutorial ou livre), se o } \\
\text { aluno está trabalhando em um } \\
\text { conceito, etc. }\end{array}$ \\
\hline AES-CS & ambiente & $\begin{array}{l}\text { - } \quad \text { Sequenciamento de currículo. } \\
\text { - } \quad \text { Utiliza técnicas de HA para adaptação da } \\
\text { navegação e de conteúdos. } \\
\text { - } \quad \text { Caracteriza uma navegação dependente ou } \\
\text { independente. } \\
\text { - } \quad \text { Adaptação baseada na definição de regras. }\end{array}$ & 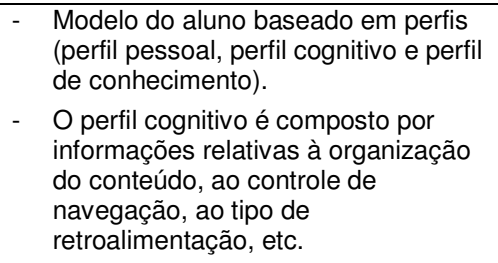 \\
\hline INSPIRE & ambiente & 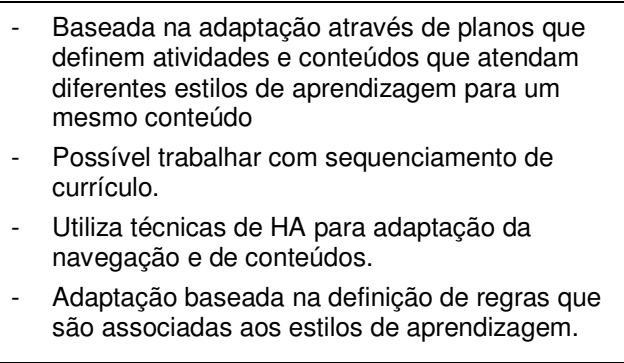 & 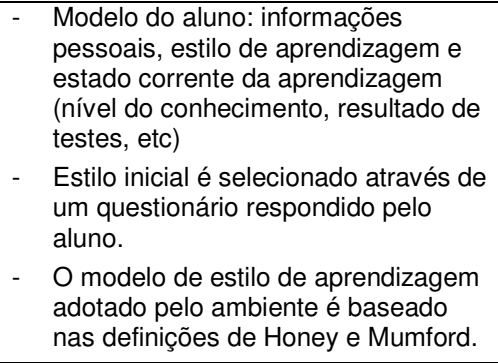 \\
\hline SEDHI & arquitetura & $\begin{array}{l}\text { - Utiliza a técnica de aprendizagem de máquina } \\
\text { baseada em exemplos para realizar a } \\
\text { adaptação. Considera um conjunto de valores } \\
\text { monitorados do aluno para realizar a adaptação. } \\
\text { - Utiliza técnicas de HA para adaptação da } \\
\text { navegação e de conteúdos. }\end{array}$ & $\begin{array}{l}\text { - O perfil é classificado como iniciante, } \\
\text { intermediário ou avançado. } \\
\text { - Define elementos como número de } \\
\text { acesso ao FAQ, número de } \\
\text { mensagens enviadas a lista de } \\
\text { discussão, etc como atributos } \\
\text { considerados durante o processo de } \\
\text { avaliação do perfil do aluno. }\end{array}$ \\
\hline PAP & arquitetura & $\begin{array}{l}\text { - Sequenciamento de Currículo: o parâmetro para } \\
\text { adaptação é verificado através da execução de } \\
\text { testes e do que deve ser considerado como } \\
\text { camada de orientação }\end{array}$ & $\begin{array}{l}\text { - Não há formalização da modelagem } \\
\text { do aluno. As ações são definidas pelo } \\
\text { conjunto de eventos oferecidos ao } \\
\text { aluno. }\end{array}$ \\
\hline
\end{tabular}


Tabela 12 - Comparação entre trabalhos estudados que adotam padrões de ensino

\begin{tabular}{|c|c|c|c|c|}
\hline Trabalho & Tipo & Características da Adaptação & Modelo do Aluno & Padrão adotado \\
\hline CopperCore & executor & $\begin{array}{l}\text { - } \quad \text { Baseado em regras. } \\
\text { - Uso de condicionais pré-definidos pelo } \\
\text { padrão do Learning Design. } \\
\text { - Implementa os níveis de A a C do LD }\end{array}$ & $\begin{array}{l}\text { Baseado nas } \\
\text { propriedades relativas } \\
\text { ao papel que o aluno } \\
\text { exerce no sistema. } \\
\text { - Não possui um } \\
\text { modelo do usuário } \\
\text { explícito. }\end{array}$ & - Learning Design \\
\hline SLeD & executor & $\begin{array}{ll}\text { - } & \text { Baseado em regras. } \\
\text { - } & \text { Uso de condicionais pré-definidos pelo } \\
\text { padrão do Learning Design. } \\
\text { - } \quad \text { Baseado no CopperCore. } \\
\text { - } \quad \text { Incorporou o padrão QTI do IMS para } \\
\text { direcionar o processo de adaptação. }\end{array}$ & 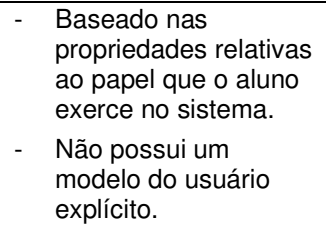 & - Learning Design \\
\hline Reload & editor & $\begin{array}{l}\text { Permite criar propriedades e regras } \\
\text { que serão utilizadas no processo de } \\
\text { adaptação. } \\
\text { - Cria atividades de aprendizagem. }\end{array}$ & $\begin{array}{l}\text { Baseado nas } \\
\text { propriedades relativas } \\
\text { ao papel que o aluno } \\
\text { exerce no sistema. } \\
\text { - Não possui um } \\
\text { modelo do usuário } \\
\text { explícito. }\end{array}$ & $\begin{array}{l}\text { - SCORM } \\
\text { - } \quad \text { Learning Design }\end{array}$ \\
\hline ALD & arquitetura & $\begin{array}{l}\text { - } \quad \text { Baseado em regras. } \\
\text { padrão do Learning Design. } \\
\text { - Cria uma separação entre módulos a } \\
\text { partir dos componentes do LD } \\
\text { definindo as responsabilidades de } \\
\text { cada um. }\end{array}$ & $\begin{array}{l}\text { Modelo do usuário } \\
\text { (características, } \\
\text { conhecimentos e } \\
\text { preferências). É } \\
\text { determinado a partir } \\
\text { das propriedades } \\
\text { definadas dentro do } \\
\text { modelo do LD. } \\
\text { - Modelo de } \\
\text { observação (o que } \\
\text { será observado } \\
\text { durante a interação } \\
\text { do usuário). }\end{array}$ & - Learning Design \\
\hline LAMS & ambiente & $\begin{array}{l}\text { - Permite criar uma sequencialização de } \\
\text { atividades de aprendizagem. } \\
\text { - Implementa o conceito de suporte a } \\
\text { adaptação da navegação através dos } \\
\text { conceitos de gates (passagem) e flows } \\
\text { (fluxo). }\end{array}$ & $\begin{array}{ll}\text { - } & \text { Realiza um } \\
\text { acompanhamento } \\
\text { aluno a aluno das } \\
\text { atividades de } \\
\text { aprendizagem } \\
\text { cursadas. } \\
\text { - Não possui um } \\
\text { modelo do usuário } \\
\text { explícito. }\end{array}$ & - Learning Design \\
\hline
\end{tabular}

\subsection{CONSIDERAÇÕES FINAIS}

A adaptação do processo de aprendizagem tem se tornado um requisito importante em sistemas de aprendizagem eletrônica na Web. Para prover mecanismos de adaptação é necessário que os ambientes de aprendizagem eletrônica possuam um controle mais preciso das interações e comportamentos do aluno. 
A especificação de padrões de ensino tem emergido com o intuito de organizar a criação de ambiente e manter a interoperabilidade não só dos ambientes eletrônicos bem como dos elementos que compõem o processo de aprendizagem, como por exemplo, os objetos de aprendizagem. Além da especificação de metadados que permitem organizar os conteúdos e os processos de aprendizagem a especificação dos padrões também tem contribuído para definição de entidades que permitam implementar conceitos de ensino-aprendizagem nos ambientes eletrônicos.

O conhecimento do contexto das interações auxilia no processo de reconhecimento das interações. A modelagem deste contexto, considerando questões sobre o local, o momento entre outras torna-se fundamental para a criação de modelos mais precisos que possam suprir o processo de adaptação do ambiente de aprendizagem.

Este capítulo apresentou os principais conceitos relacionados à aprendizagem eletrônica. Foram discutidas questões relacionadas a padrões que especificam a organização da arquitetura e do funcionamento de ambientes de aprendizagem eletrônica e de catalogação de objetos de aprendizagem, como o SCORM, o Learning Design e o LOM.

A evolução dos ambientes de aprendizagem eletrônica a partir dos modelos especificados pelas áreas de STI e de HA foi apresentada no decorrer do capítulo.

A importância da modelagem do contexto das interações do usuário foi abordada a partir das concepções relacionadas às aplicações cientes de contexto.

Para finalizar o capítulo foi apresentada uma revisão de alguns ambientes e projetos relacionados à aprendizagem eletrônica, onde foi realizada uma comparação entre os ambientes e projetos apresentados. 


\section{PROPOSTA DE UMA ARQUITETURA PARA ADAPTAÇÃO DE CENÁRIOS DE APRENDIZAGEM ATRAVÉS DA AVALIAÇÃO DO PERFIL DE APRENDIZAGEM DO ALUNO}

\subsection{CONSIDERAÇÕES INICIAIS}

Este capítulo apresenta a proposta de uma arquitetura para adaptação de Cenários de Aprendizagem baseada na avaliação do perfil do aluno. Este perfil é obtido através da avaliação das informações existentes no Modelo do Aluno proposto no Capítulo 2 deste trabalho (tópico 2.6). As informações existentes no Modelo do Aluno são provenientes da consolidação de informações do contexto da interação do aluno.

A arquitetura permite que o docente possa planejar a adaptação dos Cenários de Aprendizagem definindo estratégias de ensino que possam ser mais adequadas a um dado aprendiz. Estas estratégias estão diretamente relacionadas ao perfil de aprendizagem do aluno.

\subsection{CENÁRIOS DE APRENDIZAGEM}

Um Cenário de Aprendizagem (CA) é definido, neste trabalho, como uma entidade composta por um conjunto de estruturas de atividades que dá suporte ao aluno durante o aprendizado de um ou mais conceitos. Um CA encapsula as atividades de aprendizagem (através das estruturas de atividades) que são necessárias para dar suporte a dado processo de aprendizagem.

Durante a construção do processo de aprendizagem um determinando aluno pode ter suas preferências e necessidades de aprendizagem alteradas dependendo do escopo do ensino. Oferecer Cenários de Aprendizagem que sejam adequados às preferências de aprendizagem do aluno pode se constituir em um aspecto motivador ao estudante.

Este trabalho utiliza o modelo do aluno proposto no Capítulo 2 como suporte ao processo de construção dos CAs a serem oferecidos aos aprendizes. Um CA é construído dinamicamente considerando aspectos descritos no modelo do aluno. 
Pelo padrão do Learning Design uma atividade de aprendizagem é descrita através de um elemento denominado "item" que especifica a referência do objeto de aprendizagem que atende a dada atividade de aprendizagem. Um elemento "item" aponta para um objeto de aprendizagem que retrata um ou mais conceitos.

Neste trabalho um "item" irá apenas descrever um conceito, pois o direcionamento ao objeto de aprendizagem será dinâmico através da busca dos objetos de aprendizagem (num repositório de objetos especificados através do padrão LOM) que atendam o ensino de um determinado conceito. Quando uma atividade for suportada por uma ferramenta, como por exemplo, de chat ou fórum, o elemento "item" deve conter o direcionamento para a ferramenta em questão. Uma mesma atividade de aprendizagem pode ter mais de um "item" que a compõe. Conforme descrito no Capítulo 3 (tópico 3.3.3.2) um "item" na especificação do padrão do Learning Design aponta para o objeto de aprendizagem ou ferramenta referenciado durante a execução da atividade.

A Figura 6 ilustra o modelo conceitual de um CA. As entidades delimitadas pertencem à especificação do padrão do Learning Design.

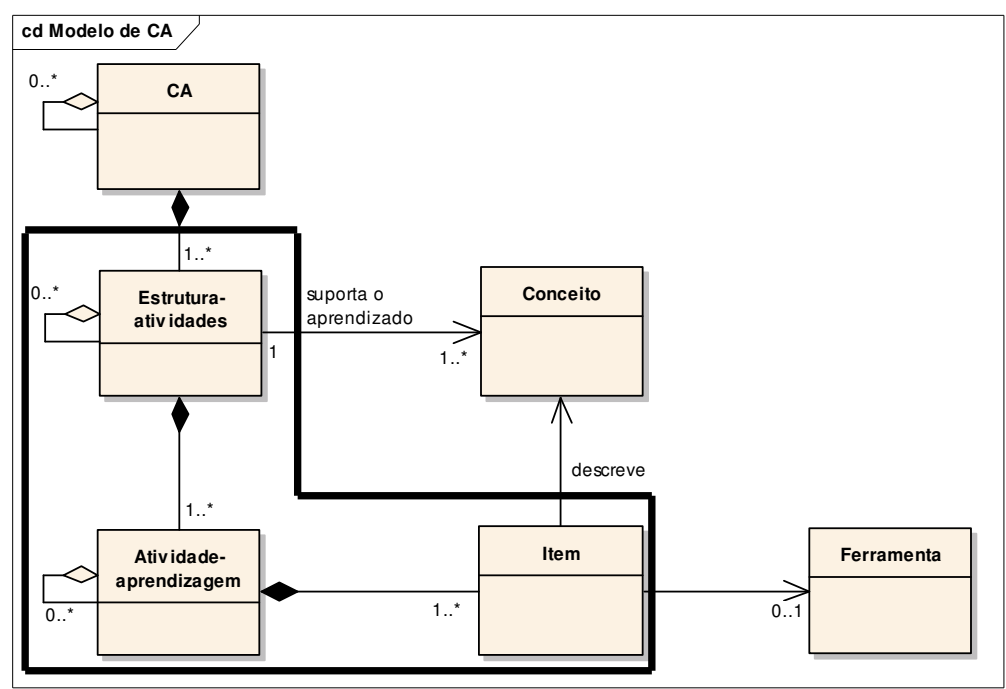

Figura 6 - Modelo conceitual de um CA

Quando o docente está planejando um CA através do padrão do Learning Design ele deve criar apenas um modelo já que os objetos de aprendizagem de fato serão relacionados dinamicamente de acordo com informações existentes no Modelo do Aluno. Portanto, quando o docente planeja um CA ele está especificando 
um Modelo de CA, já que este é utilizado como estrutura para a construção do CA adequado ao aluno.

\subsection{REQUISITOS PARA DESENVOLVIMENTO DA ARQUITETURA PROPOSTA}

Para a definição de uma arquitetura que considere a construção de CAs de acordo com as preferências de aprendizagem do aluno e das necessidades do processo de aprendizagem, podem ser enumerados os seguintes requisitos funcionais (RF):

RF1) O ambiente deve trabalhar com cenários de aprendizagem, previamente cadastrados através da especificação do padrão do Learning Design, que suportem o ensino de determinados conceitos.

RF2) Permitir que o docente aponte em quais atividades de aprendizagem e/ou ferramentas deseja observar a interação do aluno.

RF3) Permitir que o docente defina o que deseja observar sobre a interação do aluno.

RF4) Permitir que o professor cadastre um conjunto de tipos de perfis de aprendizagem que serão utilizados para classificar o aluno segundo um determinado perfil de aprendizagem.

RF5) Permitir que o professor possa também planejar a adaptação de um CA, segundo um perfil desejado, desconsiderando a classificação automática de perfis gerada pelo ambiente.

RF6) Monitorar a interação do aluno nas atividades que foram apontadas como observáveis.

RF7) Atualizar o modelo do aluno de acordo com as informações obtidas pela monitoração.

RF8) Classificar o aluno em um dado perfil de aprendizagem considerando as informações monitoradas e o conjunto de exemplos de perfis cadastrados pelo professor.

RF9) Atualizar o modelo do aluno com as informações obtidas na classificação do aluno em um dado perfil de aprendizagem. 
RF10) Realizar a adaptação do CA de acordo com as informações do Modelo do aluno e das estratégias de ensino relacionadas a um dado perfil de aprendizagem.

A Figura 7 apresenta o Diagrama de Caso de Uso nível 0 com os processos envolvidos segundo os requisitos funcionais listados e considerando a dependência entre os processos.

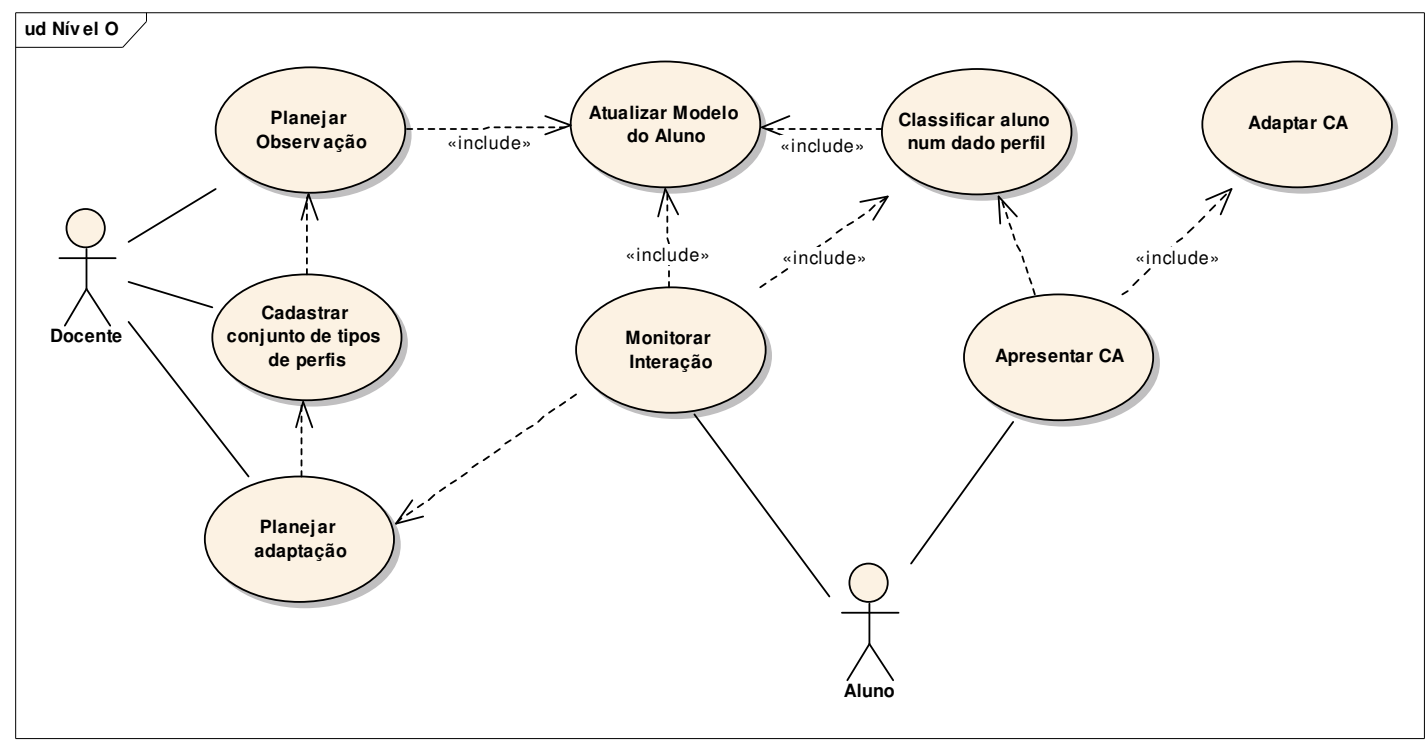

Figura 7 - Diagrama de Caso de Uso Nível 0

\subsection{ARQUITETURA PARA ADAPTAÇÃO DE CENÁRIOS DE APRENDIZAGEM}

A adaptação da aprendizagem pode ser contemplada em diferentes ângulos durante a aprendizagem eletrônica, indo desde a adaptação de conteúdos a serem estudados até a forma de visualização destes.

Independente do foco que se deseja imprimir no processo adaptativo é importante que este seja sustentado por informações sobre o aprendiz e sobre o contexto de sua interação, para que desta forma seja possível realizar a construção de cenários de aprendizagem que sejam mais adequados ao perfil do aluno.

A arquitetura proposta neste trabalho se baseia na divisão de responsabilidades empregada pelos Sistemas de Tutores Inteligentes, onde os 
módulos possuem responsabilidades específicas dentro do escopo do ambiente de ensino. Porém, sem se focar em um domínio de aprendizagem em específico. A Figura 8 apresenta um modelo conceitual da arquitetura proposta:

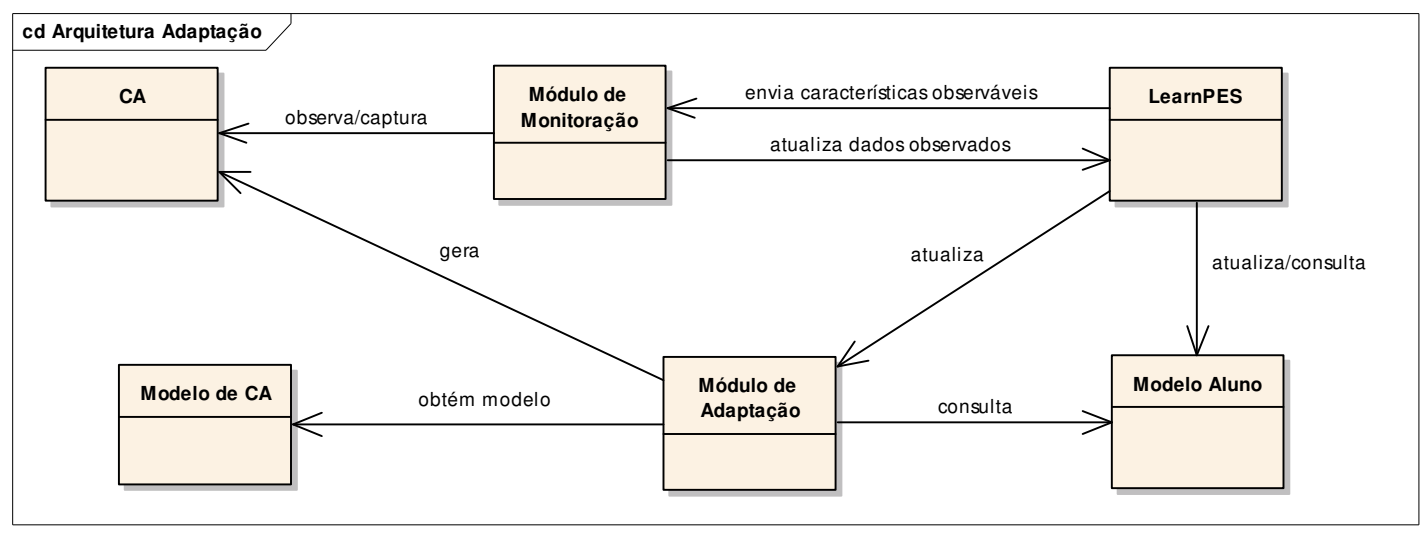

Figura 8 - Modelo conceitual da arquitetura para adaptação de CAs

Os componentes que fazem parte da arquitetura proposta serão descritos de forma sucinta a seguir e detalhados posteriormente nos Capítulos 5 e 6 . Não existem componentes reutizados de outras arquiteturas ou ambientes já existentes. Todos são criados a partir da proposta deste trabalho.

Fazem parte dos componentes propostos pela arquitetura:

- CA: Cenário de Aprendizagem construído a partir de um modelo e que será apresentada ao estudante durante o processo de aprendizagem.

- Modelo de CA: possui a estrutura base dos elementos que farão parte do CA. É construído em conformidade com o padrão do Learning Design. Possui os elementos que especificam um CA (atividades de aprendizagem, estrutura de atividades, etc). Nele são descritas as atividades de aprendizagem e os conceitos que estão relacionados ao ensino desta. Quando há uma ferramenta vinculada à atividade é especificada a referência para a ferramenta.

- LearnPES (Learning Profile Evaluator System): módulo responsável por identificar o perfil de aprendizagem do aluno, avaliando um conjunto de características que foram observadas a partir da interação do aluno. O LearnPes é responsável tanto pelo planejamento do que será observado como pela classificação dos perfis. 
- Módulo de Monitoração: recebe do LearnPES as características observáveis e monitora as interações do aluno. Envia ao LearnPES o contexto de cada interação do aluno considerando as características observáveis. Não se encontra dentro do escopo deste trabalho definições de como as informações serão monitoradas. A especificação do Módulo limita-se em estabelecer como esta recebe e envia os dados contextuais.

- Modelo do Aluno: contém as informações sobre o aluno conforme apresentado no Capítulo 2 (tópico 2.6).

- Módulo de Adaptação: a partir de informações sobre a adaptação desejada, considerando o Modelo do Aluno (perfil de aprendizagem, tecnologia, etc) e do Modelo do CA constrói o CA mais adequado ao aluno.

\subsubsection{Sistema Avaliador de Perfil de Aprendizagem - Learning Profile Evaluator System (LearnPES)}

O sistema LearnPES (Learning Profile Evaluator System) tem como objetivo sugerir o perfil de aprendizagem que seria mais adequado ao aluno segundo as características destes. O perfil é obtido a partir da análise das informações sobre o contexto de interação do aluno. O perfil de aprendizagem sugerido será armazenado no Modelo do Aluno e irá auxiliar o processo de adaptação na construção do CA mais adequado a um determinado aluno num dado momento da aprendizagem.

O perfil de aprendizagem de um aluno não pode ser considerado uma entidade estática e imutável. As necessidades do estudante podem fazer com que ele tenha alterações em seu perfil de aprendizagem durante sua participação num dado CA. É por isto que é necessário reavaliar o perfil da aprendizagem do aluno constantemente. Este trabalho propõe que o perfil de aprendizagem seja avaliado a cada novo $C A$ que o aluno interage.

O LearnPES é composto por dois módulos que permitem o planejamento da observação das interações do aluno com o ambiente e a avaliação do perfil de aprendizagem de um aluno, conforme apresentado na Figura 9: 


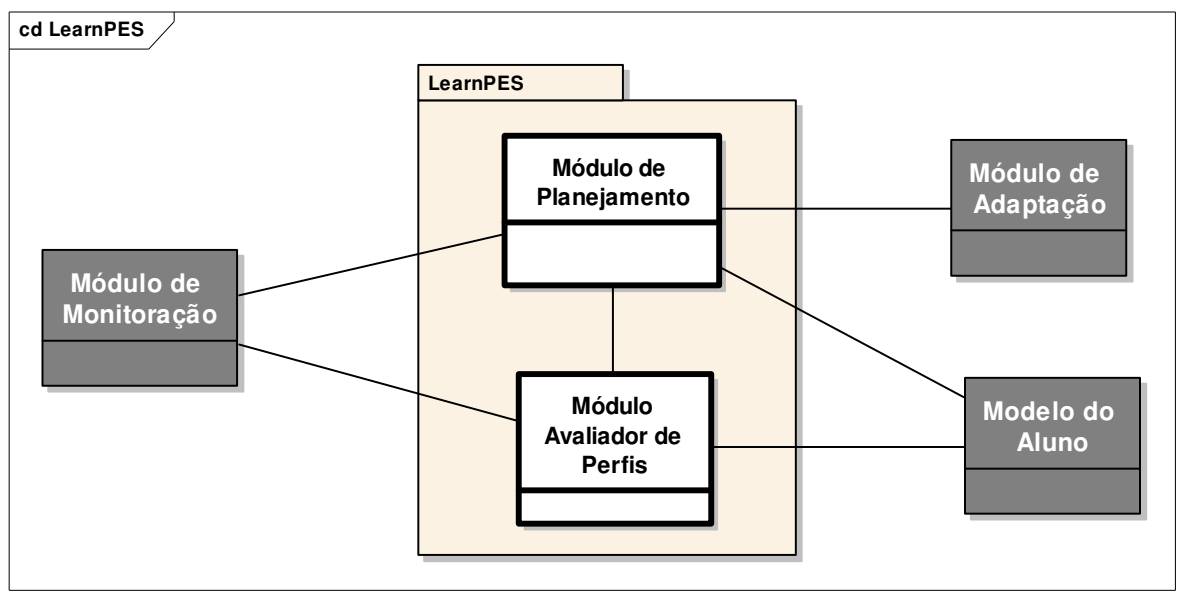

Figura 9 - Modelo Conceitual do LearnPES

O Módulo de Planejamento possibilita ao docente especificar as características que deseja observar nas interações do aluno e os tipos de perfis que serão utilizados no processo de avaliação do perfil deste aluno. Este Módulo atualiza o Modelo de Aluno com as observações que serão realizadas para que elas possam ser posteriormente utilizadas na avaliação do perfil do aluno. Além disto, atualiza o Módulo de Adaptação para que as adaptações sejam realizadas de acordo com o planejamento previamente realizado.

O Módulo Avaliador de Perfis realiza o processo de análise das informações contextuais comparando os mesmos com os exemplos de perfis cadastrados.

O perfil de aprendizagem é atualizado a cada novo CA considerando-se os resultados gerados pelo sistema LearnPES. O acompanhamento das interações do aprendiz é realizada pelo Módulo de monitoração que envia as informações ao LearnPES.

Os Módulos de Planejamento e Avaliador de Perfis serão descritos nos capítulos a seguir.

\subsection{CONSIDERAÇÕES FINAIS}

Este capítulo teve como propósito apresentar uma visão geral sobre a arquitetura proposta neste trabalho. Os próximos capítulos irão detalhar o planejamento da observação e da adaptação, o acompanhamento das interações do aluno e a avaliação do perfil, bem como a adaptação dos Cenários de Aprendizagem. 


\section{MODELAGEM E PLANEJAMENTO DA OBSERVAÇÃO, DA CLASSIFICAÇÃO DOS PERFIS DE APRENDIZAGEM E DA ADAPTAÇÃO}

\subsection{CONSIDERAÇÕES INICIAIS}

Para que o processo de adaptação possa ser realizado é preciso que o docente realize um planejamento prévio considerando o que será observado na interação do aluno e onde ocorrerá a observação. Além disto, é necessário determinar os tipos de perfis que serão utilizados durante o processo de avaliação dos perfis, bem como questões sobre a adaptação segundo os tipos de perfis previamente planejados. Este planejamento é realizado através do Módulo de Planejamento do LearnPES.

Um procedimento anterior ao planejamento da observação é a definição dos modelos de cenários de aprendizagem que serão utilizados. Os objetos de aprendizagem que serão utilizados devem estar cadastrados no repositório de objetos segundo o padrão LOM.

Este capítulo irá apresentar as etapas de planejamento da observação, da classificação dos perfis de aprendizagem e da adaptação, relacionados ao Módulo de Planejamento do LearnPES. Será realizada a definição dos conceitos envolvidos nestas etapas. Também são apresentados os modelos que são criados durante o processo de planejamento que é executado através do Módulo de Planejamento.

\subsection{DEFINIÇÃO DOS CENÁRIOS DE APRENDIZAGEM}

Os CA são a base para o ensino de conceitos. É preciso definir os CAs, ou então trabalhar com CAs que já foram definidos. Deve-se utilizar um editor que suporte o padrão do Learning Design, especificando as atividades de aprendizagem sem apontar estas atividades a objetos de aprendizagem. Este direcionamento será realizado dinamicamente durante o processo de adaptação.

A definição de cenários através da especificação do padrão do Learning Design atende o requisito funcional: 


\section{RF1) O ambiente deve trabalhar com cenários de aprendizagem, \\ previamente cadastrados através da especificação do padrão do Learning \\ Design, que suportem o ensino de determinados conceitos.}

A estrutura de um mini-curso relacionado à "Física Geral l" (Tabela 13) será utilizada como exemplo para descrever as etapas de planejamento.

Tabela 13 - Estrutura do Mini-curso - Física Geral I

\begin{tabular}{|c|c|c|}
\hline \multicolumn{3}{|c|}{ Mini curso: Física Geral I } \\
\hline CA & Estrutura de Atividades & AA \\
\hline \multirow{2}{*}{ Introdução } & \multirow{2}{*}{ Estrutura_Medição } & Conceito de medição \\
\hline & & Unidades fundamentais de medição \\
\hline \multirow{2}{*}{ Vetores e Escalares } & \multirow{2}{*}{ Estrutura_Vetores } & Método geométrico \\
\hline & & Método analítico \\
\hline \multirow{2}{*}{ Movimento Retilíneo Uniforme } & \multirow{2}{*}{ Estrutura_MRU } & Velocidade escalar \\
\hline & & Velocidade vetorial \\
\hline \multirow{2}{*}{ Movimento Circular e Uniforme } & \multirow{2}{*}{ Estrutura_MCU } & Movimento circular uniforme \\
\hline & & Movimento relativo \\
\hline
\end{tabular}

A estrutura do mini-curso possui um conjunto de CA que a compõe. Sendo que o CA é composto por estruturas de atividades que são formadas por AA, conforme descrito no Capítulo anterior.

\subsection{PLANEJAMENTO DA OBSERVAÇÃO}

É a etapa que define o que se deseja observar durante as interações do aprendiz com o ambiente de aprendizagem. É realizada pelo Módulo de Planejamento, atendendo os requisitos funcionais:

\footnotetext{
RF2) Permitir que o docente aponte em quais atividades de aprendizagem e/ou ferramentas deseja observar a interação do aluno.

RF3) Permitir que o docente defina o que deseja observar sobre a interação do aluno.
} 
O principal objetivo é definir um Modelo de Observação a ser utilizado na monitoração das ações do aluno no ambiente de aprendizagem. O Modelo de Observação é definido a partir de entidades denominadas de Características Observáveis através de um sub-módulo denominado de Configurador de Modelo de Observação.

\subsubsection{Característica Observável}

Uma Característica Observável especifica o que se deseja observar, onde ocorrerá esta observação e quando será observado. As interações do aluno que serão observadas podem ser provenientes de interações com o ambiente e/ou ferramenta (acesso a páginas, escolhas de materiais, etc) ou mesmo de resultados obtidos através de algum mecanismo de verificação explícito (testes, exercícios, etc) que é aplicado de forma pontual. Este trabalho adotará duas classificações para as Características Observáveis:

- Pontos de Checagem (PC): são inserções de testes e exercícios que permitem ao docente realizar verificações pontuais sobre o conhecimento adquirido pelo aluno ou mesmo sobre sua familiaridade e/ou preferência na adoção de um dado tipo de material ou ferramenta. São informações obtidas pela interação explícita do aprendiz.

- Interações do Aprendiz (IA): representam as interações realizadas pelo aprendiz no ambiente e/ou ferramenta. Suas preferências em relação a tipos de materiais, número de acesso a um determinado conteúdo, interações com uma ferramenta, entre outros. São informações obtidas de maneira implícita pelo sistema, sem a interferência direta do aprendiz. O escopo destas informações é diretamente ligado ao que a ferramenta e o ambiente que o aprendiz está utilizando podem produzir enquanto informações. Ou seja, as informações que podem ser utilizadas são dependentes do que se pode obter da ferramenta que o estudante está interagindo.

Uma Característica Observável será modelada estendendo as cláusulas de contexto do modelo W5H (apresentado no Capítulo 3).

Característica Observável $($ Type $)=\{$ What, Where, When, Category $\}$, onde: 
$\rightarrow$ Type $=\mathrm{PC}$ ou IA,

$\rightarrow$ What $=$ o que será observado,

$\rightarrow$ Where $=$ onde será observado (atividade de aprendizagem ou ferramenta)

$\rightarrow$ When = em que momento a observação deverá ocorrer (no início, no final, durante toda a interação com atividade de aprendizagem ou ferramenta).

$\rightarrow$ Category = a qual categoria que especifica a preferência do aluno a característica observável está relacionada.

Por exemplo, é possível definir como característica observável:

$\rightarrow$ Type $=$ Interações do Aprendiz

$\rightarrow$ What $=$ tipo de mídia acessada

$\rightarrow$ Where = na AA "Velocidade escalar"

$\rightarrow$ When = durante toda a interação

$\rightarrow$ Category = Formato-Apresentação do Conteúdo.

A dimensão Who pertencente ao W5H é incluída como padrão para identificar o aluno que está sendo observado.

Para definir uma Característica Observável do tipo Interações do Aprendiz é necessário verificar o que é realmente possível se obter, enquanto informação de interação, a partir de uma determinada ferramenta que esteja disponível no ambiente de aprendizagem.

Para isto o Módulo de Planejamento do LearnPES possui um Pesquisador de Características Monitoráveis para Ferramentas. Este sub-módulo verifica quais tipos de informações uma dada ferramenta monitora quando um aluno está interagindo com esta ferramenta. Para que isto seja possível uma ferramenta deve ter associada a si um metadado que especifica quais são as informações que esta pode monitorar (BRESSAN; RUGGIERO; FRANCO, 2005).

O pesquisador de características irá procurar em uma dada ferramenta associada a uma AA o metadado que configura as informações sobre a monitoração desta ferramenta, obtendo o que a mesma pode monitorar enquanto interação do aprendiz (Figura 10). 
Estas informações poderão variar de ferramenta para ferramenta. Uma ferramenta de fórum pode, por exemplo, permitir que se obtenham informações sobre o número de acessos a um dado assunto, enquanto que uma ferramenta de bate-papo pode permitir que se obtenha o número de mensagens enviadas para um dado participante.

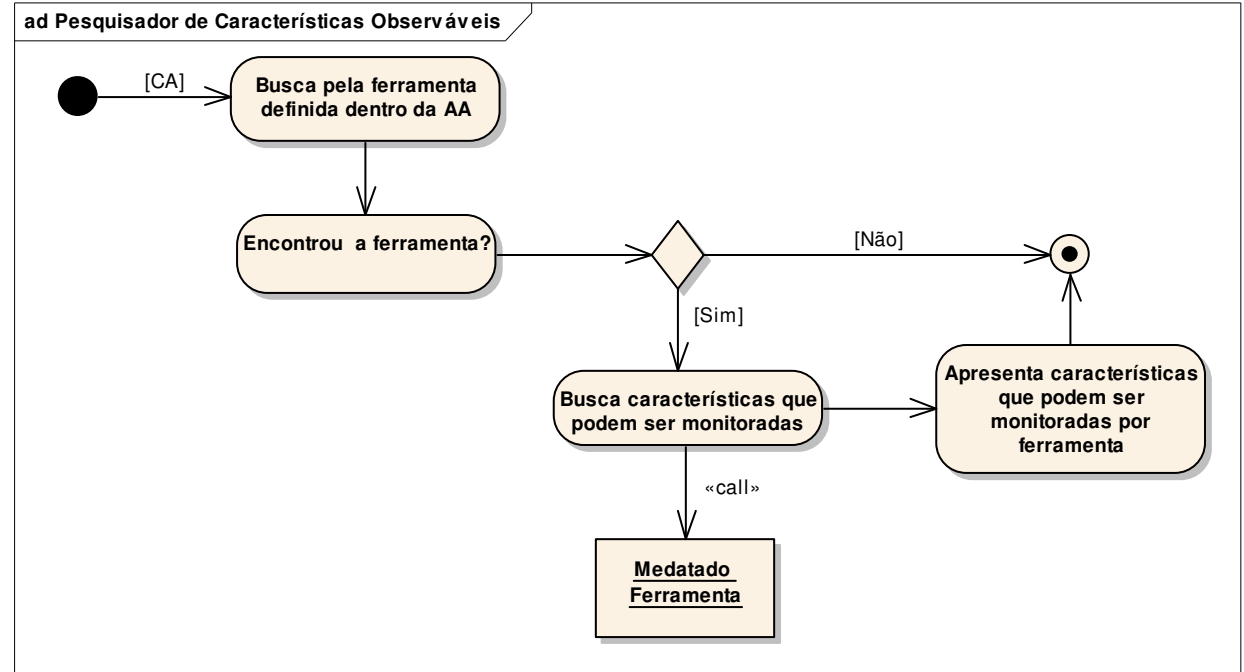

Figura 10 - Pesquisador de característica monitoráveis de uma ferramenta

As informações provenientes da importação descreverão o que pode ser observado, em uma dada ferramenta (local da observação). Cabe ao docente selecionar dentre o que pode ser observado o que ele deseja incluir como Característica Observável no Modelo de Observação que está planejando.

Portanto, uma Característica Observável do tipo IA é definida como:

Característica Observável $(\mathrm{IA})=\{$ What, Where, When, Category $\}$, onde

What é um elemento pertencente ao conjunto de informações que podem ser monitoradas.

Por exemplo, se num dado CA existem ferramentas de fórum e bate-papo disponíveis, e foi obtido que uma característica monitorável é "mensagem inserida", para ambas as ferramentas, pode-se definir a Característica Observável como:

$\rightarrow$ Type $=$ Interações do Aprendiz

$\rightarrow$ What $=$ mensagem inserida (fórum)

$\rightarrow$ Where = AA "Movimento circular uniforme"

$\rightarrow$ When $=$ durante toda $a$ interação

$\rightarrow$ Category = Participação do Aluno. 
No caso de uma Característica Observável do tipo Ponto de Checagem, o docente deve definir o que será observado na forma de questões de múltipla escolha.

Através das questões pontuais é possível associar ao PC uma ação que seja dependente da resposta do aprendiz. Isto significa que haverá uma ação diferente dependendo da escolha do aprendiz. Por exemplo, para um PC que questiona o aluno sobre a preferência dele em participar de um fórum ou um bate-papo, se o aluno selecionar bate-papo será aberto a ele uma ferramenta de bate-papo. Se selecionar fórum será aberto o ambiente de fórum.

O LearnPES possui uma Biblioteca de Funções Auxiliares que pode auxiliar a configurar uma Característica Observável. Por exemplo, se é especificado que uma característica a ser observada do tipo IA é o "tipo de mídia acessada", o Módulo de Monitoração poderá enviar ao LearnPES várias ocorrências desta observação. Porém, pode ser relevante obter qual foi o tipo de mídia mais acessado. Para que isto seja possível, o docente deve, durante a especificação de uma Característica Observável, escolher a função (existente na Biblioteca do LearnPES ou então agregar a biblioteca algortimos e/ou funções) que possibilitará encontrar o tipo de mídia mais acessada, associando esta a Característica Observável.

A Figura 11 apresenta o diagrama de classes que compõe uma Característica Observável e a Tabela 14 detalha cada entidade que faz parte do diagrama.

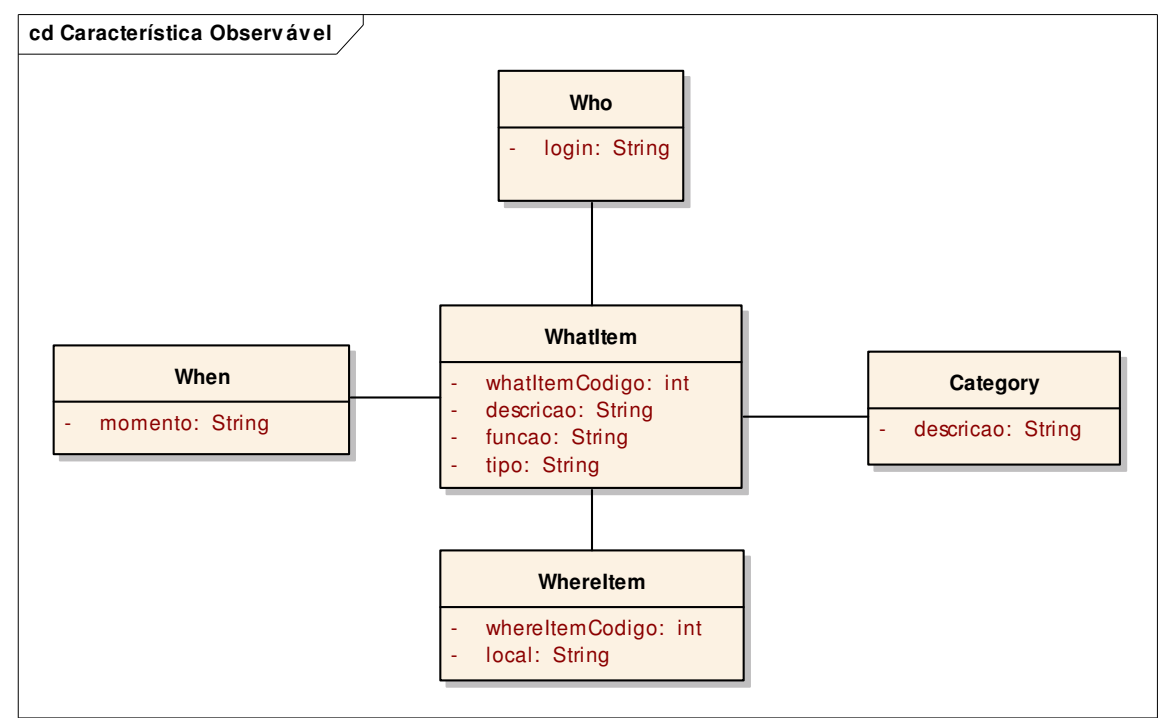

Figura 11 - Diagrama de Classes - Característica Observável 
Tabela 14 - Detalhamento das entidades do Diagrama de Classes - Característica Observável

\begin{tabular}{|c|c|c|}
\hline Entidade & Atributos & Funcionalidade \\
\hline Whatltem & $\begin{array}{l}\text { - whatltemCodigo: identificador da característica. } \\
\text { - descrição: especifica o que é a característica. } \\
\text { - Tipo: identifica a característica como interações } \\
\text { do aprendiz ou ponto de checagem. } \\
\text { - função: associa a característica observável um } \\
\text { função auxiliar proveniente da Biblioteca de } \\
\text { Funções Auxiliares. }\end{array}$ & $\begin{array}{l}\text { Representa uma característica observável } \\
\text { definida pelo docente. }\end{array}$ \\
\hline When & $\begin{array}{l}\text { - momento: em que ponto da AA ou do CA será } \\
\text { realizada a observação. }\end{array}$ & $\begin{array}{l}\text { Entidade que define o momento da } \\
\text { observação. Normalmente definida para } \\
\text { pontos de checagem. }\end{array}$ \\
\hline Whereltem & $\begin{array}{l}\text { - whereltemCodigo: identificador do local da } \\
\text { observação. } \\
\text { - local: AA ou ferramenta onde ocorrerá a } \\
\text { observação. }\end{array}$ & $\begin{array}{l}\text { Formaliza onde cada característica será } \\
\text { observada. Utilizado para determinar se o } \\
\text { acompanhamento será feito em uma dada } \\
\text { ferramenta. }\end{array}$ \\
\hline Who & $\begin{array}{l}\text { - login: identifica o aprendiz que está relacionado à } \\
\text { observação. }\end{array}$ & $\begin{array}{l}\text { Entidade que formaliza o aspecto de quem } \\
\text { está interagindo. Esta informação será } \\
\text { obtida a partir da interação. }\end{array}$ \\
\hline Category & $\begin{array}{l}\text { - descrição: indica a que categoria de preferências } \\
\text { a característica observável pertence. }\end{array}$ & $\begin{array}{l}\text { Formaliza a relação entre a característica } \\
\text { observável e as categorias de preferências } \\
\text { definidas pelo Modelo do Aluno } \\
\text { (Percepção, Formato-Apresentação do } \\
\text { Conteúdo, Participação do Aluno e Ordem- } \\
\text { Apresentação do Conteúdo). As descrições } \\
\text { das categorias encontram-se no Capítulo } 2 \\
\text { - tópico 2.6. }\end{array}$ \\
\hline
\end{tabular}

O conjunto de Características Observáveis irá constituir um Modelo de Observação.

\subsubsection{Modelo de Observação}

Um Modelo de Observação é definido a partir de características relevantes que devem ser observadas para que seja possível classificar o aluno em um perfil de aprendizagem.

O Modelo de Observação é construído a partir da definição de características observáveis organizadas a partir de cada uma das categorias que retratam as preferências do aluno (Percepção, Formato-Apresentação do Conteúdo, Participação do Aluno e Ordem-Apresentação do Conteúdo) descritas no modelo do aluno proposto no Capítulo 2 (tópico 2.6). O docente pode escolher quais categorias deseja considerar durante o processo de observação do aluno.

A definição do que observar deve ser aderente às categorias de preferências. Por exemplo, na categoria Formato-Apresentação do Conteúdo deve-se especificar características que contemplem obter informações sobre o formato mais adequado de material ao aluno. Pode-se definir que se deseja observar qual o tipo de mídia 
que foi mais acessado pelo aluno, possibilitando assim identificar se este aluno possui características visuais (uso de mídias como vídeo) ou verbais (uso de textos, sons, entre outros).

A Tabela 15 ilustra um exemplo de Modelo de Observação que contém Características Observáveis do tipo Interações do Aprendiz e do tipo Pontos de Checagem:

Tabela 15 - Exemplo de Modelo de Observação

Modelo de Observação

Descrição: Física Geral I

Lista de Características Observáveis

Tipo: Interações do Aprendiz

\begin{tabular}{|c|c|c|c|c|}
\hline $\begin{array}{c}\text { Descrição de } \\
\text { Característica } \\
\text { Observável }\end{array}$ & $\begin{array}{l}\text { Categoria de } \\
\text { Preferências }\end{array}$ & $\begin{array}{c}\text { Função Associada } \\
\text { (Biblioteca de Funções } \\
\text { Auxiliares) }\end{array}$ & Onde será Observado & $\begin{array}{c}\text { Quando será } \\
\text { observado }\end{array}$ \\
\hline Mídia Acessada & $\begin{array}{c}\text { Formato- } \\
\text { Apresentação }\end{array}$ & TipoMídiaMaisAcessada & Todo CA & $\begin{array}{c}\text { Toda } \\
\text { interação }\end{array}$ \\
\hline Exercício Acessado & $\begin{array}{c}\text { Formato- } \\
\text { Apresentação }\end{array}$ & TipoExercício & Todo CA & $\begin{array}{c}\text { Toda } \\
\text { interação }\end{array}$ \\
\hline $\begin{array}{l}\text { Inserção de } \\
\text { mensagem }\end{array}$ & Participação do Aluno & ContarMsgChat & Velocidade escalar & $\begin{array}{c}\text { Toda } \\
\text { interação }\end{array}$ \\
\hline $\begin{array}{l}\text { Inserção de } \\
\text { mensagem }\end{array}$ & Participação do Aluno & ContarMsgFórum & Movimento cicular uniforme & $\begin{array}{c}\text { Toda } \\
\text { interação }\end{array}$ \\
\hline Material Acessado & Percepção & TipoMaterialMaisAcessado & Todo CA & $\begin{array}{c}\text { Toda } \\
\text { interação }\end{array}$ \\
\hline
\end{tabular}

Tipo: Pontos de Checagem

\begin{tabular}{|c|c|c|c|c||}
\hline \hline $\begin{array}{c}\text { Descrição de } \\
\text { Característica } \\
\text { Observável }\end{array}$ & Categoria & Função Associada & Onde será observado & $\begin{array}{c}\text { Quando será } \\
\text { observado }\end{array}$ \\
\hline $\begin{array}{l}\text { Você prefere } \\
\text { resolver os } \\
\text { exercícios ou ler } \\
\text { artigos que } \\
\text { aprofundem sobre o } \\
\text { conteúdo? } \\
\text { a) } \begin{array}{l}\text { Resolver } \\
\text { exercícios } \\
\text { b) Aprofundar no } \\
\text { conteúdo }\end{array}\end{array}$ & Percepção & Ferramenta de testes & Velocidade vetorial & Fim da AA \\
\hline \hline Resposta & & Ação Associada & \\
\hline a & Carregar (exercício) \\
\hline b & Carregar (artigo, Velocidade vetorial) \\
\hline
\end{tabular}

É possível observar no exemplo anterior que a Característica Observável "Inserção de mensagem" (tipo Interações do Aprendiz), pertence à categoria "Participação do Aluno", pois o objetivo é verificar se este é um aluno que participa ativamente do processo de aprendizagem ou não. Para fazer tal verificação é utilizada uma função (proveniente da Biblioteca de Funções Auxiliares) que irá 
contabilizar o número de mensagens inseridas. Esta característica será observada numa ferramenta de chat. Foi possível inserir esta característica como observável porque foi obtido da ferramenta de chat (Pesquisador de Características Monitoráveis - Figura 10) que esta é uma informação provida pela ferramenta. Pelo fato de ser algo específico de uma ferramenta é associada à característica observável o local de sua observação (chat) e que esta deverá ser realizada durante toda a interação do aluno.

A Característica Observável do tipo Ponto de Checagem, possui informado o local onde esta será inserida, na AA "Velocidade vetorial" e em que ponto será inserida, no final da AA. Dependendo da interação do aluno com a questão serão apresentados a ele exercícios ou leituras. Isto porque nesta Característica Observável está sendo verificada a categoria Percepção do aluno, ou seja, se ele é dedutivo (gosta de atividades práticas - exercícios) ou intuitivo (gosta de atividades teóricas - leituras). Neste caso, o docente deve identificar qual será o exercício e a leitura que será carregada. Ou seja, deve ser apontado para o Objeto de Aprendizagem que irá satisfazer cada um dos itens.

Um conjunto de Características Observáveis irá compor um Modelo de Observação. O configurador utiliza as entidades What e Where para descrever atributos do Modelo de Observação (descrição e código) e para determinar em quais CA o Modelo de Observação especificado será utilizado (Figura 12):

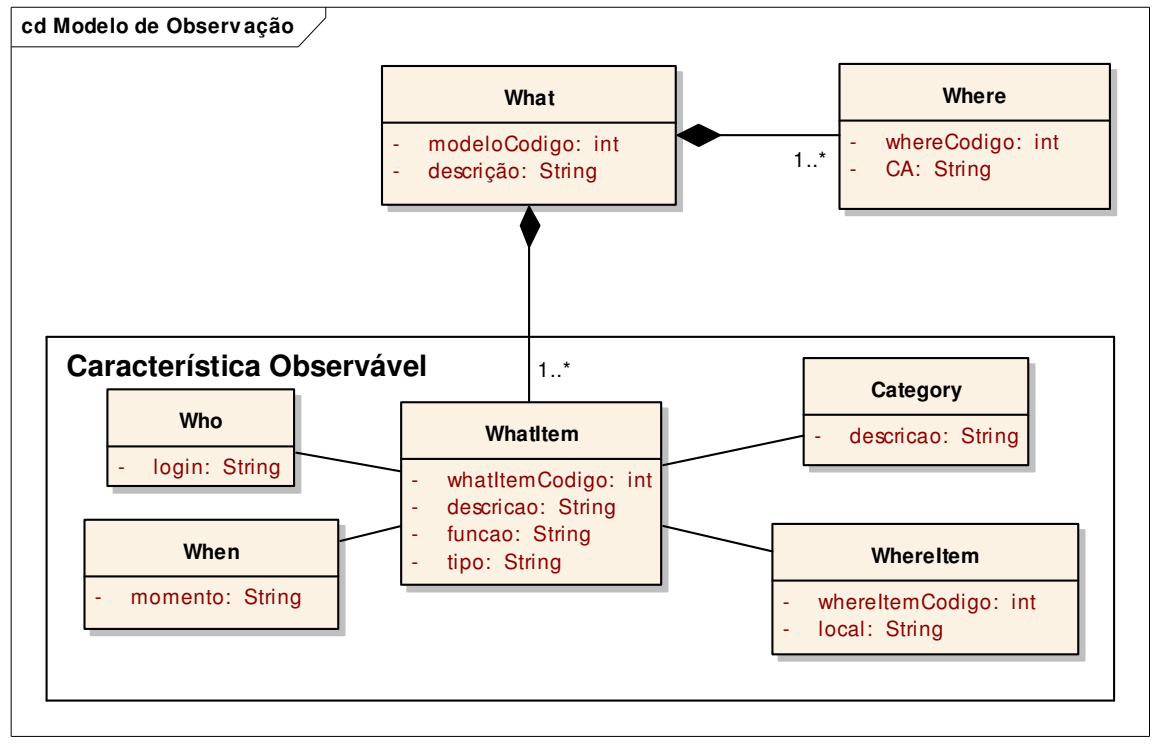

Figura 12 - Diagrama de Classes - Modelo de Observação 
O componente Preferência do Modelo do Aluno será composto pelas Características Observáveis definidas no Modelo de Observação, separando as características através de suas respectivas categorias de preferências.

\subsubsection{Construção do Modelo de Observação através do LearnPES}

O Modelo de Observação é construído pelo LearnPES através de um submódulo pertencente ao Módulo de Planejamento denominado de Configurador de Modelo de Observação. Através do configurador é que se definem as Características Observáveis que farão parte do Modelo de Observação.

Quando uma Característica Observável é definida o configurador transforma esta em um conjunto de variáveis de contexto, para que estas durante a fase de publicação do planejamento sejam enviadas ao Módulo de Monitoração. Conforme abordado no Capítulo 3 (tópico 3.5), uma informação é considerada contextual quando esta caracteriza uma dada situação. A utilização de informações contextuais através da semântica $\mathrm{W} 5 \mathrm{H}$ permitirá que as características definidas como observáveis sejam organizadas e modeladas, facilitando a comunicação do sistema LearnPES com o Módulo de Monitoração. Além disto, a especificação através de entidades contextuais irá possibilitar a criação de Modelos de Observação que podem ser reutilizáveis em diferentes escopos.

Os Modelos de Observação são armazenados no Repositório de Modelos de Observação que conterá todos os modelos definidos a partir do LearnPES. O objetivo principal é que os modelos possam ser utilizados em diferentes escopos de observação ou mesmo que possam ser definidos outros Modelos de Observação estendendo um que já exista.

A Figura 13 apresenta o modelo conceitual com as entidades que fazem parte da definição de um Modelo de Observação.

Após definir o Modelo de Observação é necessário especificar os exemplos de perfis de aprendizagem que se deseja utilizar para classificar os alunos. 


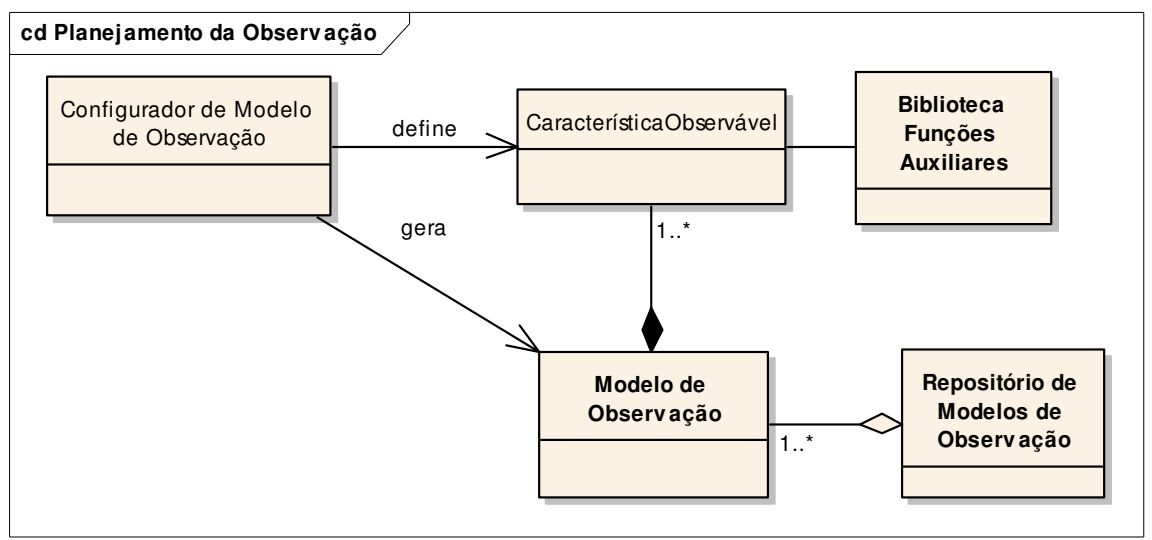

Figura 13 - Entidades para definição do Modelo de Observação

\subsection{PLANEJAMENTO DA CLASSIFICAÇÃO}

Durante a etapa de planejamento da classificação são definidos os tipos de perfis de aprendizagem que se deseja utilizar para classificar o aluno em um dado perfil. A definição dos tipos de perfis é realizada pelo Módulo de Planejamento, atendendo o requisito funcional:

\section{RF4) Permitir que o professor cadastre um conjunto de tipos de perfis de aprendizagem que serão utilizados para classificar o aluno segundo um determinado perfil de aprendizagem.}

Os tipos de perfis serão utilizados pelo Avaliador de Perfis durante a etapa de classificação do aluno em um determinado perfil de aprendizagem. Os tipos de perfis definidos serão utilizados na classificação do perfil de aprendizagem de um estudante. Os atributos que definem os tipos de perfis, características que identificam um dado perfil, são definidos a partir das Características de um dado Modelo de Observação, através de um sub-módulo denominado de Configurador de Tipos de Perfil de Aprendizagem. 


\subsubsection{Tipo de Perfil de Aprendizagem}

Um Tipo de Perfil de Aprendizagem é especificado definindo-se valores para Características Observáveis de forma que estas possam ser comparadas com valores que serão obtidos através da interação do aluno.

A partir de um Modelo de Observação o docente cria um tipo de perfil considerando as Características Observáveis do modelo. O docente pode selecionar quais características deseja considerar no tipo de perfil que está construindo.

Considerando um Modelo de Observação, são definidos valores para uma dada Característica Observável de forma que estes valores diferenciem a característica em diferentes tipos de perfis. Por exemplo, para uma Característica Observável que verifica o tipo de mídia acessada, pode-se definir que para o "VisualAtivo" ela terá o valor "vídeo" e para o "Verbal-Reflexivo" ela terá o valor "texto". Desta maneira, quando o sistema identificar, através do contexto da interação do aluno, que este acessou um vídeo, ele terá uma Característica Observável que se encaixa no "Visual-Ativo".

O docente deve indicar para cada tipo de perfil que está planejando qual o perfil de aprendizagem que este tipo de perfil contempla para cada categoria que está sendo observada. Na categoria Formato-Apresentação, por exemplo, um aluno pode ter um perfil de aprendizagem classificado como Visual ou Verbal. As configurações que podem ser realizadas para categoria foram apresentadas no Capítulo 2 (Tabela 8).

A Figura 14 e Figura 15 ilustram a criação de Tipos de Perfis de Aprendizagem considerando o exemplo de Modelo de Observação definido na Tabela 15.

É possível observar que uma mesma Característica Observável é utilizada em diferentes tipos de perfis com diferentes valores. A Característica Observável "Mídia Acessada" tem o valor "Figura ou Vídeo" especificado para o "Visual- Ativo". Porém, para o "Verbal-Reflexivo" a mesma característica possui o valor "Texto ou Som". Desta forma é possível diferenciar a característica dependendo do resultado obtido durante a monitoração das interações do aprendiz. O "Visual- Ativo" classifica o perfil de aprendizagem do aluno em Visual (categoria Formato-Apresentação), Ativa (categoria Participação do Aluno) e Concreta (categoria Percepção). Isto significa 
que a atribução de valores às categorias de preferências caracterizam o perfil de aprendizagem do aluno quando este estudante se encaixar no tipo descrito.

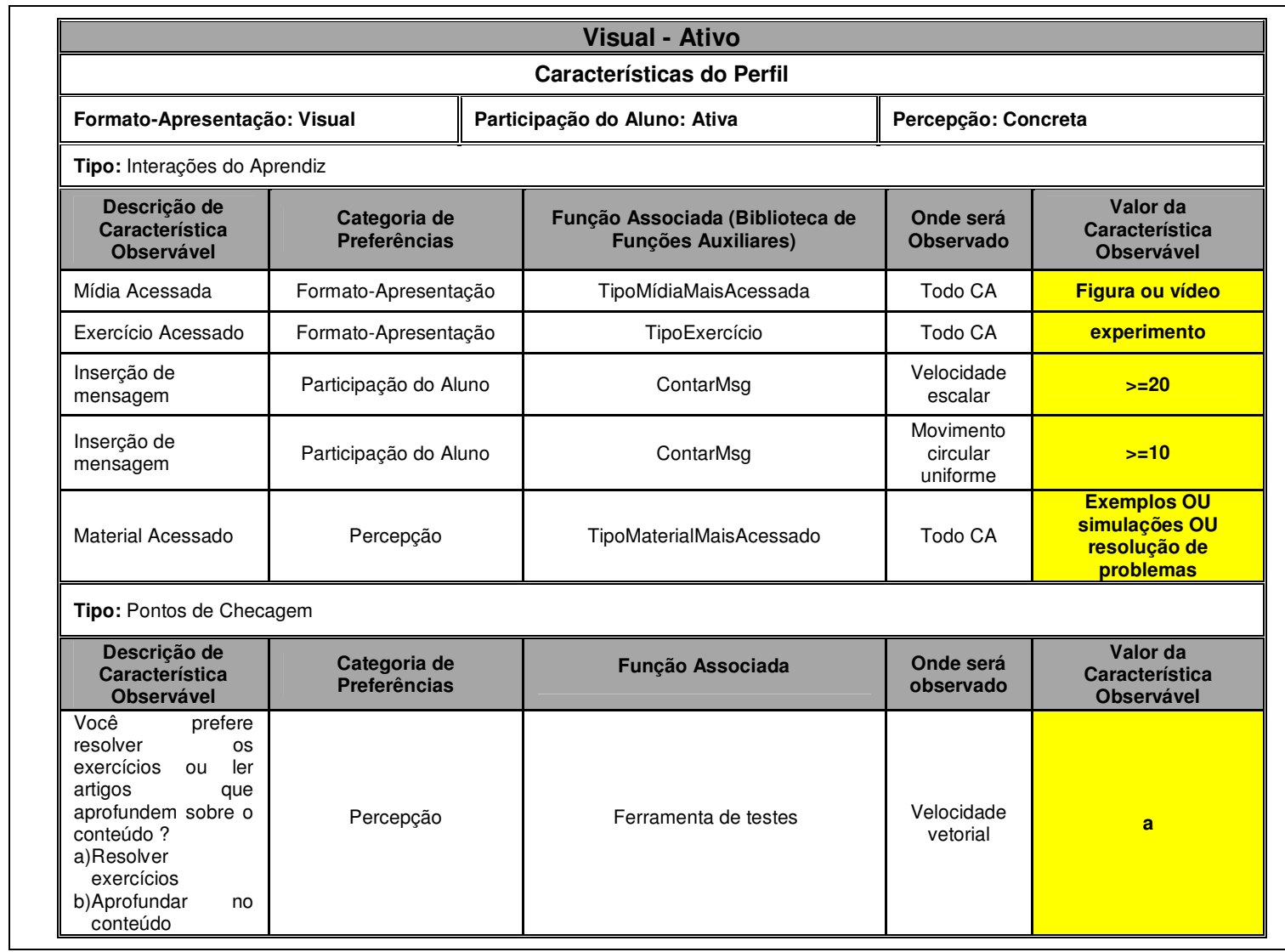

Figura 14 - Criação de Tipos de Perfis de Aprendizagem Visual-Ativo

Se o perfil de aprendizagem se encaixar no "Visual-Ativo" ele será classificado segundo as categorias de perfis especificadas neste tipo de perfil. A classificação do perfil em categorias irá influenciar diretamente nas estratégias de ensino que serão adotadas para o perfil que foi determinado. Se um perfil possui uma classificação de visual é melhor oferecer ao aluno conteúdos que potencializem tal característica. 


\begin{tabular}{|c|c|c|c|c|}
\hline \multicolumn{5}{|c|}{ Verbal- Reflexivo } \\
\hline \multicolumn{5}{|c|}{ Características do Perfil } \\
\hline \multicolumn{2}{|c|}{ Formato-Apresentação: Verbal } & Participação do Aluno: Passiva & \multicolumn{2}{|c|}{ Percepção: Abstrata } \\
\hline \multicolumn{5}{|c|}{ Tipo: Interações do Aprendiz } \\
\hline $\begin{array}{l}\text { Descrição de } \\
\text { Característica } \\
\text { Observável }\end{array}$ & $\begin{array}{l}\text { Categoria de } \\
\text { Preferências }\end{array}$ & $\begin{array}{l}\text { Função Associada (Biblioteca de } \\
\text { Funções Auxiliares) }\end{array}$ & $\begin{array}{l}\text { Onde será } \\
\text { Observado }\end{array}$ & $\begin{array}{c}\text { Valor da } \\
\text { Característica } \\
\text { Observável }\end{array}$ \\
\hline Mídia Acessada & Formato-Apresentação & TipoMídiaMaisAcessada & Todo CA & texto ou som \\
\hline Exercício Acessado & Formato-Apresentação & TipoExercício & Todo CA & dissertativo \\
\hline $\begin{array}{l}\text { Inserção de } \\
\text { mensagem }\end{array}$ & Participação do Aluno & ContarMsg & $\begin{array}{l}\text { Velocidade } \\
\text { escalar }\end{array}$ & $<20$ \\
\hline $\begin{array}{l}\text { Inserção de } \\
\text { mensagem }\end{array}$ & Participação do Aluno & ContarMsg & $\begin{array}{l}\text { Movimento } \\
\text { circular } \\
\text { uniforme } \\
\end{array}$ & $<10$ \\
\hline Material Acessado & Percepção & TipoMaterialMaisAcessado & Todo CA & $\begin{array}{l}\text { Textos expositivos } \\
\text { OU artigos }\end{array}$ \\
\hline \multicolumn{5}{|c|}{ Tipo: Pontos de Checagem } \\
\hline $\begin{array}{c}\text { Descrição de } \\
\text { Característica } \\
\text { Observável } \\
\end{array}$ & $\begin{array}{l}\text { Categoria de } \\
\text { Preferências }\end{array}$ & Função Associada & $\begin{array}{l}\text { Onde será } \\
\text { observado }\end{array}$ & $\begin{array}{c}\text { Valor da } \\
\text { Característica } \\
\text { Observável } \\
\end{array}$ \\
\hline $\begin{array}{l}\text { Você prefere resolver } \\
\text { os exercícios ou ler } \\
\text { artigos que } \\
\text { aprofundem sobre o } \\
\text { conteúdo? } \\
\text { c) Resolver } \\
\text { exercícios } \\
\text { d) Aprofundar no } \\
\text { conteúdo }\end{array}$ & Percepção & Ferramenta de testes & $\begin{array}{l}\text { Velocidade } \\
\text { vetorial }\end{array}$ & b \\
\hline
\end{tabular}

Figura 15 - Criação de Tipos de Perfis de Aprendizagem Verbal-Reflexivo

\subsubsection{Definição de Tipos de Perfil de Aprendizagem através do LearnPES}

Os Tipos de Perfis de Aprendizagem são especificados a partir do Configurador de Tipos de Perfis de Aprendizagem que é um sub-módulo do Módulo de Planejamento. O configurador permite que seja selecionado um Modelo de Observação (existente no Repositório de Modelos de Observação) dentre os modelos criados pelo professor.

O configurador apresentará sugestões de valores a serem atribuídos a cada Característica Observável considerada no tipo de perfil de acordo com a categoria (Percepção, Formato-Apresentação, etc) a que esta se encaixa. Por exemplo, se uma característica considerada está relacionada à Percepção serão apresentados como sugestão valores como simulação, exercício, resolução de problemas, entre outros. Caberá ao docente selecionar as características mais adequadas.

A Figura 16 apresenta o modelo conceitual para definição de Tipos de Perfis de Aprendizagem e a Tabela 16 apresenta a descrição das entidades que compõem o modelo: 


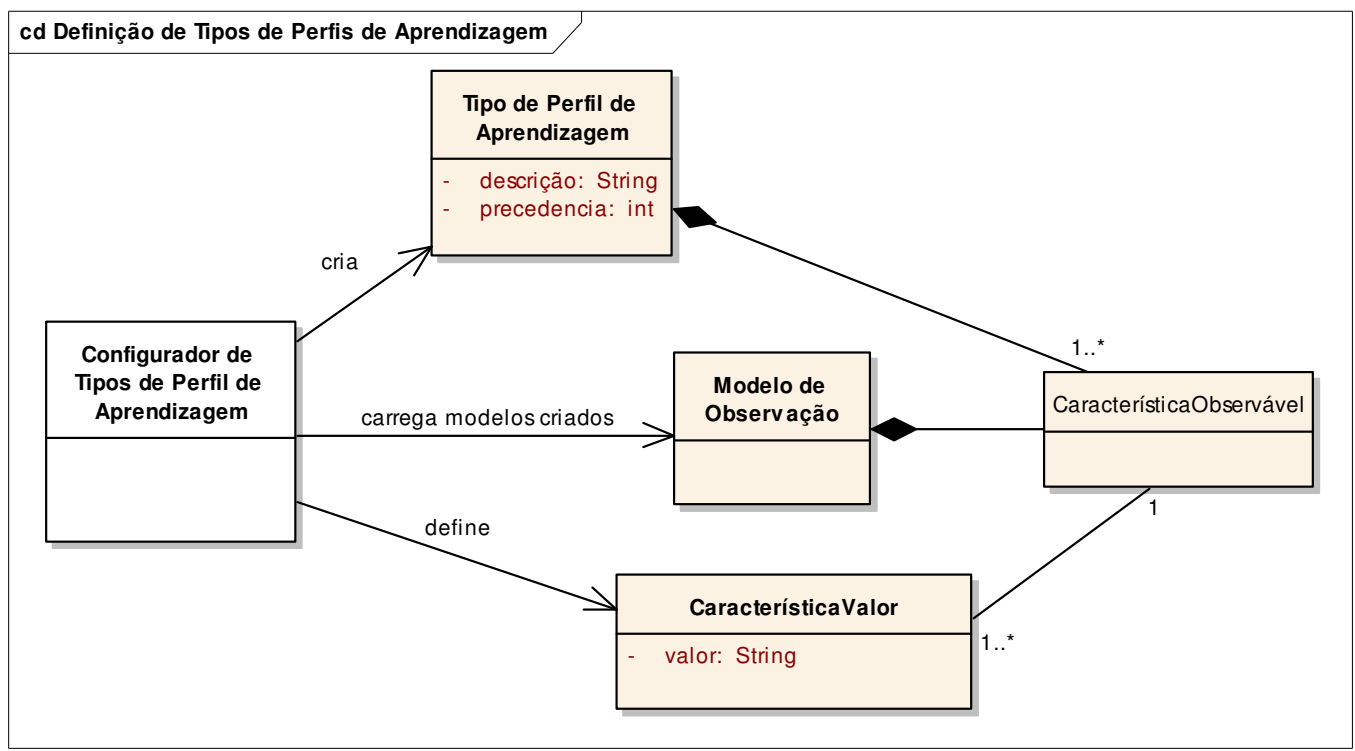

Figura 16 - Modelo Conceitual para Definição de Tipos de Perfis de Aprendizagem

Tabela 16 - Detalhamento das entidades - Tipos de Perfil de Aprendizagem

\begin{tabular}{|c|c|c|}
\hline Entidade & Atributos & Funcionalidade \\
\hline CaracterísticaValor & $\begin{array}{l}\text { - valor: especifica o valor a ser considerado } \\
\text { para uma dada característica observável. }\end{array}$ & $\begin{array}{l}\text { Representa um valor assocido a uma } \\
\text { dada característica observável. }\end{array}$ \\
\hline $\begin{array}{l}\text { Tipo de Perfil de } \\
\text { Aprendizagem }\end{array}$ & $\begin{array}{l}\text { - descrição: descreve a categoria. } \\
\text { - Precedência: indica o grau de precedência } \\
\text { de um exemplo. Esta informação é utilizada } \\
\text { pelo avaliador de perfis durante a } \\
\text { classificação de um perfil. Quando há empate } \\
\text { durante a descoberta do perfil de } \\
\text { aprendizagem é utilizado o exemplo que } \\
\text { possui maior precedência. }\end{array}$ & $\begin{array}{l}\text { Representa um tipo de perfil que é } \\
\text { composto por características } \\
\text { observáveis com valores associados. }\end{array}$ \\
\hline
\end{tabular}

Para cada tipo de perfil é determinada uma relação entre a característica observável e o valor (atributo que caracteriza o tipo de perfil) conforme pode ser observado na Tabela 17 que considera o exemplo da Figura 14:

Tabela 17 - Caracterização dos tipos de perfis

\begin{tabular}{|c|c|c|}
\hline Exemplo & $\begin{array}{c}\text { Característica } \\
\text { Observável }\end{array}$ & Característica Valor \\
\hline Visual-Ativo & Mídia Acessada & Figura ou vídeo \\
\hline Verbal-Reflexivo & Mídia Acessada & Texto ou som \\
\hline
\end{tabular}

O Configurador de Tipos de Perfis irá realizar esta associação para cada Característica Observável que for utilizada na definição dos tipos de perfis. Cada tipo 
de perfil definido pelo docente terá um conjunto de características com valores que a definam separadas por categorias, conforme ilustrado na Tabela 18 e Tabela 19:

Tabela 18 - Definição do Tipo de Perfil Visual-Ativo

\begin{tabular}{|c|c|c|}
\hline $\begin{array}{c}\text { Categoria de } \\
\text { Preferência }\end{array}$ & Característica Observável & Característica Valor \\
\hline $\begin{array}{c}\text { Formato- } \\
\text { Apresentação }\end{array}$ & Mídia Acessada & Figura ou vídeo \\
\cline { 2 - 3 } & Exercício Acessado & experimento \\
\hline \multirow{2}{*}{ Percepção } & Material Acessado & $\begin{array}{c}\text { Exemplos OU simulações } \\
\text { OU resolução de } \\
\text { problemas }\end{array}$ \\
\cline { 2 - 3 } & Você prefere resolver os ... & a \\
\hline \multirow{2}{*}{ Participação do Aluno } & Inserção de Mensagem (chat) & $>=20$ \\
\cline { 2 - 3 } & Inserção de Mensagem (fórum) & $>=10$ \\
\hline
\end{tabular}

Tabela 19 - Definição do Tipo de Perfil Verbal-Reflexivo

\begin{tabular}{|c|c|c|}
\hline $\begin{array}{c}\text { Categoria de } \\
\text { Preferência }\end{array}$ & Característica Observável & Característica Valor \\
\hline \multirow{2}{*}{$\begin{array}{c}\text { Formato- } \\
\text { Apresentação }\end{array}$} & Mídia Acessada & Texto ou som \\
\cline { 2 - 3 } & Exercício Acessado & dissertativo \\
\hline \multirow{2}{*}{ Percepção } & Material Acessado & teoria \\
\cline { 2 - 3 } & Você prefere resolver os ... & $\mathrm{b}$ \\
\hline \multirow{2}{*}{ Participação do Aluno } & Inserção de Mensagem (chat) & $<20$ \\
\cline { 2 - 3 } & Inserção de Mensagem (fórum) & $<10$ \\
\hline
\end{tabular}

\subsection{PLANEJAMENTO DA ADAPTAÇÃO}

O planejamento da adaptação é realizado através da especificação de um Mapa de Adaptação que é gerado a partir do Modelo do CA e dos tipos de perfis determinados pelo docente. A definição do mapa de adaptação é realizada pelo Módulo de Planejamento, atendendo os requisitos funcionais:

\footnotetext{
RF5) Permitir que o professor possa também planejar a adaptação de um CA, segundo um perfil desejado, desconsiderando a classificação automática de perfis gerada pelo ambiente.
} 
O sub-módulo Configurador da Adaptação pertencente ao módulo de Planejamento permite que alterações no Mapa de Adaptação possam ser realizadas.

\subsubsection{Mapa de Adaptação}

Um Mapa de Adaptação é uma entidade que contém a estrutura seqüencial que irá compor o Cenário de Aprendizagem baseado no Modelo de CA definido pelo docente.

O docente não precisa realizar nenhuma alteração no mapa caso queira trabalhar com o perfil de aprendizagem que será sugerido através da classificação de perfis de aprendizagem. O sequenciamento do processo de aprendizagem será realizado pela especificação de CA feita de acordo com a especificação do padrão do Learning Design. O oferecimento de atividades será realizado de acordo com as estratégias de ensino que estão relacionadas ao perfil de aprendizagem de um dado aluno. Este oferecimento será descrido no Capítulo seguinte.

Porém, o docente poderá especificar uma estratégia de ensino diferente da que seria automaticamente sugerida pelo ambiente de acordo com o perfil de aprendizagem em que o estudante foi classificado. Isto permite que o docente possa trabalhar uma dada habilidade em um dado momento do processo de aprendizagem. Por exemplo, é possível se ter um aluno que se encaixa no tipo de perfil "Visual-Ativo", mas que num dado momento da aprendizagem ele precisa desenvolver habilidades de reflexão sobre um dado assunto. Isto pode ser realizado através do mapa de adaptação, onde o docente pode sugerir um perfil de aprendizagem diferente daquele encontrado pelo ambiente.

A Tabela 20 apresenta o exemplo de Mapa de Adaptação definidos pelo docente. Como padrão o mapa de adaptação adota o perfil de aprendizagem sugerido. Caso queira alterar, o docente deve informar o tipo de perfil que deseja adotar e onde o mesmo será adotado. 
Tabela 20 - Exemplo de Mapa de Adaptação alterado pelo docente

\begin{tabular}{|c|c|c|c|}
\hline \multicolumn{4}{|c|}{ Mini curso: Análise e Modelagem de Requisitos de Software } \\
\hline CA & $\begin{array}{c}\text { Estrutura de } \\
\text { Atividades }\end{array}$ & AA & Perfil Adotado \\
\hline \multirow{2}{*}{ Introdução } & \multirow{2}{*}{ Estrutura_Medição } & Conceito de medição & Perfil sugerido \\
\hline & & Unidades fundamentais de medição & Perfil sugerido \\
\hline \multirow{2}{*}{ Vetores e Escalares } & \multirow{2}{*}{ Estrutura_Vetores } & Método geométrico & Perfil sugerido \\
\hline & & Método analítico & Perfil sugerido \\
\hline \multirow{2}{*}{$\begin{array}{l}\text { Movimento Retilíneo } \\
\text { Uniforme }\end{array}$} & \multirow{2}{*}{ Estrutura_MRU } & Velocidade escalar & Perfil sugerido \\
\hline & & Velocidade vetorial & Perfil sugerido \\
\hline \multirow{2}{*}{$\begin{array}{l}\text { Movimento Circular e } \\
\text { Uniforme }\end{array}$} & \multirow{2}{*}{ Estrutura_MCU } & Movimento circular uniforme & Verbal-Reflexivo \\
\hline & & Movimento relativo & Perfil sugerido \\
\hline
\end{tabular}

No exemplo é possível observar que para a AA "Movimento circular uniforme" é alterado o perfil de aprendizagem. Ou seja, durante a construção da $A A$ será adotado um perfil diferente do sugerido.

Embora esteja denominado perfil adotado no Mapa de Adaptação o que será utilizado durante o processo de adaptação serão as estratégias de ensino equivalentes ao perfil descrito, conforme poderá ser observado no próximo Capítulo.

\subsubsection{Configuração do Mapa de Adaptação através do LearnPES}

O Mapa de Adaptação é construído automaticamente pelo LearnPES. Porém - Módulo de Planejamento possui um sub-módulo denominado de Configurador de Mapa de Adaptação que permite que sejam realizadas as modificações dos perfis sugeridos.

O Configurador permitirá que o docente altere o "Perfil Adotado" para tipos de perfis que foram definidos previamente.

A Figura 17 apresenta o modelo conceitual para alteração do Mapa de Adaptação. 


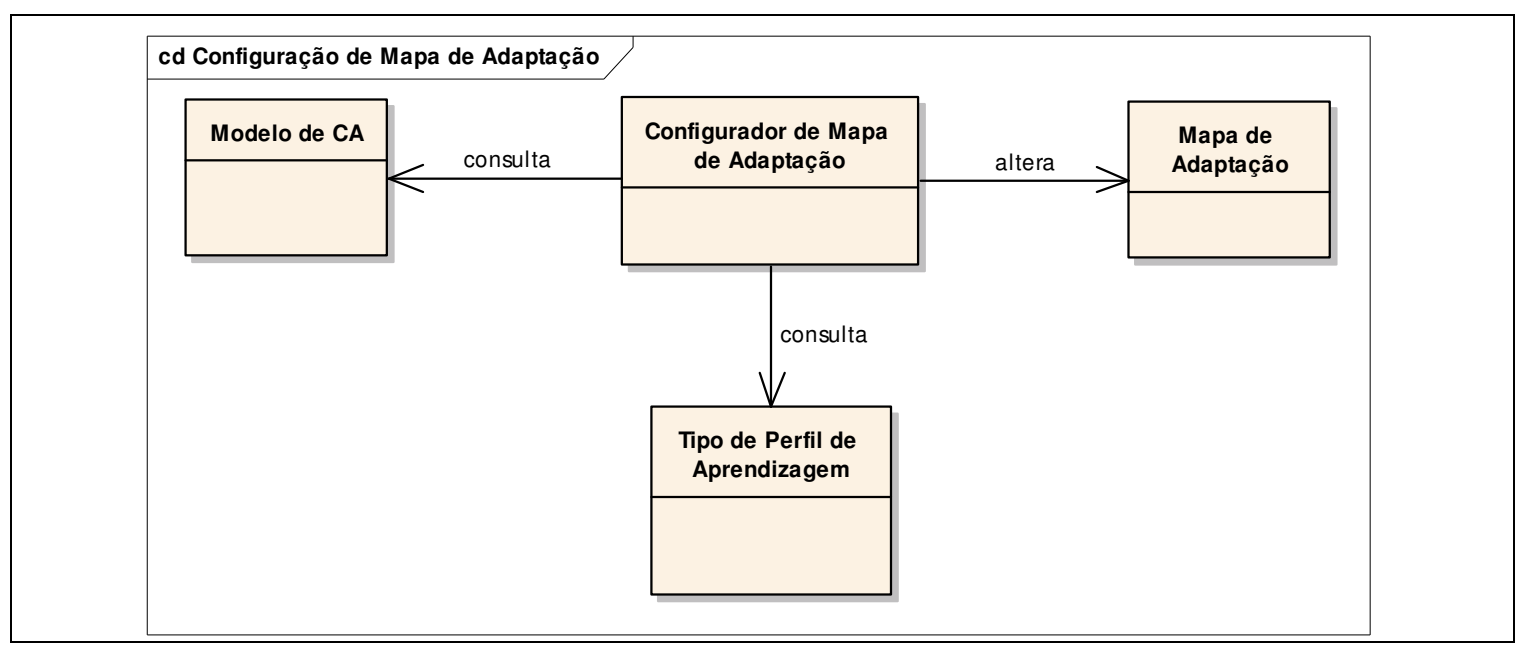

Figura 17 - Alteração do Mapa de Adaptação

\subsection{PUBLICAÇÃO DO PLANEJAMENTO}

Após construir o Modelo de Observação, gerar os Tipos de Perfis de Aprendizagem e alterar o Mapa de Adaptação (quando necessário), o docente deve publicar o Modelo de Observação que deseja utilizar. Ao publicar um modelo, o docente torna ativo o processo de acompanhamento das interações do aluno.

O Módulo de Planejamento do LearnPES possui um sub-módulo denominado de Publicador do Planejamento cujo objetivo é preparar o ambiente para as etapas futuras de acompanhamento do aprendiz, avaliação dos perfis e adaptação dos Cenários de Aprendizagem. São tarefas realizadas pelo Publicador do Planejamento:

a) Enviar o Modelo de Observação ao Módulo de Monitoração.

b) Sinalizar quais CA serão monitorados.

c) Gerar um repositório para armazenar o contexto das interações dos alunos.

d) Gerar regras de adaptação segundo os tipos de perfis planejados.

e) Enviar as características observáveis planejadas ao Modelo do Aluno.

Cada uma das tarefas apontadas anteriormente será detalhada a seguir. 


\subsubsection{Envio do Modelo de Observação ao Módulo de Monitoração}

O Modelo de Observação, na forma de variáveis de contexto, é enviado ao Módulo de Monitoração para que este possa realizar o acompanhamento das interações do aluno a partir do que foi definido como observável (Figura 18).

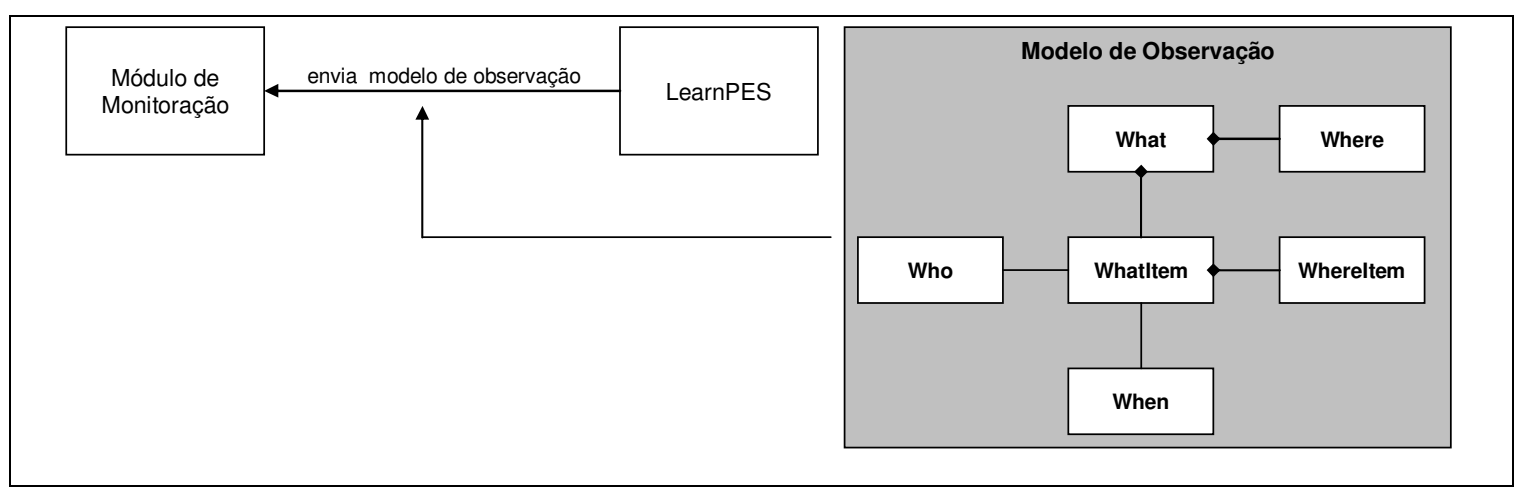

Figura 18 - LearnPES envia Modelo de Observação ao Módulo de Monitoração

\subsubsection{Sinalização dos Cenários de Aprendizagem Monitoráveis}

O LearnPES sinaliza quais são os CAs que serão monitorados no próprio CA através do atributo "modObservação", identificando qual o Modelo de Observação que será utilizado no acompanhamento do aprendiz (Figura 19).

Além disto, é preciso sinalizar, dentro do $C A$, quais são as $A A$ que serão monitoradas. Isto é possível de ser feito através da entidade de notificação (notification), disponível no padrão do Learning Design, nível C (Capítulo 3 - tópico 3.3.3.3). Através dela é possível configurar que uma dada AA receberá um evento de notificação de monitoração quando estiver sendo executada. Quando no Modelo de Observação foi definido que uma dada característica será observável durante toda a interação, o LearnPES sinaliza em todas as AA que fazem parte de um dado CA que estas são monitoráveis.

Pelo padrão do Learning Design uma entidade notificação pode ser configurada para executar uma ação após uma dada AA ser completada (a interação ser finalizada). Este tipo de notificação será utilizado para inserção de uma característica observável do tipo Ponto de Checagem. Porém, pelo padrão somente é possível inserir ações quando uma AA é completada (on-completation). Um Ponto 
de Checagem pode ser incluído no final ou no início de uma AA. Portanto, este trabalho sugere a inclusão de uma diretiva de início (on-begining).

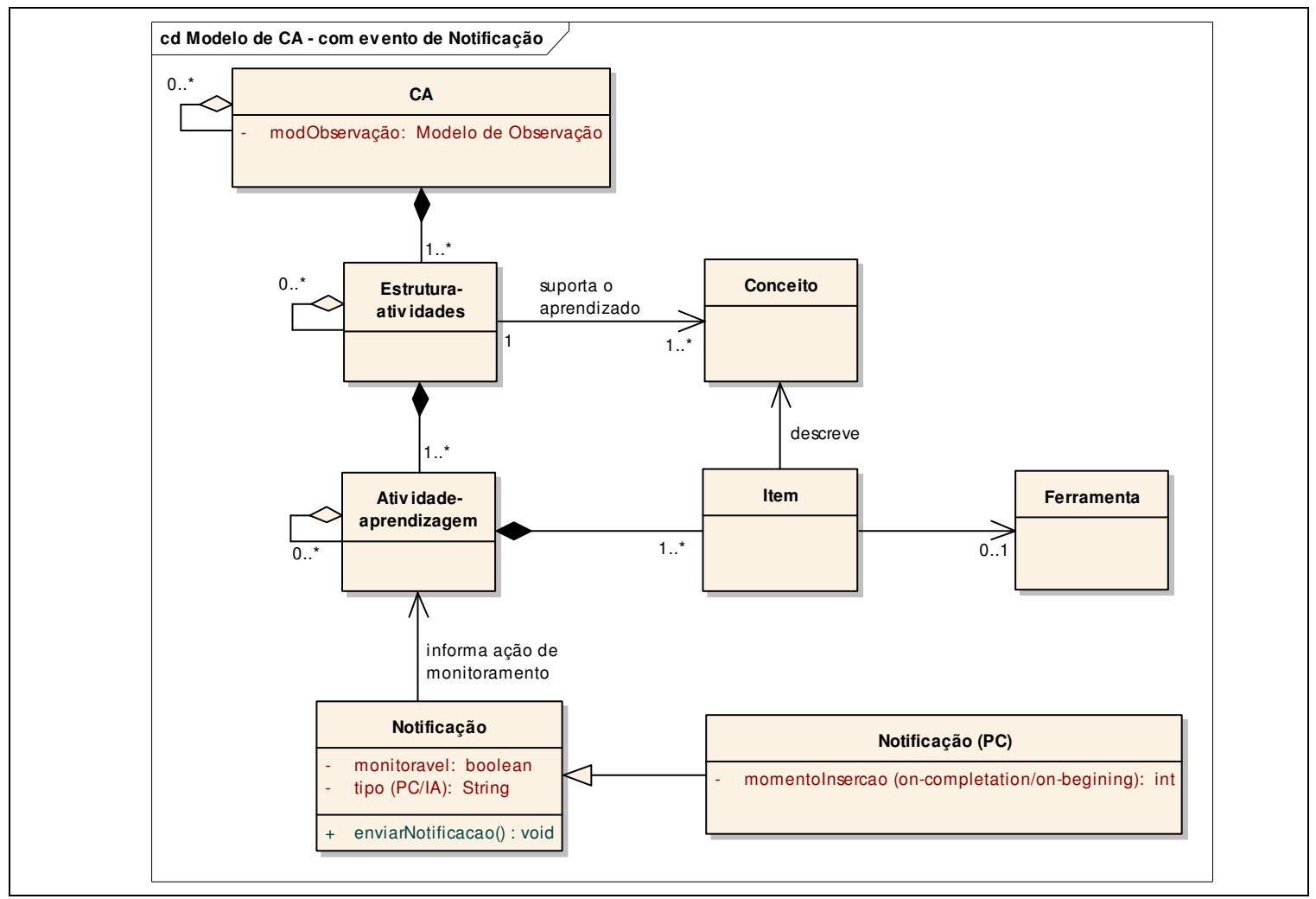

Figura 19 - Modelo de um CA com a sinalização sobre o monitoramento

A execução da notificação e do acompanhamento das interações do aprendiz será detalhada no próximo Capítulo.

\subsubsection{Geração do Repositório de Contexto}

Quando um Modelo de Observação é publicado, o publicador gera um Repositório de Contexto. O Repositório de Contexto conterá as informações sobre o contexto da interação do aluno enviadas pelo Módulo de Monitoração. As informações de contexto são referentes às Características Observáveis que fazem parte do Modelo de Observação.

O repositório de contexto será constituído pelas informações (Tabela 21): 
Tabela 21 - Informações contidas no Repositório de contexto

\begin{tabular}{|c|c|}
\hline Atributo & Descrição \\
\hline Who & Indica quem (aluno) realizou a interação. \\
\hline What & $\begin{array}{l}\text { Indica qual é a característica que está sendo observada na interação corrente. O } \\
\text { valor do what dependerá do que foi definido como observáveis pelo Modelo de } \\
\text { Observação (Whatltem). }\end{array}$ \\
\hline Where & Indica em qual AA ou ferramenta a interação ocorreu. \\
\hline When & Indica em que momento a interação ocorreu \\
\hline How & $\begin{array}{l}\text { Contém o valor relativo à interação. Apresenta a informação sobre o valor } \\
\text { associado a uma dada característica observável. Por exemplo, se a característica } \\
\text { observável for o acesso o how não conterá nenhum valor. Mas se a característica } \\
\text { observável for o tipo de mídia acessada, o how irá conter o valor relativo ao tipo } \\
\text { que foi acessado. No caso de pontos de checagem o how conterá a resposta uma } \\
\text { dada pergunta. }\end{array}$ \\
\hline
\end{tabular}

O repositório de contexto armazenará todas as interações do aluno até que o aluno finalize um dado CA e seja possível realizar uma avaliação de seu perfil.

\subsubsection{Geração de Regras de Adaptação}

Outro ponto importante durante a publicação é a geração das Regras de Adaptação que serão armazenadas no Repositório de Regras de Adaptação. As $\underline{\text { Regras de Adaptação representam para cada Tipo de Perfil planejado quais são as }}$ categorias envolvidas e os respectivos valores associados às estratégias de ensino que serão adotadas.

As regras são geradas a partir dos tipos de perfis definidos durante 0 planejamento e serão utilizadas durante o processo de adaptação do CA segundo o perfil do aluno. Considerando os tipos de perfis definidos nos exemplos apresentados na Figura 14 e na Figura 15, pode-se definir como Regras de Adaptação (Tabela 22):

Tabela 22 - Regras de Adaptação

\begin{tabular}{||c|c|c||}
\hline Tipo de Perfil & Categoria & Valor \\
\hline \hline \multirow{3}{*}{ Visual-Ativo } & Formato-Apresentação & Visual \\
\cline { 2 - 4 } & Participação do Aluno & Ativa \\
\cline { 2 - 3 } $\begin{array}{c}\text { Verbal- } \\
\text { Reflexivo }\end{array}$ & Percepção & Concreta \\
\cline { 2 - 3 } & Participação do Aluno & Verbal \\
\cline { 2 - 3 } & Percepção & Passiva \\
\hline \hline
\end{tabular}




\subsubsection{Envio das Características Observáveis ao Modelo do Aluno}

Assim que um Modelo de Observação é publicado o LearnPES envia ao Modelo do Aluno as Características Observáveis que fazem parte do modelo, agrupando as mesmas de acordo com as categorias de preferências que as descrevem.

\subsection{MODELO CONCEITUAL DO MÓDULO DE PLANEJAMENTO}

O modelo conceitual do Módulo de Planejamento, contemplando todas as entidades descritas nos tópicos anteriores é apresentada na Figura 20:

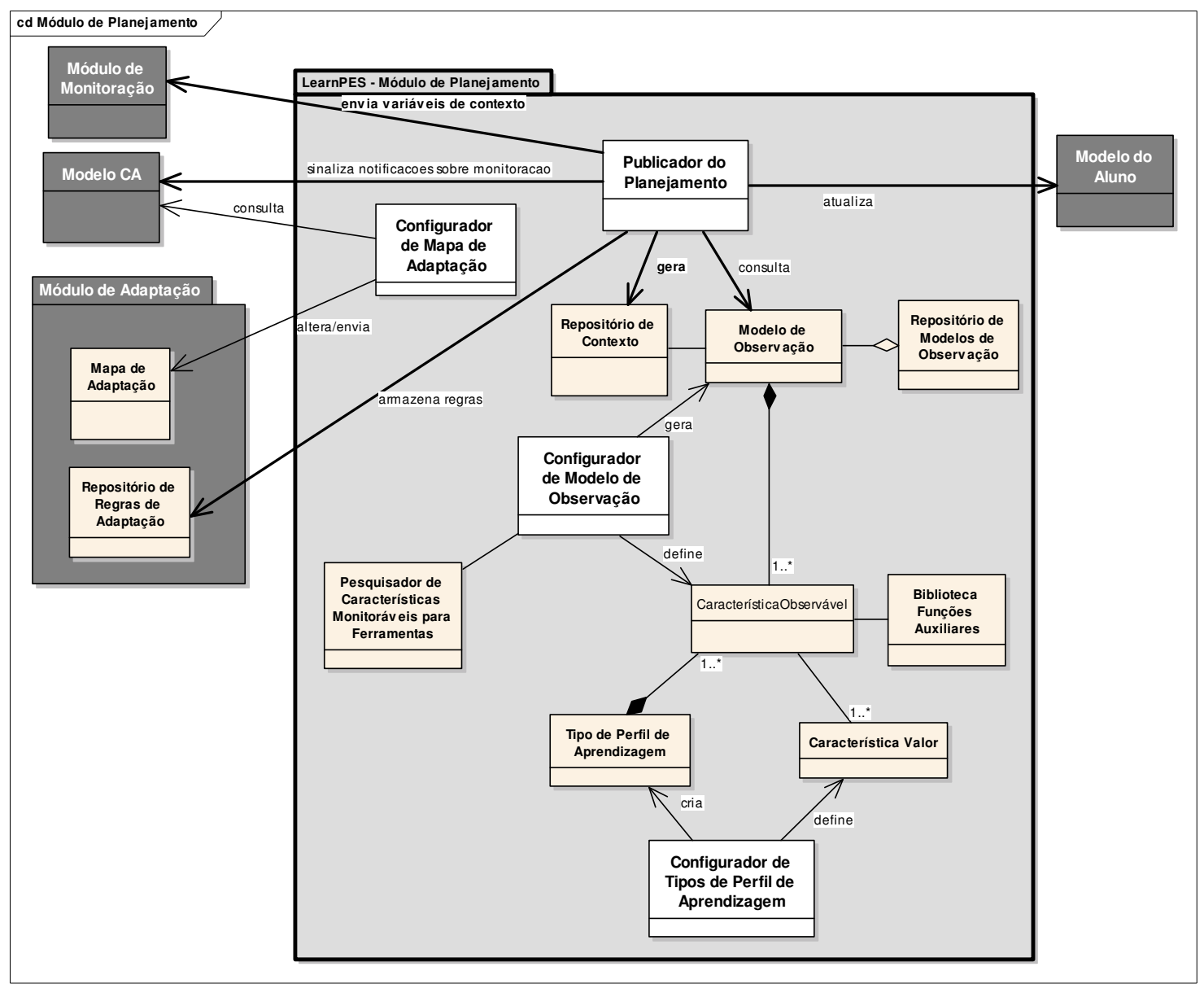

Figura 20 - Modelo conceitual do Módulo de Planejamento 


\subsection{CONSIDERAÇÕES FINAIS}

O planejamento da observação é primordial para que haja um acompanhamento adequado das interações do aluno e posteriormente a avaliação do perfil deste.

Este Capítulo apresentou as etapas referentes ao planejamento da observação, da classificação de perfis e da adaptação.

É possível observar que o docente tem que imprimir um esforço maior no planejamento da observação onde é necessário determinar as características que serão observadas. Além disto, a especificação dos tipos de perfis e a associação destes com as características observáveis e com as categorias de perfis do Modelo do Aluno são fundamentais para que seja possível realizar a adaptação. A geração de variáveis de contexto a partir das Características Observáveis permite dar uma semântica à modelagem das características e uma maior aderência entre a modelagem da observação e o acompanhamento das interações.

A geração do Mapa de Adaptação, do repositório de contexto e das Regras de Adaptação é realizada de maneira automatizada utilizando as informações provenientes do Modelo de Observação e dos Tipos de perfis cadastrados. Estender a entidade de notificação pertencente à especificação do modelo do Learning Design permitiu sinalizar as AA observáveis de forma que estas se tornem monitoráveis e possam ser acompanhadas durantes a interação do aluno

O próximo Capítulo irá detalhar o processo de acompanhamento, avaliação do perfil e adaptação de um dado CA. 


\section{ACOMPANHAMENTO DA INTERAÇÃO DO APRENDIZ, AVALIAÇÃO DO PERFIL DE APRENDIZAGEM E ADAPTAÇÃO DO CENÁRIO DE APRENDIZAGEM}

\subsection{CONSIDERAÇÕES INICIAIS}

Após realizar o planejamento da observação, da classificação dos perfis e da adaptação (módulo de Planejamento) e publicar o modelo, o sistema LearnPES passa a receber o contexto da interação do aluno obtido a partir do Módulo de monitoração, para que posteriormente possa realizar a avaliação do perfil através do Módulo Avaliador de Perfis.

Se for a primeira interação do aluno no ambiente, ou seja, se seu perfil não foi avaliado ainda, é necessário realizar a identificação inicial do perfil. Para isto o ambiente permite que $o$ aluno selecione o perfil que ele acredita ser o que melhor atende suas preferências de aprendizagem.

A partir do perfil de aprendizagem sugerido é realizada a construção dos Cenários de Aprendizagem de forma que este possa atender ao perfil de aprendizagem identificado.

\subsection{MONITORAÇÃO DO CONTEXTO DA INTERAÇÃO DO APRENDIZ}

A monitoração das interações do estudante nos CAs é realizada pelo Módulo de Monitoração e retornada ao LearnPES na forma de primitivas de contexto. A semântica $\mathrm{W} 5 \mathrm{H}$ formaliza um contexto através da definição de uma primitiva que modela a interação num dado ambiente:

contexto_interação(who,where,when,what,how,why).

Tal primitiva contextualiza o conjunto de informações considerando quem interagiu, onde e o momento em que ocorreu a interação, o que foi realizado, como foi realizado e porque foi realizado.

O Módulo de monitoração implementa o requisito funcional:

RF6) Monitorar a interação do aluno nas atividades que foram apontadas como observáveis. 
Quando uma AA recebe um evento de interação do aluno o ambiente de execução verifica se a AA que o aluno está interagindo é monitorável. Isto é possível porque as AA são sinalizadas como monitoráveis durante a publicação do Modelo de Observação (Capítulo 5 - tópico 5.6). O Módulo de monitoração terá diferentes comportamentos para características observáveis do tipo pontos de checagem ou interações do aprendiz.

Para uma característica do tipo interações do aprendiz, se a AA (where) for monitorável é capturada qual a ação (what) e é verificado se esta é uma característica observável, comparando a mesma com os whatttems definidos para a AA (whereltem) no Modelo de Observação. Caso seja observável é capturado o restante das informações que compõem o contexto: em que momento temporal a interação ocorreu (when), qual a identificação do aluno (who) e o resultado desta interação (how). Após capturar o contexto, o Módulo de monitoração envia as informações ao repositório de contexto gerado pelo LearnPES durante a publicação do Modelo de Observação (Capítulo 5 - tópico 5.6).

A Figura 21 apresenta um diagrama de seqüência que demonstra o cenário de interação quando uma característica observável é do tipo interações do aprendiz.

Quando a AA possui uma ferramenta (where) associada a ela a monitoração passa a ser dependente das informações obtidas através da ferramenta. O Módulo de monitoração recebe o conjunto de Característica Observáveis que foram planejadas e a partir disto realiza a monitoração. O contexto da interação do aluno é capturado a partir da interação dele com a ferramenta. A Figura 22 apresenta um diagrama de seqüência cujo cenário de interação é para uma característica observável do tipo interações do aprendiz, onde as monitorações ocorrem numa ferramenta.

Para uma característica do tipo ponto de checagem, se a AA (where) for monitorável é verificado o momento (when) de inserção da questão através do atributo "momentolnserção" (Capítulo 5 - Figura 19). Quando aluno atinge o momento em que o ponto de checagem deve ser exibido, a questão referente ao ponto de checagem é apresentada ao estudante. Após a interação do aluno com o Ponto de Checagem é capturada a sua resposta do estudante (how). A cláusula what conterá a descrição sobre o ponto de checagem (equivalente a descrição do what/tem). O Módulo de Monitoração também captura a identificação do aluno (who) que interagiu. Após capturar o contexto, o Módulo de monitoração envia as 
informações ao repositório de contexto gerado pelo LearnPES durante a publicação do planejamento. A Figura 23 apresenta um diagrama de seqüência que demonstra o cenário de interação quando uma característica observável é do tipo ponto de checagem.

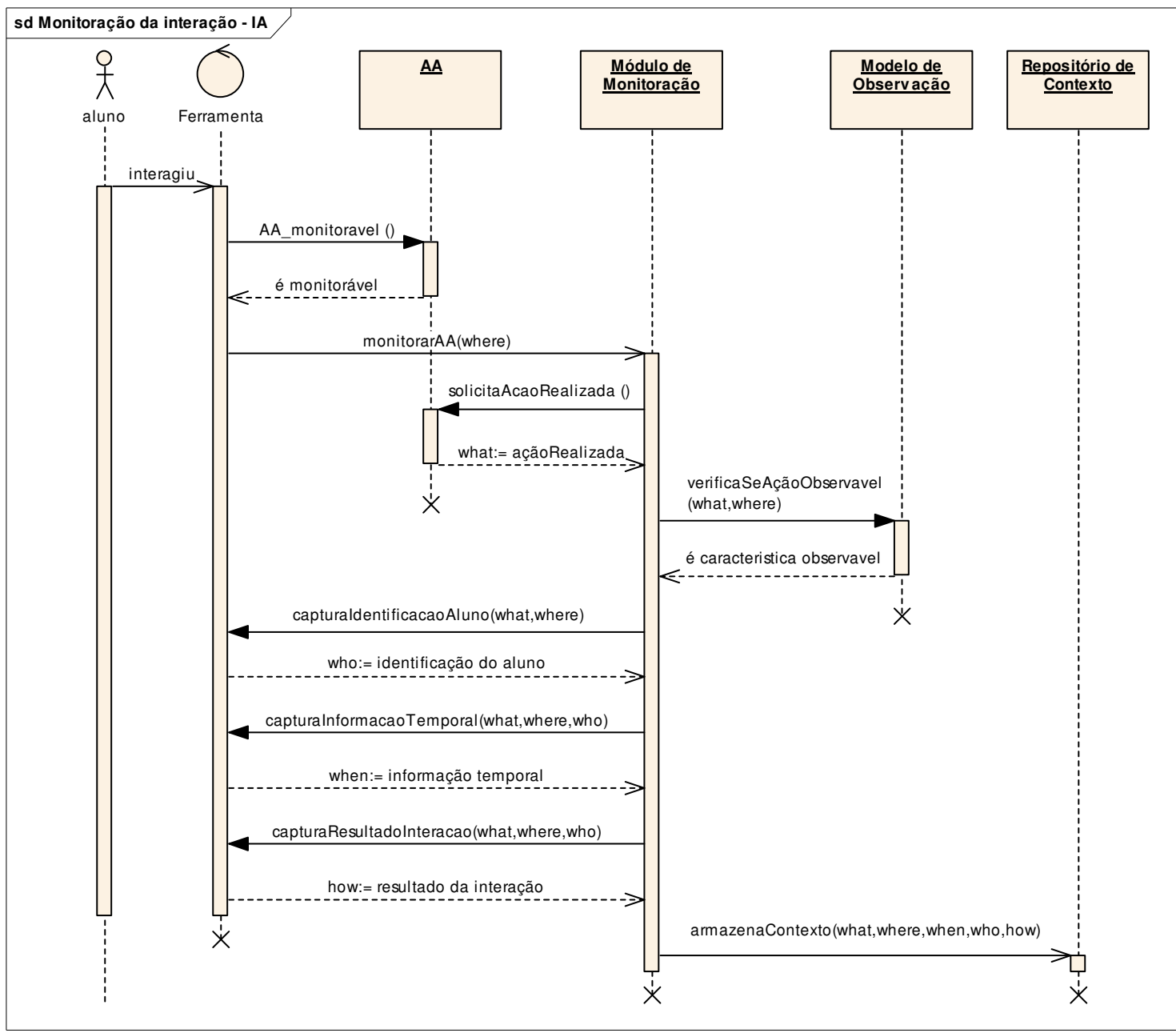

Figura 21 - Captura do contexto da interação do aprendiz para características observáveis do tipo interações do aprendiz 


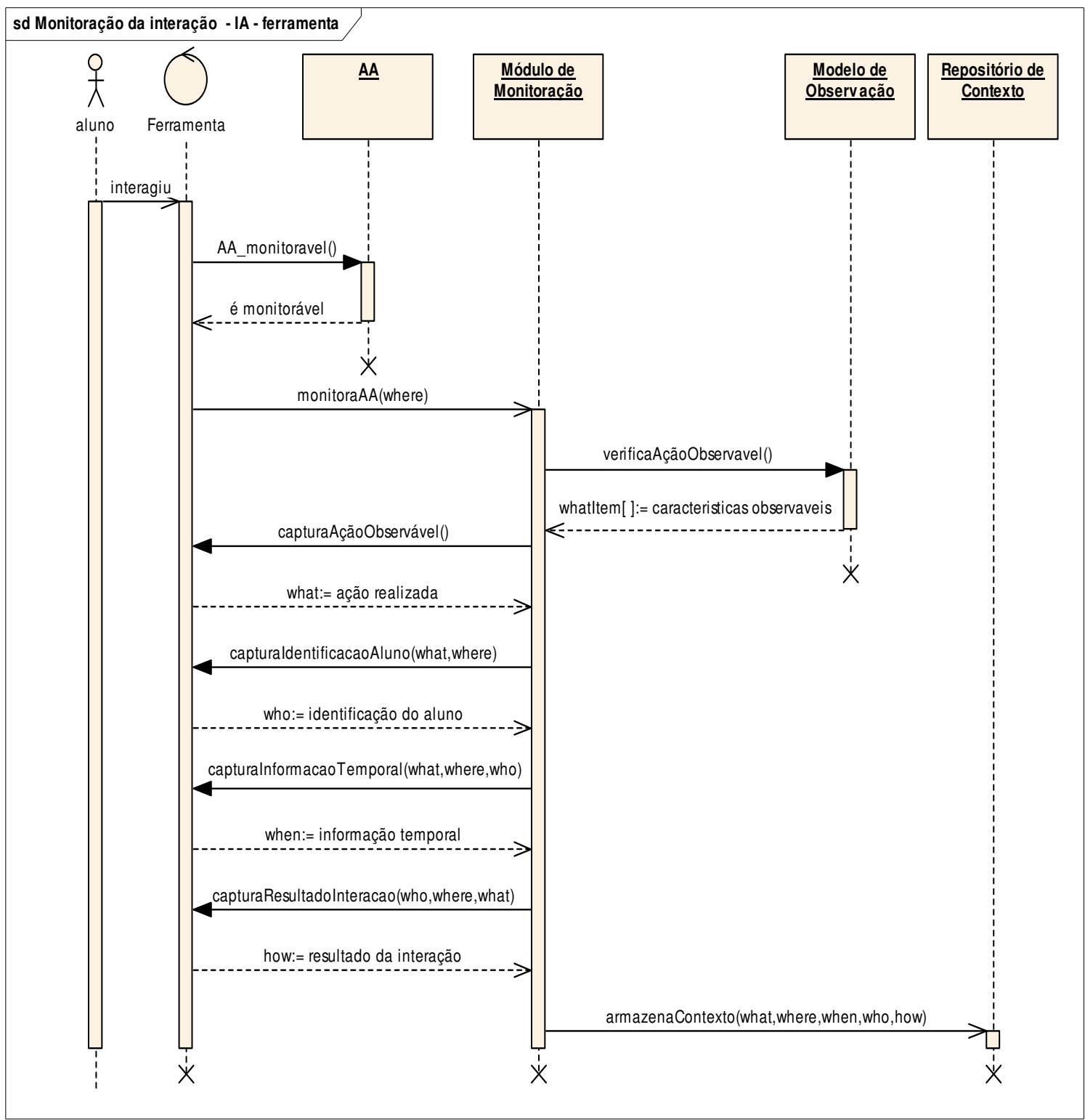

Figura 22 - Captura do contexto da interação do aprendiz através de uma ferramenta para características observáveis do tipo interações do aprendiz 


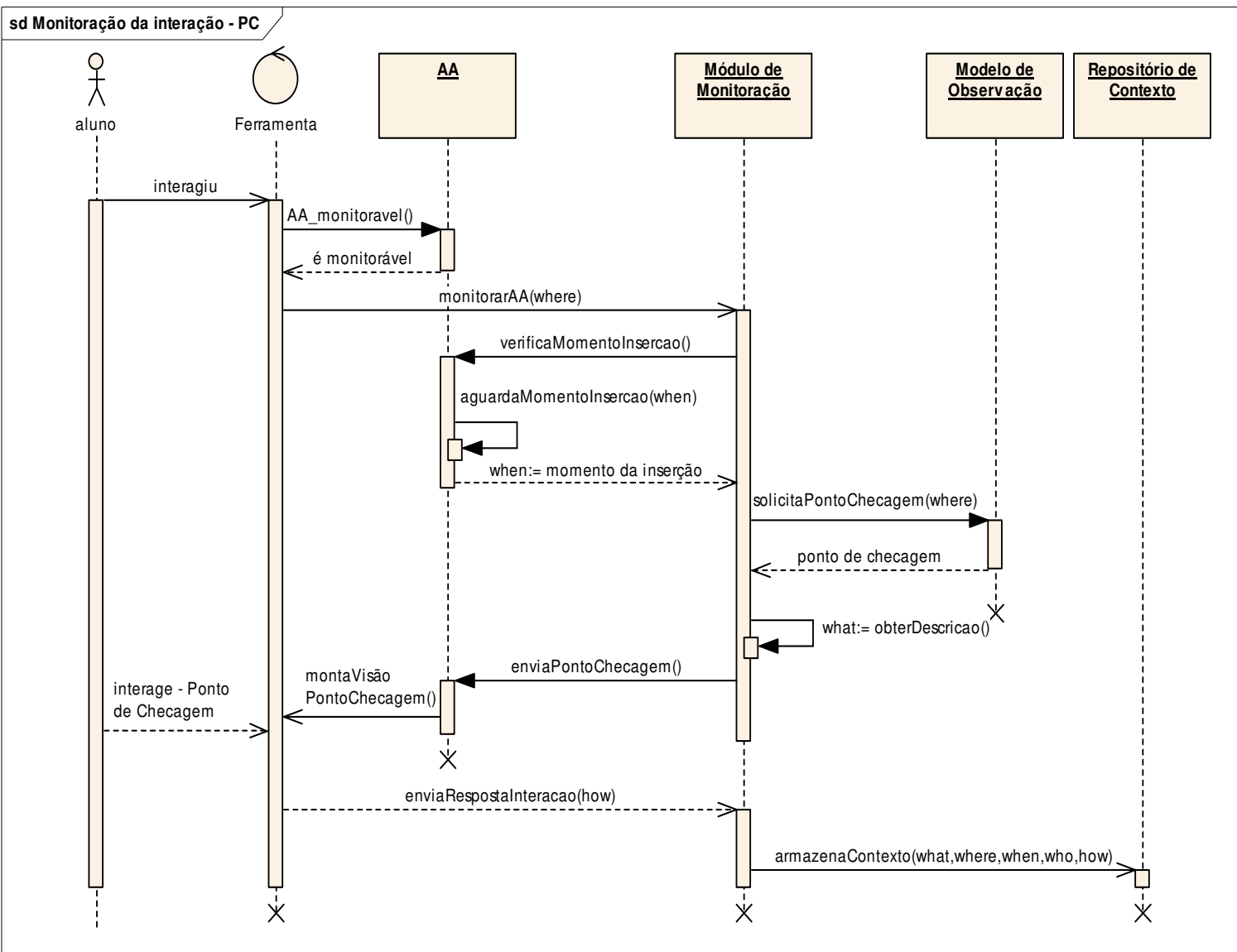

Figura 23 - Captura do contexto da interação do aprendiz para características observáveis do tipo pontos de checagem

O repositório de contexto irá conter as informações monitoradas das interações do aprendiz. A Figura 24 apresenta um exemplo de histórico de repositório de contexto considerando o roteiro planejado no Modelo de Observação (Capítulo 5 - Tabela 15). A linha em destaque apresenta o resultado obtido através da interação do aluno com um ponto de checagem. 


\begin{tabular}{|c|c|c|c|c|}
\hline who & what & where & when & how \\
\hline aluno1 & Mídia Acessada & Conceito de Medição & $28 / 05 / 06$ & video \\
\hline aluno1 & Tipo de Material Acessado & Conceito de Medição & $28 / 05 / 06$ & exemplo \\
\hline aluno1 & Mídia Acessada & Velocidade escalar & $28 / 05 / 06$ & video \\
\hline aluno1 & Tipo de Material Acessado & Velocidade escalar & $28 / 05 / 06$ & teoria \\
\hline aluno1 & Mídia Acessada & Velocidade vetorial & $28 / 05 / 06$ & texto \\
\hline aluno1 & Tipo de Material Acessado & Velocidade vetorial & $28 / 05 / 06$ & teoria \\
\hline aluno1 & Mídia Acessada & Movimento relativo & $28 / 05 / 06$ & video \\
\hline aluno1 & Você prefere resolver os ... & Velocidade vetorial & $29 / 05 / 06$ & teoria \\
\hline aluno1 & Tipo de Material Acessado & Movimento relativo & $30 / 05 / 06$ & estudo de caso prático \\
\hline aluno1 & Tipo de Material Acessado & Movimento relativo & $30 / 05 / 06$ & \\
\hline
\end{tabular}

Figura 24 - Exemplo de histórico de Repositório de Contexto

\subsection{AVALIAÇÃO DO PERFIL}

O módulo de monitoração envia um evento ao LearnPES indicando o final de um CA e que já é possível avaliar o perfil a partir das informações monitoradas.

O Módulo Avaliador de Perfis realiza o processo de classificação em duas etapas: avaliação das características observadas e classificação dos perfis.

Para exemplificar o processo executado pelo Módulo Avaliador de Perfis será considerado o CA "Movimento Retilíneo Uniforme" definido no exemplo da Tabela 13.

\subsubsection{Avaliação das Características Observadas}

Para que o processo de classificação possa ser realizado é necessário primeiro avaliar as características que foram observadas segundo os resultados obtidos através dos contextos monitorados pelo Módulo de Monitoração. A avaliação será realizada com base nas informações contextuais existentes no Repositório de Contexto. O resultado obtido através da avaliação será armazenado no Modelo do Aluno. A avaliação é realizada pelo Avaliador de Características Observáveis que é um sub-módulo do Módulo Avaliador de Perfis. O avaliador atende o requisito:

RF7) Atualizar o modelo do aluno de acordo com as informações obtidas pela monitoração. 
O Módulo de Monitoração captura todas as interações do aluno nas AA monitoradas. Porém, para uma dada Característica Observável pode ter associada a ela uma função para avaliação de dados (Módulo de Planejamento).

No exemplo de Modelo de Observação dado na Tabela 15, a Característica Observável "Mídia Acessada" tem associada a ela a função "TipoMidiaMaisAcessada". Ou seja, o que esta característica deseja obter é qual o tipo de mídia que foi mais acessada durante o período de observação. O Módulo de Monitoração captura todas as interações realizadas pelo aluno, por isto, haverá diversas ocorrências de contextos que retratam tal Característica Observável. O Avaliador de Características Observáveis irá aplicar a função associada à Característica Observável obtendo como resultado uma informação que retrate o que se deseja observar de fato. O resultado obtido é armazenado no Modelo do Aluno na respectiva Categoria de Preferência a que ele pertence.

Quando não há funções associadas à Característica Observável o Avaliador recupera o resultado da interação no Repositório de Contexto (how) e envia o resultado ao Modelo do Aluno.

O processo de avaliação é feito para cada Característica Observável que pertence ao Modelo de Observação. O diagrama de seqüência da Figura 25 descreve a avaliação para Características Observáveis que possuem funções associadas. Quando não há função associada o Avaliador considera como "result" o valor do "how" e as ações relacionadas ao uso das funções auxiliares não são executadas.

A Figura 26 apresenta o resultado da avaliação considerando o exemplo de Repositório de Contexto apresentado na Figura 24. Foram analisadas as informações do CA "Movimento Retilíneo Uniforme" que possui como AA "Velocidade escalar" e "Velocidade vetorial". O whatttem "Mídia Acessada", possuía a função "tipoMídiaMaisAcessada" associada a ele. A função irá verificar qual foi o tipo de mídia que foi mais acessada pelo aluno, considerando não somente os acessos às mídias, mas também o tempo de acesso a cada uma delas. 


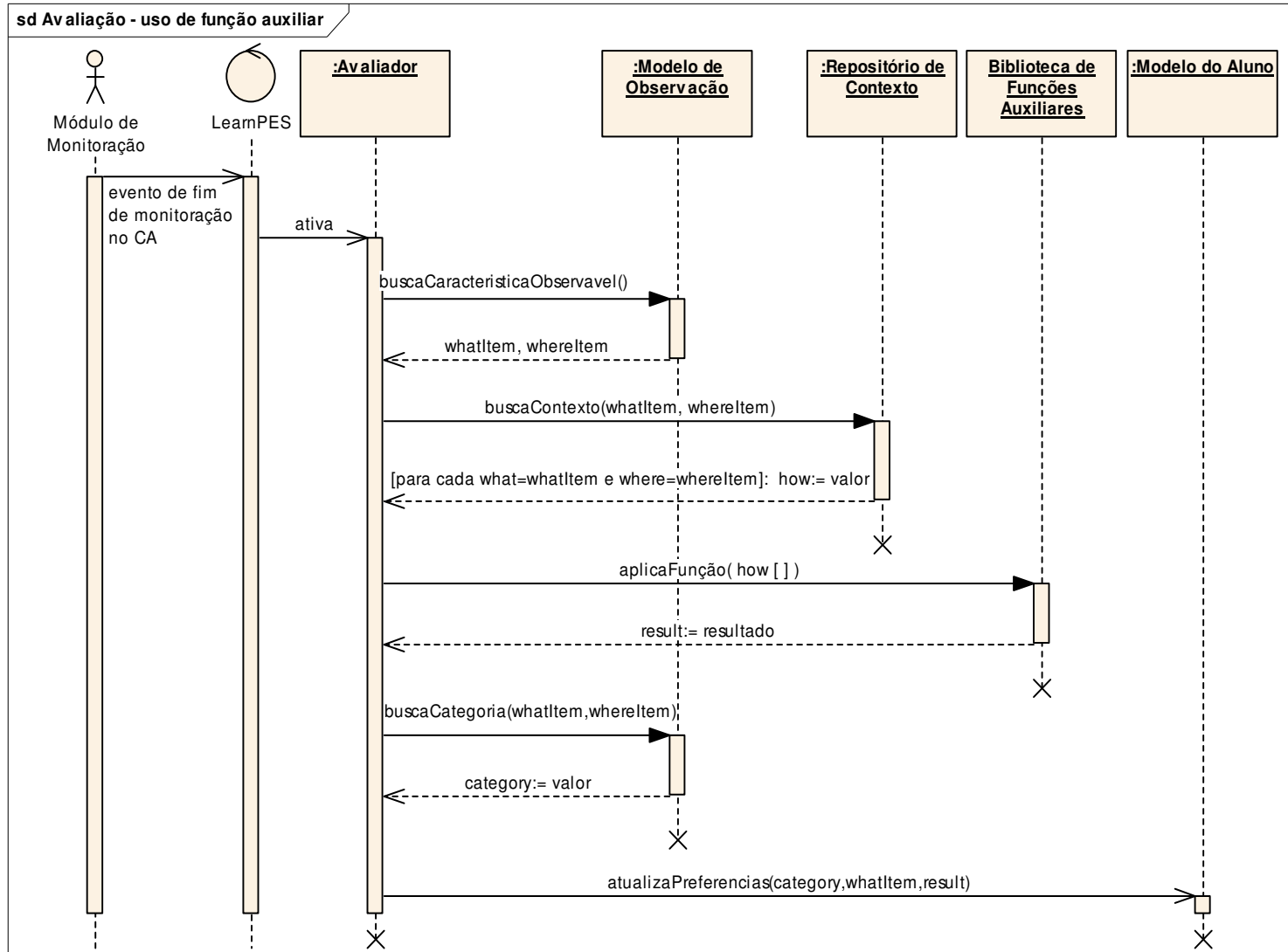

Figura 25 - Diagrama de seqüência da avaliação das características observadas e da atualização do Modelo do Aluno

\begin{tabular}{|c|c|c|c|}
\hline who & categoria & whatltem & result \\
\hline aluno1 & Formato-Apresentação & Mídia Acessada & video \\
\hline aluno1 & Percepção & Tipo de Material Acessado & teoria \\
\hline aluno1 & Percepção & Você prefere resolver os ... & a \\
\hline
\end{tabular}

Figura 26 - Informações analisadas

O Modelo do Aluno é atualizado com o resultado da avaliação das características observadas (Tabela 23):

Tabela 23 - Exemplo de Modelo do Aluno atualizado após avaliação das características observadas

\begin{tabular}{|c|c|c|}
\hline Categoria & Característica Observável & Resultado \\
\hline Formato-Apresentação & Mídia Acessada & video \\
\hline \multirow{2}{*}{ Percepção } & Material Acessado & teoria \\
\cline { 2 - 3 } & Você prefere resolver os ... & a \\
\hline
\end{tabular}




\subsubsection{Classificação dos Perfis}

A classificação do aluno em um dado perfil de aprendizagem segundo os tipos de perfis cadastrados pelo professor é realizada após a avaliação das características observadas. O processo de classificação é realizado pelo Classificador de Perfis baseando-se no conjunto de Tipos de Perfis de Aprendizagem que foram criados durante o processo de planejamento (Capítulo 5 tópico 5.4). O classificador atende os requisitos:

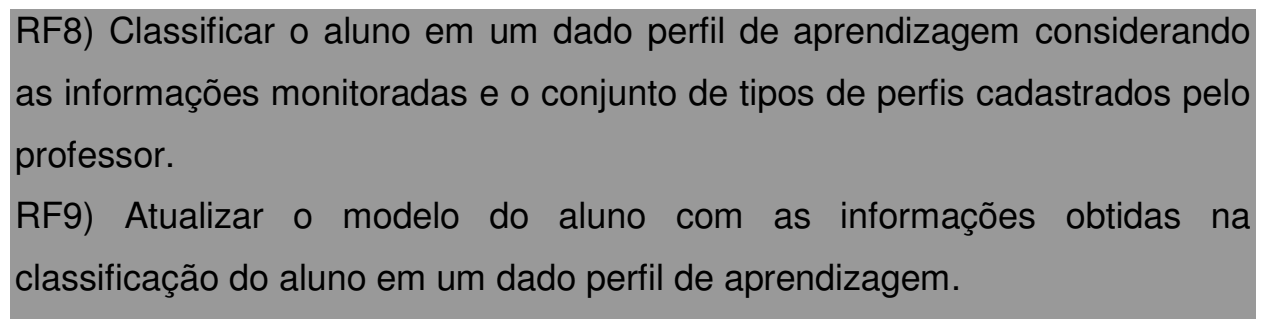

O Classificador de Perfis recebe um evento do Avaliador de Características Observáveis indicando que é para iniciar o processo de classificação. Como a classificação do perfil será realizada com base em diversas características observáveis é muito provável que não seja possível se obter valores que sejam exatamente iguais aos definidos nos tipos de perfis.

Rosatelli e Tedesco (2003) citam diversas técnicas que podem ser utilizadas para classificar o usuário em um dado perfil dentre elas a aprendizagem de máquina, as redes bayesianas, as baseadas em lógica, entre outras.

Para classificar o aluno em um tipo de perfil de aprendizagem que possui características que mais se aproximam das características observadas na interação do aluno, o Classificador de Perfis adotará um algoritmo de aprendizagem de máquina (instance-base learning) denominado de Vizinhos mais Próximos ( $k$ Nearest Neighbor). Este algoritmo foi proposto por Cover e Hart em 1967 e é um dos algoritmos mais simples de serem implementados para execução de aprendizagem de máquina (AHA; KIBLER; ALBERT, 1991). A adoção deste algoritmo se deve pelo fato de que durante a observação do aprendiz é possível se obter um grande número de informações que permitem caracterizar a interação deste aprendiz (SILVA, 2005). Não está dentro do escopo deste trabalho encontrar a melhor técnica para classificação considerando desempenho computacional. 
O algoritmo dos Vizinhos mais Próximos procura quais são os objetos vizinhos que se encontram mais próximos do objeto avaliado em um dado momento. Primeiramente, o algoritmo executa uma fase de treinamento de exemplos gerando uma lista de exemplos treinados. Depois disto, o algoritmo realiza a fase de classificação em que a partir de um novo conjunto de dados encontra os $k$ vizinhos mais próximos deste, considerando a lista de exemplos treinados. Devem ser determinados quantos $(k)$ vizinhos mais próximos deverão ser considerados, (MITCHELL, 1997).

Durante a fase de treinamento e da classificação do objeto, são utilizados atributos que caracterizam o objeto que está sendo avaliado e os exemplos treinados. Os atributos podem ser expressos em valores reais ou em valores discretos havendo um mapeamento dos valores discretos para dados quantitativos.

Aha, Kibler e Albert (1991) e Mitchell (1997) abordam que o algoritmo assume que todas as instâncias são pontos em um espaço n-dimensional. Para encontrar os vizinhos mais próximos é utilizada uma métrica que avalia aproximação do objeto observado em relação aos exemplos treinados.

Para este trabalho será considerado o algoritmo que encontra o vizinho mais próximo $(k=1)$. A partir das preferências de um determinado aprendiz armazenadas no Modelo do Aluno (que é o objeto avaliado) será encontrado o tipo de perfil de aprendizagem mais próximo a partir do conjunto de tipos de perfis que o sistema possui cadastrado.

O Classificador irá utilizar o conjunto de tipos de perfis que foi definido através do Configurador de Tipos de Perfis. Para realizar a classificação serão utilizadas as Características Observáveis existentes no Modelo do Aluno compondo um objeto denominado de $\underline{\text { Perfil Analisado. }}$ O Perfil Analisado será comparado com cada tipo de perfil que foi definido pelo docente.

O Classificador de Perfis irá buscar qual é o Tipo de Perfil (dentre os cadastrados pelo docente) que está mais próximo (vizinho mais próximo) do Perfil Analisado. Como ilustração será calculada a distância entre o Perfil Analisado e os Tipos de Perfis cadastrados. Num primeiro passo é verificada a distância entre a característica observável do Perfil Analisado e a sua correspondente em um dado Tipo de Perfil denominada de distCaracterística. Quando as características do Perfil Analisado e do Tipo de Perfil não possuem correspondência, é atribuído o valor "1". Caso contrário é atribuído o valor "0". Isto significa que quando há correspondência 
entre a característica do Perfil Analisado e a do Tipo de Perfil, a distância entre elas é zero, demonstrando que ambos são similares.

Observando-se o exemplo de Modelo do Aluno da Tabela 23, é possível verificar que o valor da Característica Observável "Mídia Acessada" é "vídeo". Para o tipo de perfil Visual-Ativo esta característica terá um valor de distância "0". Já para o tipo de perfil Verbal-Reflexivo ela terá um valor de distância "1".

A Figura 27 apresenta um exemplo de verificação das distâncias entre as características observáveis do Perfil Analisado e do tipo de perfil "Visual-Ativo". As características referentes à inserção de mensagens de fórum e chat não estão sendo analisadas porque segundo o Modelo do Aluno não possuem informações armazenadas.

\begin{tabular}{|c|c|c|c|c|c|c|c|c|}
\hline \multicolumn{9}{|c|}{ Conjunto de Tipos de Perfis } \\
\hline & & & & \multicolumn{2}{|c|}{ Visual-Ativo } & & \\
\hline & \multirow{2}{*}{ Categoria } & \multirow{2}{*}{\multicolumn{2}{|c|}{ Característica Observável }} & \multicolumn{2}{|c|}{ Característica Valor } & \multicolumn{2}{|c|}{ Característica Valor } & \\
\hline & & & & Valor & & \multicolumn{2}{|l|}{ Valor } & \\
\hline & \multirow{2}{*}{$\begin{array}{l}\text { Formato- } \\
\text { Apresentação }\end{array}$} & \multicolumn{2}{|c|}{ Mídia Acessada } & Figura ou v & & \multicolumn{2}{|c|}{ Texto ou som } & \\
\hline & & \multicolumn{2}{|c|}{ Exercício Acessado } & experimer & & \multicolumn{2}{|c|}{ dissertativo } & \\
\hline & \multirow{2}{*}{ Percepção } & \multicolumn{2}{|c|}{ Material Acessado } & Exemplo & & \multicolumn{2}{|l|}{ teoria } & \\
\hline & & \multicolumn{2}{|c|}{ Você prefere resolver os ... } & a & & \multicolumn{2}{|l|}{ b } & \\
\hline & \multirow{2}{*}{$\begin{array}{l}\text { Participação } \\
\text { do Aluno }\end{array}$} & \multicolumn{2}{|c|}{$\begin{array}{l}\text { Inserção de Mensagem } \\
\text { (chat) }\end{array}$} & $>=20$ & & \multicolumn{2}{|l|}{$<20$} & \\
\hline & & \multicolumn{2}{|c|}{$\begin{array}{l}\text { Inserção de Mensagem } \\
\text { (fórum) }\end{array}$} & $\nearrow>=10$ & & \multicolumn{2}{|l|}{$<10$} & \\
\hline \multicolumn{4}{|c|}{ Perfil Analisado } & & \multicolumn{4}{|c|}{ Comparação de distâncias } \\
\hline Categoria & Característi & Observável & Válor & & \multicolumn{2}{|c|}{$\begin{array}{c}\text { Característica } \\
\text { Observável }\end{array}$} & dist & acterística \\
\hline \multirow{2}{*}{$\begin{array}{l}\text { Formato- } \\
\text { Apresentação }\end{array}$} & \multicolumn{2}{|c|}{ Mídia Acessada } & Video & & \multicolumn{2}{|c|}{ Mídia Acessada } & & 0 \\
\hline & \multicolumn{2}{|c|}{ Exercício Acessado } & experimento & & \multicolumn{2}{|c|}{ Exercício Acessado } & & 0 \\
\hline \multirow{2}{*}{ Percepção } & \multicolumn{2}{|c|}{ Material Acessado } & teoria & & \multicolumn{2}{|c|}{ Material Acessado } & & 1 \\
\hline & \multicolumn{2}{|c|}{ Você prefere resolver os ... } & a & & \multicolumn{2}{|c|}{$\begin{array}{c}\text { Você prefere resolver } \\
\text { os ... }\end{array}$} & & 0 \\
\hline Participação & Inserção de M & nsagem (chat) & 22 & & & $\begin{array}{l}\text { erção de } \\
\text { agem (chat) }\end{array}$ & & 0 \\
\hline do Aluno & Inserção de Me & sagem (fórum) & 8 & & Men & $\begin{array}{l}\text { erção de } \\
\text { ggem (fórum) }\end{array}$ & & 1 \\
\hline
\end{tabular}

Figura 27 - Exemplo de análise de perfil de um aluno 
Após fazer a comparação entre as características observáveis do Perfil Analisado e de um dos tipos de perfis o Classificador irá calcular a distância total, considerando todas as características observáveis em conjunto. Para isto realiza um somatório entre os valores das distCaracterísticas, denominado de distPerfis:

$$
\text { distPerfis }(T P, \text { PerfilAnalisado })=\sum_{i}^{n} \text { distCaracteristica }
$$

Onde:

distPerfis = distância entre dois Perfis

TP = tipo de perfil cadastrado

i = característica observável

$\mathrm{n}=$ número de características observáveis avaliadas

distCaracteristicaPerfil = distância de dada característica observável entre o PerfilAnalisado e um Tipo de Perfil

O Classificador irá calcular a distância entre o Perfil Analisado e todos os tipos de perfis. A classificação do aluno é determinada pelo tipo de perfil que tem o menor valor dentre todas as distâncias de perfis calculadas:

$$
\begin{gathered}
\text { ClassificacaoAluno }=\text { min( } \text { distPerfis }_{1}\left(\mathrm{TP}_{1}, \text { PerfilAnalisado }\right), \ldots, \\
\left.\operatorname{distPerfis}_{\mathrm{m}}\left(\mathrm{TP}_{\mathrm{m}}, \text { PerfilAnalisado }\right)\right)
\end{gathered}
$$

Onde:

$\mathrm{m}$ = número de tipos de perfis cadastrados

O Classificador irá verificar em qual tipo de perfil que possui um valor correspondente a este para a característica em questão. Quando encontrar o valor correspondente o Classificador irá armazenar o valor do atributo "caracteristicaPerfil" pertencente ao tipo de perfil correspondente no atributo "valor" do Perfil Analisado.

A Figura 28 apresenta o diagrama com as etapas realizadas para classificar 0 aluno segundo um dado tipo de perfil cadastrado. 


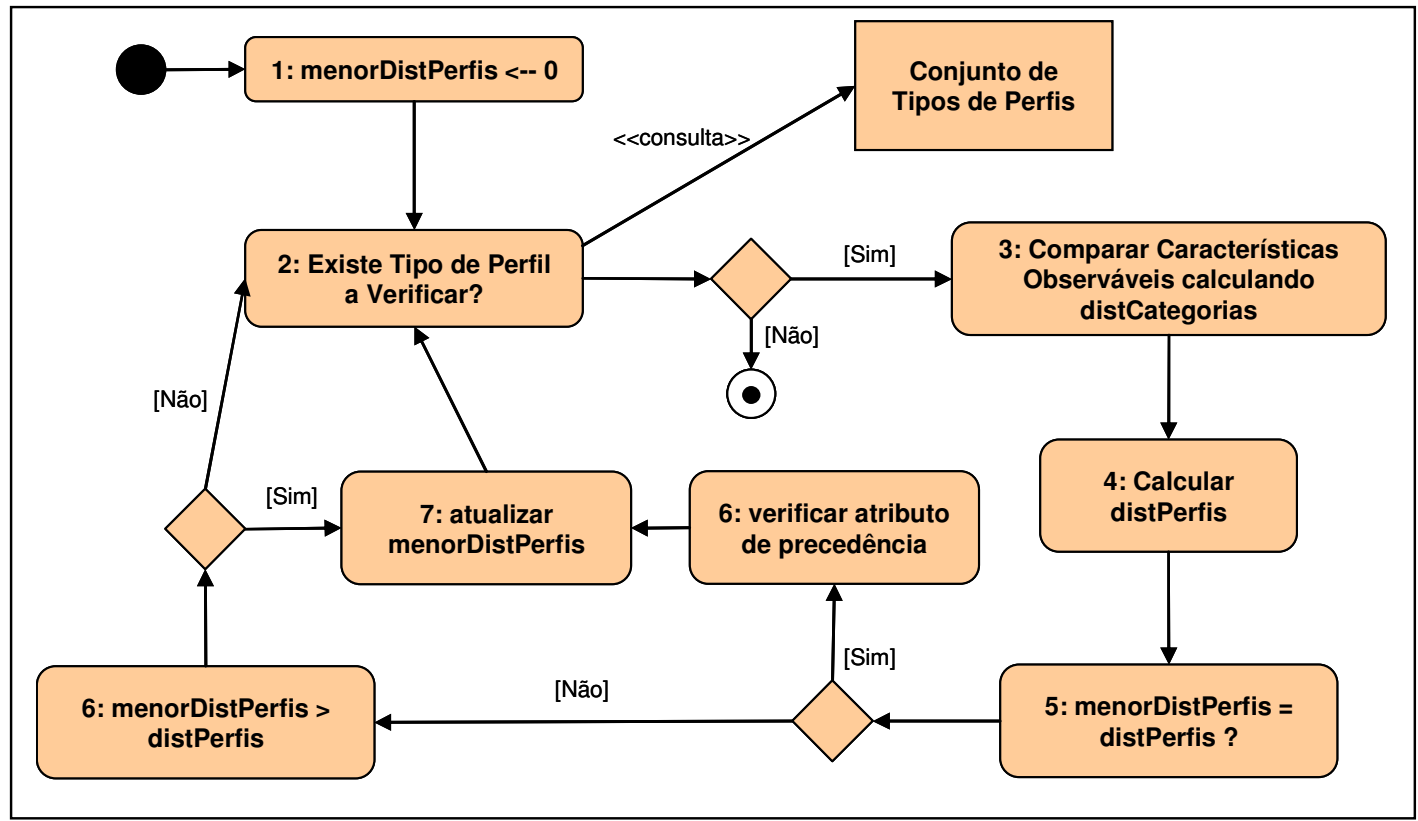

Figura 28 - Classificação do aluno através da menor distância

Considerando o exemplo utilizado na Figura 27, é calculada a distância entre os tipos de perfis (Visual-Ativo e Verbal-Reflexivo) e o Perfil Analisado. É encontrado que o Perfil Analisado está mais próximo do tipo de perfil "Visual-Ativo":

distPerfis (Visual-Ativo,PerfilAnalisado) $=0+0+1+0+0+1=2$

distPerfis (Verbal-Reflexivo,PerfilAnalisado) $=1+1+0+1+1+0=4$

O perfil de aprendizagem sugerido se baseia nas categorias adotadas para 0 "Visual-Ativo". Isto significa que o perfil de aprendizagem sugerido classifica o aluno como: Visual, Ativa e Concreta. A descrição do tipo de perfil pode ser observada na Tabela 18 no Capítulo 5.

\subsubsection{Modelo Conceitual do Módulo Avaliador de Perfis}

O modelo conceitual do Módulo Avaliador de Perfis, contemplando todas as entidades descritas nos tópicos anteriores é apresentada na Figura 29: 


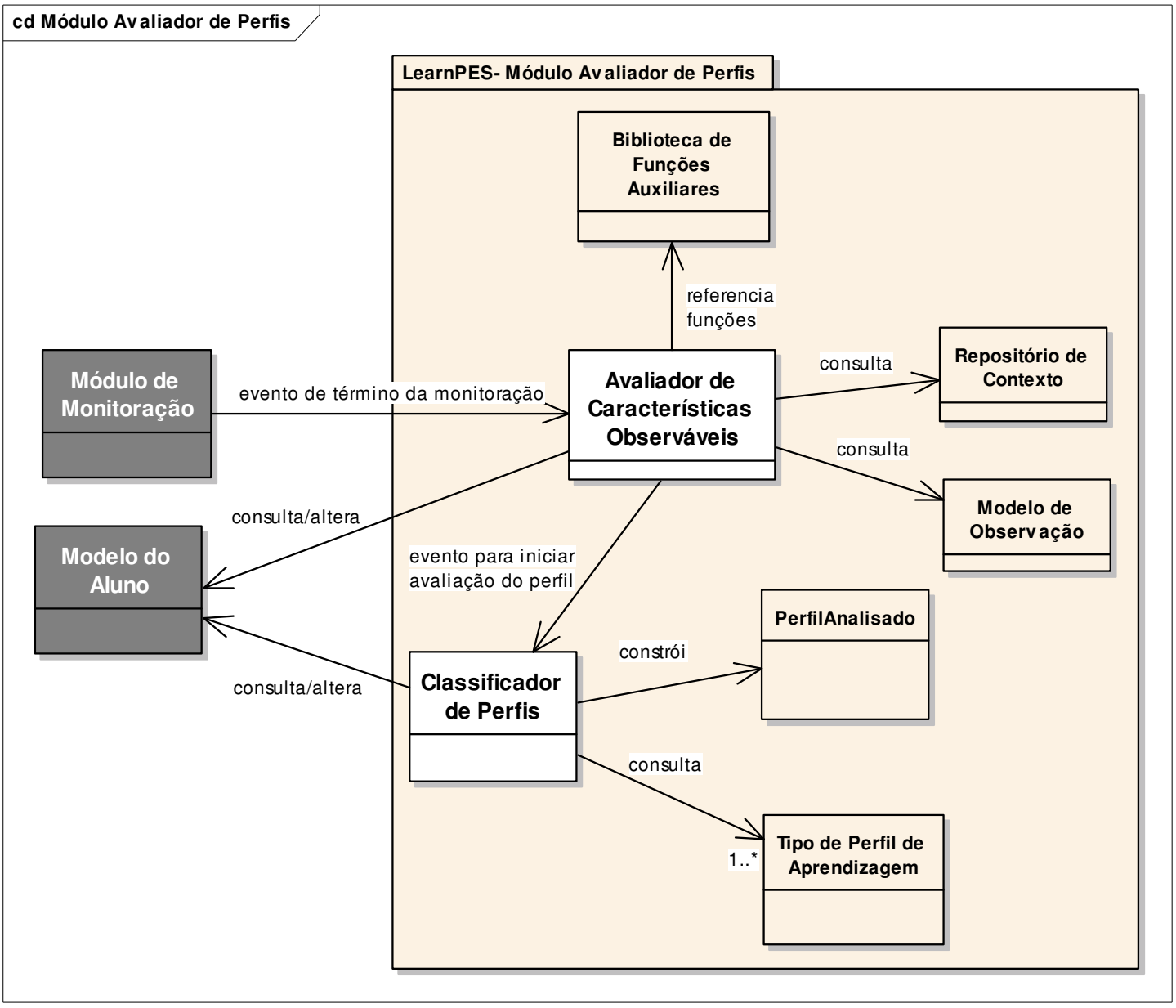

Figura 29 - Modelo conceitual do Módulo Avaliador de Perfis

\subsection{ADAPTAÇÃO DO CENÁRIO DE APRENDIZAGEM}

O Módulo de Adaptação é responsável por construir o CA mais adequado ao aluno de acordo com o Modelo do CA definido previamente e com as informações do Modelo do Aluno. O Módulo de Adaptação utiliza-se do perfil de aprendizagem do aluno e do atributo de tecnologia para realizar a construção do CA. Este módulo atende o requisito funcional:

RF10) Realizar a adaptação do CA de acordo com as informações do Modelo do aluno e das estratégias de ensino relacionadas a um dado perfil de aprendizagem. 
O CA que será apresentado ao aluno será composto pelos objetos de aprendizagem vinculados a conceitos, e será construído de forma dinâmica considerando o perfil de aprendizagem do aluno e o atributo de tecnologia.

Quando o LearnPES encontra o perfil de aprendizagem ele envia um evento ao Módulo de Adaptação que irá consultar o Mapa de Adaptação para verificar qual é o próximo CA que deve ser apresentado ao aluno e quais AA estão relacionadas a este CA.

\subsubsection{Localização de Objetos de Aprendizagem}

Para cada AA pertencente a um dado CA deve-se realizar a localização do objeto de aprendizagem aderente ao perfil de aprendizagem e aos conceitos que se deseja abordar. A localização é realizada através do Localizador de Objetos de Aprendizagem. O Localizador realiza a busca em repositórios que contém objetos catalogados segundo o padrão LOM (Capítulo 3 - tópico 3.3.1).

Conforme descrito no Capítulo 5 (tópico 0), o processo de sequenciamento das atividades é dado pelo planejamento realizado através do padrão do Learning Design. O Mapa de Adaptação é gerado automaticamente pelo módulo de Planejamento.

O Localizador verifica se no Mapa de Adaptação houve uma sugestão de um perfil adotado ou não. Conforme abordado no Capítulo 5 o docente pode sugerir o uso de um dado perfil como forma de desenvolver habilidades que o docente julga necessárias naquele momento do processo de aprendizagem. Neste caso, o objeto vinculado a AA será localizado segundo o perfil sugerido pelo docente.

O Módulo de Adaptação irá então buscar no Modelo do Aluno o perfil de aprendizagem (caso não haja perfil sugerido no Mapa de Adaptação) e consultar o atributo de tecnologia (descrito no Modelo do Aluno - Tabela 9) verificando se o aluno em questão possui uma conexão limitada ou não em termos de banda de transmissão.

Outro ponto importante é verificar no Modelo do CA quais são os conceitos que estão envolvidos com as AA que serão utilizadas para a construção deste novo CA.

O Módulo de Adaptação, através do Localizador de Objetos de Aprendizagem (um sub-módulo do Módulo de Adaptação), irá buscar no repositório de objetos de 
aprendizagem (especificado segundo o padrão LOM) os objetos que possam atender os elementos:

\section{conceitos + perfil de aprendizagem + tecnologia.}

O localizador realiza uma associação entre as categorias de um dado perfil de aprendizagem com as categorias descritoras existentes na especificação do padrão LOM. Conforme descrito no Capítulo 4, durante a especificação de um Modelo de CA é determinado para uma dada AA quais conceitos estão relacionados ao aprendizado desta. O Localizador de Objetos irá buscar quais objetos de aprendizagem que se relacionam aos conceitos utilizando os campos "título", "descrição" e "palavras-chave" (Categoria Geral). A partir dos objetos localizados é realizado o filtro para determinar quais atendem um dado perfil de aprendizagem.

Um perfil de aprendizagem reflete as características marcantes de um dado aluno durante sua interação com o processo de aprendizagem. Estas características são evidenciadas através de estilos de aprendizagem que são empregados pelo aluno durante sua interação.

Quando o docente cadastra um tipo de perfil ele vincula a este categorias que descrevem o perfil de aprendizagem. Cada categoria vinculada ao perfil descrito possui uma estratégia de ensino associada, conforme descrito no Capitulo 2 . 0 Localizador de Objetos irá buscar por objetos de aprendizagem que espelhem as estratégias de ensino vinculadas ao perfil encontrado. Por exemplo, se um aluno possui um perfil de aprendizagem descrito como Visual (Categoria FormatoApresentação), Ativo (Categoria Participação do Aluno) e Concreto (Categoria Percepção), o Localizador de Objetos irá buscar por objetos que atendam estas características, utilizando a caracterização do perfil como métodos de ensino que suportem o perfil do aluno.

Para a determinação dos objetos de aprendizagem que atendem um perfil de aprendizagem são utilizados os campos da Categoria LOM Educacional. O relacionamento entre a característica do perfil identificada e o campo do LOM da Categoria Educacional é realizado conforme descrito na Tabela 24: 
Tabela 24 - Relacionamento entre o perfil de aprendizagem e os objetos de aprendizagem

\begin{tabular}{|c|c|c|c|c|}
\hline $\begin{array}{l}\text { Campo do LOM } \\
\text { associado }\end{array}$ & Descrição da função do campo & Valor do campo & $\begin{array}{c}\text { Característica do } \\
\text { Perfil }\end{array}$ & $\begin{array}{l}\text { Categoria do } \\
\text { Perfil }\end{array}$ \\
\hline \multirow{2}{*}{$\begin{array}{l}\text { Tipo de } \\
\text { Interatividade }\end{array}$} & $\begin{array}{l}\text { Descreve objetos com } \\
\text { características concretas } \\
\text { (simulação, exercícios, estudos de } \\
\text { caso, etc). }\end{array}$ & ativo & Concreto & \multirow{2}{*}{ Percepção } \\
\hline & $\begin{array}{l}\text { Descreve objetos com } \\
\text { características abstratas } \\
\text { (conteúdos expositivos). }\end{array}$ & expositivo & Abstrato & \\
\hline \multirow{4}{*}{$\begin{array}{l}\text { Tipo de Recurso da } \\
\text { Aprendizagem }\end{array}$} & \multirow{2}{*}{$\begin{array}{l}\text { Descreve se o mesmo é uma } \\
\text { figura, diagrama, som, etc. }\end{array}$} & $\begin{array}{l}\text { Figura } \\
\text { Vídeo } \\
\text { Filme } \\
\text { entre outros }\end{array}$ & Visual & \multirow{2}{*}{$\begin{array}{l}\text { Formato- } \\
\text { Apresentação do } \\
\text { Conteúdo }\end{array}$} \\
\hline & & $\begin{array}{c}\text { Texto } \\
\text { Som } \\
\text { entre outros }\end{array}$ & Auditivo & \\
\hline & $\begin{array}{l}\text { Descreve se o mesmo é um } \\
\text { exercício prático, um estudo de } \\
\text { caso, etc. }\end{array}$ & $\begin{array}{l}\text { Exercício prático } \\
\text { Experimento } \\
\text { entre outros }\end{array}$ & Ativo & \multirow[t]{2}{*}{$\begin{array}{l}\text { Participação do } \\
\text { Aluno }\end{array}$} \\
\hline & $\begin{array}{l}\text { Descreve se o mesmo é uma } \\
\text { leitura complementar, questionário } \\
\text { teórico, etc. }\end{array}$ & $\begin{array}{l}\text { Questionário } \\
\text { Leitura }\end{array}$ & Reflexivo & \\
\hline
\end{tabular}

Quando um aluno possui como característica de perfil ser ativo ou reflexivo pode ser adotada como uma estratégia de ensino fórum, chats, discussão em grupo, etc. Estas estratégias normalmente estão vinculadas a ferramentas. Neste caso, durante o planejamento da $\mathrm{AA}$ o docente deve relacionar a mesma a dada ferramenta.

O Módulo de Adaptação possui um Repositório de Regras de Adaptação que são baseadas no relacionamento entre o perfil de aprendizagem e nos campos do LOM. Estas regras foram geradas durante a publicação do Modelo de Observação (Capítulo 5).

Além das características do perfil, também são relacionadas aos campos do LOM as questões de tecnologia e dos conceitos abordados por uma dada AA. É verificado no Modelo do Aluno o atributo de tecnologia e verificado nos campos "formato" e "tamanho" do LOM (categoria Técnica), se um dado objeto atende às necessidades da tecnologia. O objetivo é evitar que um objeto de vídeo de alta qualidade possa ser adotado para um aluno que interage através de uma conexão discada. No caso que o aluno possui uma característica de perfil visual pode ser adotado como alternativa uma seqüência de figuras explicativas. 
A Figura 30 apresenta as etapas realizadas pelo Localizador de Objetos para encontrar o objeto de aprendizagem que possa atender os elementos de conceitos, perfil de aprendizagem e tecnologia e a relação destas com os campos que compõem a especificação do padrão LOM:

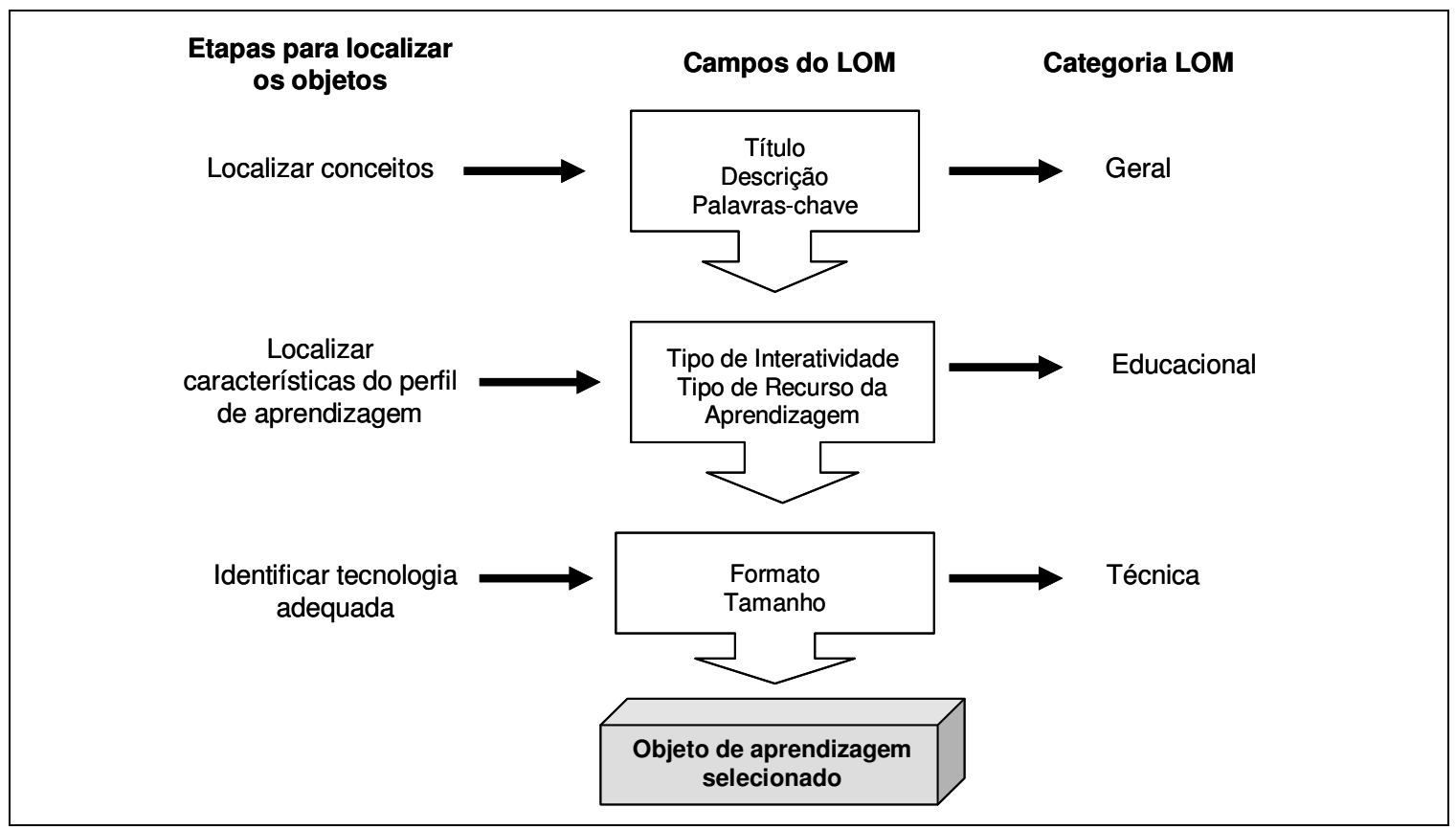

Figura 30 - Etapas para localizar o objeto de aprendizagem

O processo de localização de objetos de aprendizagem será realizado para toda AA que possuir o atributo "item" não vinculado a uma ferramenta (Capítulo 4 tópico 4.2). A Figura 31 apresenta o diagrama de seqüência que descreve a localização dos objetos considerando o Modelo do Aluno e o Mapa de Adaptação. Para cada conceito relacionado à AA são localizados os objetos que atendam este conceito. Depois disto é verificado se existe algum perfil sugerido no Mapa de Adaptação. Se não existir o localizador irá buscar o perfil de aprendizagem no Modelo do Aluno. Se existir adota o perfil sugerido pelo mapa. Busca pelas regras de adaptação para que seja possível identificar, segundo o perfil de aprendizagem adotado qual é a identificação de cada Categoria de Perfil. E por último verifica se existem restrições quanto à tecnologia para selecionar os objetos mais adequados. O Localizador retorna os objetos de aprendizagem que atenderam aos critérios utilizados na busca. 


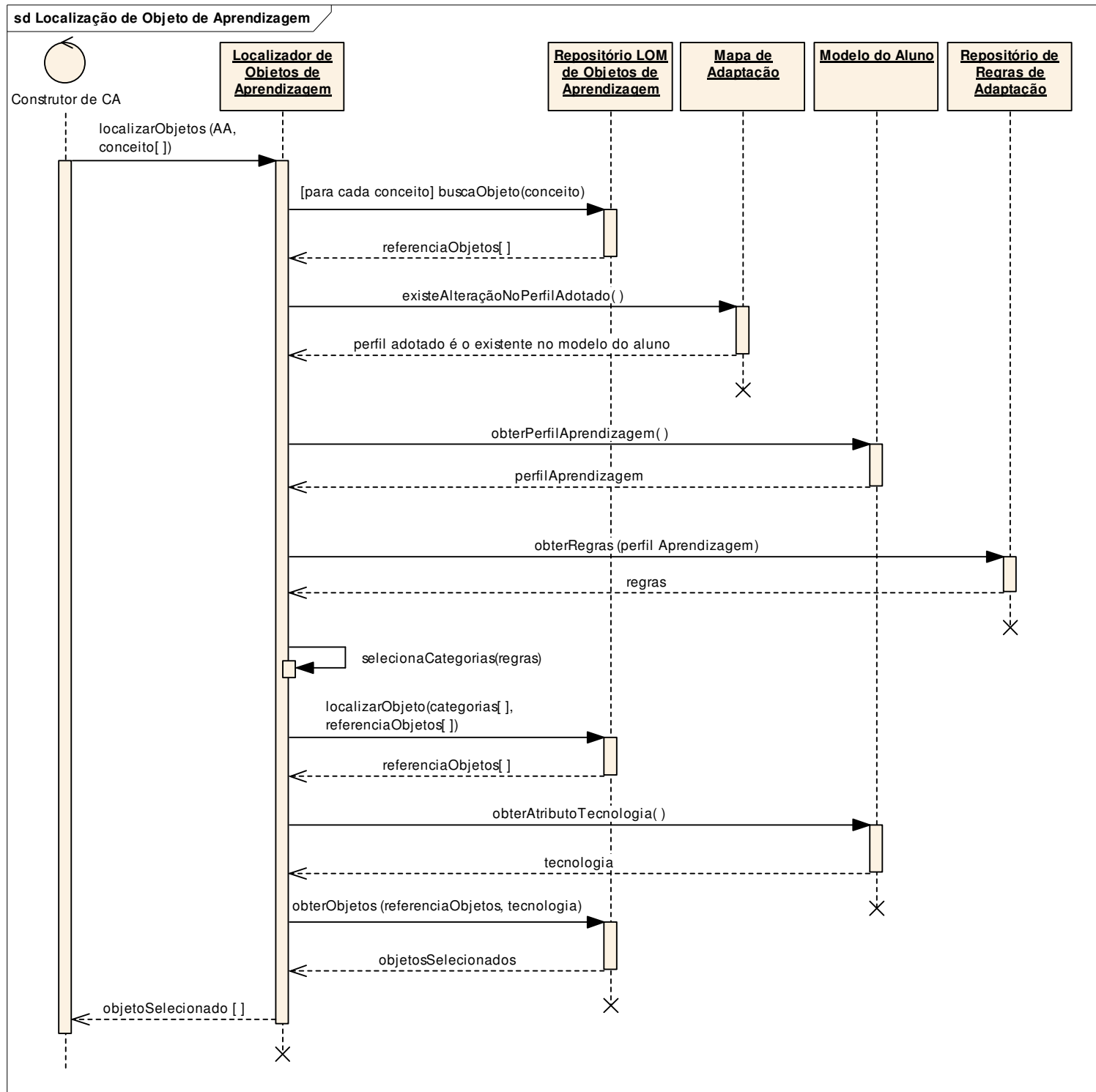

Figura 31 - Localização do objeto de aprendizagem

\subsubsection{Construção do Cenário de Aprendizagem}

A construção do CA é baseada no Modelo de CA que foi especificado segundo o padrão do Learning Design (Capítulo 4 - tópico 4.2). É realizada pelo submódulo do Módulo de Adaptação denominado de Construtor de CA. O Construtor chama o Localizador de Objetos de Aprendizagem para cada AA que faz parte da estrutura de atividades definida no Modelo do CA.

Todas as Categorias de Perfil são utilizadas para localização do objeto de aprendizagem menos a Categoria de Ordem-Apresentação do Conteúdo. Conforme 
abordado no Capítulo 2, esta categoria evidencia a forma lógica de sequenciamento das atividades.

O aluno que possui a característica ordem-apresentação seqüencial terá seu CA apresentado na forma progressiva. As AA somente serão liberadas para acesso de forma seqüencial. Isto será controlado através da entidade de notificação (notification) descrita no padrão do Learning Design utilizando o parâmetro de AA completada (on-completation). Quanto o aluno finalizar o acesso a uma dada AA a entidade de notificação enviará um evento indicando que a mesma foi completada e que é possível liberar o acesso a próxima AA. A Figura 32 apresenta a estrutura de CA com a característica seqüencial aplicada:

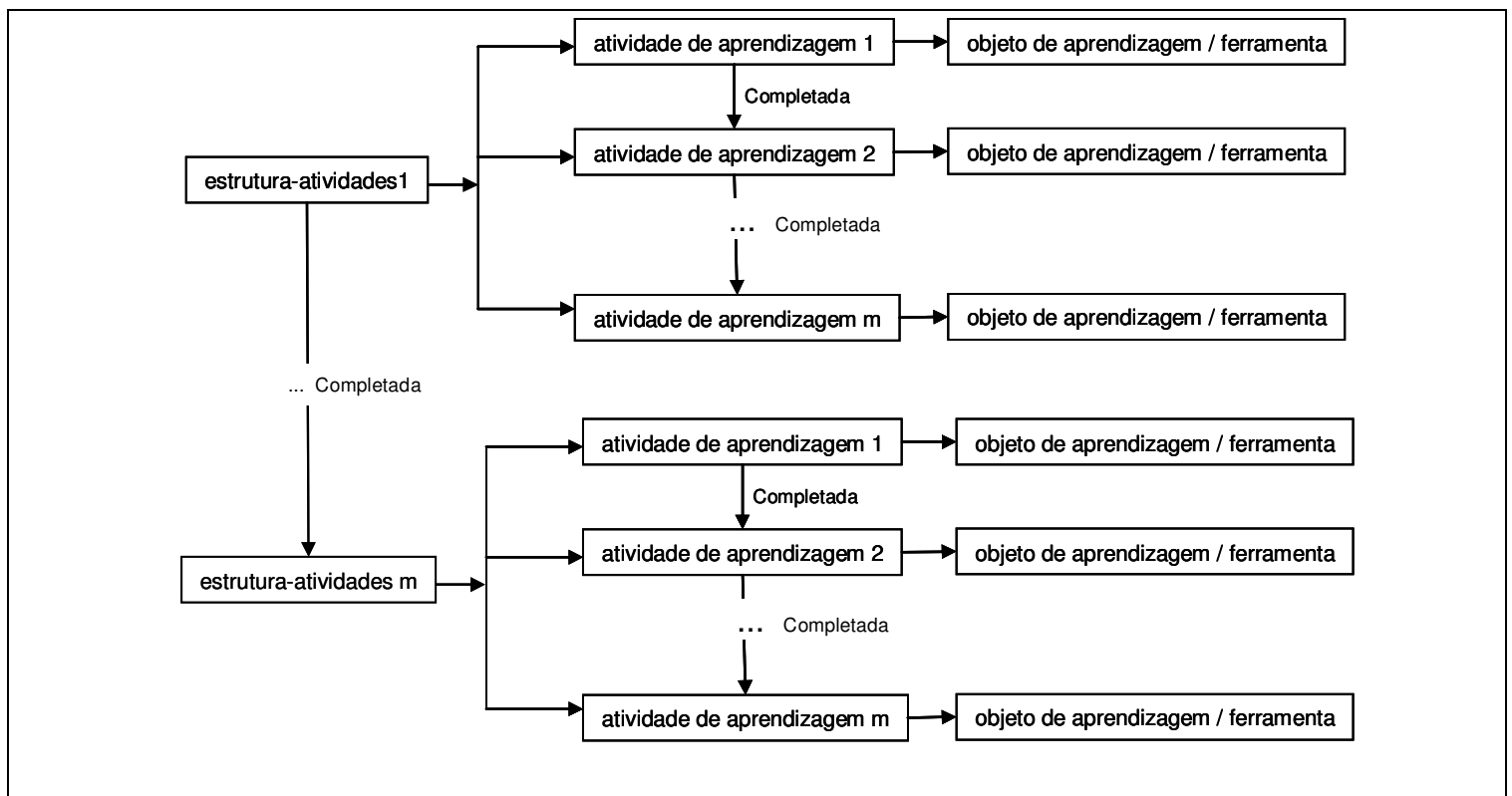

Figura 32 - Estrutura de um CA para perfil com característica seqüencial

Já no caso do aluno que possui a característica ordem-apresentação global não haverá controle de liberação de acesso das atividades. Todas as AA são apresentadas deixando a cargo do aluno o sequenciamento que ele achar mais adequado. Durante a construção do CA que será apresentado ao aluno são consideradas as questões de observação da interação do aprendiz conforme descrito no Capítulo 4 (Planejamento). Quando o planejamento da observação é feito, as AA que compõem o Modelo do CA recebem a sinalização de monitoramento quando estas são configuradas como monitoráveis (Capítulo 5 - tópico 5.6.2). Quando o Construtor de CA constrói o novo CA este terá todas as marcações de monitoração que foram planejadas anteriormente. 
A Figura 33 apresenta o diagrama de seqüência para construção de um CA considerado que o aluno possui uma característica de Ordem de Apresentação seqüencial.

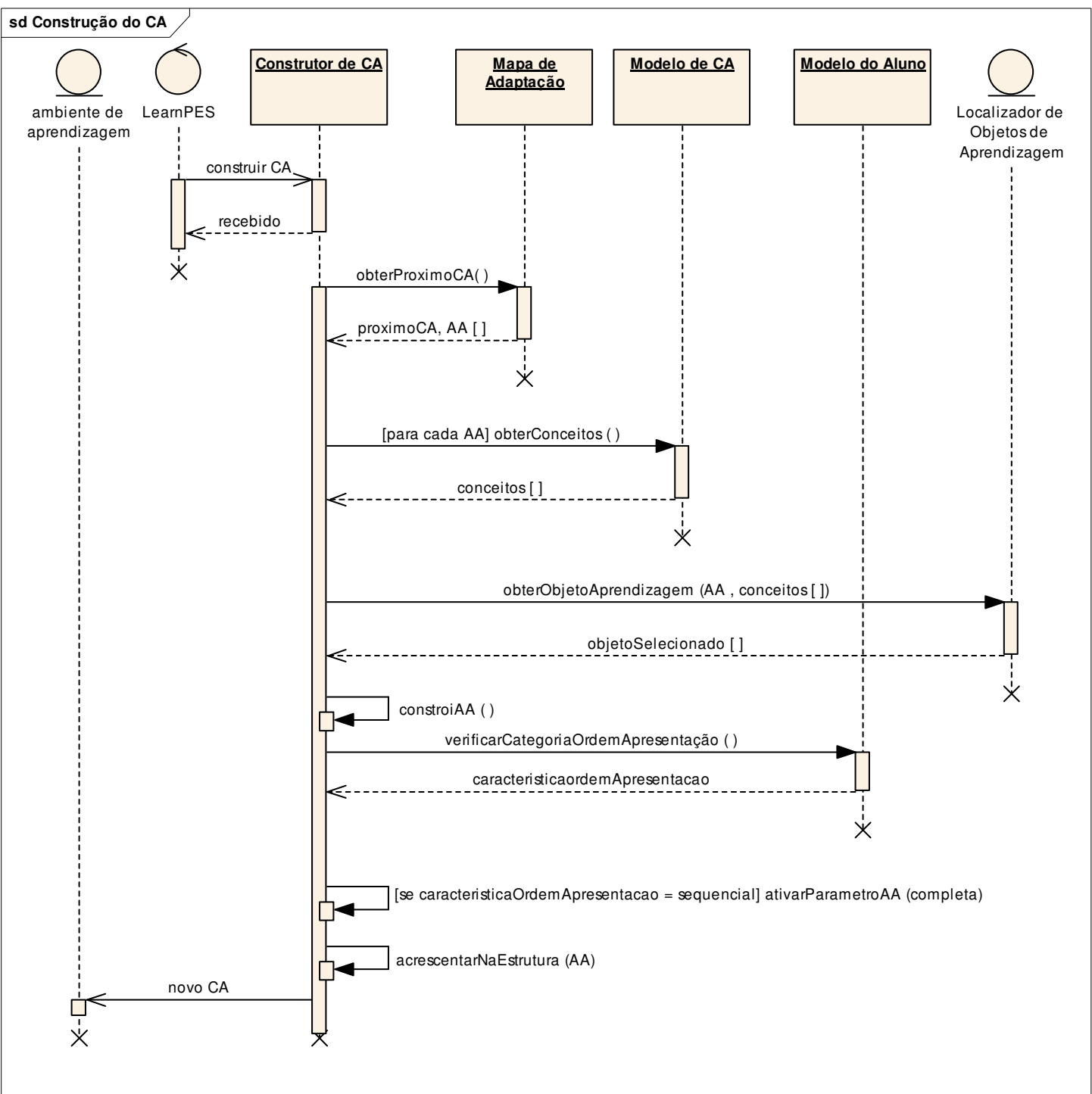

Figura 33 - Construção do CA para alunos com característica de ordem de apresentação seqüencial

\subsubsection{Modelo Conceitual do Módulo de Adaptação}

A Figura 34 apresenta o diagrama conceitual do Módulo de Adaptação e a interação deste com outras entidades da arquitetura: 


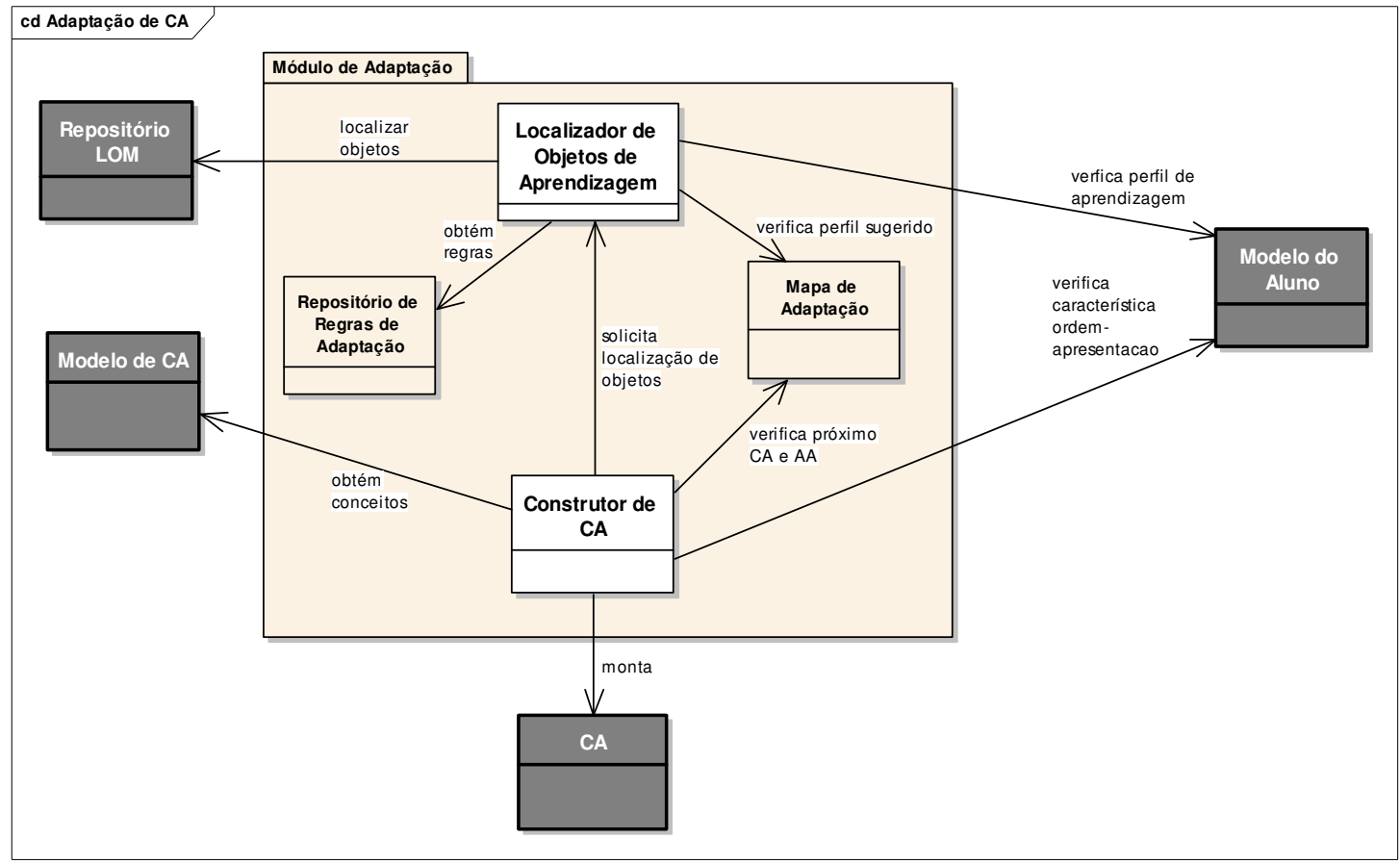

Figura 34 - Modelo conceitual do Módulo de Adaptação

\subsection{MODELO DO ALUNO INCORPORADO AO MODELO CONCEITUAL DO LEARNING DESIGN}

Considerando as entidades descritas neste trabalho é possível incorporar o modelo do aluno proposto ao modelo conceitual do padrão do Learning Design apresentado no Capítulo 3, relacionando as entidades já existentes no modelo com entidades referentes ao Modelo do Aluno.

A Figura 35 apresenta o modelo estendido, onde as entidades acrescentadas estão destacadas bem como as associações destas com as entidades pertencentes ao modelo original. Foram apresentadas apenas as entidades do modelo original necessárias para o entendimento.

É possível verificar que a entidade de notificação é responsável pela geração de atualizações no modelo do aluno já que esta será utilizada para sinalizar as atividades de aprendizagem que serão monitoráveis. Os objetos de aprendizagem são adotados de acordo com o Modelo do Aluno. Por conseqüência, as atividades de aprendizagem são apresentadas de acordo com este modelo. Um Modelo do Aluno está relacionado a um aprendiz. 


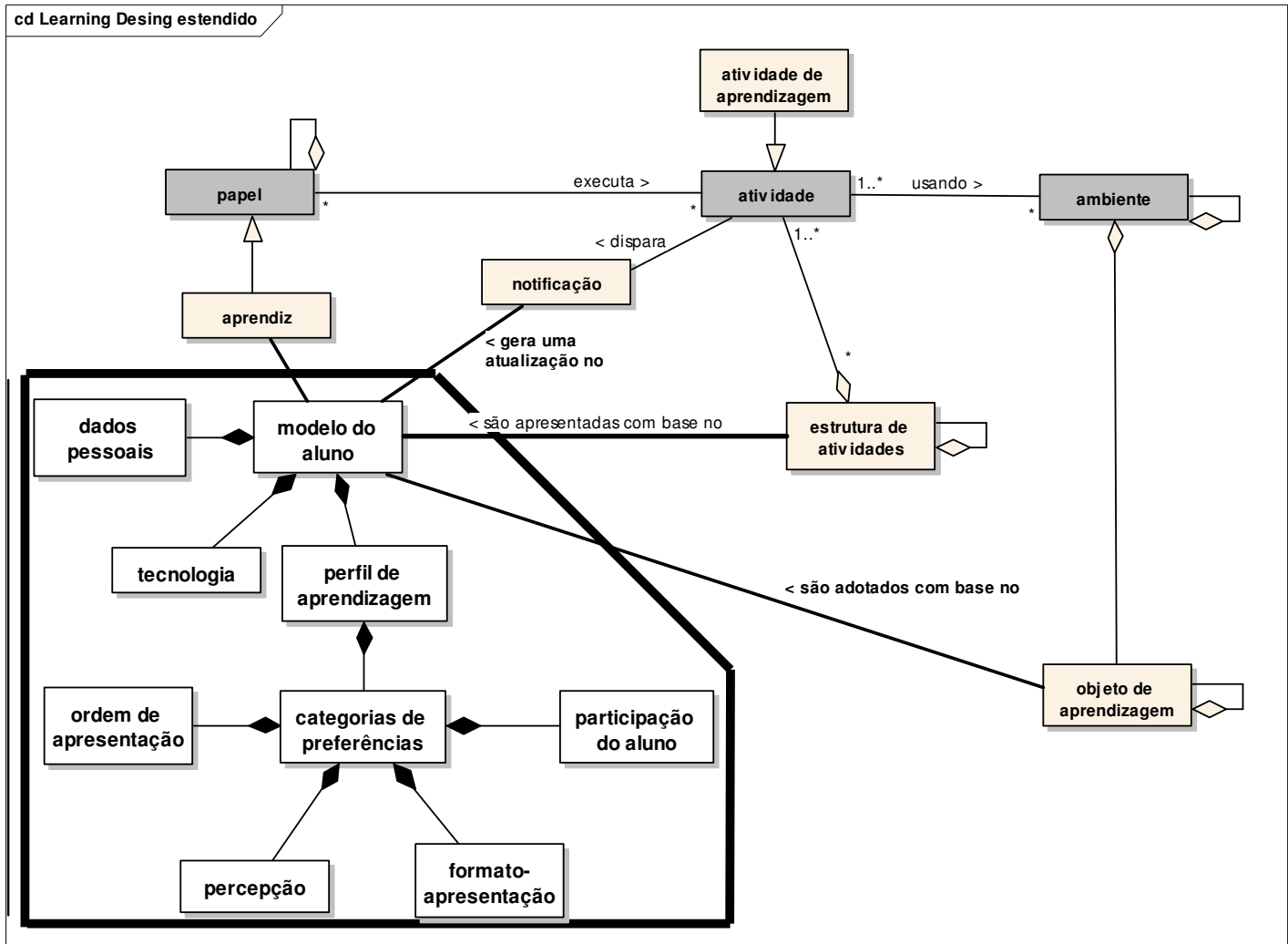

Figura 35 - Modelo do aluno incorporado ao modelo conceitual do Learning Design

\subsection{CONSIDERAÇÕES FINAIS}

A criação de diferentes Cenários de Aprendizagem considerando o perfil do aluno é um aspecto essencial para se atender às necessidades individuais dos alunos.

O acompanhamento das interações do aluno realizado através de primitivas de contexto permite que haja uma maior aderência entre o Modelo de Observação e a monitoração.

O relacionamento entre os dados que foram monitorados e os especificados nos exemplos de perfis cadastrados pode nem sempre convergir para um resultado exato. O uso do algoritmo do vizinho mais próximo permite que o perfil que está sendo analisado encontre um exemplo de perfil que seja mais adequado segundo os dados analisados.

Realizar o processo de adaptação do CA em conformidade com as informações do Modelo do Aluno permite não só prover o aluno com visões 
adequadas ao seu perfil, como também vincular as características observadas na interação do aluno com as estratégias de ensino adotadas. 


\section{ESTUDO DE CASO}

\subsection{CONSIDERAÇÕES INICIAIS}

Para demonstrar a aplicabilidade da proposta deste trabalho apresentada nos Capítulos 4, 5 e 6 será realizado um estudo de caso hipotético através da definição de um mini-curso. Durante a apresentação deste capítulo serão utilizados alguns protótipos de telas para ilustrar o funcionamento da arquitetura.

O estudo de caso será dividido em cinco passos, onde cada um deles será composto por atividades. A Figura 36 apresenta um diagrama de atividade descrevendo as etapas e suas respectivas atividades. Cada atividade será detalhada no decorrer deste capítulo.

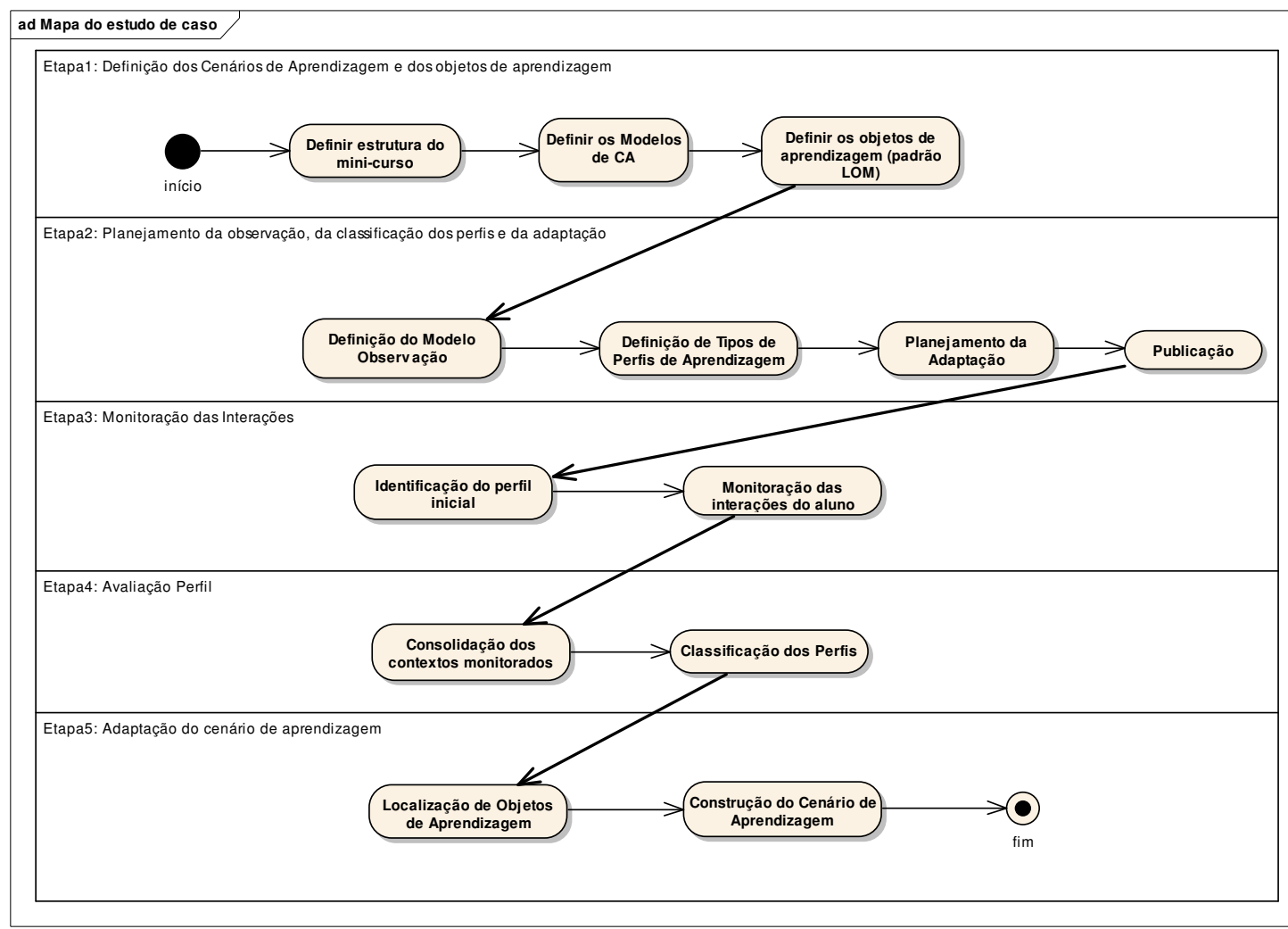

Figura 36 - Etapas que serão realizadas no estudo de caso 


\subsection{DEFINIÇÃO DOS CENÁRIOS DE APRENDIZAGEM E DOS OBJETOS DE APRENDIZAGEM}

Os modelos de cenários de aprendizagem que irão compor o mini-curso de "Conceitos de Linguagem de Programação" devem ser especificados segundo o padrão do Learning Design seguindo o modelo de Cenários de Aprendizagem de acordo com o que foi apresentado no Capítulo 4 (tópico 4.2).

É necessário definir as estruturas de atividades que compõem cada cenário bem como as atividades de aprendizagem. Conforme descrito no Capítulo 4, o elemento "item" irá conter apenas a descrição de um conceito relacionado à atividade, para que este seja utilizado na busca de objetos de aprendizagem posteriormente. Porém, quando a atividade de aprendizagem for suportada por uma ferramenta, como chat, fórum, etc, o elemento "item" deverá conter a referência para tal ferramenta.

A Tabela 25 apresenta a estrutura do mini-curso bem como os elementos que o compõe.

É possível observar que existem três $A A$ que possuem ferramentas associadas. Nestes casos, o elemento "item", passa a apontar para a ferramenta que deve ser referenciada quando o aluno estiver executando a AA.

Outro ponto importante é que existem objetos de aprendizagem que possam atender às atividades descritas. Os objetos devem ter sido catalogados segundo o padrão de especificação LOM. 
Tabela 25 - Estrutura do Mini-curso

\begin{tabular}{|c|c|c|c|c|}
\hline \multicolumn{5}{|c|}{ Mini curso: Conceitos de Linguagem de Programação } \\
\hline CA & Estrutura de Atividades & AA & Item & Ferramenta \\
\hline \multirow{12}{*}{$\begin{array}{l}\text { Estrutura da } \\
\text { Linguagem de } \\
\text { Programação }\end{array}$} & \multirow{5}{*}{$\begin{array}{l}\text { Estrutura_Introd_ } \\
\text { Ling_Progr }\end{array}$} & \multirow{4}{*}{$\begin{array}{l}\text { Propriedades de um } \\
\text { Projeto de Ling. de } \\
\text { Programação }\end{array}$} & Legibilidade & \\
\hline & & & Confiabilidade & \\
\hline & & & Portabilidade & \\
\hline & & & $\begin{array}{l}\text { Facilidade de } \\
\text { Aprendizado }\end{array}$ & \\
\hline & & $\begin{array}{l}\text { Paradigmas das } \\
\text { Linguagens de } \\
\text { Programação }\end{array}$ & Paradigmas_chat & chat \\
\hline & \multirow{7}{*}{$\begin{array}{c}\text { Estrutura_Ling_Progr_Expr } \\
\text { _Com }\end{array}$} & \multirow{7}{*}{$\begin{array}{l}\text { Expressões e } \\
\text { comandos }\end{array}$} & Operadores & \\
\hline & & & Tipos de dados & \\
\hline & & & $\begin{array}{c}\text { Estruturas } \\
\text { condicionais }\end{array}$ & \\
\hline & & & $\begin{array}{l}\text { Estruturas de } \\
\text { repetição }\end{array}$ & \\
\hline & & & $\begin{array}{l}\text { Tipos de } \\
\text { parâmetros }\end{array}$ & \\
\hline & & & Expr_forum & fórum \\
\hline & & & Expr_chat & chat \\
\hline \multirow{3}{*}{ Procedimentos } & \multirow{3}{*}{ Estrutura_Procedimentos } & $\begin{array}{l}\text { Passagem de } \\
\text { Parâmetros }\end{array}$ & $\begin{array}{l}\text { Passagem por valor } \\
\text { Passagem por } \\
\text { referência }\end{array}$ & \\
\hline & & Procedimentos e & Procedimentos & \\
\hline & & runçoes & $\begin{array}{l}\text { Rotinas que } \\
\text { retornam valor }\end{array}$ & \\
\hline \multirow{4}{*}{ Abstrações } & \multirow{4}{*}{ Estrutura_Abstracoes } & Reutilzação & Reuso de código & \\
\hline & & Manutenção & $\begin{array}{l}\text { Identificação de } \\
\text { modificações }\end{array}$ & \\
\hline & & \multirow{2}{*}{ Encapsulamento } & $\begin{array}{l}\text { Ocultamento das } \\
\text { informações }\end{array}$ & \\
\hline & & & $\begin{array}{c}\text { Grau de } \\
\text { encapsulamento }\end{array}$ & \\
\hline \multirow{5}{*}{$\begin{array}{l}\text { Tratamento de } \\
\text { exceções }\end{array}$} & \multirow{5}{*}{ Estrutura_Excecoes } & \multirow{2}{*}{ Tipos de exceções } & $\begin{array}{c}\text { Exceções } \\
\text { verificadas }\end{array}$ & \\
\hline & & & $\begin{array}{l}\text { Exceções não } \\
\text { verificadas }\end{array}$ & \\
\hline & & $\begin{array}{c}\text { Tratamento de } \\
\text { exceções }\end{array}$ & $\begin{array}{c}\text { Tratadores de } \\
\text { exceções }\end{array}$ & \\
\hline & & \multirow{2}{*}{$\begin{array}{l}\text { Lançamento de } \\
\text { exceções }\end{array}$} & $\begin{array}{l}\text { Lançamento de } \\
\text { exceção }\end{array}$ & \\
\hline & & & $\begin{array}{l}\text { Relançamento de } \\
\text { exceção }\end{array}$ & \\
\hline
\end{tabular}

\subsection{PLANEJAMENTO DA OBSERVAÇÃO, DA CLASSIFICAÇÃO DOS PERFIS E DA ADAPTAÇÃO}

O planejamento pode ser dividido em três pontos principais que são o planejamento do que se deseja observar, quais são os perfis que serão utilizados 
para a classificação e como será a adaptação segundo os cenários de aprendizagem e os perfis de aprendizagem descritos. A definição destes passos é realizada no Módulo de Planejamento.

\subsubsection{Definição do Modelo Observação}

A observação é realizada com base nos Cenários de Aprendizagem especificados.

O Modelo de Observação é definido com base nos modelos de Cenários especificados e nas características que se deseja observar. Conforme apresentado no Capítulo 5, o Modelo de Observação é constituído por um conjunto de Características Observáveis que definem o que de fato é relevante no acompanhamento do aluno.

Para cada Característica Observável devem ser cadastrados os dados sobre seu tipo, sua descrição, categoria a que ela pertence, local onde a mesma será observada e quando a observação irá acontecer. A Figura 37 apresenta um exemplo de cadastro de característica observável "Material Acessado":

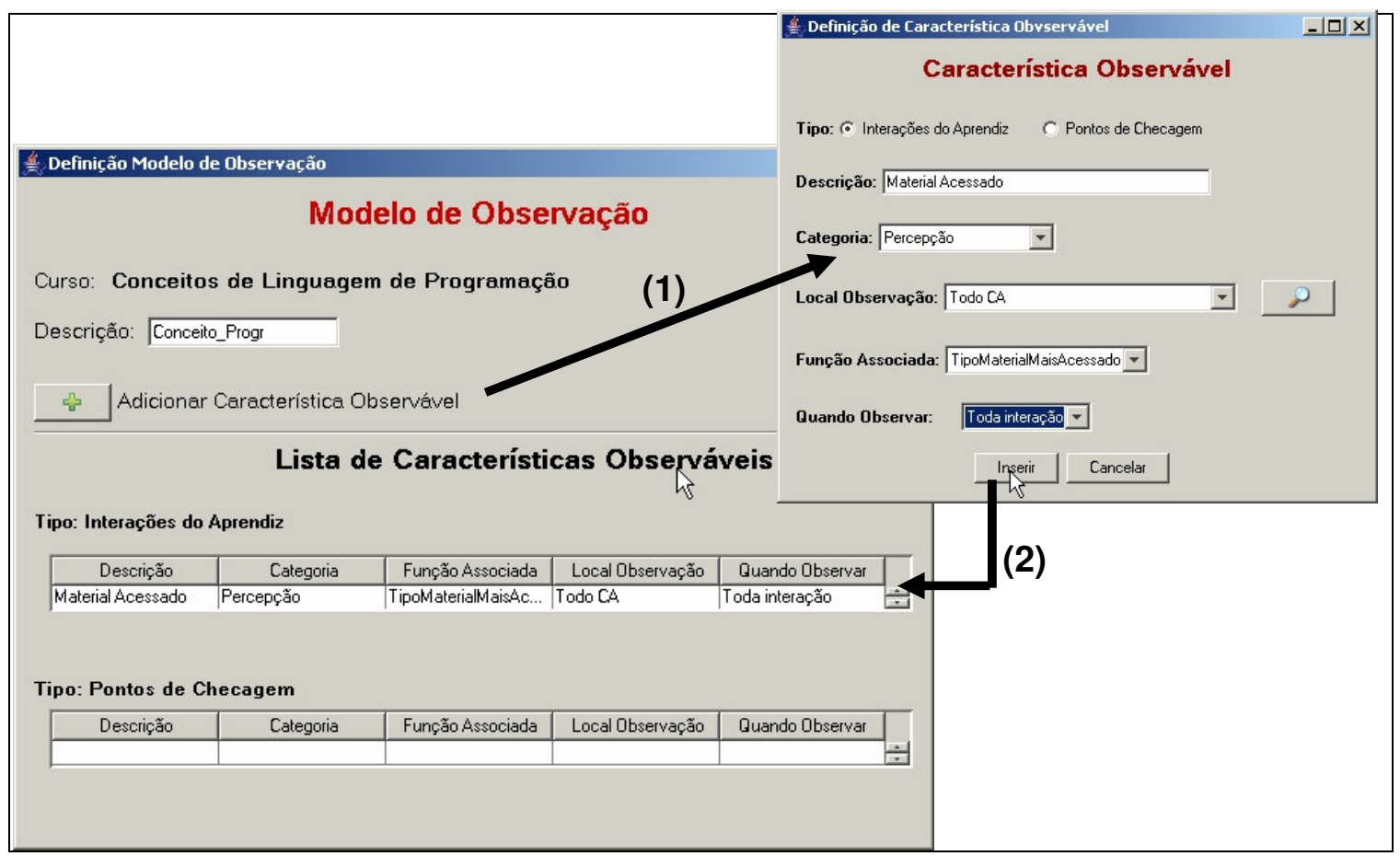

Figura 37 - Exemplo de cadastro de Característica Observável do tipo Interação do Aprendiz 
O campo "Função associada" apresenta um conjunto de funções existentes na Biblioteca de Função Auxiliares. O "Local Observação" permite escolher uma determinada estrutura de atividades ou uma atividade de aprendizagem, além da opção de acompanhamento por todo o CA.

Quando uma Característica Observável estiver relacionada a uma atividade de aprendizagem ligada a uma ferramenta, como por exemplo, a atividade "Paradigmas das Linguagens de Programação" (relacionada a uma ferramenta de chat), deve-se, durante o cadastro da característica, pesquisar quais são as características que podem ser monitoradas pela ferramenta (Figura 38). Esta pesquisa é realizada através do Pesquisador de Características Monitoráveis para Ferramentas apresentado no Capítulo 5 (Figura 10).

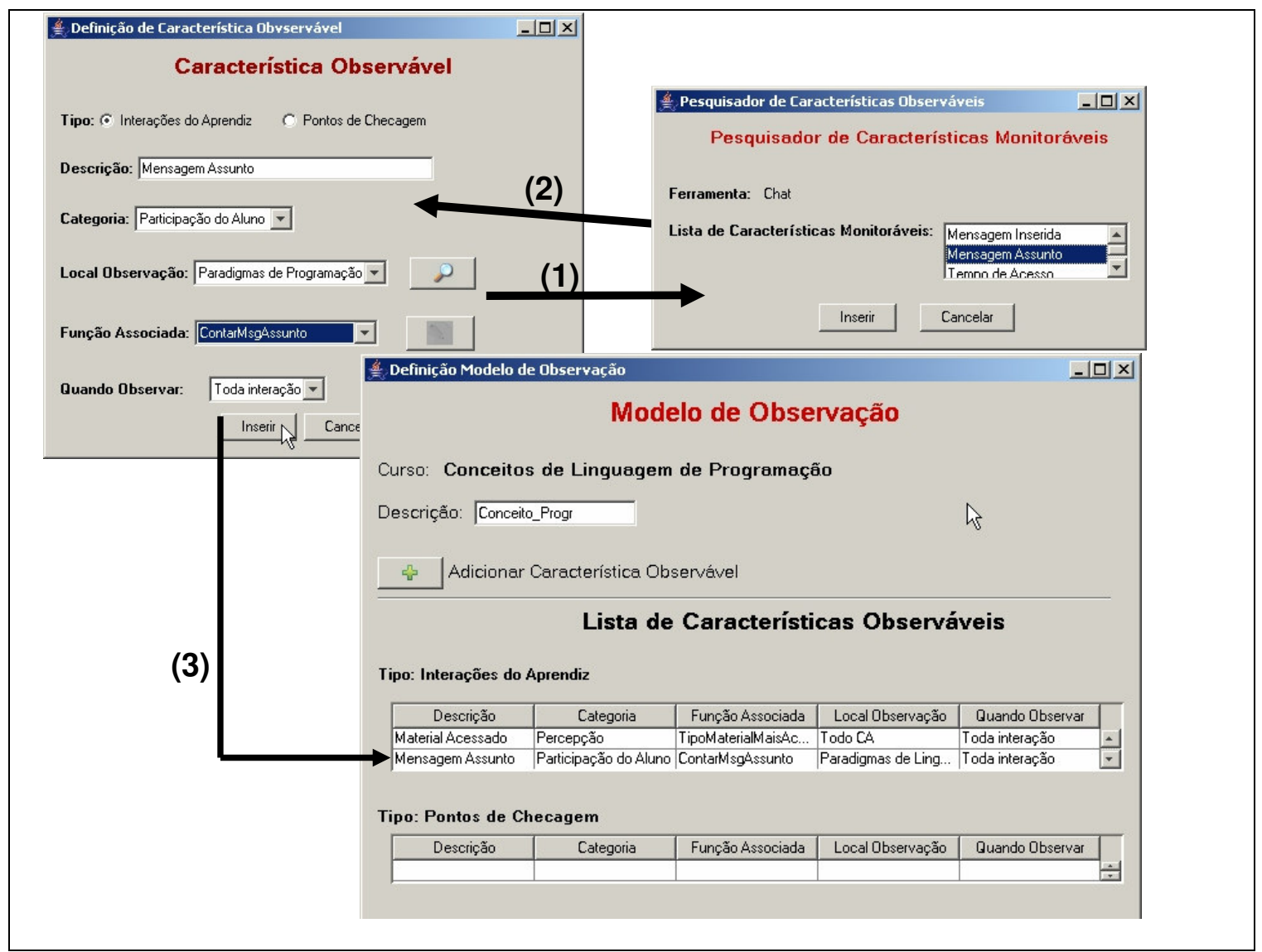

Figura 38 - Exemplo de cadastro de Característica Observável relacionada a uma ferramenta monitorável

Esse Pesquisador irá obter as informações através de um metadado descritor da ferramenta de quais são as características monitoráveis da ferramenta, conforme exemplo apresentado na Figura 39. 


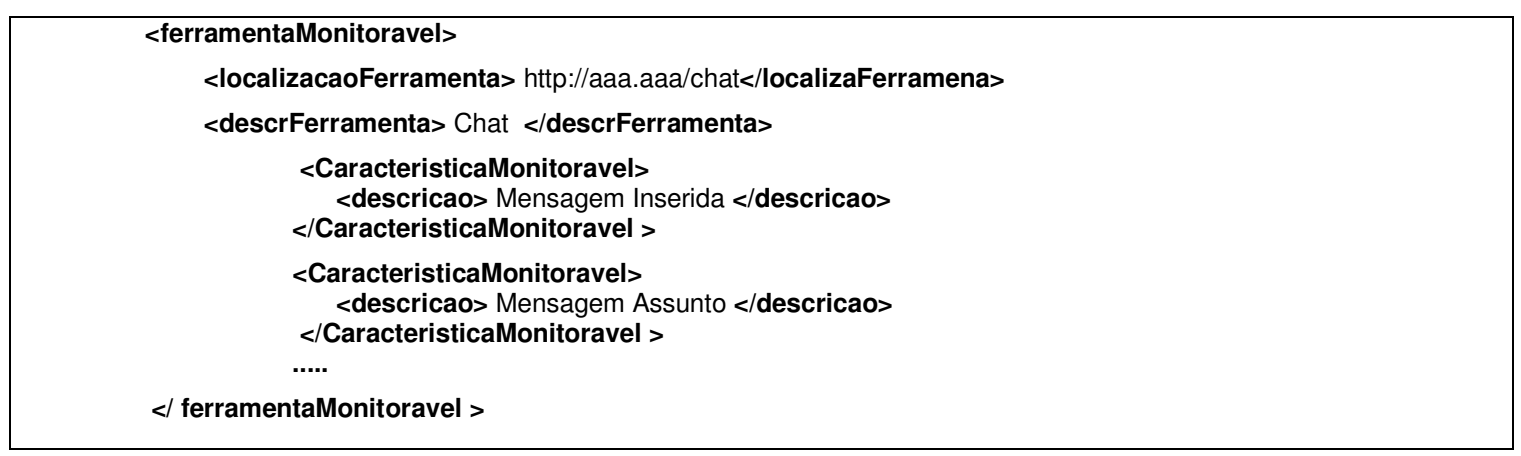

Figura 39 - Exemplo de metadado que descreve caracteristicas monitoráveis

No caso de inserção de pontos de checagem deve haver uma ferramenta de testes que possibilite cadastrar questões. Quando é selecionado o tipo Ponto de Checagem é ativado o ícone que permite acesso à ferramenta de cadastro de questões. A Figura 40 apresenta um exemplo de cadastro de Característica Observável do tipo Ponto de Checagem.

Para cada Característica Observável cadastrada no Modelo de Observação são geradas as variáveis de contexto, conforme descrito no Capítulo 5 (tópico 5.3.1), para que estas sejam enviadas posteriormente para o Módulo de Monitoração. O Apêndice A apresenta o exemplo de metadado gerado pelo Modelo de Observação segundo os exemplos de Características Observáveis descritos nas Figura 37, Figura 38 e Figura 40 .

A Tabela 26 apresenta todas as Características Observáveis do Modelo de Observação utilizado como exemplo. 


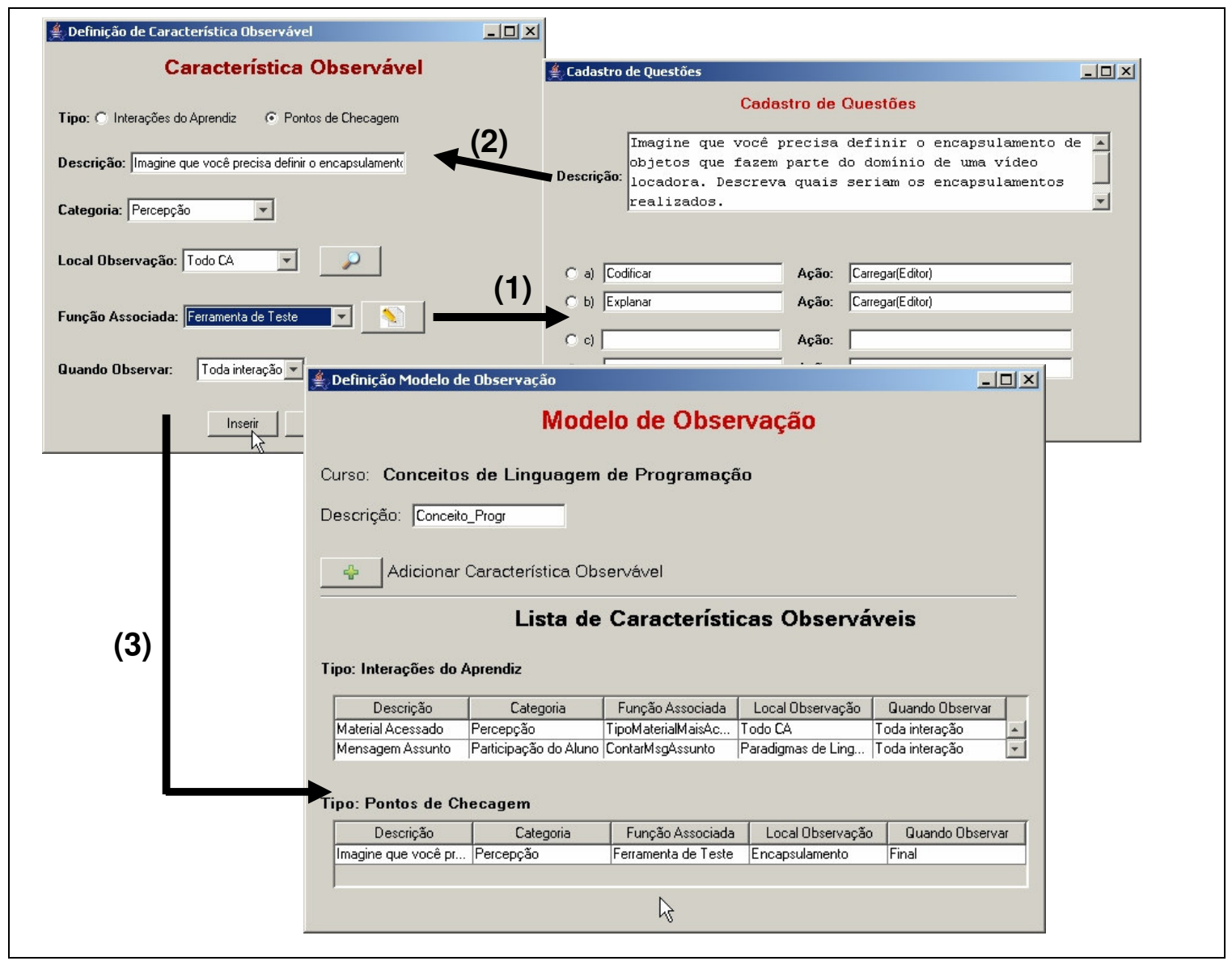

Figura 40 - Exemplo de cadastro de Característica Observável do tipo Ponto de Checagem

Tabela 26 - Modelo de Observação - Conceito_Progr

\begin{tabular}{|c|c|c|c|c|c|}
\hline Tipo & Descrição & Categoria & Função Associada & $\begin{array}{c}\text { Local } \\
\text { Observação }\end{array}$ & $\begin{array}{l}\text { Quando } \\
\text { Observar }\end{array}$ \\
\hline \multirow{7}{*}{ 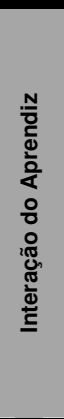 } & Mídia Acessada & $\begin{array}{c}\text { Formato- } \\
\text { Apresentação }\end{array}$ & TipoMidiaMaisAcessada & Todo CA & $\begin{array}{c}\text { Toda } \\
\text { interação }\end{array}$ \\
\hline & Material Acessado & Percepção & TipoMaterialMaisAcessado & Todo CA & $\begin{array}{c}\text { Toda } \\
\text { interacão }\end{array}$ \\
\hline & Mensagem inserida (fórum) & $\begin{array}{l}\text { Participação do } \\
\text { Aluno }\end{array}$ & ContarMsg & $\begin{array}{c}\text { Expressões e } \\
\text { comandos }\end{array}$ & $\begin{array}{c}\text { Toda } \\
\text { interação }\end{array}$ \\
\hline & Mensagem inserida (chat) & $\begin{array}{l}\text { Participação do } \\
\text { Aluno } \\
\end{array}$ & ContarMsg & $\begin{array}{c}\text { Expressões e } \\
\text { comandos }\end{array}$ & $\begin{array}{c}\text { Toda } \\
\text { interação }\end{array}$ \\
\hline & $\begin{array}{l}\text { Mensagem assunto } \\
\text { (chat) }\end{array}$ & $\begin{array}{l}\text { Participação do } \\
\text { Aluno }\end{array}$ & ContarMsgAssunto & $\begin{array}{l}\text { Paradigmas de } \\
\text { Linguagem de } \\
\text { Programação }\end{array}$ & $\begin{array}{l}\text { Toda } \\
\text { interação }\end{array}$ \\
\hline & $\begin{array}{l}\begin{array}{l}\text { Mensagem assunto } \\
\text { (fórum) }\end{array} \\
\end{array}$ & Percepção & ContarMsgAssunto & $\begin{array}{c}\text { Expressões e } \\
\text { comandos }\end{array}$ & $\begin{array}{c}\text { Toda } \\
\text { interação }\end{array}$ \\
\hline & Exercício acessado & Percepção & TipoExercícioMaisAcessado & Todo CA & $\begin{array}{c}\text { Toda } \\
\text { interação }\end{array}$ \\
\hline \multirow{3}{*}{ 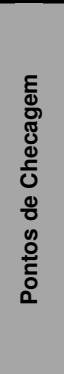 } & $\begin{array}{l}\text { Imagine que você precisa } \\
\text { definir o encapsulamento... }\end{array}$ & Percepção & Ferramenta de teste & Encapsulamento & Final \\
\hline & $\begin{array}{l}\text { Você gostaria de estudar o } \\
\text { assunto através de um } \\
\text { estudo de caso prático, um } \\
\text { artigo teórico ou através da } \\
\text { comparação com outras } \\
\text { estruturas? }\end{array}$ & Percepção & Ferramenta de teste & $\begin{array}{l}\text { Expressões e } \\
\text { comandos }\end{array}$ & Início \\
\hline & $\begin{array}{l}\text { Você gostaria de estudar o } \\
\text { assunto através de um } \\
\text { estudo de caso prático, um } \\
\text { artigo teórico ou através da } \\
\text { comparação com outras } \\
\text { estruturas? }\end{array}$ & Percepção & Ferramenta de teste & $\begin{array}{l}\text { Tratamento de } \\
\text { exceções }\end{array}$ & Início \\
\hline
\end{tabular}




\subsubsection{Definição de Tipos de Perfis de Aprendizagem}

Após planejar o Modelo de Observação é necessário definir os tipos de perfis que serão utilizados durante o processo de classificação do aluno. Os tipos são especificados a partir do Modelo de Observação criando valores para cada Característica Observável de forma de que estas possam ser diferenciadas entre os tipos definidos.

A Figura 41 apresenta um exemplo de especificação de tipos de perfis baseados no Modelo de Observação definido na Tabela 26. A partir da escolha do Modelo de Observação é possível definir os tipos de perfis. Para cada tipo de perfil definido devem ser especificadas as categorias de preferências que este perfil está refletindo e os valores de cada característica observável.

O exemplo apresenta a definição de um perfil "Pragmático" onde será observado se o aluno possui características que indiquem tal perfil. É possível observar que para a categoria de preferência ordem-apresentação não foi indicado nenhum elemento. Isto significa que tal categoria não será considerada para este tipo de perfil. A precedência é colocada automaticamente, porém esta pode ser alterada pelo docente. Conforme apresentado no Capítulo 5, a precedência é utilizada quando há empate durante a identicação do tipo de perfil de um dado aluno.

É possível alterar um perfil já cadastrado selecionando o mesmo e clicando no botão de alterar.

A Tabela 27, Tabela 28 e Tabela 29 apresentam os tipos de perfis cadastrados a partir do Modelo de Observação planejando na Tabela 26. A visão dos tipos de perfis pode ser observada na Figura 42. 


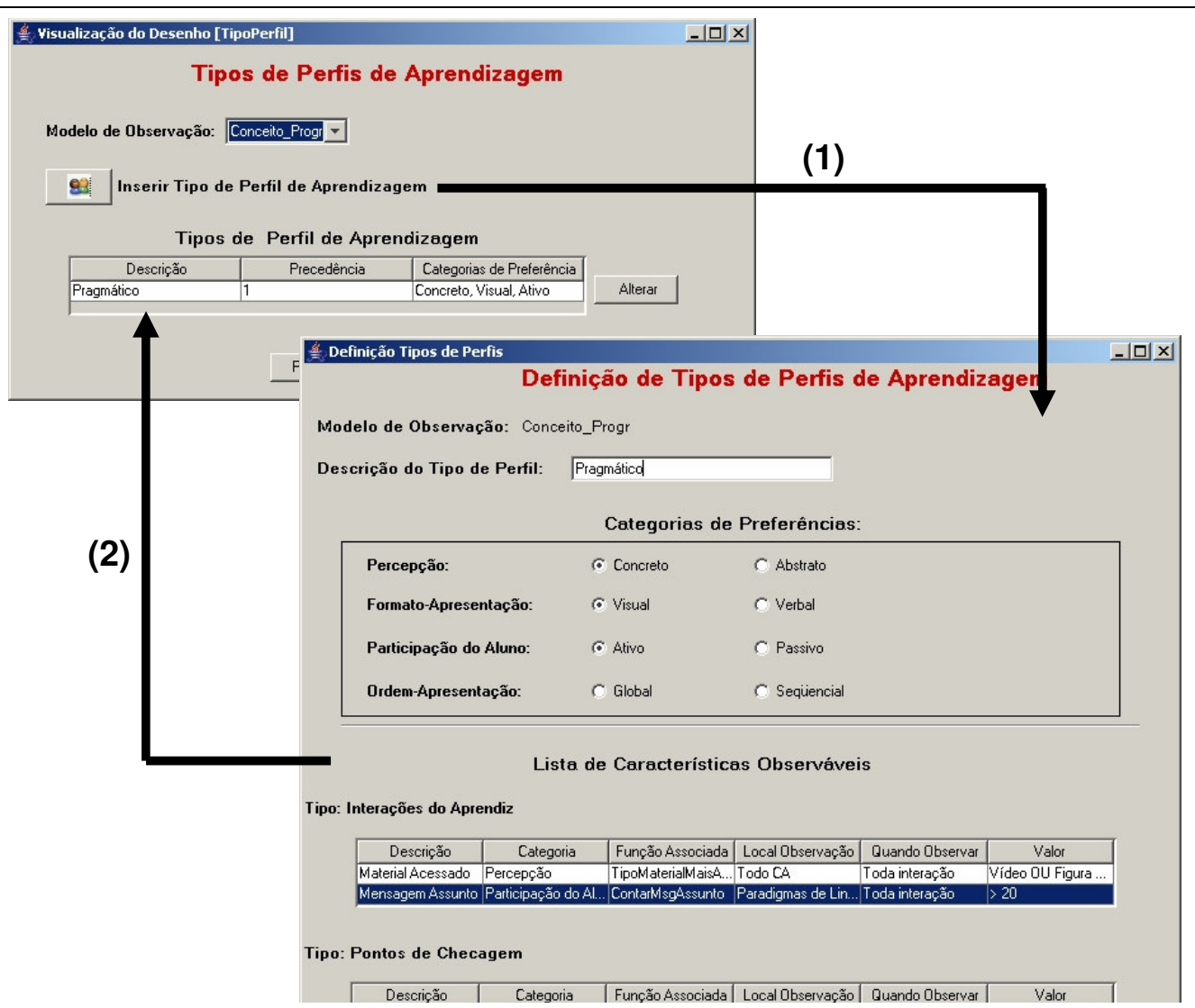

Figura 41 - Exemplo de cadastro de Tipo de Perfil de Aprendizagem

Tabela 27 - Tipo de Perfil Pragmático - Conceito_Progr

\begin{tabular}{|c|c|c|c|c|}
\hline Тіро & Descrição & Categoria & Função Associada & Valor \\
\hline \multirow{7}{*}{ 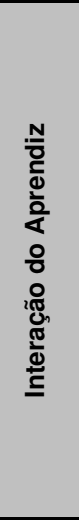 } & Mídia Acessada & $\begin{array}{c}\text { Formato- } \\
\text { Apresentação }\end{array}$ & TipoMidiaMaisAcessada & $\begin{array}{l}\text { Figura OU } \\
\text { Vídeo }\end{array}$ \\
\hline & $\begin{array}{c}\text { Material } \\
\text { Acessado }\end{array}$ & Percepção & TipoMaterialMaisAcessado & exemplo \\
\hline & $\begin{array}{c}\text { Mensagem } \\
\text { inserida (fórum) }\end{array}$ & $\begin{array}{c}\text { Participação } \\
\text { do Aluno }\end{array}$ & ContarMsg & $>10$ \\
\hline & $\begin{array}{c}\text { Mensagem } \\
\text { inserida (chat) }\end{array}$ & $\begin{array}{l}\text { Participação } \\
\text { do Aluno }\end{array}$ & ContarMsg & $>=50$ \\
\hline & $\begin{array}{c}\text { Mensagem } \\
\text { assunto } \\
\text { (chat) }\end{array}$ & $\begin{array}{l}\text { Participação } \\
\text { do Aluno }\end{array}$ & ContarMsgAssunto & $\begin{array}{l}\text { Exemplos } \\
\text { Práticos }\end{array}$ \\
\hline & $\begin{array}{l}\text { Mensagem } \\
\text { assunto } \\
\text { (fórum) }\end{array}$ & Percepção & ContarMsgAssunto & $\begin{array}{l}\text { Exemplos } \\
\text { Práticos }\end{array}$ \\
\hline & $\begin{array}{l}\text { Exercício } \\
\text { acessado }\end{array}$ & Percepção & TipoExercícioMaisAcessado & Estudo de caso \\
\hline \multirow{3}{*}{ 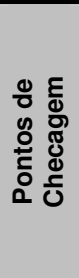 } & $\begin{array}{l}\text { Imagine que você } \\
\text { precisa definir o } \\
\text { encapsulamento... }\end{array}$ & Percepção & Ferramenta de teste & a \\
\hline & $\begin{array}{c}\text { Você gostaria de } \\
\text { estudar o } \\
\text { assunto.. } \\
\end{array}$ & Percepção & Ferramenta de teste & a \\
\hline & $\begin{array}{l}\text { Você gostaria de } \\
\text { estudar o } \\
\text { assunto... }\end{array}$ & Percepção & Ferramenta de teste & a \\
\hline
\end{tabular}


Tabela 28 - Tipo de Perfil Reflexivo - Conceito_Progr

\begin{tabular}{|c|c|c|c|c|}
\hline Tiро & Descrição & Categoria & Função Associada & Valor \\
\hline \multirow{7}{*}{ 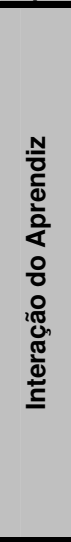 } & Mídia Acessada & $\begin{array}{c}\text { Formato- } \\
\text { Apresentação }\end{array}$ & TipoMidiaMaisAcessada & $\begin{array}{l}\text { Figura OU } \\
\text { Vídeo }\end{array}$ \\
\hline & $\begin{array}{c}\text { Material } \\
\text { Acessado }\end{array}$ & Percepção & TipoMaterialMaisAcessado & artigo \\
\hline & $\begin{array}{c}\text { Mensagem } \\
\text { inserida (fórum) }\end{array}$ & $\begin{array}{l}\text { Participação } \\
\text { do Aluno }\end{array}$ & ContarMsg & $<10$ \\
\hline & $\begin{array}{c}\text { Mensagem } \\
\text { inserida (chat) }\end{array}$ & $\begin{array}{l}\text { Participação } \\
\text { do Aluno }\end{array}$ & ContarMsg & $<50$ \\
\hline & $\begin{array}{c}\text { Mensagem } \\
\text { assunto } \\
\text { (chat) }\end{array}$ & $\begin{array}{c}\text { Participação } \\
\text { do Aluno }\end{array}$ & ContarMsgAssunto & $\begin{array}{c}\text { Comparação } \\
\text { entre } \\
\text { paradigmas }\end{array}$ \\
\hline & $\begin{array}{l}\text { Mensagem } \\
\text { assunto } \\
\text { (fórum) }\end{array}$ & Percepção & ContarMsgAssunto & $\begin{array}{l}\text { Comparação } \\
\text { entre estruturas }\end{array}$ \\
\hline & $\begin{array}{l}\text { Exercício } \\
\text { acessado }\end{array}$ & Percepção & TipoExercícioMaisAcessado & expositivo \\
\hline \multirow{3}{*}{ 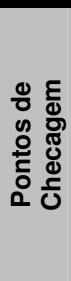 } & $\begin{array}{l}\text { Imagine que você } \\
\text { precisa definir o } \\
\text { encapsulamento... }\end{array}$ & Percepção & Ferramenta de teste & $b$ \\
\hline & $\begin{array}{l}\text { Você gostaria de } \\
\text { estudar o } \\
\text { assunto... }\end{array}$ & Percepção & Ferramenta de teste & c \\
\hline & $\begin{array}{l}\text { Você gostaria de } \\
\text { estudar o } \\
\text { assunto... }\end{array}$ & Percepção & Ferramenta de teste & c \\
\hline
\end{tabular}

Tabela 29 - Tipo de Perfil Teórico - Conceito_Progr

\begin{tabular}{|c|c|c|c|c|}
\hline Tipo & Descrição & Categoria & Função Associada & Valor \\
\hline \multirow{7}{*}{ 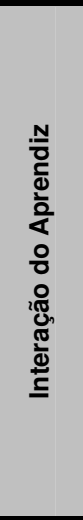 } & Mídia Acessada & $\begin{array}{c}\text { Formato- } \\
\text { Apresentação }\end{array}$ & TipoMidiaMaisAcessada & Texto OU Som \\
\hline & $\begin{array}{c}\text { Material } \\
\text { Acessado }\end{array}$ & Percepção & TipoMaterialMaisAcessado & texto \\
\hline & $\begin{array}{c}\text { Mensagem } \\
\text { inserida (fórum) }\end{array}$ & $\begin{array}{c}\text { Participação } \\
\text { do Aluno }\end{array}$ & ContarMsg & $>10$ \\
\hline & $\begin{array}{c}\text { Mensagem } \\
\text { inserida (chat) }\end{array}$ & $\begin{array}{l}\text { Participação } \\
\text { do Aluno }\end{array}$ & ContarMsg & $>=50$ \\
\hline & $\begin{array}{c}\text { Mensagem } \\
\text { assunto } \\
\text { (chat) }\end{array}$ & $\begin{array}{l}\text { Participação } \\
\text { do Aluno }\end{array}$ & ContarMsgAssunto & $\begin{array}{l}\text { Definição de } \\
\text { conceitos dos } \\
\text { paradigmas }\end{array}$ \\
\hline & $\begin{array}{l}\text { Mensagem } \\
\text { assunto } \\
\text { (fórum) }\end{array}$ & Percepção & ContarMsgAssunto & $\begin{array}{c}\text { Definição das } \\
\text { estruturas }\end{array}$ \\
\hline & $\begin{array}{l}\text { Exercício } \\
\text { acessado }\end{array}$ & Percepção & TipoExercícioMaisAcessado & expositivo \\
\hline \multirow{3}{*}{ 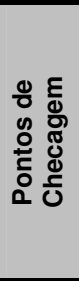 } & $\begin{array}{l}\text { Imagine que você } \\
\text { precisa definir o } \\
\text { encapsulamento... }\end{array}$ & Percepção & Ferramenta de teste & $b$ \\
\hline & $\begin{array}{l}\text { Você gostaria de } \\
\text { estudar o } \\
\text { assunto... } \\
\end{array}$ & Percepção & Ferramenta de teste & b \\
\hline & $\begin{array}{l}\text { Você gostaria de } \\
\text { estudar o } \\
\text { assunto... }\end{array}$ & Percepção & Ferramenta de teste & b \\
\hline
\end{tabular}




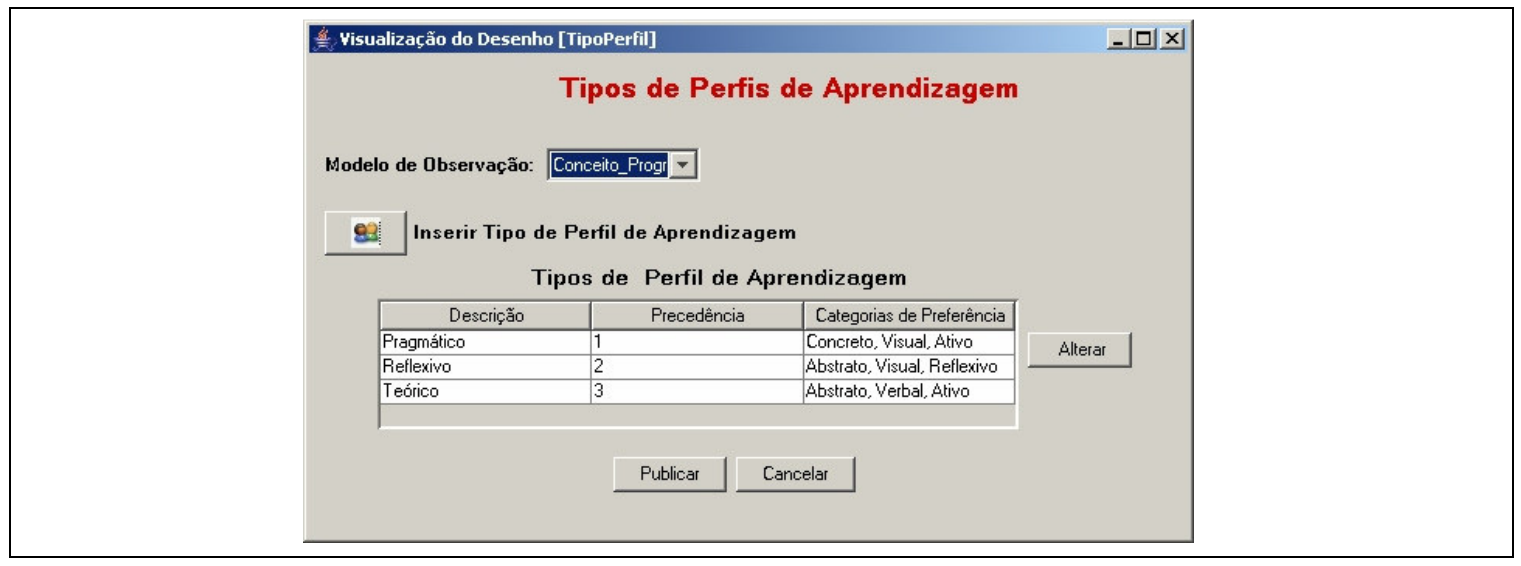

Figura 42 -Tipos de Perfil de Aprendizagem Cadastrados

Os tipos de perfil cadastrados serão posteriormente comparados com as informações do Modelo do Aluno para que então seja sugerido o perfil de aprendizagem do estudante.

\subsubsection{Planejamento da Adaptação}

Caso o docente deseje, ele pode realizar modificações no Mapa de Adaptação. Por padrão o mapa considera a estrutura dos Cenários de Aprendizagem definidos bem como a ordem das atividades que foram definidas. Porém, é possível alterar o tipo de perfil adotado para uma dada atividade de aprendizagem. De acordo com o que foi descrito no Capítulo 5 (tópico 5.5.1), o docente pode considerar importante oferecer ao aluno estratégias de aprendizagem que estejam relacionadas a um tipo de perfil, desconsiderando o perfil sugerido pelo ambiente durante o processo de classificação de perfis.

A Figura 43 demonstra a alteração do Mapa de Adaptação padrão. O perfil adotado na atividade de aprendizagem "Passagem de Parâmetros" é configurado como "Teórico". Isto significa que quando o aluno estiver interagindo na AA seu perfil será considerando "Teórico" independente do resultado que tenha sido obtido durante a classificação dos perfis de aprendizagem. 


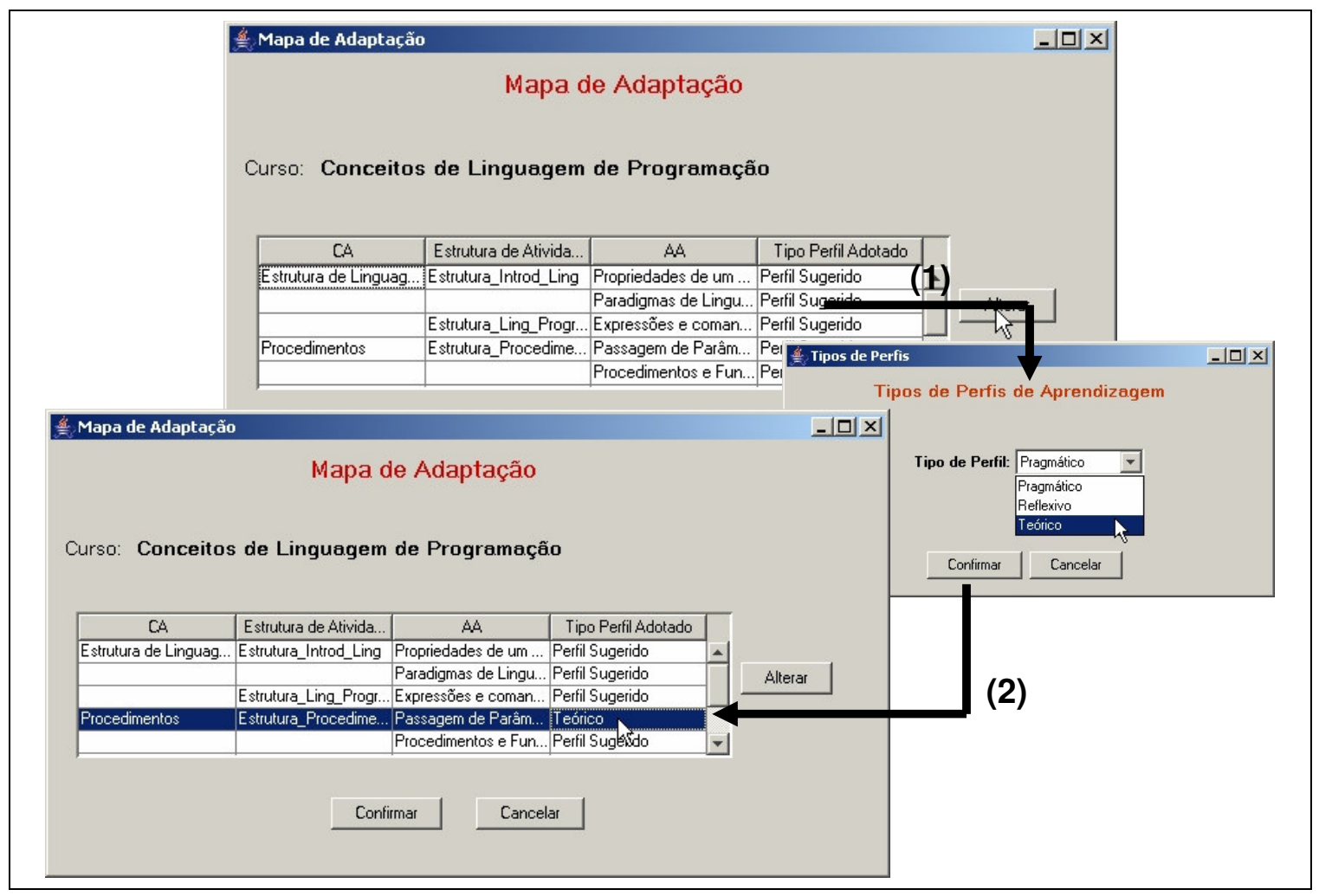

Figura 43 - Alteração do tipo de perfil adotado pelo Mapa de Adaptação

\subsubsection{Publicação}

A publicação do planejamento desencadeia um processo de preparação para o acompanhamento das interações do aluno com o ambiente de aprendizagem eletrônica. A publicação irá realizar os seguintes processos:

- Envio das variáveis de contexto para o Módulo de Monitoração: as variáveis são geradas a partir das Características Observáveis cadastradas, conforme apresentado no tópico 7.3.1.

- Marcação das AA monitoráveis: as atividades de aprendizagem que são monitoráveis são sinalizadas através da entidade de notificação, conforme modelo apresentado no Capítulo 5 (Figura 19). A Figura 44 apresenta um exemplo de AA monitorável para características do tipo Interações do Aprendiz e a Figura 45 apresenta um exemplo para Pontos de Checagem. Os exemplos consideram as AA descritas durante a definição dos cenários de aprendizagem (tópico 7.2) neste Capítulo. 
- Geração do repositório de contexto: é gerado um repositório de contexto que irá armazenar as informações de contexto obtidas pelo Módulo de Monitoração.

- Geração das regras de adaptação: as regras são geradas com base nos tipos de perfis de aprendizagem cadastrados e serão utilizadas posteriormente para construção do CA que será apresentado ao aluno segundo o perfil de aprendizagem identificado. A Tabela 30 apresenta as regras de adaptação geradas a partir do exemplo apresentado no tópico 7.3.2.

- Atualização do modelo do aluno: o componente de Categorias de Preferências que retrata as categorias utilizadas no acompanhamento e identificação do perfil do aprendiz é atualizado segundo o Modelo de Observação planejado. A Tabela 31 apresenta o componente Categorias de Preferências do Modelo do Aluno atualizado considerando o Modelo de Observação descrito na Tabela 26.

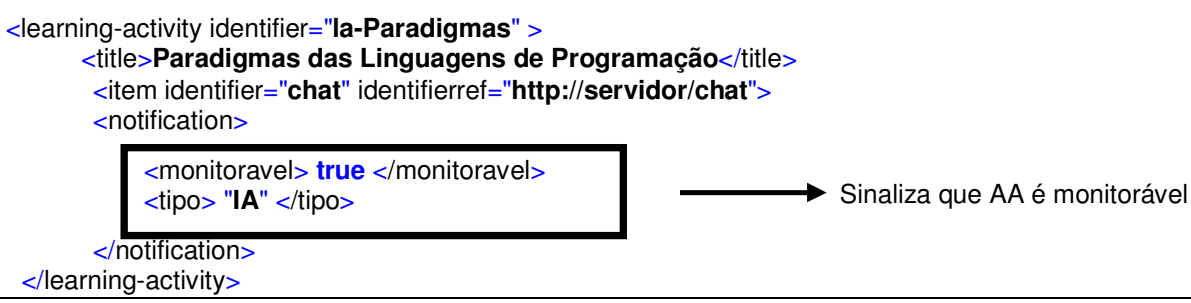

Figura 44 - Sinalização de AA do tipo interações do aprendiz monitorável

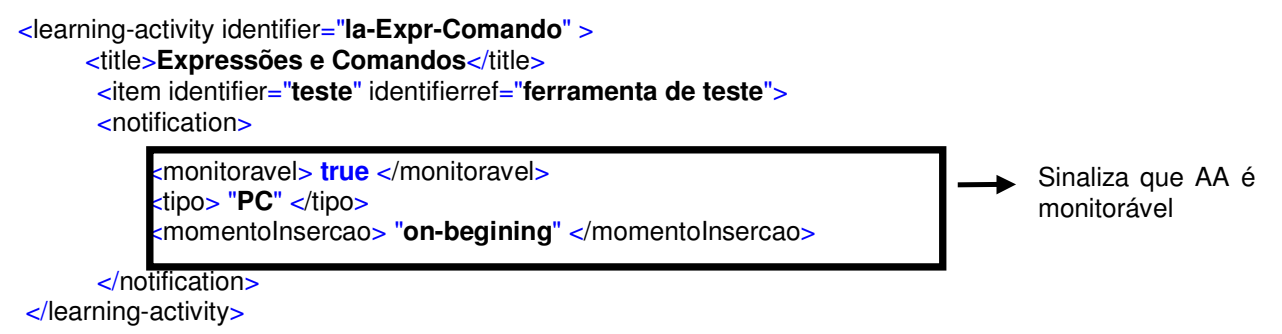

Figura 45 - Sinalização de AA do tipo ponto de checagem monitorável 
Tabela 30 - Regras de Adaptação

\begin{tabular}{|c|c|c|}
\hline $\begin{array}{c}\text { Tipo de Perfil de } \\
\text { Aprendizagem }\end{array}$ & Categoria de Preferência & Valor \\
\hline \multirow{3}{*}{ Pragmático } & Formato-Apresentação & Visual \\
\cline { 2 - 3 } & Participação do Aluno & Ativa \\
\cline { 2 - 3 } & Percepção & Concreto \\
\hline \multirow{2}{*}{ Reflexivo } & Formato-Apresentação & Visual \\
\cline { 2 - 3 } & Participação do Aluno & Passiva \\
\cline { 2 - 3 } & Percepção & Abstrato \\
\hline \multirow{2}{*}{ Teórico } & Formato-Apresentação & Verbal \\
\cline { 2 - 3 } & Participação do Aluno & Ativo \\
\cline { 2 - 3 } & Percepção & Abstrato \\
\hline
\end{tabular}

Tabela 31 - Categorias de Preferências do Modelo do Aluno

\begin{tabular}{|c|c|}
\hline Categorias de Preferências & Característica Observávael \\
\hline Formato-Apresentação & Mídia Acessada \\
\hline \multirow{3}{*}{ Participação do Aluno } & Mensagem inserida (fórum) \\
\hline & Mensagem inserida (chat) \\
\hline & $\begin{array}{c}\text { Mensagem assunto } \\
\text { (chat) }\end{array}$ \\
\hline \multirow{6}{*}{ Percepção } & Material Acessado \\
\hline & $\begin{array}{c}\text { Mensagem assunto } \\
\text { (fórum) }\end{array}$ \\
\hline & Exercício acessado \\
\hline & Imagine que você precisa definir o encapsulamento... \\
\hline & Você gostaria de estudar o assunto ... \\
\hline & Você gostaria de estudar o assunto ... \\
\hline
\end{tabular}

\subsection{MONITORAÇÃO DAS INTERAÇÕES}

Quando for a primeira interação do aprendiz ele deve escolher o tipo de perfil que considera ser mais adequado as suas preferências de aprendizagem.

Após realizar o processo de publicação do planejamento é iniciado o acompanhamento das interações do aprendiz através do Módulo de Monitoração.

O Módulo de Monitoração irá capturar dados sempre que houver interações em locais que foram planejados como observáveis, onde houverem as marcações de AA monitoráveis. O Módulo de Monitoração envia ao repositório de contexto a primitiva de contexto a cada interação do aluno que represente uma característica planejada como observável. A primitiva de contexto é formada pelos dados: 
contexto_interação(who, what, where,when,how).

A primitiva a seguir, por exemplo, apresenta a interação do aluno1 (who), considerando a característica observável "Mídia Acessada" (what), que foi observado na AA “Expressões e Comandos" (where), no dia 11/03/2007 (when), cujo valor observado foi "vídeo" (how).

contexto_interação(aluno1, Mídia Acessada, Expressões e Comandos,11/03/2007,vídeo)

Todas as primitivas que o Módulo de Monitoração captura são enviadas ao Repositório de Contexto para que posteriormente sejam analisadas.

\subsection{AVALIAÇÃO PERFIL}

Quando um aluno finaliza um CA é enviado ao LearnPES uma mensagem indicando que o aluno chegou ao final. O LearnPES recebe a identificação do aluno (who) para que então possa iniciar o processo de avaliação do perfil deste aluno. A avaliação é realizada pelo Módulo Avaliador de Perfis e é composta pelas etapas de Avaliação das característica observadas e Classificação dos perfis.

\subsubsection{Avaliação das Características Observadas}

O Avaliador de Perfis realiza a avaliação das informações que estão armazenadas no repositório de contexto armazenando os resultados no Modelo do Aluno.

O repositório de contexto irá possuir várias ocorrências de uma mesma Característica Observável. Isto porque o Módulo de Monitoração pode capturar uma mesma característica em diferentes AA. O Avaliador irá aplicar a função auxiliar associada à característica observável para obter o resultado relacionado a esta.

Por exemplo, considerando que foi observado o CA "Estrutura da Linguagem de Programação" para o aluno "amandat". É possível observar que existem várias ocorrências no repositório através do histórico apresentado na Tabela 32 da Característica Observável "Material Acessado". Aplicando a função "TipoMaterialMaisAcessado" se chegará ao valor de que desta característica que é 
"exemplos práticos". Este valor é enviado ao Modelo do Aluno para preencher o atributo da respectiva característica observável. O Apêndice B apresenta o exemplo completo do histórico obtido a partir do repositório de contexto.

Tabela 32 - Exemplo de histórico de repositório de contexto

\begin{tabular}{|c|c|c|c|c|}
\hline who & what & where & when & how \\
\hline amandat & $\begin{array}{c}\text { Material } \\
\text { Acessado }\end{array}$ & Propriedades de um Projeto & $14 / 3 / 2007$ & artigo \\
\hline amandat & $\begin{array}{c}\text { Material } \\
\text { Acessado }\end{array}$ & Propriedades de um Projeto & $14 / 3 / 2007$ & $\begin{array}{c}\text { exemplos } \\
\text { práticos }\end{array}$ \\
\hline amandat & $\begin{array}{c}\text { Material } \\
\text { Acessado }\end{array}$ & Propriedades de um Projeto & $14 / 3 / 2007$ & artigo \\
\hline amandat & $\begin{array}{c}\text { Material } \\
\text { Acessado }\end{array}$ & Expressões e comandos & $16 / 3 / 2007$ & $\begin{array}{c}\text { exemplos } \\
\text { práticos }\end{array}$ \\
\hline amandat & $\begin{array}{c}\text { Material } \\
\text { Acessado }\end{array}$ & Expressões e comandos & $16 / 3 / 2007$ & $\begin{array}{c}\text { exemplos } \\
\text { práticos }\end{array}$ \\
\hline amandat & $\begin{array}{c}\text { Material } \\
\text { Acessado }\end{array}$ & Expressões e comandos & $16 / 3 / 2007$ & $\begin{array}{c}\text { exemplos } \\
\text { práticos }\end{array}$ \\
\hline amandat & $\begin{array}{c}\text { Material } \\
\text { Acessado }\end{array}$ & Expressões e comandos & $16 / 3 / 2007$ & simulações \\
\hline amandat & $\begin{array}{c}\text { Material } \\
\text { Acessado }\end{array}$ & Expressões e comandos & $16 / 3 / 2007$ & texto teórico \\
\hline amandat & $\begin{array}{c}\text { Material } \\
\text { Acessado }\end{array}$ & Expressões e comandos & $16 / 3 / 2007$ & texto teórico \\
\hline
\end{tabular}

O Avaliador irá analisar todas as características observáveis aplicando as respectivas funções associadas. A Tabela 33 apresenta o Modelo do Aluno observado (amandat) após a avaliação, considerando que o CA observado foi o "Estrutura da Linguagem de Programação". Os atributos não preenchidos são aqueles que não foram observados durante o dado $\mathrm{CA}$.

Tabela 33 -Modelo do Aluno após a avaliação das informações de contexto

\begin{tabular}{|c|c|c|}
\hline $\begin{array}{l}\text { Categorias de } \\
\text { Preferências }\end{array}$ & Característica Observável & Resultado \\
\hline $\begin{array}{c}\text { Formato- } \\
\text { Apresentação }\end{array}$ & Mídia Acessada & vídeo \\
\hline \multirow{3}{*}{$\begin{array}{l}\text { Participação do } \\
\text { Aluno }\end{array}$} & Mensagem inserida (fórum) & 12 \\
\hline & Mensagem inserida (chat) & 0 \\
\hline & $\begin{array}{c}\text { Mensagem assunto } \\
\text { (chat) }\end{array}$ & Comparação entre paradigmas \\
\hline \multirow{6}{*}{ Percepção } & Material Acessado & exemplos práticos \\
\hline & $\begin{array}{l}\text { Mensagem assunto } \\
\text { (fórum) }\end{array}$ & Comparação entre estruturas \\
\hline & Exercício acessado & estudo de caso prático \\
\hline & $\begin{array}{c}\text { Imagine que você precisa definir o } \\
\text { encapsulamento... }\end{array}$ & \\
\hline & Você gostaria de estudar o assunto ... & a \\
\hline & Você gostaria de estudar o assunto ... & \\
\hline
\end{tabular}




\subsubsection{Classificação dos Perfis}

O Classificador de Perfis irá verificar, através dos dados avaliados, a qual tipo de perfil cadastrado o perfil do aluno se encontra mais próximo. É calculada a distância entre o Perfil Analisado e cada tipo de perfil cadastrado.

A partir dos dados das Características Observáveis existentes no modelo do aluno o classificador irá criar o Perfil Analisado. É realizada a comparação entre as características observáveis do Perfil Analisado e cada Tipo de Perfil obtendo a distância entre cada característica observável.

Considerando os tipos de perfil da Figura 46 é possível obter a distância entre cada característica (distCategoria) e o Perfil Analisado e a distância total entre os perfis (distPerfis), conforme apresentado na Figura 47 .

\begin{tabular}{|c|c|c|c|c|c|}
\hline \multicolumn{6}{|c|}{ Tipos de Perfis } \\
\hline \multirow{2}{*}{ Tipo } & \multirow{2}{*}{ Categoria } & \multirow{2}{*}{$\begin{array}{c}\text { Característica } \\
\text { Observável }\end{array}$} & Pragmático & Reflexivo & Teórico \\
\hline & & & Valor & Valor & Valor \\
\hline \multirow{7}{*}{ 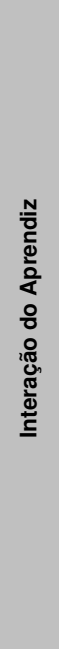 } & $\begin{array}{c}\text { Formato- } \\
\text { Apresentação }\end{array}$ & Mídia Acessada & Figura OU Vídeo & Figura OU Vídeo & Texto OU Som \\
\hline & Percepção & $\begin{array}{l}\text { Material } \\
\text { Acessado }\end{array}$ & exemplo & artigo & texto \\
\hline & $\begin{array}{l}\text { Participação } \\
\text { do Aluno }\end{array}$ & $\begin{array}{c}\text { Mensagem } \\
\text { inserida (fórum) }\end{array}$ & $>10$ & $<10$ & $>10$ \\
\hline & $\begin{array}{c}\text { Participação } \\
\text { do Aluno }\end{array}$ & $\begin{array}{c}\text { Mensagem } \\
\text { inserida (chat) }\end{array}$ & $>=50$ & $<50$ & $>=50$ \\
\hline & $\begin{array}{l}\text { Participação } \\
\text { do Aluno }\end{array}$ & $\begin{array}{c}\text { Mensagem } \\
\text { assunto (chat) }\end{array}$ & $\begin{array}{c}\text { Comparação entre } \\
\text { paradigmas }\end{array}$ & $\begin{array}{l}\text { Comparação entre } \\
\text { paradigmas }\end{array}$ & $\begin{array}{l}\text { Definição de } \\
\text { conceitos dos } \\
\text { paradigmas }\end{array}$ \\
\hline & Percepção & $\begin{array}{c}\text { Mensagem } \\
\text { assunto (fórum) }\end{array}$ & $\begin{array}{c}\text { Comparação entre } \\
\text { estruturas }\end{array}$ & $\begin{array}{c}\text { Comparação entre } \\
\text { estruturas }\end{array}$ & $\begin{array}{c}\text { Definição das } \\
\text { estruturas }\end{array}$ \\
\hline & Percepção & $\begin{array}{l}\text { Exercício } \\
\text { acessado }\end{array}$ & $\begin{array}{l}\text { Estudo de caso } \\
\text { prático }\end{array}$ & expositivo & expositivo \\
\hline \multirow{3}{*}{ 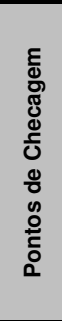 } & Percepção & $\begin{array}{c}\text { Imagine que } \\
\text { você precisa } \\
\text { definir o } \\
\text { encapsulamento. } \\
\text {.. } \\
\end{array}$ & a & $b$ & $b$ \\
\hline & Percepção & $\begin{array}{c}\text { Você gostaria de } \\
\text { estudar o } \\
\text { assunto.. }\end{array}$ & a & c & $b$ \\
\hline & Percepção & $\begin{array}{c}\text { Você gostaria de } \\
\text { estudar o } \\
\text { assunto... }\end{array}$ & a & c & $b$ \\
\hline
\end{tabular}

Figura 46 - Conjunto de tipos perfis cadastrados 


\begin{tabular}{|c|c|c|c|c|}
\hline \multicolumn{3}{|c|}{ Perfil Analisado } & \multicolumn{2}{|c|}{ Comparação de distâncias (Pragmático) } \\
\hline \multicolumn{2}{|c|}{ Característica Observável } & Valor & $\begin{array}{l}\text { Característica } \\
\text { Observável }\end{array}$ & distCaracterística \\
\hline \multicolumn{2}{|l|}{ Mídia Acessada } & vídeo & Mídia Acessada & 0 \\
\hline \multicolumn{2}{|c|}{ Mensagem inserida (fórum) } & 12 & $\begin{array}{c}\text { Mensagem inserida } \\
\text { (chat) }\end{array}$ & 1 \\
\hline \multicolumn{2}{|c|}{ Mensagem inserida (chat) } & 0 & $\begin{array}{c}\begin{array}{c}\text { Mensagem inserida } \\
\text { (fórum) }\end{array} \\
\end{array}$ & 0 \\
\hline \multirow{2}{*}{\multicolumn{2}{|c|}{$\begin{array}{l}\text { Mensagem assunto } \\
\text { (chat) }\end{array}$}} & Comparação & Material Acessado & 0 \\
\hline & & paradigmas & $\begin{array}{l}\text { Mensagem assunto } \\
\text { (fórum) }\end{array}$ & 0 \\
\hline \multicolumn{2}{|l|}{ Material Acessado } & $\begin{array}{l}\text { exemplos } \\
\text { práticos }\end{array}$ & & \\
\hline \multirow{2}{*}{\multicolumn{2}{|c|}{$\begin{array}{l}\text { Mensagem assunto } \\
\text { (fórum) }\end{array}$}} & Comparação & Material Acessado & 0 \\
\hline & & entre estruturas & Você gostaria de & 0 \\
\hline \multicolumn{2}{|l|}{ Exercício acessado } & $\begin{array}{l}\text { estudo de caso } \\
\text { prático }\end{array}$ & \multicolumn{2}{|c|}{ distPerfis (Pragmático, PerfilAnalisado) $=1$} \\
\hline \multicolumn{2}{|c|}{$\begin{array}{c}\text { Você gostaria de estudar o } \\
\text { assunto ... }\end{array}$} & a & & \\
\hline \multirow{2}{*}{\multicolumn{3}{|c|}{ Comparação de distâncias (Teórico) }} & \multicolumn{2}{|c|}{ Comparação de distâncias (Reflexivo) } \\
\hline & & & & \\
\hline \multirow{2}{*}{$\begin{array}{l}\text { Característica } \\
\text { Observável }\end{array}$} & \multirow{2}{*}{\multicolumn{2}{|c|}{ distCaracterística }} & Observável & distCaracteristica \\
\hline & & & Mídia Acessada & 0 \\
\hline Mídia Acessada & \multicolumn{2}{|r|}{1} & Mensagem inserida & 0 \\
\hline \multirow{2}{*}{$\begin{array}{c}\text { Mensagem inserida } \\
\text { (chat) }\end{array}$} & \multirow{2}{*}{\multicolumn{2}{|c|}{1}} & (chat) & 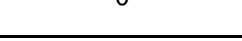 \\
\hline & & & $\begin{array}{l}\text { Mensagem inserida } \\
\text { (fórum) }\end{array}$ & 1 \\
\hline $\begin{array}{c}\text { Mensagem inserida } \\
\text { (fórum) }\end{array}$ & \multicolumn{2}{|r|}{0} & Material Acessado & 1 \\
\hline Material Acessado & \multicolumn{2}{|r|}{1} & Mensagem assunto & \\
\hline $\begin{array}{l}\text { Mensagem assunto } \\
\text { (fórum) }\end{array}$ & \multicolumn{2}{|r|}{1} & (fórum) & 0 \\
\hline \multirow{2}{*}{ Material Acessado } & \multirow{2}{*}{\multicolumn{2}{|c|}{1}} & Material Acessado & 1 \\
\hline & & & Você gostaria de & \\
\hline \multirow{2}{*}{$\begin{array}{c}\text { Você gostaria de } \\
\text { estudar o assunto ... }\end{array}$} & \multirow{2}{*}{\multicolumn{2}{|c|}{1}} & estudar o assunto ... & 1 \\
\hline & & & \multicolumn{2}{|c|}{ distPerfis (Reflexivo, PerfilAnalisado) $=4$} \\
\hline \multicolumn{3}{|c|}{ distPerfis (Teórico, PerfilAnalisado) $=6$} & & \\
\hline
\end{tabular}

Figura 47 - Cálculo das distâncias entre os tipos de perfis e o perfil analisado

É possível observar que o Perfil Analisado encontra-se mais próximo do tipo de perfil "Pragmático". O perfil sugerido é então armazenado no Modelo do Aluno.

\subsection{ADAPTAÇÃO DO CENÁRIO DE APRENDIZAGEM}

O LearnPES irá enviar um evento ao Módulo de Adaptação para que este construa o CA a partir dos modelos de CA existentes. Segundo o planejamento apresentado na Tabela 25 o próximo CA a ser apresentado é o de "Procedimentos".

Os CA serão construídos considerando o perfil de aprendizagem sugerido, os conceitos envolvidos nas AA do CA e o atributo de tecnologia do Modelo do Aluno. 
Para construir o novo CA é necessário primeiro localizar os objetos que atendam as necessidades do perfil de aprendizagem.

\subsubsection{Localização de Objetos de Aprendizagem}

Durante o planejamento dos tipos de perfis são especificados quais são as categorias de preferências que estão relacionadas a estes tipos de perfis (Figura 42). Estas categorias são utilizadas para localizar os objetos de aprendizagem que irão atender o perfil sugerido, relacionado às categorias de preferências aos campos do LOM.

No exemplo apresentado o perfil de aprendizagem sugerido ao aluno é o "Pragmático" que possui como categorias de preferências "ativo", "visual" e "concreto".

O Localizador de Objetos irá utilizar a descrição dos conceitos e das AA para realizar a primeira etapa de localização. Para isto utiliza a categoria "Geral" da especificação do LOM. São utilizadas as descrições da AA e de seus conceitos.

A Figura 48 apresenta uma simulação de localização de objetos de aprendizagem da primeira etapa de localização. Foi utilizado a descrição da AA "Passagem de Parâmetros" e os dois itens "Passagem de Parâmetro por valor" e "Passagem de Parâmetro por referência" que foram definidos no mini-curso da Tabela 25. O Localizador de Objetos irá buscar no repositório de objetos de aprendizagem (descrito através do padrão LOM) os objetos que possuem tais descrições utilizando na localização dos campos da categoria Geral do LOM: Título, Descrição e Palavras-Chaves. O resultado da busca será uma primeira seleção dos possíveis objetos que poderão ser utilizados para a construção do novo CA. 


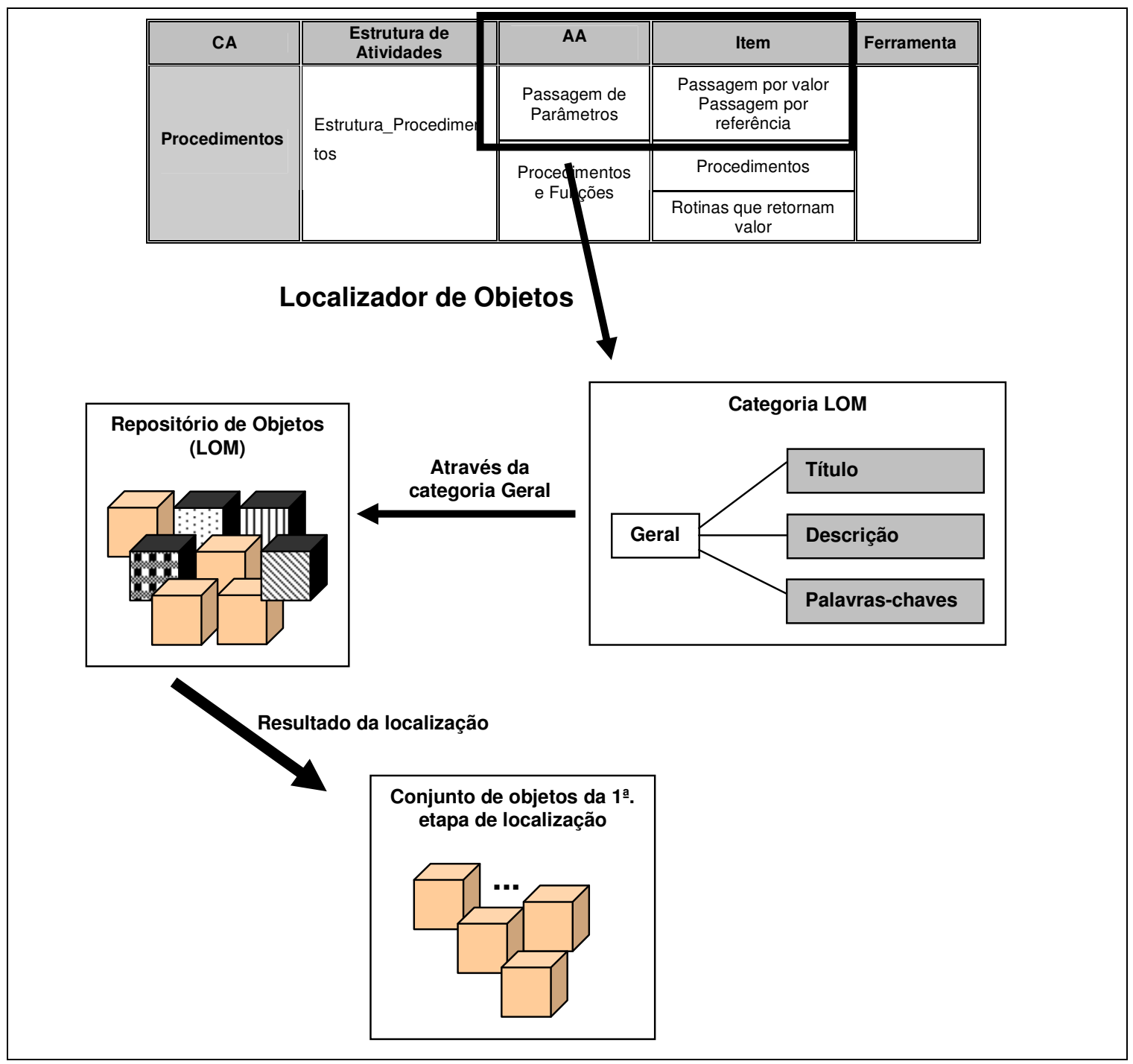

Figura 48 - Primeira etapa de localização de objetos de aprendizagem

A segunda etapa de localização se constitui em encontrar, no conjunto de objetos selecionados na primeira etapa, aqueles que atendem o perfil de aprendizagem do aluno. Para isto é verificado no Modelo do Aluno o perfil de aprendizagem do estudante.

No exemplo (Figura 49) é verificado que o aluno possui um perfil "Pragmático", que está relacionado com as categorias de preferências "Ativo", "Visual" e "Concreto", conforme descrito no tipo de perfil (Tabela 27). O Localizador irá através da categoria "Educacional" do LOM (campos Interatividade e Recurso da Aprendizagem) localizar, a partir do conjunto de objetos obtidos na primeira etapa de localização, quais atendem as preferências relacionadas ao perfil de aprendizagem do aluno. O Localizador irá utilizar a tabela de relacionamento entre os campos do 
LOM e as características dos perfis para encontrar os objetos que estejam relacionados ao perfil de aprendizagem do aluno.

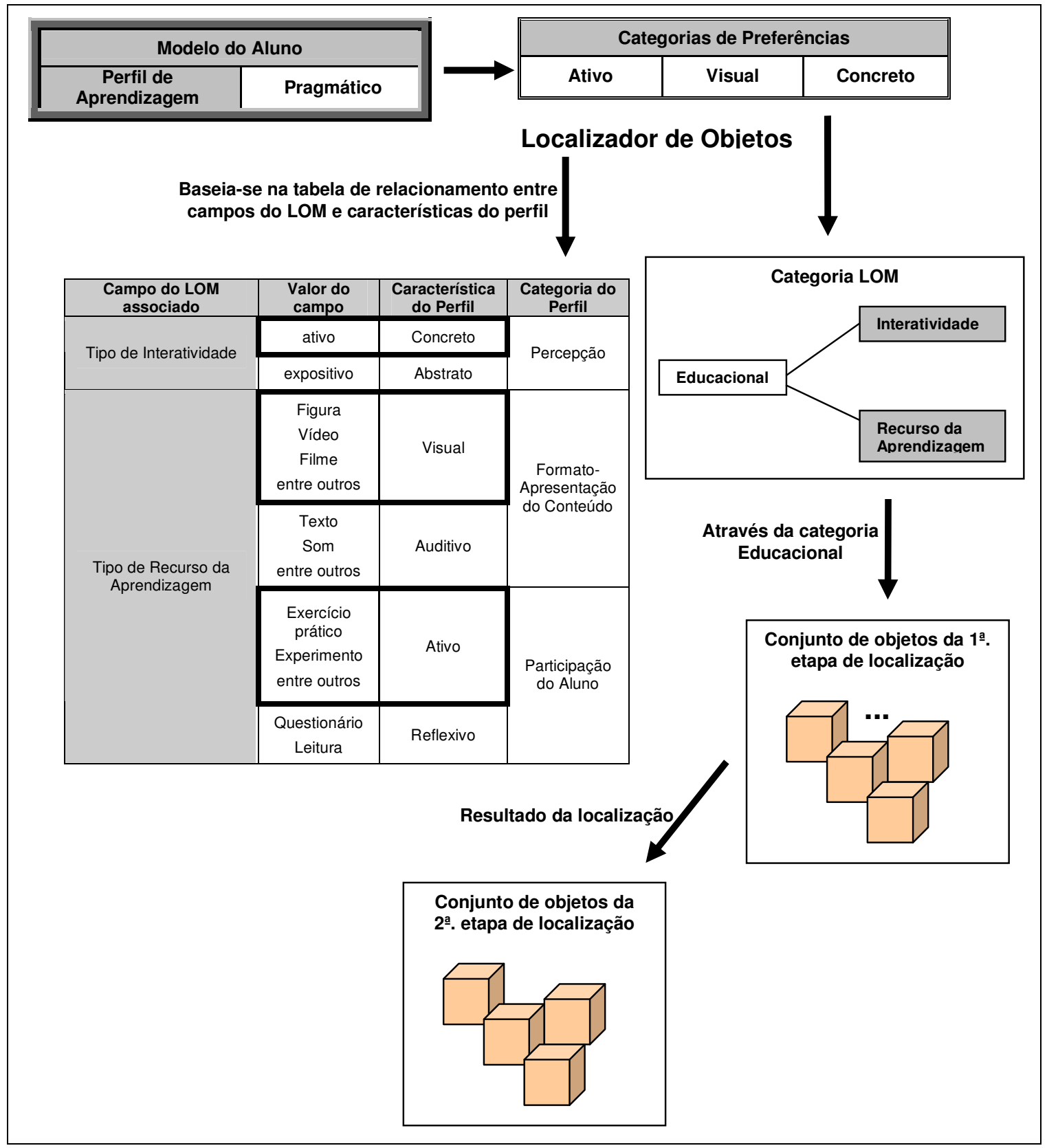

Figura 49 - Segunda etapa de localização de objetos de aprendizagem

Após obter o conjunto de objetos que podem atender o perfil de aprendizagem o Localizador irá realizar a terceira etapa de localização que verificará que objetos podem ser utilizados na construção do CA de forma a atender requisitos de conexão. Através do atributo "Tecnologia" definido no Modelo do aluno serão 
verificados quais objetos estão adequados tecnicamente ao tipo de conexão que o aluno está utilizado durante a interação com o ambiente de aprendizagem.

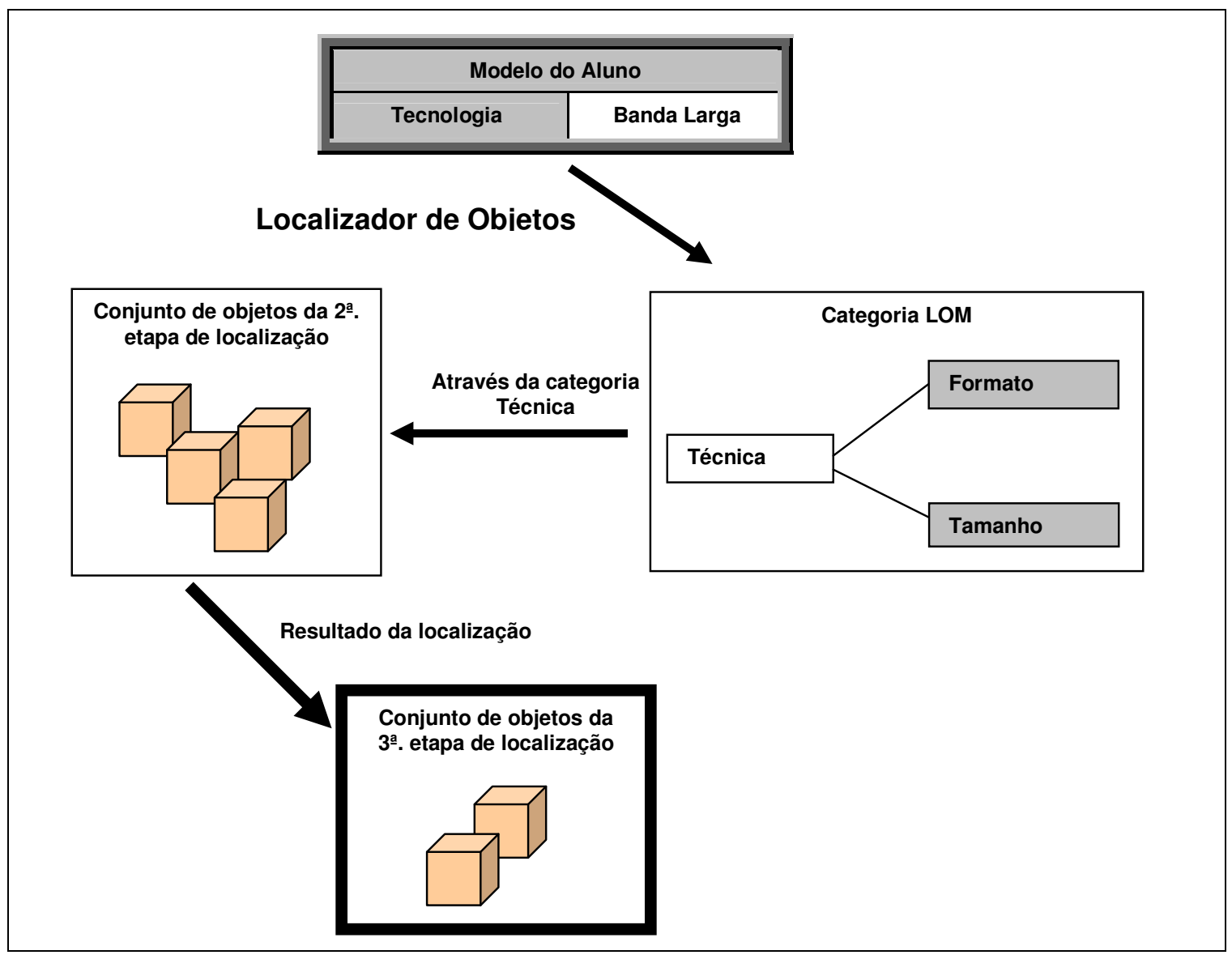

Figura 50 - Terceira etapa de localização de objetos de aprendizagem

No exemplo (Figura 50) o Modelo do Aluno descreve que a conexão é "Banda Larga" o que permite que possam ser utilizados vídeos de alta resolução, por exemplo. Neste caso, não há restrições quanto ao formato das mídias nem ao seu tamanho. O Localizador irá buscar dentro do conjunto de objetos obtidos na segunda etapa quais podem ser utilizados de acordo a tecnologia adotada. Para isto é utilizada a categoria LOM "Técnica" observando os campos "Formato" e "Tamanho". O resultado será o conjunto de objetos que podem ser utilizados para construção do novo Cenário ao aluno.

Deve-se observar que o procedimento descrito anteriormente deve ser efetuado para cada AA que pertence ao modelo de CA que será construído. 


\subsubsection{Construção do Cenário de Aprendizagem}

O novo CA será construído com base nos objetos de aprendizagem localizados. Por padrão é definido que a preferência de ordem-apresentação como seqüencial. Com isto as AA que fazem parte do cenário serão apresentadas sempre que $o$ aluno finalizar a $A A$ anterior.

A Figura 51 apresenta o CA "Procedimentos". Quando o aluno clicar na referência do conceito "Passagem por valor" será apresentado a ele materiais que atendam o conceito e que estejam de acordo com seu perfil.

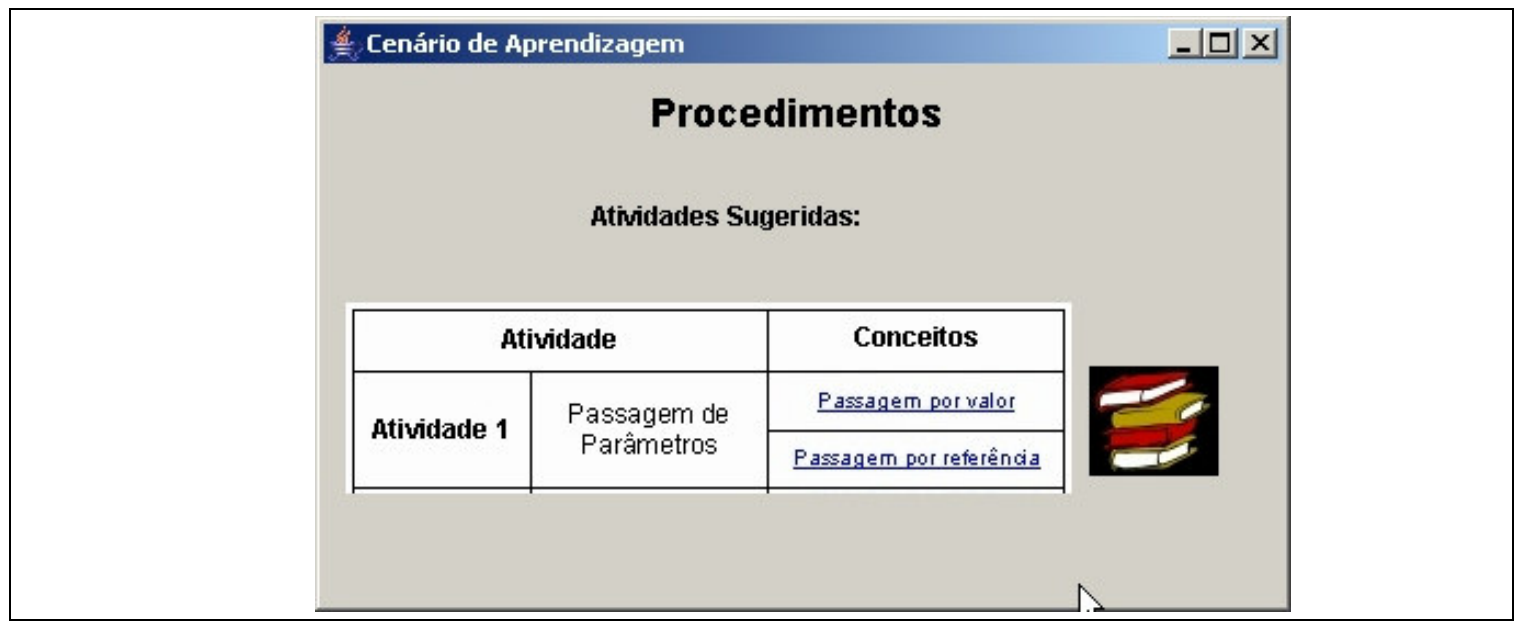

Figura 51 - Cenário de Aprendizagem apresentado ao aluno

É disponibilizada ao aluno a opção de acesso a outros materiais sobre os conceitos envolvidos no CA. Os outros materiais são objetos de aprendizagem que não estão relacionados ao perfil de aprendizagem do aluno, mas que atendem o ensino dos conceitos. Isto porque o ambiente permite que o aluno possa selecionar materiais diferentes dos sugeridos. Desta forma, é possível ao aluno navegar por diversos tipos de objetos de acordo com suas necessidades.

Quando o aluno finalizar a atividade 1 será disponibilizado no CA a atividade 2 (Figura 52): 


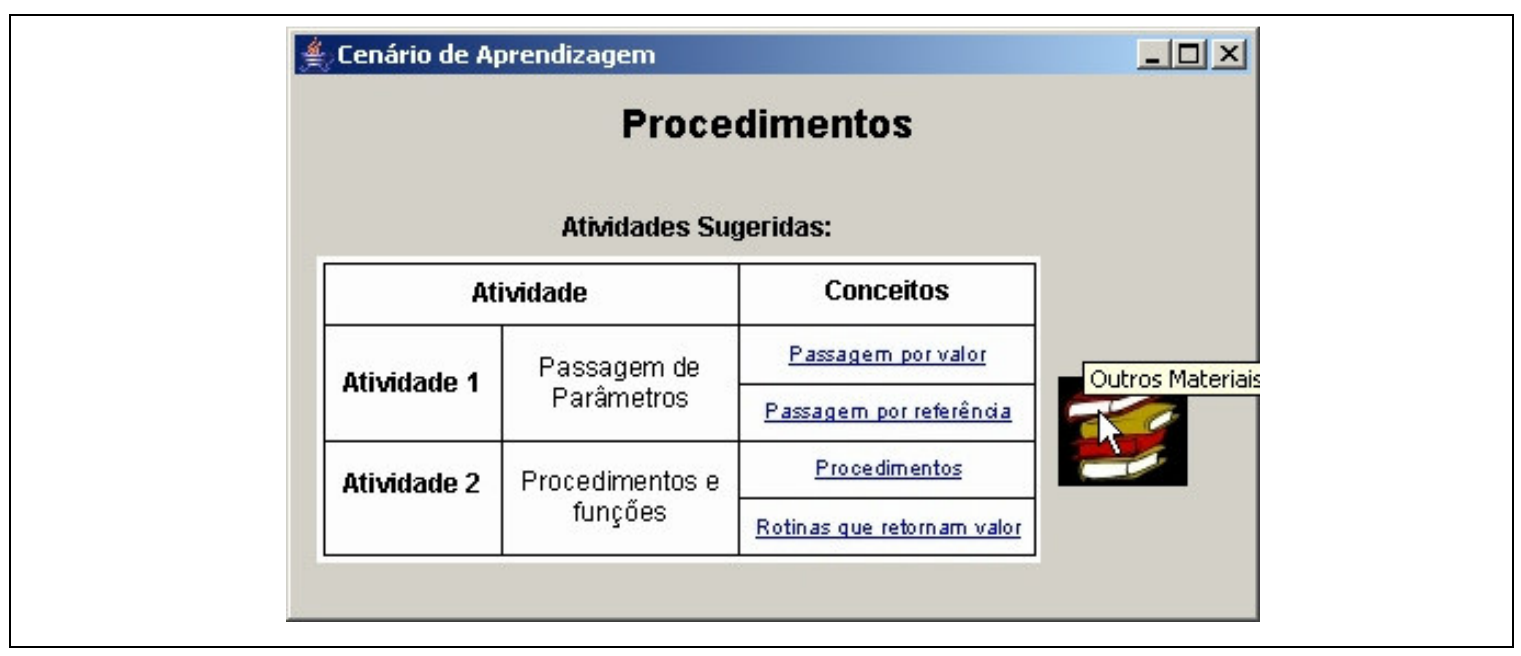

Figura 52 - Próxima atividade apresentada ao aluno

\subsection{CONSIDERAÇÕES FINAIS}

Este capítulo apresentou um estudo de caso considerando um mini-curso sobre "Conceitos de Linguagem de Programação" com o objetivo de mostrar a aplicabilidade da proposta deste trabalho.

É possível observar que o processo de planejamento da observação se constitui em algo trabalhoso. Porém, os modelos criados podem ser reutilizados em outras situações.

Um ponto fundamental é a relação entre o perfil de aprendizagem e os objetos de aprendizagem que são apresentados ao aluno. O relacionamento entre eles permite que haja um maior dinamismo na apresentação de elementos que compõem o processo de aprendizagem e também auxiliam na adaptação dos cenários. 


\section{CONCLUSÃO}

Este trabalho teve como objetivo propor uma arquitetura que permitisse a modelagem de perfis de aprendizagem e a adaptação de cenários de aprendizagem em um determinado ambiente de aprendizagem eletrônica baseando-se nas informações sobre o contexto da interação do aluno.

O resultado apresentado foi a especificação da arquitetura detalhando as diversas fases existentes no processo de modelagem de perfis de aprendizagem e adaptação de cenários.

A tese inicialmente apresentou um estudo teórico sobre tópicos relacionados ao perfil do aluno, conceituando aspectos importantes como perfil do aluno, modelo do aluno e estilo e perfil de aprendizagem. Alguns modelos de estilos de aprendizagem bem como a aplicação destes na aprendizagem eletrônica foram estudados e abordados no Capítulo 2. Este estudo permitiu que fosse decidido sobre o modelo a ser adotado para definição do Modelo do Aluno proposto neste trabalho.

Conceitos sobre aprendizagem eletrônica e padrões para implementação de ambientes de aprendizagem eletrônica (SCORM, Learning Design e LOM) possibilitaram se ter uma visão sobre os fundamentos da aprendizagem eletrônica na Web. O modelo definido pelo padrão do Learning Design foi estendido para definir atividades de aprendizagem de forma que o oferecimento destas ao aluno se torne mais flexível. É proposto que sejam especificados apenas os conceitos envolvidos na atividade de aprendizagem sem realizar o apontamento para o objeto de aprendizagem que atenderá a atividade. A construção do cenário passa a estar vinculado ao Modelo do Aluno.

Além disto, os aspectos relacionados à Hipermídia adaptativa e a Sistemas de tutores inteligentes possibilitaram se ter a visão sobre o processo de adaptação de um ambiente de aprendizagem eletrônica. Através do modelo de funcionamento dos tutores inteligentes e da hipermídia adaptativa foi possível definir questões sobre a avaliação do perfil a partir do modelo do aluno.

A pesquisa sobre conceitos relacionados à ciência de contexto foi fundamental para escolha do modelo que seria utilizado para definição do Modelo de Observação.

Um estudo de ambientes e projetos que realizam aprendizagem adaptativa foi apresentado no Capítulo 3, apresentando ao final uma comparação entre os 
trabalhos pesquisados. Este estudo permitiu se ter uma visão sobre o desenvolvimento dos ambientes que tivessem relação com a criação de modelos do aluno.

Baseando-se nos estudos bibliográficos realizados foi proposta uma arquitetura para adaptação de cenários de aprendizagem baseando-se no perfil do aluno. Nos ambientes pesquisados não foram encontrados trabalhos que utilizassem questões relativas a modelagem do contexto da interação de forma que estes interferissem diretamente na classificação do perfil de aprendizagem do aluno. Além disto, o relacionamento entre o perfil de aprendizagem e a oferta de objetos de aprendizagem caracterizam um aspecto importante dentro da proposta deste trabalho.

O perfil do aluno é construído a partir da monitoração das interações deste aluno em um dado ambiente e formalizado através do Modelo do Aluno proposto no Capítulo 2.

A identificação do perfil de aprendizagem do aluno é baseada no Modelo do Aluno através da análise dos resultados obtidos a partir da interação do aluno.

A apresentação da arquitetura proposta foi dividida em diferentes Capítulos (Capítulo 4, Capítulo 5 e Capítulo 6) de forma a facilitar o detalhamento da mesma.

A arquitetura proposta está dividida em três módulos (Figura 8 - Capítulo 4):

- LearnPES: módulo responsável pelo planejamento do processo de observação, classificação de perfis e adaptação. Este módulo é dividido em Planejamento e Avaliação de Perfis (Figura 9).

- Módulo de Monitoração: responsável pelo acompanhamento das interações do aluno no ambiente de aprendizagem, segundo o planejamento da observação previamente realizado.

- Módulo de Adaptação: responsável pela construção de Cenários de Aprendizagem de acordo com o perfil do aluno.

Cada um dos módulos possui módulos internos com a finalidade de permitir a organização e execução das funcionalidades propostas pela arquitetura.

Um outro ponto importante foi a definição de conceitos e modelos que dessem suporte a arquitetura proposta. Estes modelos foram definidos nos Capítulos 5 e 6. 
Para a fase de planejamento da observação (Capítulo 5) realizada pelo LearnPES foram definidos os conceitos e modelos de:

- Característica Observável: entidade responsável por identificar uma característica que será observada na interação do aluno. Sua modelagem foi realizada estendendo as cláusulas de contexto a partir da proposta W5H (Figura 11).

- Modelo de Observação: entidade que define o conjunto de características observáveis que serão utilizadas para o acompanhamento do aprendiz durante sua interação com o ambiente de aprendizagem (Figura 12).

Para a fase de planejamento da classificação de perfis (Capítulo 5), também realizada pelo LearnPES, foi definido o conceito e modelo de:

- Tipo de Perfil de Aprendizagem: entidade que define um tipo de perfil que será utilizado durante o processo de classificação de perfis. É baseada no Modelo de Observação. Um tipo de perfil é especificado através da definição de valores a cada característica observável que será utilizada na identificação de um perfil (Figura 16).

Para o planejamento da adaptação (Capítulo 5) foi determinada a entidade:

- Mapa de Adaptação: define o sequenciamento de apresentação de Cenários de Aprendizagem e permite que 0 docente possa sugerir diferentes estratégias de ensino através da especificação de diferentes perfis. O Mapa de Adaptação pode ser configurado através do LearnPES e é enviado ao Módulo de Adaptação.

A etapa de planejamento é finalizada com a publicação dos modelos que darão suporte aos processos de observação, classificação e adaptação. Durante a publicação algumas tarefas são realizadas pelo LearnPES (Capítulo 5):

- Envio do Modelo de Observação na forma de variáveis de contexto ao Módulo de Monitoração para que o acompanhamento do estudante possa ser realizado segundo planejamento previamente realizado.

- Sinalização dos cenários de aprendizagem que serão monitorados através da estensão da entidade de notificação do Learning Design.

- Geração do repositório de contexto que irá armazenar as interações do aluno com o ambiente de aprendizagem segundo o modelo de observação. 
- Geração de regras de adaptação que são baseadas nos tipos de perfis determinados durante o planejamento de tipos de perfis. São enviadas ao Módulo de Adaptação.

- Atualização do Modelo do Aluno segundo o Modelo de Observação para que este contenha informações que serão utilizadas durante o processo de identificação do perfil.

A Figura 20 do Capítulo 5 apresenta o modelo conceitual, contendo as entidades envolvidas no processo, do Módulo de Planejamento (LearnPES) responsável por toda a etapa de planejamento e publicação do planejamento

O Módulo de Monitoração (Capítulo 6) apresentou a dinâmica que como as informações contextuais são capturadas de acordo com o Modelo de Observação previamente planejado.

A avaliação dos perfis realizada pelo Módulo Avaliador de Perfis do LearnPES foi dividida em duas etapas (Capítulo 6):

- Avaliação de Características Observáveis onde é realizada uma consolidação das informações monitoradas e a aplicação de funções que avaliem cada caracterísitca observada atualizando o Modelo do Aluno.

- Classificação de Perfis realizada através da análise das características observáveis em conjunto sugerindo um perfil de aprendizagem ao aluno a partir dos tipos de perfis especificados.

A Figura 29 apresenta o modelo conceitual do Módulo Avaliador de Perfis (LearnPES).

O último ponto descrito na arquitetura é a adaptação dos cenários de aprendizagem realizada pelo Módulo de Adaptação segundo o Modelo do Aluno encontrado (Capítulo 6). A adaptação se baseia no perfil de aprendizagem do aluno e nos modelos de CA previamente especificados. São localizados objetos de aprendizagem que possam atender um dado perfil de aprendizagem em conjunto com os conceitos necessários ao processo de ensino.

O modelo conceitual do Módulo de Adaptação é apresentado na Figura 34. 


\subsection{CONTRIBUIÇÕES}

O trabalho tem por objetivo geral contribuir para a área de modelagem e adaptação de aprendizado eletrônico definindo uma arquitetura de adaptação que seja baseada no modelo do perfil do aprendiz, considerando não só as ações momentâneas da interação, mas também uma análise sobre os dados anteriores do aluno. A seguir serão apresentadas as contribuições específicas do trabalho.

\subsubsection{Modelo do Aluno}

Através dos estudos apresentados no Capítulo 2 foi possível propor um Modelo do Aluno, que pudesse ser aplicado em ambiente de aprendizagem eletrônica, onde as preferências fossem organizadas através de categorias baseadas no modelo proposto por Felder e Silverman (1988). A organização através de categorias possibilitou que houvesse uma relação entre os estilos de aprendizagem e os métodos de ensino adotados para atenderem estes estilos.

O modelo proposto foi adotado na arquitetura apresentada armazenando e organizando através das categorias de preferências as informações sobre o perfil do aluno. Durante o planejamento do acompanhamento do aluno o professor definirá quais características deseja observar e como estas serão aplicadas na identificação do perfil de aprendizagem do aluno.

Embora os perfis de aprendizagem utilizados devam ser definidos pelo docente, a organização das características que definem o perfil em categorias permite que a avaliação destas possa convergir para a adoção de métodos de ensino mais adequados ao perfil que for identificado no aluno.

Outro ponto importante é a relação entre as categorias de preferências definidas no Modelo do Aluno com as categorias descritoras dos objetos de aprendizagem do padrão LOM. O relacionamento entre o Modelo do Aluno e a descrição dos objetos de aprendizagem permitiu haver uma maior aderência entre o perfil de aprendizagem identificado no aluno e os objetos de aprendizagem disponíveis. As categorias do LOM permitiriam criar um relacionamento com os métodos de ensino equivalentes a cada categoria de preferências definida no Modelo do Aluno. 
O modelo conceitual do padrão do Learning Design foi estendido propondo-se a integração do Modelo do Aluno apresentado neste trabalho. O modelo conceitual do padrão não possui atualmente entidades que sejam responsáveis pela identificação de perfis de aprendizagem que sustentem a construção de atividades de aprendizagem de acordo com as preferências do estudante. É possível criar variáveis que permitam um acompanhamento das interações do aprendiz através do modelo proposto pelo nível C. Os executores do padrão como o 4 (tópico 3.6 .9 Capítulo 3) capturam os valores das variáveis de acordo com as interações do aprendiz. Porém, a análise conjunta destas variáveis deve ser previamente planejada pelo docente através da construção de linhas de comandos condicionais. Este processo ainda é pouco automatizado pelo padrão.

Este trabalho sugere integrar o Modelo do Aluno proposto de forma que a identificação de perfis permita que o oferecimento de atividades de aprendizagem seja mais flexíveis. O Modelo do Aluno passa a fazer parte integrante do processo de identificação dos objetos de aprendizagem que farão parte das atividades de aprendizagem.

\subsubsection{Modelagem da Observação e Monitoração das Interações do Aluno}

Um estudo sobre aplicações cientes de contexto permitiu modelar as características que serão observáveis nas interações do aluno com o ambiente através de variáveis de contexto, utilizando-se o modelo W5H proposto por Morse, Armstrong e Dey (2000). Tal modelagem empregou uma maior aderência entre as características que serão observadas e a monitoração das interações do aluno no ambiente de aprendizagem. O Módulo de Monitoração recebe informações de observação no formato de contexto para que o acompanhamento esteja atrelado ao contexto da interação do aluno.

As características observáveis foram classificadas como pontos de checagem e interações do aprendiz o que permite que o processo de monitoração seja diferenciado para estas características. Além disto, foi especificado para as características do tipo interações do aprendiz, cuja observação está relacionada a interações com ferramentas, uma forma de obter o que cada ferramenta pode prover 
como informação sobre as interações de um determinado aluno, baseando-se na proposta de Bressan, Ruggiero e Franco (2005).

A entidade notificação (notification), proposta no padrão do Learning Design teve sua funcionalidade estendida, pois passou a ser uma disparadora de eventos notificadores de monitoração auxiliando no processo de acompanhamento das interações do aluno.

\subsubsection{Avaliação do Perfil de Aprendizagem e Adaptação de Cenários de Aprendizagem}

Como a evolução do aprendizado não pode ser considerada algo estático é necessário que a avaliação do perfil do aluno seja realizada constantemente. Não é adequado rotular um aluno num único estilo de aprendizagem durante toda a sua interação. Ele pode ter variações de preferências de acordo com o ambiente e com o conteúdo em que ele interage, como também durante sua evolução ao longo do processo de aprendizagem. Por isto, foi proposto que o aluno tivesse seu perfil avaliado a cada novo cenário de aprendizagem.

O resultado obtido na avaliação do perfil de aprendizagem do aluno será utilizado para o processo de adaptação dos cenários de aprendizagem. Existem casos em que os dados monitorados e modelados apresentam como resultado que atendem a um dos perfis especificados pelo docente. Porém, pode haver situações em que resultado não seja exato, ou seja, o perfil não pode ser determinado com exatidão, não se encaixando aos perfis especificados pelo docente. A arquitetura adotou um algoritmo de aprendizagem de máquina (instance-base learning) denominado de Vizinhos mais Próximos (k-Nearest Neighbor) proposto por Cover e Hart em 1967 através do cálculo da distância entre o perfil do aluno e os perfis especificados pelo docente. É importante deixar claro que não foi objetivo do trabalho encontrar o melhor método para identificação do perfil de aprendizagem do aluno.

Os métodos de ensino que foram definidos a partir das categorias de preferências no Modelo do Aluno são utilizados para localização dos objetos de aprendizagem que pode atender o perfil de aprendizagem do aluno e os conceitos envolvidos nas atividades de aprendizagem que compõem o cenário de aprendizagem em questão. Foi proposto um mecanismo em que o objeto de 
aprendizagem é localizado de acordo com o perfil de aprendizagem do aluno e com os conceitos que estão relacionados com a dada atividade de aprendizagem, empregando um maior dinamismo na construção dos cenários de aprendizagem apresentados ao aluno.

\subsection{TRABALHOS FUTUROS}

Considerando a arquitetura proposta neste trabalho seria relevante a continuidade a pesquisa na área de perfil do aluno e adaptação de ambientes de aprendizagem na Web.

Algumas sugestões para futuros trabalhos são descritas a seguir.

\subsubsection{Incorporação da proposta da tese no projeto Tidia-AE}

Uma continuidade importante do projeto seria integração do mesmo a proposta e a arquitetura do LMS do projeto Tidia-AE ${ }^{30}$. O intuito é fornecer ao LMS já desenvolvido a possibilidade de adaptação dos cenários de aprendizagem dos alunos através da avaliação do perfil do aprendiz.

Atualmente o projeto Tidia-AE está incorporando no desenvolvimento de seu LMS os resultados existentes no Projeto Sakai ${ }^{31}$, que é um projeto que procura unir esforços do mundo todo para o desenvolvimento colaborativo de ambientes de aprendizagem.

Para que seja possível incorporar a proposta deste trabalho será necessário realizar a adequação com arquitetura empregada pelo Sakai, que é baseada na proposta do $\mathrm{OKI}^{32}$ (Open Knowledge Initiative). Uma sugestão seria definir os módulos da arquitetura proposta neste trabalho em camadas definindo interfaces de comunicação, conforme proposto na arquitetura do Sakai e do Tidia-AE (ZAINA; BRESSAN; RUGGIERO, 2006).

Embora a proposta deste trabalho utilize das entidades especificadas no modelo conceitual do Learning Design, este fato não impede a adoção da mesma

\footnotetext{
${ }^{30}$ http://tidia-ae.incubadora.fapesp.br/portal

${ }^{31} \mathrm{http}: / /$ sakaiproject.org/index.php?option=com_frontpage\&Itemid=1

32 http://www.okiproject.org/
} 
para ambientes que não adotam o padrão. Não foram realizadas especificações rigorosas que deixem arquitetura proposta dependente da utilização do padrão.

\subsubsection{Realização de testes com a arquitetura para diferentes modelos de perfis}

A implementação da arquitetura proporcionaria a aplicação de testes utilizando diferentes modelos de perfis de aprendizagem. Recomenda-se que o ambiente desenvolvido seja seja utilizado em situações reais de ensinoaprendizagem para que seja possível coletar dados que permitam comparar a utilização de diversos modelos de perfis com diferentes alunos.

Dentro deste escopo, pode-se também realizar testes com ambientes que envolvam trabalho colaborativo estendendo os modelos propostos de forma que estes possam atender tais ambientes.

\subsubsection{Adoção de técnicas otimizadas para classificação de perfis}

Outro ponto importante que pode ser explorado é pesquisar e comparar o desempenho de diferentes técnicas para classificação dos perfis do aluno. Este trabalho sugeriu a técnica dos vizinhos mais próximos. Porém, não foi realizado nenhum estudo sobre o desempenho destas técnicas em situações reais.

Pesquisar outras técnicas adotando-as em situações reais seria um trabalho importante dentro do escopo de desempenho do sistema. A definição de métricas de desempenho pode auxiliar no processo comparativo e decisório sobre as melhores técnicas a serem adotadas.

\subsubsection{Estender a arquitetura para aplicações de aprendizagem móveis}

Outro aspecto relevante é estender a arquitetura proposta para adoção da mesma em ambientes de aprendizagem móvel. A expansão do uso da computação móvel dentro do escopo de ensino, denominada de m-learning (mobile learning), tem crescido com o objetivo de contribuir na pluralidade no desenvolvimento de ambiente de aprendizado eletrônico. 
Neste caso, além da adaptabilidade ligada ao perfil do aprendiz deve-se observar também a adaptabilidade do ambiente (local) com que este interage. A adaptação passa a contemplar não apenas os sistemas no aspecto relativo à interface com o usuário ou mesmo de conteúdo adequado aos perfis, mas também o dispositivo (equipamento) utilizado no momento da interação (por exemplo celulares, PALMs, etc).

Um dos aspectos fundamentais para a adaptação dentro do escopo de mobilidade é a interpretação do contexto de interação. Dentro disto, será necessário realizar um estudo mais profundo sobre as necessidades contextuais e como estas impactam diretamente no perfil do aluno. 


\section{REFERÊNCIAS BIBLIOGRÁFICAS}

ADL (2004). Advanced Distributed Learning Overview. SCORM 2004. Sharable Content Object Reference Model 2004. Disponível em: www.adlnet.org. Acessado em: 04/06/2005.

AHA, David W.; KIBLER, Dennis; ALBERT, Marc K. (1991). Instance-Based Learning Algorithms. Machine Learning Journal, v.6, n.1, pp. 37-66, 1991.

AKHRAS, Fábio N; SELF, John A (2000). Modeling the Process, not the Product of Learning. Computer as Cognitive Tools - No More Walls. Edited by Susanner P Lajoie, pp. 3-28, 2000.

BERLANGA, Adriana J; GARCÍA, Francisco; CARABIAS, Jorge (2006). Authoring Adaptive Learning Design Using IMS LD. In: Proceedings of Adaptive Hypermedia. pp. 31-40, Dublin, Irlanda, 2005.

BERLANGA, Adriana J; GARCíA, Francisco (2005a). Authoring Tools for Adaptive Learning Designs in Computer-Based Education. In: Proceedings of the 2005 Latin American Conference on Human-Computer Interaction, Cuernavaca - Mexico, vl. 124, pp. $190-201,2005$.

BERLANGA, Adriana J; GARCíA, Francisco (2005b). Using IMS LD for Characterizing Techniques and Rules in Adaptive Educational Hypermedia Systems. In: Proceedings of the UNFOLD/Prolearn Joint Workshop Current State on IMS Learning Design, Valkenburg, pp. 61-79, September 2005.

BRESSAN, Graça; FRANCO, Eduardo; RUGGIERO, Wilson V . Tool Manager for Tidia-ae Learning Management System. Proceedings of III Workshop TIDIA, São Paulo, 2005.

BRÉZILLON, Patrick (1999). Context in Problem Solving: A Survey. The Knowledge Engineering Review, vl. 18, n. 2, pp. 1-40, 1999.

BRITAIN, Sandy (2004). A Review of Learning Design: Concept, Specifications and Tools. JISC E-learning Pedagogy Programme, Maio 2004. Disponível em: http://www.jisc.ac.uk/uploaded documents/ACF83C.doc. Acessado em: 10/10/2005.

BRUNETTO, Maria Angélica C. et al (2003). AdaptWeb: um ambiente para Ensinoaprendizagem Adaptativo na Web. Educar em Revista, Curitiba, n. 107, p. 175-198, 2003. 
BRUSILOVSKY, Peter (1999). Adaptive and Intelligent Technologies for Web-based Education. Edited by C. Rollinger and C. Peylo. Special Issue on Intelligent Systems and Teleteaching, Künstliche Intelligence, n. 4, pp. 19-25, 1999.

BRUSILOVSKY, Peter (2001). Adaptive Hypermedia. User Modeling and UserAdapted Interaction, Netherlands, n.1, pp. 87-110, 2001.

BRUSILOVSKY, Peter (2003). A distributed architecture for adaptive and intelligent leaning management systems. Proceedings of Workshop on Intelligent Learning Management Systems at Al-ED'2003, Sydney, Australia, pp. 106-114, 2003.

BRUSILOVSKY, Peter; KARAGIANNIDIS, Karagiannidis; SAMPSON, Demetrios (2004). Layered Evaluation of Adaptive Learning Systems. International Journal of Continuing Engineering Education and Lifelong Learning, vl 14, n. 4-5, pp. 402 $-421,2004$.

BRUSILOVSKY, Peter; PEYLO, Christoph (2003) Adaptive and intelligent Webbased educational systems. Edited by P. Brusilovsky and C. Peylo. International Journal of Artificial Intelligence in Education, Special Issue on Adaptive and Intelligent Web-based Educational Systems, vl. 13, n.2-4, pp. 159-172, 2003.

BULCÃO NETTO, Renato F.; PIMENTEL, Maria G. C. (2005). Toward a DomainIndependet Semantic Model for Context-Aware Computing. Proceedings of the Third Latin American Web Congress. LAR-WEB’05, México, 2005.

BURGOS, Daniel; TATTERSALL, Colin; KOPER, Rob (2006). Representing adaptive eLearning strategies in IMS Learning Design. Proceedings of TENCompetence Conference, Bulgaria, 2006.

CIU, Yan (2005). SCORM 2004 vs SCORM 1.2. A Comparison of Recent Version of Sharable Content Object Reference Model, 2005. Disponível em:

http://www.kom.tudarmstadt.de/fileadmin/Externer Bereich/Teaching/Seminars/CommunicationSystem sMM/SS05/12.ppt. Acessado em: 20/06/2006.

COFFIELD, Frank et al (2004). Learning styles and pedagogy in post-16 learning. A systematic and critical review. Learning and Skills Research Centre, 2004.

DALZIEL, James (2003). Implementing Learning Design: The Learning Activity Management System (LAMS). Macquarie E-learning Centre of Excellence, Macquarie University, Austrália.

Disponível em:

http://www.melcoe.mq.edu.au/documents/ASCILITE2003\%20Dalziel\%20Final.pdf. Acessado em: 20/08/2007. 
DE BRA, Paul; AROYO, Lora; CRISTEA, Alexandra (2004). Adaptive Web-based Educational Hypermedia. Web Dynamics, Adaptive to Change in Content, Size, Topology and Use, pp. 387-410, Springer, United Kingdom, 2004.

DERNTL, Michael; HUMMEL, Karin A (2005). Modeling Context-Aware e-Learning Scenarios. Proceedings of Third IEEE International Conference on Pervasive Computing and Communications Workshops (PERCOMW'05), pp. 337-342, 2005.

DEY, Anind K. (2001). Understanding and Using Context. Personal and Ubiquitous Computing, vl 5, n. 1, pp 4-7, 2001.

DIAZ, David P.; CARTNAL, Ryan B. (1999). Students' learning styles in two classes: Online distance learning and equivalent on-campus. College Teaching, vl.47, n.4, pp. 130-135, 1999.

Disponível em:

http://www.serprofessoruniversitario.pro.br/ler.php?modulo=8\&texto=316. Acessado em: 02/07/2007

DOLOG, Peter; SCHAEFER, Michael (2005). A Framework for Browsing, Manipulating and Maintaining Interoperable Learner Profiles. Proceedings of UM2005 - $10^{\text {th }}$ International Conference on User Modeling, Springer Verlag, United Kingdom, 2005.

FELDER, Richard M; BRENT, Rebecca (2005). Understanding Student Differences. Journal of Engineering Education. VI. 94, N. 1, pp 57-72.

FELDER, Richard M; SILVERMAN, Linda K (1988). Learning and Teaching Styles in Engineering Education. Engineering Education, vl. 78, n. 7, pp 674-681, 1988.

FENRICH, Peter (2006). Practical Suggestions for Addressing Learning Styles in Computer-Based Simulations. Proceedings of The Ninth IASTED International Conference on Computers and Advanced Technology in Education, Peru, pp 61-66, 2006.

FISHER, Gerhard (2001). User Modeling in Human-Computer Interaction. User Modeling and User-Adapted Interaction, vl 11, n. 1/2, pp. 65-86, 2001.

FREEDMAN, Reva (2000). What is an Intelligent Tutoring System? Intelligence, vl 11, n. 3, pp15-16, 2000.

HENRICKSEN, Karen; INDULSKA, Jadwiga; RAKATONIRAINY, Andry (2002). Modeling Context Information in Pervasive Computing System. Proceedings of the 
First International Conference on Pervasive Computing. Lecture Notes in Computer Science; vl. 2414, pp. 167 - 180, 2002.

HENRICKSEN, Karen; INDULSKA, Jadwiga. (2006) Developing context-aware pervasive computing applications: Models and approach. Pervasive and Mobile Computing, n. 2, pp. 37-64, Elsevier, 2006.

IMSCPIM (2004). IMS Content Packaging Information Model. Disponível em: http://www.imsglobal.org. Acessado em: 10/09/2006.

IMSLDBP (2003). IMS Learning Design Best Practice and Implementation Guide. Version 1.0 Final Specification. Disponível em: http://www.imsglobal.org/learningdesign/ldv1p0/imsld_bestv1p0.html\#1501775. 2003. Acessado em: 10/09/2006.

IMSLDIM (2003). IMS Learning Design Information Model. Disponível em: http://www.imsglobal.org/learningdesign/index.cfm, 2003. Acessado em: 10/09/2006.

IMSLDXB (2003). IMS Learning Design XML Binding. Disponível em:

http://www.imsglobal.org/learningdesign/ldv1p0/imsld_bindv1p0.html\#1503397, 2003. Acessado em: 10/09/2006.

JAMESON, Anthony (2001). Modeling Both the Context and the User. Personal and Ubiquitous Computing, vl 5, n. 1, pp. 29-33, 2001.

KOBSA, Alfred (2001). Generic User Modeling Systems. User Modeling and UserAdapted Interaction, vl 11, n. 1/2, pp 49-63, 2001.

KOBSA, Alfred; KOENEMANN, Jürgen; POHL, Wolfgang (2001). Personalised hypermedia presentation techniques for improving online customer relationships. The Knowledge Engineering Review, vl. 16, n. 2, pp. 111-155, 2001.

KOPER, Rob.; MANDERVELD, Jocelyn (2004). Educational modeling language: modeling reusable, interoperable, rich and personalized units of learning. British Journal of Educational Technology, vl 35, n. 5, pp. 537-551, 2004.

KOPER, Rob; OLIVIER, Bill (2004). Representing the Learning Design of Units of Learning. Educational Technology \& Society, vl. 7, n. 3, pp. 97-111, 2004.

KOPER, Rob (2001). Modeling units of study a pedagogical perspective. The pedagogical meta-model behind EML. Technical Report. Disponível em: http://eml.ou.nl. Acessado em: 05/04/2006. 
KURTI, Arianit et al (2006). Designing and Implementing Ubiquitous Learning Activities Supported by Mobile and Positioning Technologies. Proceedings of The Ninth IASTED International Conference on Computers and Advances Technology in Education, Peru, pp. 193-199, 2006.

LEE, Catherine $\mathrm{H} \mathrm{M}$ et al (2005). What affect student cognitive style in the development of hypermedia learning system?. Computer and Education, vl. 45, n. 1, pp 1-19, 2005.

LIU, Yuliang; GINTHER, Dean (1999). Cognitive Styles and Distance Education. Online Journal of Distance Learning Administration, vl. II, n. III. State University of West Georgia, Distance Education, Fall1999. Disponível em: http://www.westga.edu/ distance/liu23.html. Acessado em: 10/07/2006.

LOM (2002). Draft standard for learning object metadata, 2002. Disponível em: http://ltsc.ieee.org.wg12/index.html. Acessado em: 20/10/2007.

MAGOULAS, George D; PAPANIKOLAOU, Kyparisia, GRIGORIADOU, Maria. (2003). Adaptive web-based learning: accommodating individual differences through system's adaptation. British Journal of Educational Technology, vl. 34, n. 4, pp. 511-527, United Kington, 2003.

MCGREAL, Rory (2004). Learning Objects: A Practical definition. International Journal of Instructional Technology and Distance Learning, vl 1, n. 9, 2004. Disponível em: http://itdl.org/Journal/Sep_04/Sep_04.pdf\#page=25. Acessado em: 02/07/2007.

MITCHELL, Tom M (1997). Machine Learning. Ed. The MCGRAW-Hill Companies: EUA, 1997.

MORSE, David R; ARMSTRONG, Stephen; DEY, Anind K (2000). The What, Who, Where, When, and How of Context-Awareness. CHI 2000. Workshop on the What, Who, Where, When, and How of Context-Awareness, Nova Zelândia, 2000.

MUÑOZ, Lydia Silva; OLIVEIRA, José Palazzo M. (2004). Adaptive Web-based courseware development using metadata standards and ontologies. Lecture Notes in Computer Science, vl 3084, pp. 414-428, 2004.

NEVEN, Filip; DUVAL, Erik (2002). Reusable learning objects: a survey of LOMbased repositories. Proceedings of the tenth ACM international conference on Multimedia, pp. 291 - 294, França, 2002. 
PAPANIKOLAOU, Kyparisia A et al (2001). INSPIRE: an intelligent system for personalized instruction in a remote environment. Proceedings of 3rd Workshop on Adaptive Hypertext Hypermedia. Lecture Notes in Computer. Science. Springer-Verlag, Berlin, 2001.

RICHMOND, Aaron S; CUMMINGS, Rhoda (2005). Implementing Kolb's learning styles into online distance education. International Journal of Technology in Teaching and Learning, vl.1, n. 1, pp. 45-54, 2005.

ROSATELLI, Marta C; TEDESCO, Patricia A. (2003). Diagnosticando o Usuário para Criação de Sistemas Personalizáveis. Anais do XXIII Congresso do SBC - III Jornada de MCIA, vl III, pp. 153-201, Porto Alegre, RS, 2003.

ROSATELLI, Marta C. (2000). Novas tendências da pesquisa em inteligência artificial na educação. VIII Escola de Informática da SBC Sul, Porto Alegre: Ed. da UFRGS, pp.179-210, 2000.

SCHMIDT, Andréas (2005). Potentials and Challenges of Context-Awareness for Learning Solutions. Proceedings of the $13^{\text {th }}$ Annual Workshop of the SIG Adaptivity and User Modeling in Interactive Systems, Saorbriichen, 2005.

SCHWEITZER, Christiane M (2004). Mecanismo de consolidação de confiança distribuída para Redes Ad Hoc. Tese de Doutorado apresentada a EPUSP. 100p. São Paulo, 2004.

SILVA, Gisele T; ROSATELLI, Marta C. (2006). Adaptation in Educational Hypermedia based on the Classification of the User Profile. Proceedings of the $9^{\text {th }}$ International Conference on Intelligent Tutoring Systems (ITS 2006), pp. 268277, Berlin: Springer Verlag, 2006.

SILVA, Gisele T (2005). Adaptação em um Sistema Educacional Hipermídia Baseada na Classificação de Perfis de Usuários. Dissertação de Mestrado apresentada na Universidade Federal de Santa Catarina. Florianópolis, 2005.

SOLES, Carolyn; MOLLER, Leslie (2001). Myers Briggs Type Preferences in Distance Learning Education. International Journal of Educational Technology, vl. 2, n. 2, 2001.

STASH, Natalia; CRISTEA, Alexandra; DE BRA, Paul (2004). Authoring of Learning Styles in Adaptive Hypermedia: Problems and Solutions. Proceedings of the WWW 2004 Conference, pp. 114-123, Nova lorque, 2004. 
STEWART, Avaré; NIEDERÉE; METHA, Bhaskar (2004). State of the Art in User Modeling for Personalization in Content, Service and Interaction. Technical Report, NSF/DELOS. Report on Personalization.

Disponível em: http://www.ipsi.fraunhofer.de/ mehta/stateoftheart.pdf. Acessado em 16/01/2006.

STIUBIENER, Itana; ROSATELLI, Marta C.; RUGGIERO, Wilson V (2007). An approach to personalisation in e-learning. IEEE International Conference on Advanced Learning Technologies, Japão, 2007.

TARPIN-BERNARD, Franck; HABIEB-MAMMAR, Halima (2005). Modeling Elementary Cognitive Abilities for Adaptive Hypermedia Presentation. User Modeling and User-Adapted Interaction, vl. 15, n. 5, pp. 459-495, 2005.

TRIANTAFILLOU, Evangelos; POMPORTSIS, Andréas; DEMETRIADIS, Stavros (2003). The design and the formative evaluation of an adaptive educacional system based on cognitive styles. Computers \& Education, vl. 41, n.1, pp. 87-103, 2003.

TRIANTAFILLOU, Evangelos; POMPORTSIS, Andréas; GEORGIADOU, Elissavet (2002). EAS-CS: Adaptive Educational System based on Cognitive Styles. $\mathbf{2}^{\text {nd }}$ International Conference on Adaptive Hypermedia and Adaptive Web Based Systems, Espanha, 2002.

VAN ROSMALEN, P. et al (2006). Authoring a full life cycle model in standardsbased, adaptive e-learning. Journal of Technology \& Society, vl. 9, n.1, pp. 72-83, 2006.

WEBER, Gerhard e BRUSILOVSKY, Peter (2001). ELM-ART: An Adaptive Versatile System for Web-based Instruction. International Journal of Artificial Intelligence in Education, vl. 12, pp. 351-384, 2001.

WENGER, Etienne (1987). Artificial Intelligence and Tutoring Systems : Computational and Cognitive Approaches to the Communication of Knowledge. Morgan Kaufmann Publishers,1987.

WU, Hongjing (2002). A Reference Architecture for Adaptive Hypermedia Applications. Tese (Doutorado), Eindhoven University of Technology. Disponível em: http://wwwis. win.tue.nl/ah/thesis/wu.pdf. Acessado em: 13/07/2006.

ZAINA, Luciana A M (2002). Acompanhamento do Aprendizado do Aluno em Cursos a Distância através da Web: Metodologias e Ferramenta. São Paulo. Dissertação (Mestrado) - Escola Politécnica da Universidade de São Paulo. 
ZAINA, Luciana A M; BRESSAN, Graça; RUGGIERO, Wilson V (2006). Learning Management System of Tidia-Ae Project. Proceedings of the Ninth lasted International Conference on Computers and Advanced Technology in Education, 2006. 


\section{APÊNDICE A - EXEMPLOS DE METADADOS}

\section{A.1. Variáveis de Contexto - Característica Observável:}

$<$ caracteristicaObservavel>

<who> </who>

$<$ whatltem $>$

$<$ whatltemCodigo $>1<$ whatltemCodigo >

<descricao> Mídia Acessada </descricao >

< função> TipoMídiaMaisAcessada </função>

$<$ tipo > Interações do Aprendiz </tipo>

$<$ /whatltem $>$

<category> Percepção </category>

$<$ whereltem>

$<$ whereltemCodigo $>1</$ whereltemCodigo >

$<$ local> Todo $\mathrm{CA}<$ /local>

$<$ whereltem>

$<$ when> Toda interação </when>

$<$ /caracteristicaObservavel>

A.2. Variáveis de Contexto - Modelo de Observação:

$<$ what $>$

<modeloCodigol> $22<$ /modeloCodigo>

$<$ descricao $>$ Conceito_Progr $</$ descricao $>$

$<$ where $>$

$<$ whereCodigo $>1<$ whereCodigo $>$

$<$ CA $>$ todos $<$ CA $>$

$<$ where $>$

$<$ caracteristicaObservavel>

$<$ who $<$ /who $>$

$<$ whatltem>

$<$ whatltemCodigo $>1<$ whatltemCodigo >

<descricao> Mídia Acessada </descricao>

<função> TipoMídiaMaisAcessada </função>

<tipo> Interações do Aprendiz </tipo>

$<$ whatltem>

<category> Percepção </category>

$<$ whereltem>

$<$ whereltemCodigo $>1<$ whereltemCodigo >

$<$ local > Todo CA </local>

$</$ whereltem $>$

$<$ when> Toda interação </when>

$<$ caracteristicaObservavel>

<caracteristicaObservavel>

$<$ who $>$ <who

$<$ whatltem $>$

$<$ whatltemCodigo $>2<$ whatltem Codigo > 


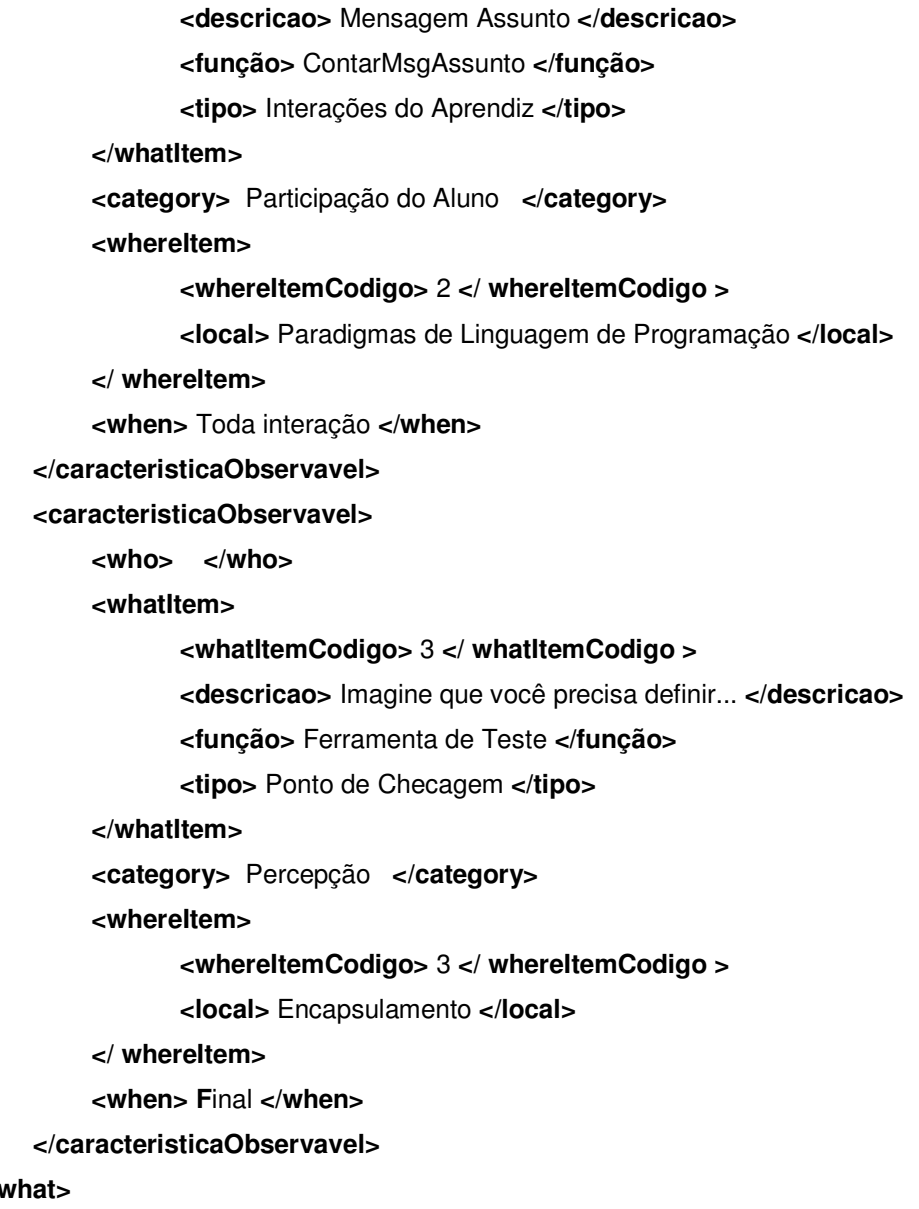




\section{APÊNDICE B - EXEMPLO DE HISTÓRICO REPOSITÓRIO DE CONTEXTO}

\section{O CA considerado foi o "Estrutura da Linguagem de Programação".}

\begin{tabular}{|c|c|c|c|c|}
\hline who & what & where & when & how \\
\hline amandat & Exercício Acessado & Propriedades de um Projeto & $14 / 3 / 2007$ & discussão teórica \\
\hline amandat & Exercício Acessado & Propriedades de um Projeto & $14 / 3 / 2007$ & discussão teórica \\
\hline amandat & Material Acessado & Propriedades de um Projeto & $14 / 3 / 2007$ & artigo \\
\hline amandat & Material Acessado & Propriedades de um Projeto & $14 / 3 / 2007$ & texto teórico \\
\hline amandat & Material Acessado & Propriedades de um Projeto & $14 / 3 / 2007$ & artigo \\
\hline amandat & Midia Acessada & Propriedades de um Projeto & $14 / 3 / 2007$ & texto \\
\hline amandat & Midia Acessada & Propriedades de um Projeto & $14 / 3 / 2007$ & vídeo \\
\hline amandat & Midia Acessada & Propriedades de um Projeto & $14 / 3 / 2007$ & figura \\
\hline amandat & Midia Acessada & Propriedades de um Projeto & $14 / 3 / 2007$ & vídeo \\
\hline amandat & Midia Acessada & Expressões e comandos & $14 / 3 / 2007$ & texto \\
\hline amandat & Midia Acessada & Expressões e comandos & $14 / 3 / 2007$ & vídeo \\
\hline amandat & Mensagem assunto (chat) & Paradigmas & $15 / 3 / 2007$ & Exemplos Práticos \\
\hline amandat & Mensagem assunto (chat) & Paradigmas & $15 / 3 / 2007$ & Definição de Conceitos \\
\hline amandat & Mensagem assunto (chat) & Paradigmas & $15 / 3 / 2007$ & Definição de Conceitos \\
\hline amandat & Mensagem assunto (chat) & Paradigmas & $15 / 3 / 2007$ & Definição de Conceitos \\
\hline amandat & Mensagem assunto (chat) & Paradigmas & $15 / 3 / 2007$ & Definição de Conceitos \\
\hline amandat & Mensagem assunto (chat) & Paradigmas & $15 / 3 / 2007$ & Definição de Conceitos \\
\hline amandat & Mensagem assunto (chat) & Paradigmas & $15 / 3 / 2007$ & Exemplos Práticos \\
\hline amandat & Mensagem assunto (chat) & Paradigmas & $15 / 3 / 2007$ & Exemplos Práticos \\
\hline amandat & Mensagem assunto (chat) & Paradigmas & $15 / 3 / 2007$ & Exemplos Práticos \\
\hline amandat & Mensagem assunto (chat) & Paradigmas & $15 / 3 / 2007$ & Exemplos Práticos \\
\hline amandat & Mensagem assunto (chat) & Paradigmas & $15 / 3 / 2007$ & Exemplos Práticos \\
\hline amandat & Mensagem assunto (chat) & Paradigmas & $15 / 3 / 2007$ & Exemplos Práticos \\
\hline amandat & Mensagem assunto (chat) & Paradigmas & $15 / 3 / 2007$ & Exemplos Práticos \\
\hline amandat & Mensagem assunto (chat) & Paradigmas & $15 / 3 / 2007$ & Definição de Conceitos \\
\hline amandat & Mensagem assunto (chat) & Paradigmas & $15 / 3 / 2007$ & Definição de Conceitos \\
\hline amandat & Exercício Acessado & Expressões e comandos & $16 / 3 / 2007$ & estudo de caso prático \\
\hline amandat & Exercício Acessado & Expressões e comandos & $16 / 3 / 2007$ & estudo de caso prático \\
\hline amandat & Exercício Acessado & Expressões e comandos & $16 / 3 / 2007$ & estudo de caso prático \\
\hline amandat & Exercício Acessado & Expressões e comandos & $16 / 3 / 2007$ & estudo de caso prático \\
\hline amandat & Material Acessado & Expressões e comandos & $16 / 3 / 2007$ & exemplos práticos \\
\hline amandat & Material Acessado & Expressões e comandos & $16 / 3 / 2007$ & exemplos práticos \\
\hline amandat & Material Acessado & Expressões e comandos & $16 / 3 / 2007$ & exemplos práticos \\
\hline amandat & Material Acessado & Expressões e comandos & $16 / 3 / 2007$ & simulações \\
\hline amandat & Material Acessado & Expressões e comandos & $16 / 3 / 2007$ & texto teórico \\
\hline amandat & Material Acessado & Expressões e comandos & $16 / 3 / 2007$ & texto teórico \\
\hline amandat & Midia Acessada & Expressões e comandos & $16 / 3 / 2007$ & figura \\
\hline amandat & Midia Acessada & Expressões e comandos & $16 / 3 / 2007$ & som \\
\hline amandat & $\begin{array}{c}\text { Você gostaria de estudar o } \\
\text { assunto... }\end{array}$ & Expressoes e comandos & $16 / 3 / 2007$ & $\mathrm{a}$ \\
\hline amandat & Mensagem assunto (fórum) & Expressões e comandos & $17 / 3 / 2007$ & $\begin{array}{c}\text { Comparação entre } \\
\text { estruturas }\end{array}$ \\
\hline amandat & Mensagem assunto (fórum) & Expressões e comandos & $17 / 3 / 2007$ & $\begin{array}{c}\text { Comparação entre } \\
\text { estruturas }\end{array}$ \\
\hline amandat & Mensagem assunto (fórum) & Expressões e comandos & $17 / 3 / 2007$ & $\begin{array}{c}\text { Comparação entre } \\
\text { estruturas }\end{array}$ \\
\hline amandat & Mensagem assunto (fórum) & Expressões e comandos & $17 / 3 / 2007$ & $\begin{array}{c}\text { Comparação entre } \\
\text { estruturas }\end{array}$ \\
\hline
\end{tabular}




\begin{tabular}{|c|l|l|l|l|} 
amandat & Mensagem assunto (fórum) & Expressões e comandos & $17 / 3 / 2007$ & $\begin{array}{c}\text { Comparação entre } \\
\text { estruturas }\end{array}$ \\
\hline amandat & Mensagem assunto (fórum) & Expressões e comandos & $17 / 3 / 2007$ & Exemplos Práticos \\
\hline amandat & Mensagem assunto (fórum) & Expressões e comandos & $17 / 3 / 2007$ & Exemplos Práticos \\
\hline amandat & Mensagem assunto (fórum) & Expressões e comandos & $17 / 3 / 2007$ & Exemplos Práticos \\
\hline amandat & Mensagem inserida (fórum) & Expressões e comandos & $17 / 3 / 2007$ & \\
\hline amandat & Mensagem inserida (fórum) & Expressões e comandos & $17 / 3 / 2007$ & \\
\hline amandat & Mensagem inserida (fórum) & Expressões e comandos & $17 / 3 / 2007$ & \\
\hline amandat & Mensagem inserida (fórum) & Expressões e comandos & $17 / 3 / 2007$ & \\
\hline amandat & Mensagem inserida (fórum) & Expressões e comandos & $17 / 3 / 2007$ & \\
\hline amandat & Mensagem inserida (fórum) & Expressões e comandos & $17 / 3 / 2007$ & \\
\hline amandat & Mensagem inserida (fórum) & Expressões e comandos & $17 / 3 / 2007$ & \\
\hline amandat & Mensagem inserida (fórum) & Expressões e comandos & $17 / 3 / 2007$ & \\
\hline amandat & Mensagem assunto (fórum) & Expressões e comandos & $18 / 3 / 2007$ & Comparação entre \\
\hline amandat & Mensagem inserida (fórum) & Expressões e comandos & $18 / 3 / 2007$ & \\
\hline amandat & Mensagem assunto (fórum) & Expressões e comandos & $19 / 3 / 2007$ & Comparação entre \\
\hline amandat & Mensagem assunto (fórum) & Expressões e comandos & $19 / 3 / 2007$ & Exemplos Práticos \\
\hline amandat & Mensagem inserida (fórum) & Expressões e comandos & $19 / 3 / 2007$ & \\
\hline amandat & Mensagem inserida (fórum) & Expressões e comandos & $19 / 3 / 2007$ & \\
\hline amandat & Mensagem assunto (fórum) & Expressões e comandos & $20 / 3 / 2007$ & Comparação entre \\
\hline amandat & Mensagem inserida (fórum) & Expressões e comandos & $20 / 3 / 2007$ & \\
\hline & & & & \\
\hline
\end{tabular}

